University of Louisville

ThinkIR: The University of Louisville's Institutional Repository

Electronic Theses and Dissertations

$12-2018$

\title{
Exploring the capabilities approach in a sport for development and peace setting.
}

Jeffrey F. Levine

University of Louisville

Follow this and additional works at: https://ir.library.louisville.edu/etd

Part of the Other International and Area Studies Commons, Politics and Social Change Commons, and the Sports Studies Commons

\section{Recommended Citation}

Levine, Jeffrey F., "Exploring the capabilities approach in a sport for development and peace setting." (2018). Electronic Theses and Dissertations. Paper 3097.

https://doi.org/10.18297/etd/3097

This Doctoral Dissertation is brought to you for free and open access by ThinkIR: The University of Louisville's Institutional Repository. It has been accepted for inclusion in Electronic Theses and Dissertations by an authorized administrator of ThinkIR: The University of Louisville's Institutional Repository. This title appears here courtesy of the author, who has retained all other copyrights. For more information, please contact thinkir@louisville.edu. 


\title{
EXPLORING THE CAPABILITIES APPROACH IN A SPORT FOR DEVELOPMENT AND PEACE SETTING
}

\author{
By \\ Jeffrey F. Levine \\ B.S. University of Michigan, 2004 \\ J.D. Tulane University Law School, 2008 \\ A Dissertation \\ Submitted to the Faculty of the \\ College of Education and Human Development \\ in Fulfillment of the Requirements \\ for the degree of
}

Doctor of Philosophy in Educational Leadership and Organizational Development

Educational Leadership, Evaluation and Organizational Development University of Louisville Louisville, Kentucky

December, 2018 
Copyright 2018 by Jeffrey F. Levine

All rights reserved 



\section{EXPLORING THE CAPABILITIES APPROACH IN A SPORT FOR DEVELOPMENT AND PEACE SETTING}

By

Jeffrey F. Levine

B.S. University of Michigan, 2004

J.D. Tulane University Law School, 2008

A Dissertation Approved on

November 19, 2018

By the following Dissertation Committee

Mary Hums, Co-chair

Anita Moorman, Co-chair

Meg Hancock

Brad Shuck 


\section{DEDICATION}

For my family and friends, whose unwavering support inspired and steeled me throughout this journey. You showed me how to live, how to sacrifice, how to love, how to motivate, how to be supportive, how to be humble, how to be empathetic, how to follow your dreams, and how to put in the work to achieve.

If you will it, it is no dream. 


\section{ACKNOWLEDGEMENTS}

I want to express my heartfelt gratitude to so many people because, in my case, it really did take a village. Starting with my parents, for instilling into me the values of hard work, honesty, integrity, and the courage to take the path less traveled. To my brothers, who were incredible exemplars to model myself after and whose passion for life inspired me to find my own fire. From the bottom of my heart, thank you.

Thank you to my University of Louisville family. Starting with Mary Hums and Anita Moorman. My co-advisors and dissertation co-chairs. You provided safe harbor to a doc student in need. As a person forging a new path seeking to make the world a better place, I had many questions. You both made time for me, were patient, and were kind. I will always be grateful. I also want to thank the other two members of my dissertation committee, Meg Hancock and Brad Shuck. Thank you for zeal, passion, warmth, kindness, and wisdom. Thank you to Chris Greenwell, Marion Hambrick, Megan Shreffler, and Gin Presley, for your professionalism, mentorship, and friendship.

I was surrounded by so many smart people and kind souls while a doc student. So, thank you to Alicia Cintron, Sam Schmidt, Chris Hanna, Sun Kang, Matt Huml, Jason Rice, Per Svensson, Seonghun Lee, Sin-Wook Yoo, Dylan Naegar, Sarah 
Williams, and James Weiner. I cannot express enough to everyone how grateful I am for your friendship and support throughout my doctoral experience.

Thank you to the family I gained once leaving Louisville. Thank you to Don Melrose, Toyin Ajisafe, Mikaela Boham, Randy Bonnette, Liana Davis, Misty Kesterson, Brian Menaker, Dan Newmire, Lon Seiger, Frank Spaniol, Heather Webb, Seth Oppenheimer, and Liz Perez. Also thank you to Larry Cohen, Joel Maxcy, Ellen Staurowsky, and Karen Weaver. You all were incredibly supportive and watched over me throughout this process.

A special thank you to Youth Odyssey and everyone who took part in this study. I will be forever grateful that you welcomed me with open arms.

Finally, thank you to Tammy Knecht and Jordan Kobritz. Tammy, we experienced the grass, the oceans, the mountains, and the valleys. I would not be who I am without you. Jordan, you are one of the chief reasons why I started and finished this climb. Thank you for your time, mentorship, wisdom, and friendship. 


\section{ABSTRACT \\ EXPLORING THE CAPABILITIES APPROACH IN A SPORT FOR DEVELOPMENT AND PEACE SETTING \\ Jeffrey F. Levine}

November 19, 2018

Sport for Development and Peace (SDP) has become a popular approach to development due to the inherent attractiveness of using sport as a vehicle to facilitate social change. However, critical scholars remain skeptical of SDP's effectiveness. Utilizing a holistic approach that includes local voices may help a program's effectiveness. Scholars are still searching for a framework flexible enough to accommodate the varied nature of SDP programs. One such theoretical approach is the Capabilities Approach, which evaluates well-being based on what people can do and be.

This case study explored the Capabilities Approach in an SDP setting. Youth Odyssey, a non-profit organization that works with at-risk youth through adventure programming, was the case. This case study explored what role does an SDP program play in participants achieving their capabilities, focusing on identifying functionings, barriers, and capabilities. Twenty-one interviews, 43 field observations and over 100 document/artifacts provided a holistic analysis of the case through triangulation. 
In RQ1, (a) being more comfortable and capable in social settings and interactions, (b) using logical reasoning and analytical skills, (c) being part of a community, and (d) doing new activities and experiences emerged as themes. In RQ2, the study identified (a) barriers that participants faced related to absent or inconsistent adult role models and the disruptive influences from peers, (b) barriers connected to a fear of failure or of being vulnerable, and (c) barriers related to a participant's difficult home or environmental influences emerged. Finally, in RQ 3, the data suggested Youth Odyssey created capabilities for participants that involved (a) choice to exercise agency through self-awareness, self-reflection, and perceptions of selfdetermination, (b) the opportunity to hone one's social skills, and (c) having the choice to access support and resources.

The findings add to the limited literature exploring SDP using the Capabilities Approach. It highlighted the Capabilities Approach's potential to use local context and address concerns of critical scholars regarding SDP from a planning/execution/evaluation standpoint. It was one of the first studies to understand the role an SDP organization played in increasing an individual's functionings, freedoms, and capabilities using qualitative data. 


\section{TABLE OF CONTENTS}

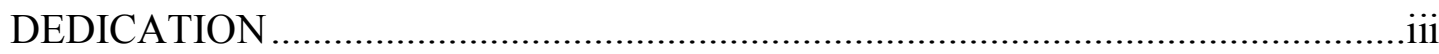

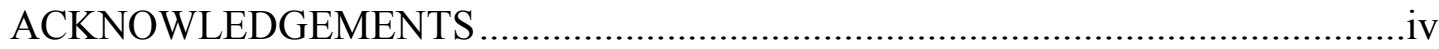

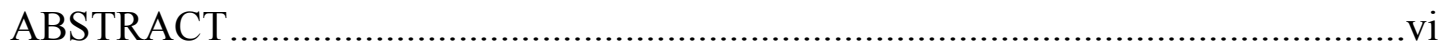

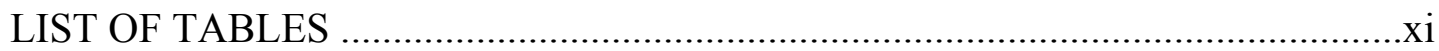

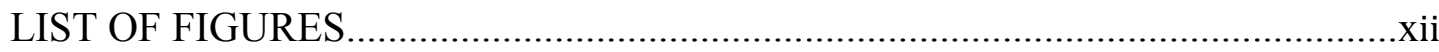

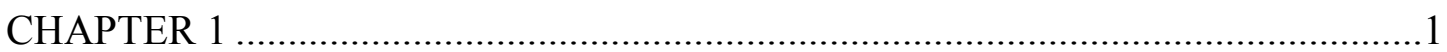

Sport for Development and Peace ………………………………………………….....

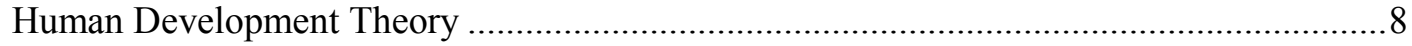

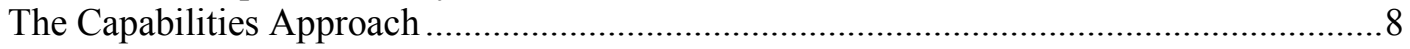

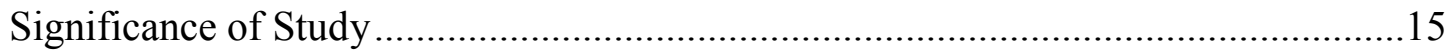

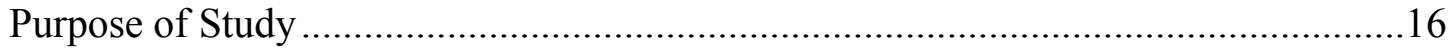

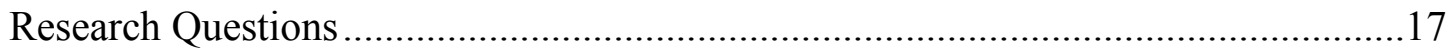

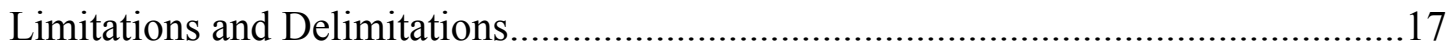

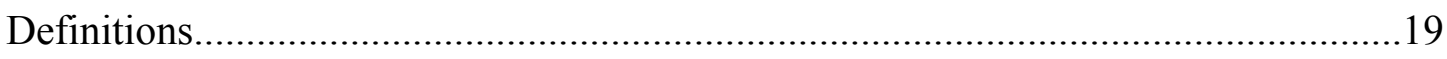

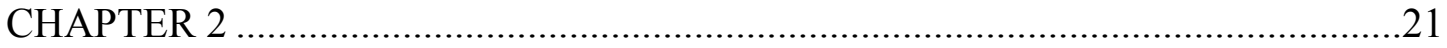

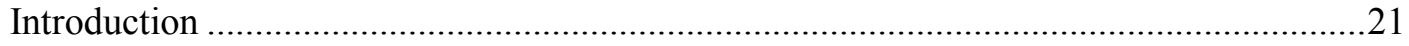

Human Development Theory ……………………………………………………....25

The Capabilities Approach ...........................................................................................32

Functionings, Freedoms, and Capabilities ...................................................................35

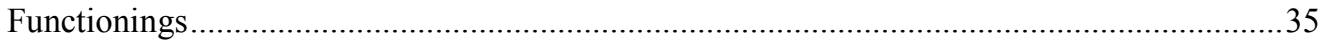

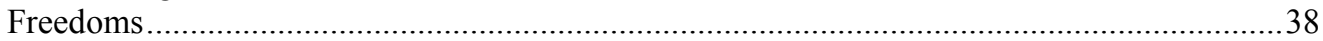

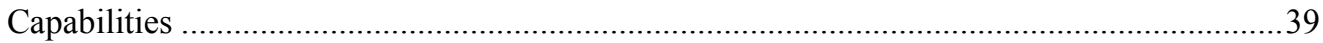

Summary of the Capabilities Approach ................................................................................42

Strengths of the Capabilities Approach...……………………………………………....4

Criticisms of the Capabilities Approach …………………………………………….....4

Central Capabilities ................................................................................................

Operationalizing the Capabilities Approach ……………………………………........51

Capabilities Approach Operationalized in Different Disciplines ..........................................55

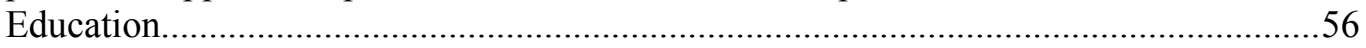

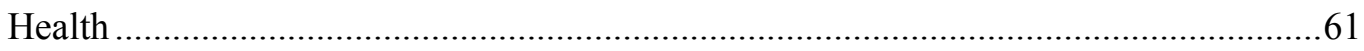

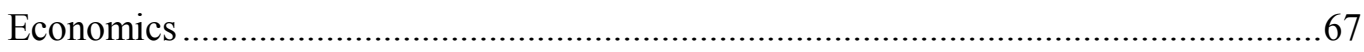

Summary of operation in education, health, and economics...............................................69

Sport for Development and Peace .............................................................................

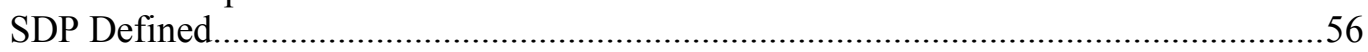

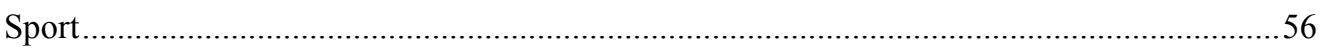

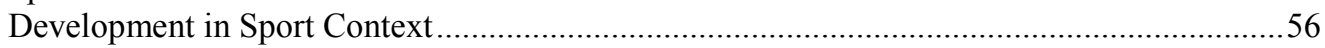




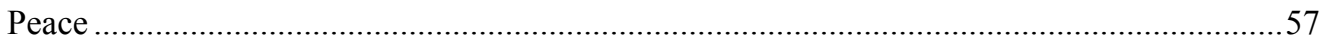

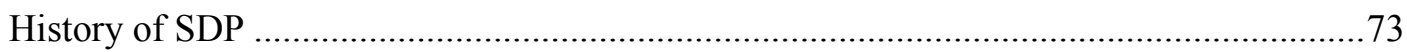

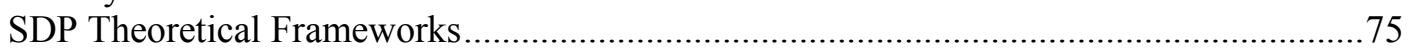

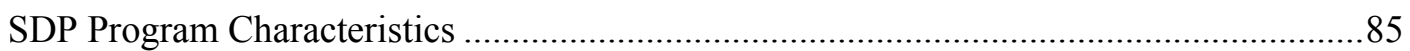

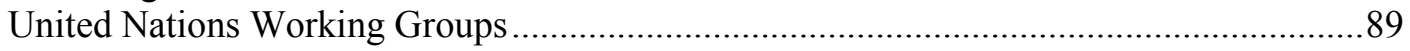

Sport and Child \& Youth Development ................................................................. 90

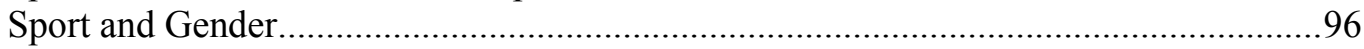

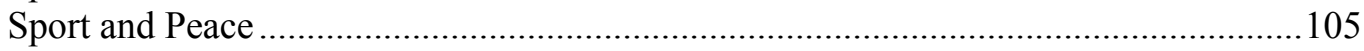

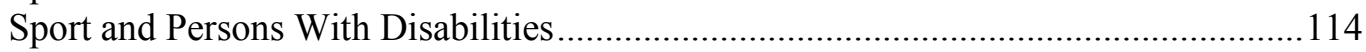

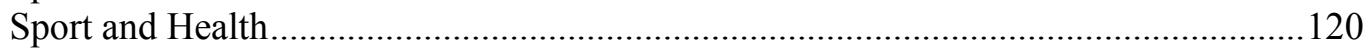

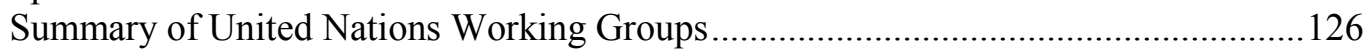

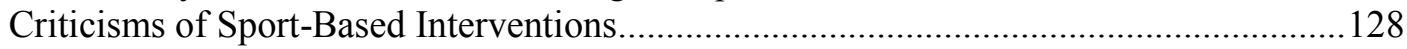

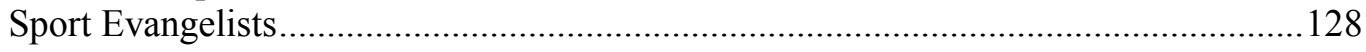

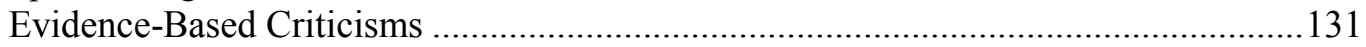

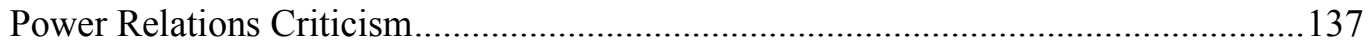

Summary of Criticisms of Sport-Based Interventions ..............................................140

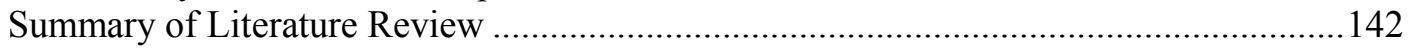

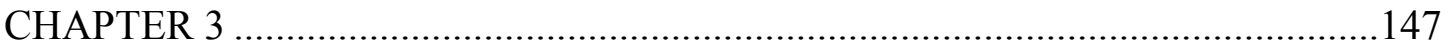

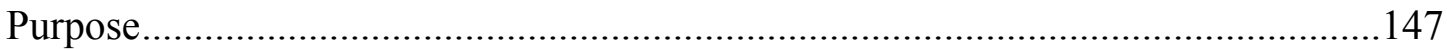

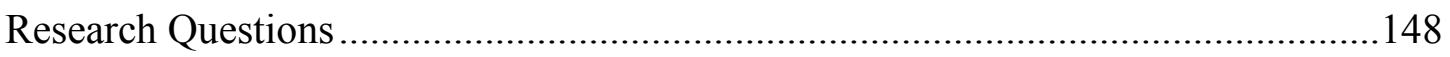

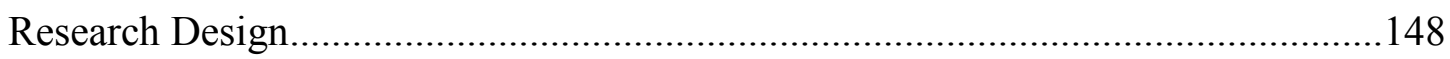

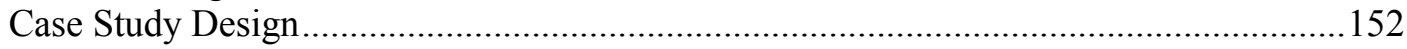

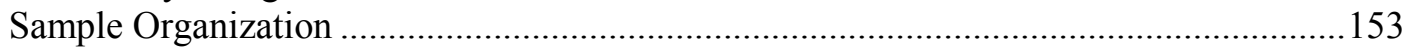

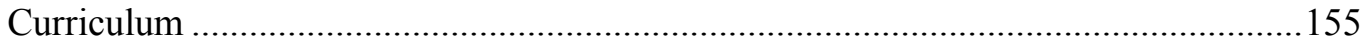

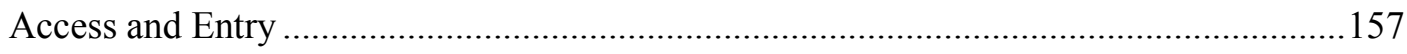

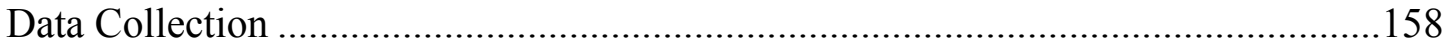

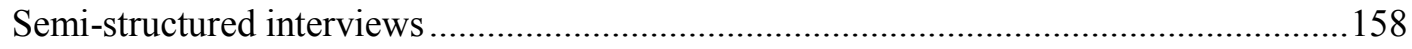

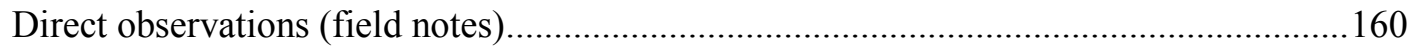

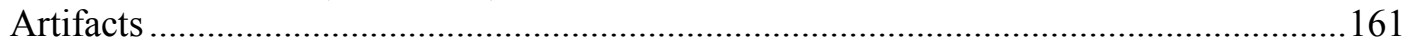

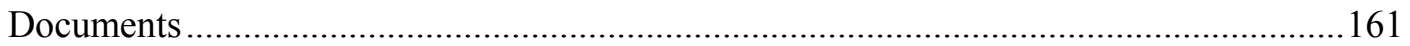

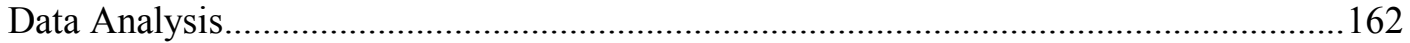

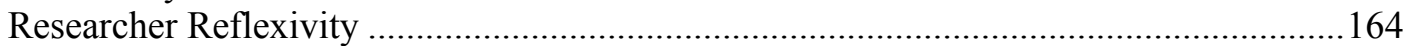

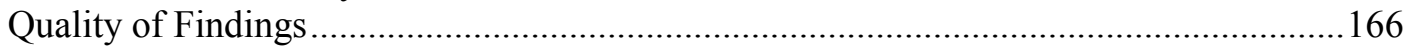

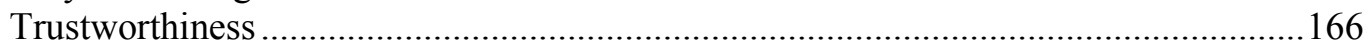

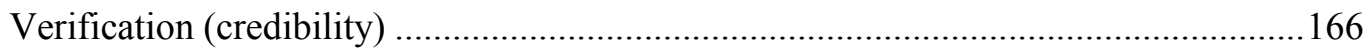

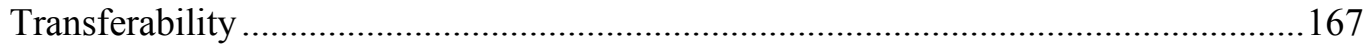

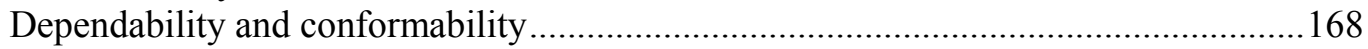

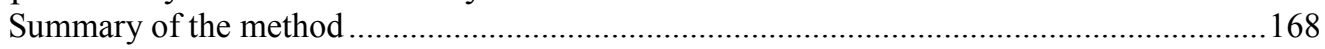

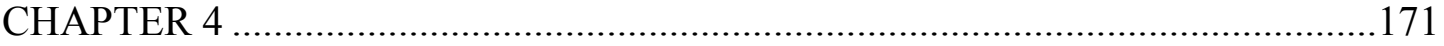

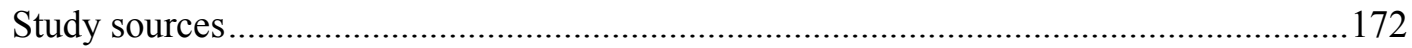

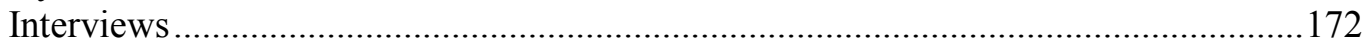

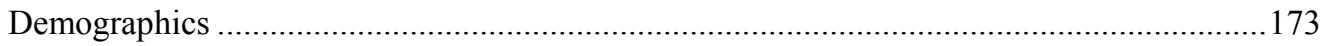

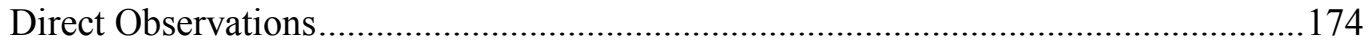

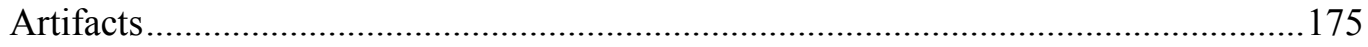

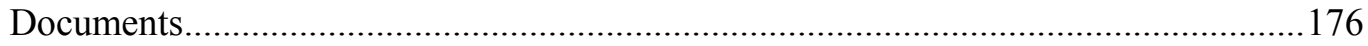

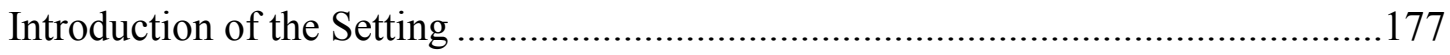

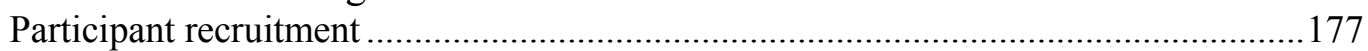




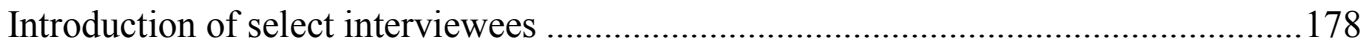

RQ1: What functionings are being supported by Youth Odyssey? ..........................180

Theme 1: Being more comfortable and capable in social settings and interactions..........181

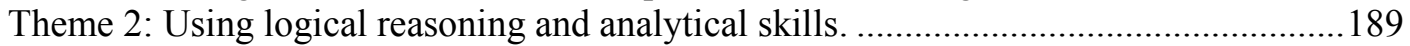

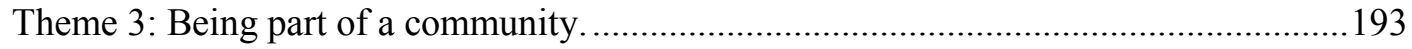

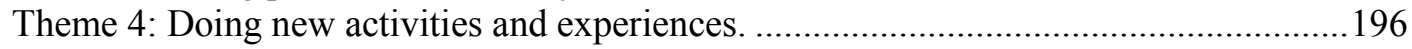

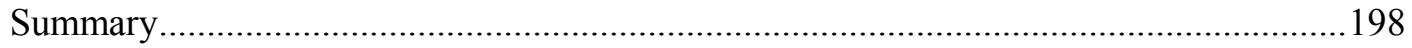

RQ2: How does Youth Odyssey help remove barriers for participants? ...................199

Theme 1: Reflecting positive role models and social behaviors ....................................201

Theme 2: Emphasizing personal growth and confidence ...............................................207

Theme 3: Countering difficult home or environmental influences..................................212

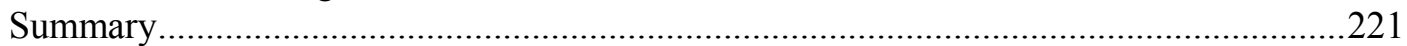

RQ3: What capabilities are Youth Odyssey creating for its participants?................222

Theme 1: Freedom to exercise agency through increased self-awareness, self-reflection,

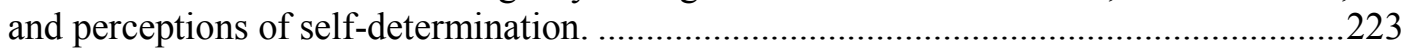

Theme 2: Opportunity to hone social skills....................................................................228

Theme 3: Having the freedom and ability to access support and resources.....................233

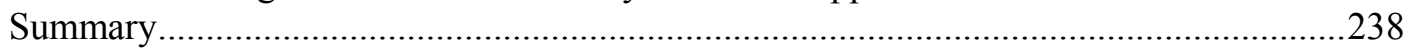

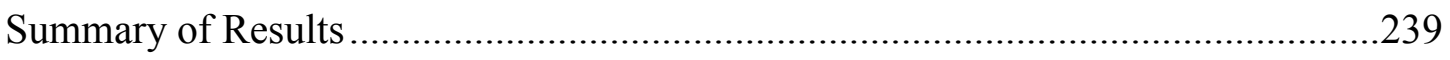

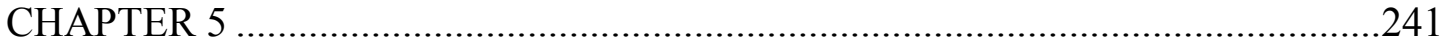

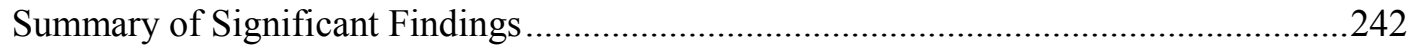

Theoretical Implications for SDP and Capabilities Approach Framework .......................244

Functionings Supported by Youth Odyssey Programs.................................................24

How does Youth Odyssey help remove barriers for participants? ...............................250

Capabilities Youth Odyssey created for its participants ............................................256

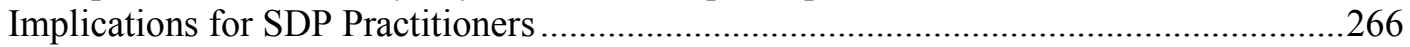

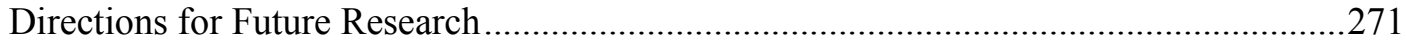

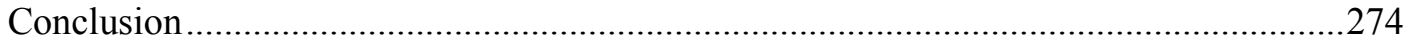

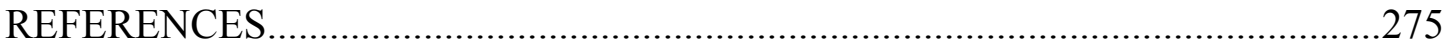

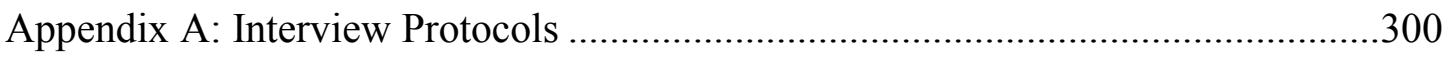

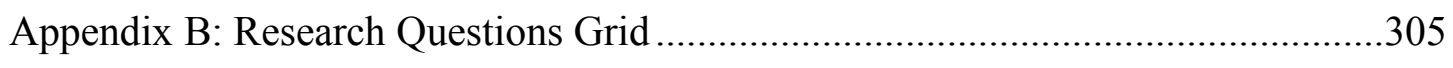

Appendix C: Interview Informed Consent Agreement .........................................309

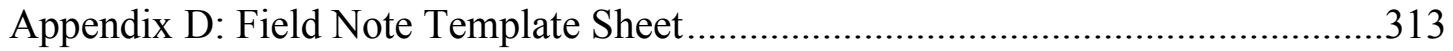

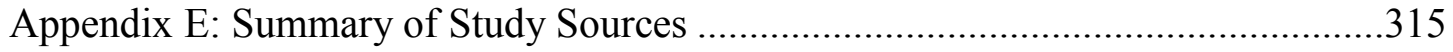

Appendix F: List of Identified Capabilities ...................................................... 327

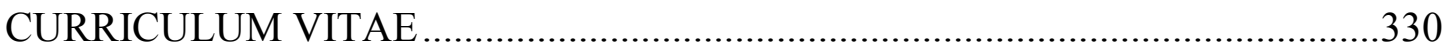




\section{LIST OF TABLES}

\section{TABLE}

PAGE

Table 1. List of Youth Odyssey employee interview subjects................................173

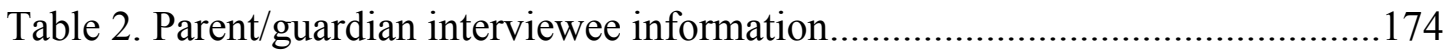

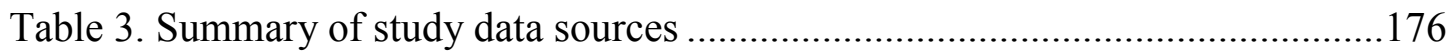

Table 4. Parent motivations to enroll participants into Youth Odyssey ....................179

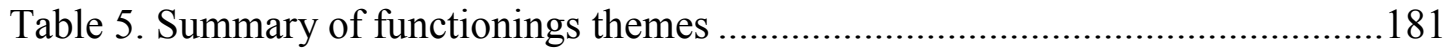

Table 6. Summary of participant barriers theme ..............................................20

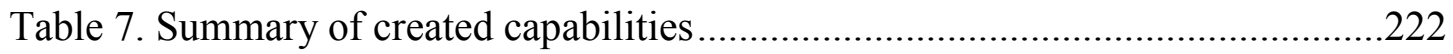

Table 8 Summary of subject names, designation, interview date, and time length ...315

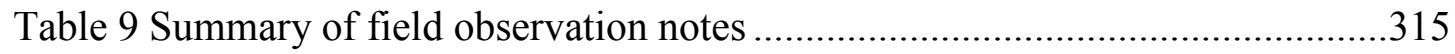

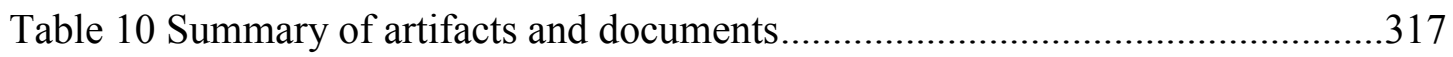




\section{LIST OF FIGURES}

Figure 1. Simplified visual interpretation of the Capabilities Approach ....................42

Figure 2. Flowchart of the Capabilities Approach based on case study ..................240 


\section{CHAPTER I}

\section{INTRODUCTION}

Sport is a global phenomenon. Whether it is a small community in rural Africa, or a neighborhood on the South Side of Chicago, chances are a group of individuals are taking part in either an organized game or engaging in free play. Sport's global popularity brings people together because sport is a universal language (Levermore, 2008a). For this reason, sport managers and sport researchers often make the case that sport can facilitate dialogue among different types of people to address larger societal issues. This belief has led to the creation of a movement known as Sport for Development and Peace (SDP).

SDP organizations use sport as the conversation starter to address societal issues unrelated to sport. Although there might be a connection to sport, these issues usually go beyond the playing field (Sanders, 2016). For example, an SDP organization may use soccer as a way to bring two different groups of people together, such as Israeli and Palestinian children, but then transition away from soccer to promote dialogue between the groups in hopes of breaking down existing barriers (Sugden, 2006). SDP organizations incorporate a range of theoretical frameworks to guide programming. Some examples include systems theory and structural, attitudinal, and transactional theory (Massey, Whitley, Blom, \& Gerstein, 2015), contact theory (Allport, 1954; Lecrom, \& Dwyer, 2013; Lyras \& Hums, 2009) as well as SDP-specific theory such as sport-fordevelopment theory (Lyras \& Welty Peachey, 2011). Although a program may have sound objectives, a program's design and structure will ultimately dictate whether it is 
successful (Coakley, 2011; Coalter, 2010; Darnell \& Black, 2011; Hartmann \& Kwauk, 2011; Levermore, 2008b; Spaaij \& Jeanes, 2013; Sugden, 2015). A well-tailored theoretical framework may help guide a program's design and structure.

Although some may believe that sport, by itself, promotes social change, some programs using sport have produced outcomes that actually reinforce negative social structures (Coakley, 2011). For example, a program used sport to teach socially vulnerable youth how to conform to the rules of traditional society as opposed to exercising their own individuality (Haudenhuyse, Theeboom, \& Coalter, 2012). In another study, sport and play was used as a coping mechanism to familiarize youth with traditional society's way of life in an attempt to do away with participants' undesirable social traits like resistance to authority (Burnett, 2001). The thought was, through participating in sport, participants learned lessons about societal values such as respecting authority, self-control and conforming to society's rules. In other words, participating in sport did away with elements that traditional dominant society viewed as deviant (Coakley, 2011). Thus, instead of the program helping each participant deal with the root of their individual struggles, it used sport to socialize participants into complying with dominant, and sometimes inequitable, social norms. This begs the questions, what solution did the program actually provide to participants, what problem did it solve and what theory, if anything, guided this process?

The importance of using theory to guide SDP programs has been well-established (Schulenkorf \& Spaaij, 2015). Although many guiding frameworks for SDP exist, programmers must choose a theory that is well-suited to effectively implement the objectives of their organizations and address the issues the program seeks to address. 
Further, a program should focus on the needs of those they seek to serve (Spaaij \& Jeanes, 2013). One way of doing so is incorporating local stakeholder voices into the planning process (Schulenkorf \& Spaaij, 2015). Because sport can be used in a variety of ways, and the needs of the people an organization seeks to help can differ from person to person, the objectives of SDP organizations vary. Studying SDP therefore requires choosing a flexible theoretical framework that can accommodate this variety. One alternative framework that has not been fully conceptualized to SDP is the Capabilities Approach (Rossi, 2015). This study introduces the Capabilities Approach and explores its potential as a theoretical framework used in SDP research as well as programming. The Capabilities Approach has been utilized in various disciplines, such as health, education, and economics, so it is my hope that it can also be operationalized as a guiding framework for SDP programing.

\section{Sport for Development and Peace}

Research on Sport for Development and Peace (SDP) is relatively new. The concept of social development, the process of improving someone's life through sport, however, is not a new phenomenon. Sport was historically used as part of the colonization process to socialize foreign populations into embracing the social structures and political systems of the conquering culture (Cavallo, 1981; Darnell \& Kaur, 2015; Kidd, 2008; MacAloon; 2006; Pitter \& Andrews, 1997). While remnants of these ideals exist today, the more common understanding of SDP is the use of sport as a vehicle for broad, sustainable interventions with various goals in mind (Hartmann \& Kwauk, 2011; Kidd, 2008; Schulenkorf, Sherry, \& Rowe, 2015). 
The concept of SDP is diverse and cross-disciplinary, so practitioners and academics define SDP differently. For the purposes of this study, SDP is defined as efforts to use sport, play or physical activity as a tool to advance social change (Coakley, 2011; Levermore \& Beacom, 2009). Sport refers to more than just competitive play; instead sport refers to some sort of physical activity in the context of leisure (Haudenhuyse et al., 2012). Development, in a sport context, connotes the process of improving a person's life chances through what s/he learns in the program (Levermore \& Beacom, 2009). In other words, development is the process of improving a person's quality of life. Finally, peace refers to the process of decreasing violence and increasing distributive justice within a society (Gilbert \& Bennett, 2012).

SDP has become increasingly popular as a global development tool and the United Nations embraced sport, play, and physical activity as tools to help the process of development. As a result of the United Nations' support of SDP, programs proliferated throughout the world. Many programs fall within one of the five thematic groups created by the UN Inter-Agency Taskforce on SDP: (a) sport and child and youth development, (b) sport and gender, (c) sport and peace, (d) sport and persons with disabilities, and (e) sport and health (United Nations Sport for Development and Peace International Working Group, 2008). The working groups facilitated information-sharing based on practitioner insight and what was occurring in the field (United Nations Office of Sport for Development and Peace, 2011). Some examples of SDP programs include ones focused on sport and youth socialization (Haudenhuyse, et al., 2012), sport and gender equity in sport and society (Swiss Academy of Development, 2005), sport and empowerment (Hayhurst, 2013), sport and peace-building (Schulenkorf, 2010; Sugden, 2006, 2010, 
2015), sport and cultural understanding (Lecrom, \& Dwyer, 2013), sport and disability (Goodwin et al., 2004), and sport and health (Clark et al, 2006). Each program used sport as a tool to advance social change.

While SDP is more frequently being used as a tool to advance social change, concerns exist regarding sport-based programming. First, an unfounded belief exists among some organizations and their stakeholders that sport can solve the world's problems (Coakley, 2011; Schulenkorf \& Spaaij, 2015). Sport itself is neither inherently positive or negative (Coakley, 2011; Hums \& Wolff, 2014; Kidd, 2008; Sugden, 2010). Therefore, any theoretical framework that accompanies SDP programming is crucial in determining its success. Critical literature has identified the phenomenon of the sport evangelist, individuals who believe sport is a panacea for addressing many of society's issues (Coalter, 2007; Giulianotti, 2004).

Sport evangelists view sport "as an effective activity for solving problems and improving quality of life for individuals and society alike" (Coakley, 2011, p. 307). However, as discussed by Schulenkorf and Spaaij (2015), sport evangelists are often unequipped "to facilitate complex changes that are meaningful to local communities. Instead, to make a realistic and beneficial difference to disadvantaged groups, SDP interventions must be properly conceptualized and theorized" (p. 72). Critical scholars have drawn attention to the philosophical underpinnings and results of SDP programming using a sport evangelist approach (Coakley, 2011). This is the case because often times these programs use sport to control the groups participating in the program or modify their behavior to conform to the values espoused by the sport evangelists as opposed to assisting a participant to address his or her individual needs (Spaaij \& Jeanes, 2013). 
Programs utilizing a sport evangelist framework have at times avoided critical scrutiny, even after failing, because of the general belief that sport is inherently positive and thus a positive influence for program participants (Coakley, 2011).

The second challenge is criticism concerning SDP program strategies. Criticism exists about the potential negative aspects of using sport as the hook for development and socialization purposes. Policies underpinning SDP programs are at times unclear, poorly conceived and executed, or use ideology that reinforces western social norms, sometimes to the detriment of those who are meant to benefit from the programs (Hartmann \& Kwauk, 2011; Hayhurst, 2009; Nicholls, Giles, \& Sethna, 2010). A program may also be dominated by its external funding partner, which could compromise its mission or effectiveness (Burnett, 2015). When a program becomes dependent on its funding source, the objectives or beliefs of SDP donors may at times supersede the values of the SDP programs themselves to ensure funding is received (Burnett, 2015). This could further compromise the program's mission to the detriment of participants (Hartmann \& Kwauk, 2011; Hayhurst, 2009; Nicholls, Giles, \& Sethna, 2010).

A third and final concern regarding the use of SDP is the tendency of programs to exclude the voices of the people they seek to serve from the planning process. Critics argue that the local voices of those impacted by the program are often displaced by agendas from the industrialized world (Burnett, 2015; Spaaij \& Jeanes, 2013). This creates issues concerning how practitioners obtain a holistic and contextual understanding of programs and the populations the programs aim to serve without collaborating with stakeholders who best know the needs of the local community. Thus, SDP administrators 
at times fail to address the needs of the populations they seek to serve because of their misplaced perspective.

In order to overcome this issue, the needs of the local community must be put ahead of the agendas of outside stakeholders such as funding agencies. Instead of using a pre-packaged SDP curriculum that may not fit the needs of the local community, practitioners should spend prolonged time in the local community to understand its social, political, and societal contexts (Hartmann \& Kwauk, 2011; Spaaij \& Jeanes, 2013). By understanding the contexts and what is important to participants, a program can empower participants to live what they individually believe are meaningful lives (Burnett, 2015; Darnell \& Kaur, 2015; Hartmann \& Kwauk, 2011; Lyras \& Welty Peachey, 2011; Massey et al., 2015; Schulenkorf, 2012; Schulenkorf \& Spaaij, 2015; Spaaij \& Jeanes, 2013).

To understand what is important to the people an SDP program seeks to serve, a theoretical framework is necessary to help gain the proper perspective to design and implement more effective programing. SDP programs have been paired with theory from outside sport management such as systems theory (Massey, et al., 2015), structural, attitudinal, and transactional theory (Massey, et al., 2015), contact theory (Allport, 1954; Lecrom, \& Dwyer, 2013; Lyras \& Hums, 2009), post-colonial theory (Darnell \& Kaur, 2015) and critical left-realist theory (Sugden, 2010) as well as SDP-specific theory such as sport-for-development theory (Lyras \& Welty Peachey, 2011). Each framework differs in terms of how it guides SDP programming; however, each theory articulates the need for SDP programs to understand and respect the nuances of local society (Burnett, 2015; Darnell \& Kaur, 2015; Lyras \& Welty Peachey, 2011; Massey, et al., 2015; Schulenkorf 
\& Spaaij, 2015; Spaaij \& Jeanes, 2013; Sugden, 2010). Therefore, exploring paradigms and theories that account for local context may help SDP programmers become more effective at planning, execution, and evaluation. SDP scholars are still searching for a framework flexible enough to accommodate the varied nature of SDP programs and enable practitioners to deliver meaningful outcomes for participants (Welty Peachey, 2015). One such paradigm is Human Development Theory, specifically the Capabilities Approach.

\section{Human Development Theory}

Similar to SDP, which defines development as improving a person's "life chances" (Levermore \& Beacom, 2009, p. 7), Human Development Theory defines development as the process of enlarging a person's choices so that s/he can lead a long, healthy, and creative life (Haq, 1995). Instead of viewing development onedimensionally, such as focusing on accumulating money to achieve well-being, Human Development Theory views development as encompassing cultural, social, political, and other aspects that lead to enriching a person's life and finding well-being in his/her life (Alkire \& Deneulin, 2009; Haq, 1995). This way, people are empowered to live the lives they want and pursue their passions.

Unlike other approaches to development that may focus on accumulating money or acquiring material goods, neither of which may result in achieving well-being (Sen, 1985), Human Development Theory is concerned with what matters to each individual person (Alkire \& Deneulin, 2009). People's abilities, such as improved health, knowledge and skills, should be cultivated so they can be used to lead productive lives, to live what each person feels is a "worthwhile" life (Alkire \& Deneulin, 2009; United 
Nations Human Development Report, 1990). However, what matters to each person is differs from person to person because each person possesses different values. So human development, fundamentally, is defined as a process of helping a person achieve what is valuable to that person individually at a specific moment in time (Alkire \& Deneulin, 2009). What is important may change over time. Ultimately, people themselves decide what kind of life they would like for themselves (Alkire \& Deneulin, 2009). Therefore, expanding a person's freedom to achieve different goals is important. Increasing one's freedoms is done through removing barriers to freedom in a person's life so s/he has more choices while respecting what types of advancement society will permit.

Viewing development in terms of freedom may also relate to SDP. Each person who participates in an SDP program has different reasons for taking part. When SDP programmers use an approach that does not take the time to learn about the local populations they seek to serve, and instead use a one-size fits all approach or a sport evangelist approach, they do not understand what is important to each participant. SDP programs should seek to help serve the individual needs of their participants so that these people can pursue living what they individually feel are worthwhile lives. In other words, an SDP programmer should ask what is important to that participant, or ask what can that person do and be in society? Hence, an SDP program's shortcomings may be addressed by adopting a guiding theoretical framework that looks to what people can accomplish as a way evaluate well-being and to meet the individualized needs of the local population it seeks to serve. One possible framework that evaluates well-being based on social arrangements is known as the Capabilities Approach. 


\section{The Capabilities Approach}

The Capabilities Approach is a normative framework, one that is ethical and based on values of society (Alkire \& Deneulin, 2009), that evaluates individual wellbeing based on what people are able to do and be in society (Robeyns, 2006). The Capabilities Approach was pioneered by Amartya Sen and further developed by his colleague Martha Nussbaum. A basis of their work was the premise that quality of life goes beyond the purely financial (Sen, 1985). Sen understood improving quality of life was based on removing obstacles that limit a person's freedom. Such obstacles may include cultural structures like religious beliefs or political agendas that persecute a certain gender or ethnicity, inhibiting a person from living the kind of life he or she values (Sen, 1999). The Capabilities Approach consists of a combination of inter-related fundamental concepts. These three fundamental concepts are (a) functionings, (b) freedoms, and (c) capabilities. These components are intended to help measure a person's well-being and help remove barriers. Negotiating these barriers helps people to pursue and achieve what matters to them on an individual basis so that they can live what they believe is a fulfilling life (Alkire \& Deneulin, 2009; Robeyns, 2005).

Functionings are what a person achieves during his or her life (Robeyns, 2017). They are accomplishments that a person values (Robeyns, 2005). Functionings are either states of mind (e.g. feeling well-rested) or activities (e.g. going to school) (Alkire, 2002a; Robeyns, 2011; Sen, 1999). No two persons' desires and ambitions are identical, making functionings very subjective (Frediani, 2010; Sen, 2005). A person's individual circumstances impact his/her ability to achieve a functioning. The ability of an individual to transform something s/he owns, (e.g. a bicycle) into a functioning (e.g. cycling as 
means of transportation), is influenced by what Robeyns (2005) calls conversion factors. A conversion factor is the "degree in which a person can transform a resource into a functioning" (Robeyns, 2005, p. 99). Conversion factors vary depending on the local environment in which one lives, including aspects such as local customs dictated by societal norms, and the characteristics a person was born with such as one's biological sex. Conversion factors highlight the importance of local context, meaning one's personal, cultural, and environmental surroundings, which come into play and may influence the application of the Capabilities Approach.

The second contextual aspect important to the Capabilities Approach is what Sen (1999) terms "freedoms." The Capabilities Approach recognizes two types of freedoms: process freedoms (what is important to an individual) and opportunity freedoms (a person's real opportunity to achieve a valued functioning, based on the culture and norms of a society) (Sen, 1999). Freedoms are important because they play a central role in what someone is allowed to do or be in life. Going back to the bicycle example, even if a woman wants to ride the bike but lacks the freedom to do so because society forbids women from riding bikes, the freedom to ride a bike does not truly exist. Not having the freedom to ride a bike limits mobility, thereby limiting access to education or employment. Increased freedom allows a person to pursue the life he or she envisions (Sen, 1999). However, decreased freedom hinders a person from living the life he or she envisions. The context of society therefore impacts the freedoms a person can exercise. The final critical element is known as capabilities. Capabilities "describe the real actual possibilities open to a person" to achieve what $\mathrm{s} / \mathrm{he}$ is passionate about (Alkire, 2005, p. 2). In other words, capabilities are a person's allowed ability to achieve 
something. Capabilities are influenced by what is taking place within society, because what is taking place in society impacts a person's functionings, and freedoms. Capabilities range in complexity from the most essential (e.g. the real ability to receive basic nutrition, find lodging and meet other the requirements necessary for survival), to the advanced (e.g., earning a doctorate or traveling the world). Therefore, although capabilities may refer to a diverse range of activities, each has the same goal of improving well-being.

The Capabilities Approach has been praised for its flexibility (Clark, 2005a, 2005b; Sen, 1999). Sen (1999) intentionally designed the framework to be adaptable to other disciplines, such as education, economics, and health, with the intent that it be used to address unique challenges. Further, by using the concepts of functionings, freedoms, and capabilities to expand a person's individual freedoms in life, the Capabilities Approach is a framework that implicitly embraces the importance of development on a personal level (Robeyns, 2003). Thus, this approach acknowledges that people, cultures, and social norms are different; therefore, a one-size-fits-all or group approach to development is not appropriate. Instead, individuals can select their own capabilities based on a society's freedoms and, in doing so, weigh each one based on his or her personal value judgments as well as societal influences (Clark, 2006).

A person seeks the freedom to choose activities and goals that he or she individually is passionate about and values. If $\mathrm{s} / \mathrm{he}$ is passionate about the world of business and wishes to pursue a career in business (a functioning), the Capabilities Approach dictates that sufficient freedoms (process and opportunity freedoms) should be present to allow this person to achieve the real possibility (a capability) of entering the 
business world regardless of, for example, gender or religious background. Or, from a more basic standpoint, if someone wishes to live a life where he or she receives adequate nourishment (a functioning), the Capabilities Approach should facilitate meaningful freedoms (process and opportunity freedoms) to make sure this person experiences the real possibility of being nourished (a capability). In both examples, the individual's desires are driving development, hence the Capabilities Approach's emphasis on individuality and diversity.

While individuality and diversity are perceived strengths of the Capabilities Approach, both aspects can also create challenges. The Capabilities Approach is intentionally designed to be vague (Sen, 1999). This vagueness can create questions, however, about how a practitioner or researcher actually operationalizes and implements the Capabilities Approach (Gasper, 2007). Another aspect that may complicate applying the Capabilities Approach to various fields is the role the concept of "central" capabilities, a list of basic or fundamental capabilities to which every individual is entitled (e.g. the right to life, bodily health, and bodily integrity) (Nussbaum, 2003, 2011). A difference of opinion exists among Capabilities Approach researchers as to whether there is a list of fundamental or universal capabilities to which all people are entitled. Should capabilities selection be based solely on the context of a situation (Clark, 2005a)? Should there even be a list at all (Sen, 2004)? Therefore, this disagreement exists within the literature.

The Capabilities Approach has been operationalized as a theoretical framework in a variety of settings in other fields of study. Operationalization is the process of adding sufficient specifics to a theory so researchers can apply it in a given discipline to solve 
specific real-world problems (Alkire, 2001; Comim, 2001). The approach has been applied to a diverse range of disciplines such as education (McLean \& Walker, 2012; Satio, 2003), geography (Lambert, Solem, \& Tani, 2015), disability (Terzi, 2005), health (Dubois \& Trani, 2009), economics (Schischka, Dalziel, \& Saunders, 2008), environmental refugees (Kim, 2012), self-determination of indigenous people (Murphy, 2014), intergenerational justice (Gutwald, Lebmann, Masson, \& Rauschmayer, 2014), and the tourism industry (Croes, 2012). Because of its diversity, those seeking to operationalize the Capabilities Approach must engage local stakeholders to gain a specific local context by which to apply the theoretical framework. Operationalizing the Capabilities Approach varies from discipline-to-discipline, presenting unique opportunities and challenges.

This emphasis on engaging local stakeholders and understanding community values is what makes the Capabilities Approach an attractive potential framework to SDP. For an SDP program to succeed, the local community's needs must be placed above the agendas of the agencies involved in the program (Spaaij \& Jeanes, 2013). Practitioners should engage the whole local community to understand their needs before designing a program. Spending time with the local community builds understanding of what is important to the locals, which is what should be emphasized. Svensson and Levine (2017) suggested the Capabilities Approach could be explored as an alternative framework for SDP programs because it is based on understanding what is important to those in the local community. 


\section{Significance of Study}

Although the SDP field has experienced tremendous growth, critics question the actual benefits of SDP and whether SDP should be integrated into a broader framework of development (Darnell \& Black, 2011; Levermore, 2008; Spaaij \& James, 2013; Sugden, 2015). While increased numbers of researchers and practitioners have elevated the popularity of SDP, criticisms concerning SDP programs remain. Some programs operate on the belief that sport can solve the world's problems, while others are dominated by outside stakeholders, and many more marginalize local stakeholders by not including their voices when planning programming. The field needs a theory that is wellsuited to implement the wide-ranging objectives of the many SDP organizations and addresses criticisms that question the general belief that sport can be used as an effective tool to address societal problems (Welty Peachey, 2015).

In order for target groups to benefit from SDP programs, programs must be properly conceptualized and grounded in an appropriate theoretical framework (Schulenkorf \& Spaaij, 2015). Researchers critical of SDP programs have called for alternative theoretical frameworks to challenge the naïve and at times damaging structures sometimes used in SDP programming that promote the premise that sport is the cure for all of the world's ills, or the belief that Western values are preferred to those of the developing world (Coakley, 2011; Coalter, 2010; Darnell, 2007; Hayhurst, 2013). Such a framework should incorporate a more locally grounded, holistic approach that listens to a local population's voices in order to build a meaningful understanding of the local context where the program operates to address each participant's individual needs (Hayhurst, 2013; Spaaij \& Jeanes, 2013). 
The Capabilities Approach is premised on the notion that what people believe and aspire to be is going to differ from person to person. The role of government and society's private institutions is to negotiate as many obstacles as possible that prevent a person from pursuing and accomplishing what is important to him/her on an individualized basis so s/he can live a meaningful life. This fundamental tenant embraces the notion of respecting local context from individual, community and societal standpoints, something has been highlighted by other frameworks used in SDP as being critical to a program's success. This is also a concept critical scholars point to as necessary for successful outcomes. Therefore, because of its flexibility as well as emphasis on local factors, local voices, and agency, the Capabilities Approach may address the criticism from SDP scholars that program practitioners fail to focus on local context as well as help facilitate more successful SDP programs (see Rossi, 2015).

\section{Purpose of Study}

The purpose of this study was to explore what role an SDP program plays in participants achieving their capabilities. This purpose was chosen for two reasons. First, the SDP literature criticizes program effectiveness from planning, execution, and evaluation standpoints. Second, when designing programs, critical scholars have called for the use of alternative theoretical frameworks that respect a program's local context and incorporate the viewpoints of local stakeholders into the planning process (Schulenkorf \& Spaaij, 2015). If the Capabilities Approach can help facilitate inclusion of local context and demonstrate that SDP programs play a role in improving a participant's well-being, it could serve as a guiding framework to improve SDP programs. Further, Svensson and Levine (2017) believe the Capabilities Approach can 
promote a greater understanding of SDP from theoretical, policy, and practitioner perspectives. Svensson and Levine (2017, p. 919) encouraged future research to consider the varying perspectives of the Capabilities Approach and "its usefulness as well as its limitations for enhancing our knowledge of SDP" practice, policy and research. The organization chosen for this qualitative case study was Youth Odyssey, a 503(c)(3) nonprofit organization located in Corpus Christi, Texas that works with at-risk youth through adventure programming.

\section{Research Questions}

This study was guided by an overarching research question: what role does Youth Odyssey, a youth oriented SDP program located in an urban setting in the southern United States, play in participants achieving their capabilities? The following three research questions assist in answering the aforementioned question and address the purpose of the study:

RQ1: What functionings are being supported by Youth Odyssey?

RQ2: How does Youth Odyssey help remove barriers for participants?

RQ3: What capabilities are Youth Odyssey creating for its participants?

\section{Limitations and Delimitations}

No research design is perfect (Patton, 2014). Tradeoffs exist due to aspects such as limited time, limited resources, and failure to grasp complex concepts (Patton, 2014). This study had several limitations. First, the inherent weakness of qualitative research must be addressed. In qualitative research, the researcher himself or herself is the one gathering information and thus serves as an instrument (Creswell, 2014). Although qualitative researchers often use an interview protocol as part of research, they are the 
ones asking questions directly and can follow up with additional questions of their own choice in a fluid environment. Further, a researcher may collect field observations using a protocol. In this study, I was the one responsible for capturing data taken from the natural setting through interviews and field observations. Therefore, the researcher's background, experience, and biases must be limited as much as possible (Patton, 2014). Second, the findings in this study were limited to one specific organization because this study used a case study approach. These findings cannot be generalized, instead subsequent replications of studies exploring operationalizing of the Capabilities Approach to an SDP organization must occur.

Finally, several delimitations exist. Social constructivism was used as the research design for this study. It was used instead of other research designs because it captures the complexity of the data collected in qualitative research (Creswell, 2013; Lincoln \& Guba, 2013). Social constructivism honors the belief that people construct multiple realities through their interactions with others and their lived experiences (Creswell, 2013; Gergen \& Gergen, 2008; Glesne, 2016). Individual values are to be honored by the researcher, and I sought to understand these values in the realm of SDP (Creswell, 2013). In this study, data were collected from multiple individuals who may have different constructed realities, meaning they might experience the same event differently. Each reality, and each subject's individual values, should be respected, as respect for individualism is also an important defining feature of social constructivism as well as the theoretical framework used for this study, the Capabilities Approach (Sen, 1999).

The other study delimitation dealt with the study's sample organization. Although this study focused on one SDP organization in a specific setting, other organizations 
pursuing similar objectives exist all over the world (Schulenkorf, et al., 2015). This organization was chosen to learn more about what operationalizing the Capabilities Approach in an SDP program might look like because the sample organization fit the criteria of a typical SDP organization. Further, this study focused solely on the Capabilities Approach as a theoretical framework. However, many additional frameworks exist that SDP practitioners may utilize (Edwards, 2015; Lyras \& WeltyPeachey, 2011; Schulenkorf, 2012; Sugden, 2010). This study chose to solely explore the Capabilities Approach.

\section{Definitions}

The Capabilities Approach - A normative framework that evaluates individual well-being and social arrangements based on what people are able to do and be in society (Robeyns, 2006). The Capabilities Approach is grounded in the notion that development is concerned with the process of enhancing quality of life by expanding the freedoms an individual enjoys (Sen, 1999).

Capabilities -The actual possibilities open to a person in life (Alkire, 2005).

Development - The processes of improving a person's overall quality of life (Alkire \& Deneulin, 2009). It is further defined as a scientific approach towards modernization trying to improve the "life chances" of those that a program serves (Levermore \& Beacom, 2009, p. 7).

Freedoms - The ability to act on behalf of what matters to a person, and one's real opportunity to achieve a valued functioning, based on societal norms and culture.

Functionings - The achieved actions and activities people value and have reason to value within the context of societal norms (Robeyns, 2005, 2017). 
Global North - Developed, high income nations often in the western hemisphere (Levermore \& Beacom, 2009).

Global South - Low income nations often in the developing world (Levermore \& Beacom, 2009).

Human Development Theory - A holistic paradigm that defines development as the process of enlarging a person's choices so that s/he can lead a long, healthy, and creative life (Haq, 1995)

Peace - A "process-oriented pattern of the international system, which is marked by decreasing violence and increasing distributive justice" (Gilbert \& Bennett, 2012, p.

$6)$.

Sport for Development and Peace - An approach that utilizes sport as a vehicle or a hook for broad, sustainable interventions with various goals in mind (Hartmann \& Kwauk, 2011; Kidd, 2008; Schulenkorf et al., 2016).

Sport - All physical activity that contributes to physical fitness, mental wellbeing and social interaction (United Nations, 2003). Sport also includes play, organized sport at both the casual or competitive level, and all indigenous sports or games (United Nations, 2003). 


\section{CHAPTER II}

\section{LITERATURE REVIEW}

\section{Introduction}

Development, the processes of improving a person's overall quality of life (Alkire \& Deneulin, 2009), is an evolving phenomenon. Approaches to development come in different forms (Levermore \& Beacom, 2009). Development was traditionally thought of in economic terms, in which a person's overall quality of life would improve by increasing one's financial resources (Anand \& Sen, 2000). Through increased buying power, a person could gain more material goods, and hopefully improve his or her wellbeing. However, increased financial resources and material goods only provide a partial interpretation of well-being. Well-being is complex. Economist Amartya Sen described the complexity of well-being, which may not be so easily addressed through an economic solution.

There are many different approaches to understanding a person's interests and judging whether the person is doing well. Various, though related, questions can be asked: "Is he well off? Is she happy? Does he feel fulfilled? Does she have much freedom? Can he get what he wants? Can she do what she would like to do? Is society being good to him? Is she having a good life? These distinct questions have their own peculiar relevance in particular contexts and each has an importance of its own (Sen, 1985, p. 1). 
Sen (1985) defined well-being as relating to one's personal achievement: "how 'well' is his or her "being"” (p. 5)? Whether someone had achieved well-being was not a yes or no question. It involved more complex issues. Answering these questions raised by Sen required a more in-depth understanding of well-being that went beyond the procurement of material goods. Sen spent several decades attempting to develop answers to these questions, and his approach to understanding well-being evolved throughout this process. Sen's original theory on development and well-being focused on material goods, which he called commodities (Sen, 1981). Sen developed this theory while studying famine and starvation in regions throughout the developing world. In particular, Sen identified a famine that occurred in India where, although food existed, access to the food was not attainable for many people (Sen, 1981). People starved because not enough people had the ability to access and obtain the food. Maybe the person was too poor to afford food at the current price, perhaps an individual could afford food but could not travel to where food was being distributed, or corrupt government officials may had been hording food for themselves. Therefore, under Sen's entitlement approach, the focus was on what someone was entitled to fairly and legally receive according to the rules of society. Here, avoiding starvation focused on a person's ability to fairly command the commodity of food through legal means (Sen, 1981). Those who could command food by traveling to where it was located and paying, or accessed it through other means received it; those who did not starved.

Sen's entitlement approach focused on how people can gain access to commodities within the rules of society. Securing commodities (e.g. food) allowed a person to access its characteristics (e.g. eat the food) and benefits (e.g. nourishment) 
(Sen, 1985). However, if a person can access the commodity (e.g. food) but cannot utilize its benefits because of other reasons (e.g. disease prevents adequate digestion), then that need (e.g. nourishment) is not met. In Sen's example, if a person does not have an entitlement to a commodity such as food, s/he will starve. But how does that entitlement to the food help to achieve well-being if something else such as a disease deprives someone of adequately using the commodity? Possessing a commodity does not fully explain well-being. Therefore, Sen's theory of well-being continued to evolve as he attempted to better understand how one achieves well-being.

Instead of focusing solely on access to commodities to achieve well-being, Sen (1985) looked to what a person could succeed in doing with the commodities that $\mathrm{s} / \mathrm{he}$ owned. By focusing on what a person can do or be, as opposed to what material goods a person can own or access, the concept of well-being went beyond money and material wealth to a matter of personal achievement. Sen compared his approach to development with other approaches, such as commodities or a utility-based approach. He quickly dispensed with why a commodities-based approach was a flawed way to achieve wellbeing: "a person's well-being is not really a matter of how rich he or she is...Commodity command is a means to the end of well-being, but can scarcely be the end itself" (Sen, 1985, p. 28). In other words, collecting more materials, by itself, will not make someone happy. Gaining commodities may help get a person on the road toward well-being, but it does not guarantee that well-being will be achieved or that a person will become happy.

Utility is concerned with a person's mental characteristics such as happiness, pleasure, or desire (Sen, 1992, 1999). However, utility is very subjective. Under a utility approach, well-being is understood according to how a person values the life s/he is 
living, rather than the life s/he aspires to live (Sen, 1985). So long as a person is subjectively happy and/or their desires are being met, well-being is present. However, such a limited inquiry into well-being distorts the concept of well-being itself (Sen, 1999).

Utility can provide a limited understanding of well-being because a person can learn to accept a deplorable life. "A person who is ill-fed, undernourished, unsheltered and sick can still be high up in the scale of happiness or desire-fulfillment if he or she has learned to have 'realistic' desires and to take pleasure in small mercies" (Sen, 1985, p. 21). With utility, one's mental state is what is important. If a person is happy with the status quo - with little freedom, food, or living in an unjust society - high utility exists (Sen, 1999).

Seeking a more comprehensive understanding of well-being, Sen's entitlement approach evolved from one that focused on commodities into one that focused on freedom and what someone could do and be in society. Sen (1999) concluded that expanding freedom was the primary end and means of development. Freedom plays an instrumental role in the "different kinds of rights, opportunities, and entitlements contribute to the expansion of human freedom in general, and thus to promoting development" (Sen, 1999, p.37). Commodities only go so far if a person is constrained by society and does not have the opportunity to utilize them and utility can form the basis of happiness but still mean a person has not achieved well-being. But, by focusing on freedom and what someone could do and be, Sen placed freedoms at the center of a development approach that focused on an individualized understanding of well-being. 
As part of his approach to well-being that promotes freedom, Sen identified five types of freedoms that play an important role in a free society. They are "(1) political freedoms, (2) economic freedoms, (3) social opportunities, (4) transparency guarantees, and (5) protective security" (Sen, 1999, p. 38). Political freedoms are one's civil rights. Economic freedoms reflect a person's ability to produce, sell/acquire, and consume commodities, all which relate to income. Social opportunities are society's ability to provide education, healthcare, and the like to citizens. Transparency guarantees are the ability for people to live in an open society that guarantees disclosure of information to help prevent corruption, and unethical behavior. Finally, protective security is the ability of a society to provide social safety net services for those who face starvation or unemployment to make sure that the most vulnerable citizens do not slip through the cracks (Sen, 1999). Societies that have all five instrumental freedoms enable a person the freedom and ability to pursue well-being through achieving a life that he or she values. The question becomes, how does one integrate people into development so that the human aspects of development are emphasized? It is this question that helped facilitate the creation of Human Development Theory.

\section{Human Development Theory}

Human Development Theory was established under the leadership of Mahbub U1 Haq (1995), a Pakistani economist and further developed under Sen (2009). Human Development Theory defines development as the process of enlarging a person's choices so that people can lead long, healthy, and creative lives (Haq, 1995, Ranis, Stewart, \& Ramirez, 2000). Human Development Theory views development as expanding a person's choices in all areas of life, beyond economics and into the realms of social 
justice and equality (Anand \& Sen, 2000). Through enlarging a person's life choices, a person can enjoy longer, healthier, and more creative lives (Haq, 1995).

The difference between economic development theories and Human Development Theory is that economic development theory measures well-being according to a person's economic ability and access to commodities, while human development evaluates wellbeing by examining what a person has the freedom to do and be in society. When comparing the two approaches, there are two shifts: "first, the analysis shifts from the economy to the person. Second, the currency of assessment shifts from money to the things people can do and be in their lives, now and in the future" (Alkire and Deneulin, 2009, p. 23).

Human Development Theory "performs an important service in questioning the presumed automatic link between expanding income and expanding human choices" (Haq, 1995, p. 15). Rising incomes and expanding outputs, in the human development framework, are seen as the means and not the ends of development (Fukuda-Parr \& Kumar, 2009). Higher incomes, by themselves, might not guarantee that one improves well-being (Fukuda-Parr \& Kumar, 2009). Improving a person's individual freedoms, one's ability to perform a diverse range of activities in life, is more likely to improve well-being (Sen, 1985). Therefore, individualism is at the center of human development (Haq, 1995).

Human development has several defining features. First, Human Development Theory focuses on people and how they benefit from policy (Haq, 1995). Development is analyzed and understood in terms of people, and how much people benefit from a nation's policy. Although generating money is important, the focal point for success in 
human development policies is whether people's lives are bettered, as opposed to just whether the they experienced positive economic growth (Alkire and Deneulin, 2009; Haq, 1995). Second, Human Development Theory examines two types of functionings those that are a part of being a human, such as improving a person's knowledge, health, and the like, and those that a person acquires over their life, such as employment opportunities to attain better jobs or political opportunities such as the opportunity to vote (Haq, 1995). Both types of functionings must exist in society; a person must be able to improve themselves throughout life and also have equitable access to opportunities throughout life.

Another defining feature of Human Development Theory is its holistic nature. Economic prosperity is just one way of enriching people's lives (Sen, 1989). Human Development Theory embraces not just a nation's economy, but also its social, political, and cultural systems so that all receive equal attention (Haq, 1995). Finally, Human Development Theory embraces the notion that ople are both the means and ends of development. This means that people are not to be thought of as human capital that are part of the economy. Instead, "human beings are the ultimate end of development - not convenient fodder for the materialistic machine" (Haq, 1995, p. 16).

Human Development Theory is also ground in four essential components: equity, sustainability, productivity and empowerment (Alkire and Deneulin, 2009; Haq, 1995). Since the purpose of development is to enlarge people's choices, people must have equal access to opportunities. If the process of development occurs without equity, a society restricts access to choices and opportunities for some individuals in a society, which is fundamentally unfair. The emphasis on equity draws on the notion of distributive justice, 
and that some people may require preferential treatment due to disadvantage in their life (Alkire and Deneulin, 2009). However, equity is limited only to equity in opportunity, it is up to the individual person to achieve their desired result on his or her own merit.

The second component is sustainability. Simply, sustainability refers to the need for future generations to enjoy the same opportunities that were afforded to the current generation (Haq, 1995). The next generation should be able to enjoy using different resources, whether it be "physical, human, financial and environmental" so that they can enjoy similar levels of well-being (Haq, 1995, p. 18). Just as with equity, "everyone should have equal access to development opportunities - now and in the future" (Haq, 1995, p. 19). The third essential component of human development is productivity, which is in reference to the need for people to maximize their potential (Haq, 1995). Although economic productivity is a part of human development, it should be considered only part of the human development model. Empowerment is the final component (Alkire \& Deneulin, 2009; Haq, 1995). Human development is concerned with making people active participants in their lives so that they have the power to take control and make decisions that shape their lives (Haq, 1995). Once empowered, a person can make choices that relate to his or her values. Each person has different values that change over time, so human development must accommodate the changes that occur in a person over time (Alkire \& Deneulin, 2009).

Human Development Theory is often compared with human capital theory. Although the two approaches sound similar, they are very different. Human capital theory is a theoretical approach that seeks to augment a person's abilities through skill and knowledge accumulation so s/he can better produce in the workplace, and contribute to 
economic output (Sen, 1997, 1998). However, with human development, the abilities of a person are improved so that person can accomplish the things that they have reason to value, as opposed to improve economic output (Fukuda-Parr, 2002; Sen, 1998). The major difference between the two approaches is that human capital is focused on economic growth as the way to achieving well-being while human development seeks to build a person's ability to pursue his or her individualized passions as the way to achieve well-being (Fukuda-Parr, 2002). Human development is intended to help promote what that person is seeking to achieve in life (Sen, 1998).

To reflect the holistic nature of development that was emphasized in Human Development Theory, Haq began publishing human development reports through the United Nations Development Program. The first human development report was published in 1990, analyzing the state of human development (McNeill, 2007). Today, human development reports are published annually, drawing on data concerning nutrition, health, education, political freedom, work, the environment, security, and other aspects of a person's life (Alkire \& Deneulin, 2009). Each human development report has a focus or theme. The first human development report was on human rights and human development (United Nations, 1990). Human development reports have been credited with impacting the international community and its way in which development is understood (McNeill, 2007, Sen, 1999).

Operationalizing the human development approach involves embedding elements of the framework in a manner that allows the measuring of variables corresponding to the aspects of freedom (Fukuda-Parr, 2003). One such way of operationalizing the human development approach was creating the human development index. The human 
development index (HDI) is a composite index regarding socio-economic progress intended to measure human the basic concept well-being according to enlarging an individual's choices (Haq, 1995). Robeyns (2006) explained the HDI in detail and also discussed some elements of human development reports:

The HDI is an index between 0 and 1 , whereby a country that would have the highest average achievement on each of the functionings would score 1 . The functionings selected for the HDI are life expectancy at birth, education (measured by adult literacy and educational enrollment rates, whereby the former is weighted for $2 / 3$, and the latter for $1 / 3$ ), and adjusted GDP per capita, which serves as a proxy for the material aspects of functionings well-being. The position of some countries differs significantly depending on whether countries are ranked using GDP or HDI. For example, in 2004 the United Arab Emirates ranked 23th in terms of GDP per capita, but only $46^{\text {th }}$ in terms of HDI (mainly due to its relatively poor educational performance). However, the Human Development Reports contain more than just human development statistics: each year the report focuses on a theme that is of particular importance to development... (p. 361). Although the HDI's accuracy has been criticized (Neumayer, 2001; Srinivasan, 1994), the HDI and human development reports assist in measuring human development and allow researchers to operationalize the human development approach. Peercy and Svenson (2016) used relevant data from several HDI and human development reports and found an association between higher national social equity levels and higher national post-secondary educational levels. Fukuda-Parr, Raworth and Kumar (2002) reviewed how the HDI has been used as an evolution tool for public policy. Desai (1994) used the 
HDI to measure political freedoms among nations by creating a political freedom index. Therefore, the HDI and human development reports have led to the creation of varied studies.

Although some have embraced Human Development Theory, others have criticized its underpinnings. For example, Ranis, Stewart, and Ramirez (2000) argued the definition of human development was very broad and that the theory must be strengthened before any positive relationship between of human development and economic growth can exist (Ranis et al., 2000). Srinivasan (1994) criticized the HDI, questioning the underlying data and collection methods that make up the HDI and the statistics calculated. Srinivasan (1994) argued

the HDI is conceptually weak and empirically unsound, involving serious problems of noncomparability over time and space, measurement errors, and biases. Meaningful inferences about the process of development and performance as well as policy implications could hardly be drawn from variations in HDI (p. 241).

Srinivasan's (1994) criticism of how HDI was calculated was not a unique argument, as others have questioned the HDI's methodology (Neumayer, 2001). Thus, a lack of consensus regarding the HDI's methodology may be a drawback of Human Development Theory.

Despite this criticism, Human Development Theory has established itself as a holistic, human centered approach. While Human Development Theory is people-centric, each person is different. The choices a person makes in life relate to one's individual values. Therefore, one's values are important because they dictate what a person does in 
life. Since each person possesses different values human development is, fundamentally, a process of helping individuals achieve what is valuable for them at a specific moment in time (Alkire \& Deneulin, 2009).

Human Development Theory's emphasis on individualism led Sen's (1989) evaluation of development and achieving well-being to focus on the process of enabling individuals to possess the freedom to choose between different ways of living. Alkire and Deneulin (2009) agreed with Sen's (1989) thought process to focus on freedom, as they said, "to become agents of their own lives [and live the lives they value], people need the freedom to be educated, to speak in public without fear... [and to have basic rights such as the] freedom of expression and association" (p. 28). The key to development for Sen is freedom and the essential question is "whether people have greater freedoms today than they did in the past" (Alkire \& Deneulin, 2009, p. 31). Therefore, quality of life can be improved by negotiating barriers and hindrances that prevent a person from exercising freedom of choice and obstruct opportunities to live the lives a person values (Alkire \& Deneulin, 2009). This emphasis on removing obstacles to an individual's freedoms and enlarge a person's choices in life led to the creation of a normative framework to assess well-being as part of facilitating the objective of Human Development Theory. This framework is known as the Capabilities Approach. The following is a comprehensive overview of the Capabilities Approach.

\section{The Capabilities Approach}

The Capabilities Approach is a normative framework that evaluates individual well-being and social arrangements based on what people are able to do and be in society (Robeyns, 2006). Alkire and Deneulin (2009) argue that the fundamental idea of the 
Capabilities Approach is that "social arrangements should aim to expand people's capabilities - their freedom to promote or achieve what they value doing and being" ( $\mathrm{p}$. 31). Therefore, the framework assesses quality-of-life by asking the question "what is each person able to do and to be" (Nussbaum, 2011, p. 18).

The Capabilities Approach was pioneered by Sen and later furthered by his colleague, Martha Nussbaum. Grounding the Capabilities Approach in Human Development Theory, Sen emphasized a person's freedoms and the ability to achieve what $\mathrm{s} / \mathrm{he}$ values and has reason to value as the basis for determining well-being as opposed to economic measures (Sen, 1999). Nussbaum viewed the Capabilities Approach through a gender, human rights, and social justice lenses. Nussbaum further expanded on the Capabilities Approach by examining what she called entitlements. Nussbaum defined entitlements as basic guarantees to citizens, such as "political liberties, the freedom of association, the free choice of occupation, and a variety of economic and social rights" (Nussbaum, 2003, p. 36). Nussbaum's viewed entitlements as universal indicators of developmental well-being.

Sen $(1999$, p. 3) viewed development as "a process of expanding the real freedoms that people enjoy.” This approach builds off Human Development Theory's notion that development is based on expanding a person's choices in life and that wellbeing is based on freedoms understood in what one has the ability to do and be in life (Robeyns, 2011). Building a person's freedoms helps to achieve well-being. For example, under the Capabilities Approach, the freedom to be nourished or freedom to practice the religion of one's choice helps an individual work toward reaching well-being. 
The Capabilities Approach seeks to expand freedoms by counteracting the different types of obstacles to freedoms in an individual's life (Sen, 1999). The major obstacles that leave people without a meaningful choice are defined as unfreedoms (Sen, 1999). Oppressive political regimes, lack of clean drinking water, and a cultural structure that persecutes a certain gender or ethnicity are forms of unfreedoms because they are obstacles or challenges that may prevent an individual from enjoying his/her life (Robeyns, 2005). By negotiating or overcoming these unfreedoms, an individual improves his/her quality of life by living the kind of life he or she values.

While freedom is not the only basis to evaluate development, freedom facilitates other aspects of life. One's richness in life goes beyond the purely financial (Sen, 1985, 2003). Just like commodities, although wealth helps to make possible certain opportunities, it only goes so far. Thus, wealth cannot be treated as an end in itself (Sen, 1985). Instead of wealth measurements, the Capabilities Approach is based on what people can effectively be and do in society (Robeyns, 2005).

Development has to be more concerned with enhancing the lives we lead and the freedoms we enjoy. Expanding the freedoms that we have reason to value not only makes our lives richer and more unfettered, but also allows us to be fuller social persons, exercising our own volitions and interacting... (Sen, 1999 pp. 14$15)$.

Greater freedom enhances one's ability to succeed and to influence aspects of life one values and has reason to value (Sen, 1999). The ability to act upon one's functionings is a central process of development. 
Freedoms and positive societal arrangements increase the presence of meaningful life opportunities. The presence of these opportunities facilitates what one is able to be or do in life (Robeyns, 2005). In the end, the success of a society is judged not solely on economic success. Instead, success is based on how society and its political system works to give citizens freedoms they can enjoy and do enjoy (Vizard, 2006).

The Capabilities Approach, in contrast to narrower development viewpoints such as those that focus on money, provides a framework that is diverse enough to include all aspects of human well-being within development (Clark, 2005a). Key components of the Capabilities Approach include functionings, freedoms, and capabilities. Through these components, people are able to pursue and achieve what matters to them on an individual basis (Alkire \& Deneulin, 2009; Robeyns, 2005). Comprehending the notions of a "functioning," "freedom," and "capability" are therefore paramount to understanding the Capabilities Approach.

\section{Functionings, Freedoms, and Capabilities}

A foundational concept of the Capabilities Approach is giving people the freedom to pursue and achieve what is important to them subjectively (Robeyns, 2005). The Capabilities Approach's key components in pursuing well-being are functionings, freedoms, and capabilities (Alkire, 2005; Robeyns, 2005; Sen, 2005). The following sections provide more information concerning these The Capabilities Approach concepts.

\section{Functionings}

Functionings are a person's individual accomplishments (Robeyns, 2017).

Functionings are thus subjective and may differ from person-to-person and society-tosociety. Functionings are classified as either "beings" or "doings" (Alkire, 2002a; 
Robeyns, 2011; Sen, 1999). Beings are physiological conditions or states of mind while doings refer to activities (Robeyns, 2011). Examples of beings include resting, being nourished, being free from avoidable disease, or being respected (Sen, 1999; Alkire, 2002a; Robeyns, 2005, 2011). Doings may include going to school, donating money to charity, or taking part in the democratic process of elections (Robeyns, 2011).

Frediani (2010), who studied the Capabilities Approach and compared it to other development frameworks, classifies functionings as "achievements" that a person manages to do or be in life, thus reflecting who an individual is as a person. The end goal is for individuals to possess the requisite amount of freedoms to live the lives they envision, value, and have reason to value (Robeyns, 2005). Although individuals may possess similar functionings, the end goal may be achieved by different means from one person to the next.

Scholars have illustrated the Capabilities Approach through a bicycle metaphor (Robeyns, 2011; Sen, 1999). The goal of the Capabilities Approach is to leverage a resource and a capability, (defined as the actual possibility to utilize resources) into a functioning to work toward achieving well-being. A bicycle leads to the capability of travel, which is increased mobility, travel, transport, play, exercise and other characteristics. These are all valuable functionings. Therefore, a bike functions as more than just a toy because, if someone owns a bicycle, he or she possesses a resource, which could lead to greater well-being. However, it may be unclear whether that individual possesses the ability to fully utilize the bicycle, a resource. For example, the person may lack the capability to ride the bicycle because he or she is malnourished, lacks balance, or lost his or her legs. The person may also lack the capability to ride the bike if cultural 
norms or political systems outlaw such actions, such as in places where it may be frowned upon for girls or women to be physically active. If he or she is unable to utilize the bike for any reason, while it remains a resource, may not contribute to greater wellbeing. However, if the individual possesses the bicycle, the knowledge of how to ride, and lives in an environment that allows him or her to ride, that person achieved the functioning of mobility and the capability to ride around town.

The relationship between a good and achieved functioning is the conversion factor, defined as the "degree in which a person can transform a resource into a functioning" (Robeyns, 2005, p. 99). Conversion factors are often placed into three groups: personal conversion factors, social conversion factors, and environmental conversion factors (Robeyns, 2011). Personal conversion factors are part of a person's personal characteristics such as one's metabolism, physical condition, gender, reading skill, or intelligence (Robeyns, 2005, 2011). One's disability, physical condition or lack of knowledge concerning a specific skill may mean that an individual lacks a personal conversion factor to convert a resource into a functioning (Robeyns, 2005, 2011). Social conversion factors are aspects of life dictated by society. These include public policies, social norms, practices and hierarchies (Robeyns, 2011). An example of a social conversion factor is a societal practice of discriminating against individuals of a certain race, gender, or sexual orientation. Someone negatively impacted by these societal policies and values may lose the ability to transform a resource into a functioning. For example, if same sex marriage is not allowed due to societal values, an individual wishing to marry someone of the same sex in that society will lose the capability to marry, therefore, reducing someone's well-being. 
Finally, environmental conversion factors describe the physical environment where an individual resides (Robeyns, 2005, 2011). These include the geographic location where someone lives and the conditions connected with this location. These conditions may include (a) natural weather-related phenomena such as precipitation, temperature, earthquakes or (b) human-made improvements such as roads, buildings, bridges, and utilities, or a lack thereof (Robeyns, 2011). For example, if a family lives in an area that is riddled with smog and other types of environmental pollution, it may cause health-related repercussions that prevent them from achieving functionings such as being healthy. All of these conversion factors impact the ability of a person to change goods to a functioning.

\section{Freedoms}

Freedom also plays a key role in the Capabilities Approach. "Expansion of freedom is viewed, in [the Capabilities Approach], both as the primary end and as the principal means of development" (Sen, 1999, p. 36). One's specific freedoms act as the basic building blocks of one's life (Sen, 1999). Such freedoms facilitate real opportunities for an individual to pursue and achieve what s/he values and has reason to value (Alkire, 2002a; Sen, 1992, 1999), ultimately improving a person's well-being (Sen, 1999).

However, a lack of freedom may obstruct the path toward well-being. Going back to the bicycle example, although an individual may possess a bike and the ability to convert it into a functioning, such as being healthy enough and knowing how to ride it, he or she may not be able to utilize the bicycle if s/he lacks freedom. For instance, if a woman lives in a society that forbids females from riding a bicycle publicly, she lacks the freedom to ride the bicycle because of societal norms, and the bicycle remains a resource. 
Freedom is only possible if a process exists to allow for actions and decisions and if people are given actual opportunities to exercise those freedoms (Sen, 1999).

Therefore, the Capabilities Approach classifies freedoms into two different types: process freedoms and opportunity freedoms (Sen, 1999). Process freedoms are one's ability to act according to what matters to an individual, and whether such freedom actually exist in society (Sen, 1999). Alkire (2011, p. 13) defines process freedoms as the "ability to act on behalf of what matters." Process freedoms may take the form of political institutions, movements and democratic practices; the focus is on processes that promotes political discourse (Robeyns, 2011). An example of a process freedom is society that allows people an avenue to exercise their political rights, has political institutions and democratically elected representatives of the people that form a government to enact, enforce, and interpret laws. Opportunity freedoms, on the other hand, are one's real opportunity to achieve a valued functioning, based on societal norms and culture (Robeyns, 2011; Sen, 1999). If someone is prevented from riding a bike because society forbids such actions and there are no political processes to achieve this goal, then the process and opportunity aspect of freedom are hardly present. However, if sufficient freedoms to pursue a functioning exist, then nothing stands in the person's way to utilize a capability (Robeyns, 2017; Taylor, 1979). Thus, fostering conditions necessary to remove barriers an individual faces in his or her respective life is an important aspect of the Capabilities Approach.

\section{Capabilities}

Capabilities are the output of a person's freedoms and functionings, the "real opportunity for beings and doings" (Robeyns, 2017, p. 171). Capabilities "describe the 
real actual possibilities open to a person" (Alkire, 2005, p. 2). Capabilities are a person's ability, his or her real freedom, to achieve a functioning or a bundle of functionings at this very moment in society. Capabilities reflect the different states of being and activities that a person may achieve at present time based on their place in life (Dang, 2014). Going back to the bicycle example, a female adolescent who owns a bicycle and lives in a society that affords female teenagers the freedom and ability to ride it without supervision is granted the choice to access the capability of travel. A person may choose to ride, but they still have that freedom - that choice (Robeyns, 2017). Capabilities range in complexity from the most essential capabilities such as basic nutrition and being free of disease, accessing reasonably adequate lodging, and other requirements necessary for survival to more advanced capabilities such as obtaining a doctorate or traveling the world. Again, regarding nourishment, a person may choose to eat or to fast - but it is their choice because society provides that freedom to make a choice. Therefore, although capabilities may refer to a diverse range of activities, each has the same goal of improving a person's subjective well-being.

Initially, Sen (1985) made the distinction between capabilities and what he called basic capabilities. Basic capabilities referred to the minimum baseline states of being and activities that allowed for a minim adequate quality of life (Sen, 1999). Capabilities such as access to basic shelter, education, nutrition and adequate health all allow someone the ability to survive in life, but not pursue what s/he may value. However, Sen's approach to capabilities evolved to include basic capabilities as a subset of capabilities having to do with inequality (Sen, 1999). 
Capabilities incorporate the idea that freedom allows a person the real opportunity to live a life that s/he has reason to choose and value (Dang, 2014). One's capabilities should evolve beyond basic needs. As Alkire and Deneulin (2009) explain, capabilities are the freedom to enjoy valuable functionings. So they combine functionings with a kind of opportunity freedom. Just like a person with a pocket full of coins can buy many different combinations of things, a person with many capabilities can elect between many different functionings and pursue a variety of different life paths (p. 32).

A person's capabilities can be enhanced by public policy, such as economic, social, and political processes (Sen, 1999). However, "the direction of public policy can be influenced by the effective use of [a person's] participatory capabilities by the public" (Sen, 1999, p. 18). This two-way relationship between a person's capabilities and public policy is central to the Capabilities Approach.

The Capabilities Approach embraces the notion that "people should be equal with respect to...freedom" (Gasper, 2007, p. 337) and pursue "the various things a person may value doing or being" (Sen, 1999, p. 75), with the ultimate goal of increasing well-being. By negotiating obstacles to freedom, individuals are allowed to achieve their respective aspirations (Robeyns, 2017). If a person's capabilities are enhanced, then they should also be able to lead more productive live, both socially and economically. Figure 1.1 provides a simplified visual interpretation of the Capabilities Approach. 


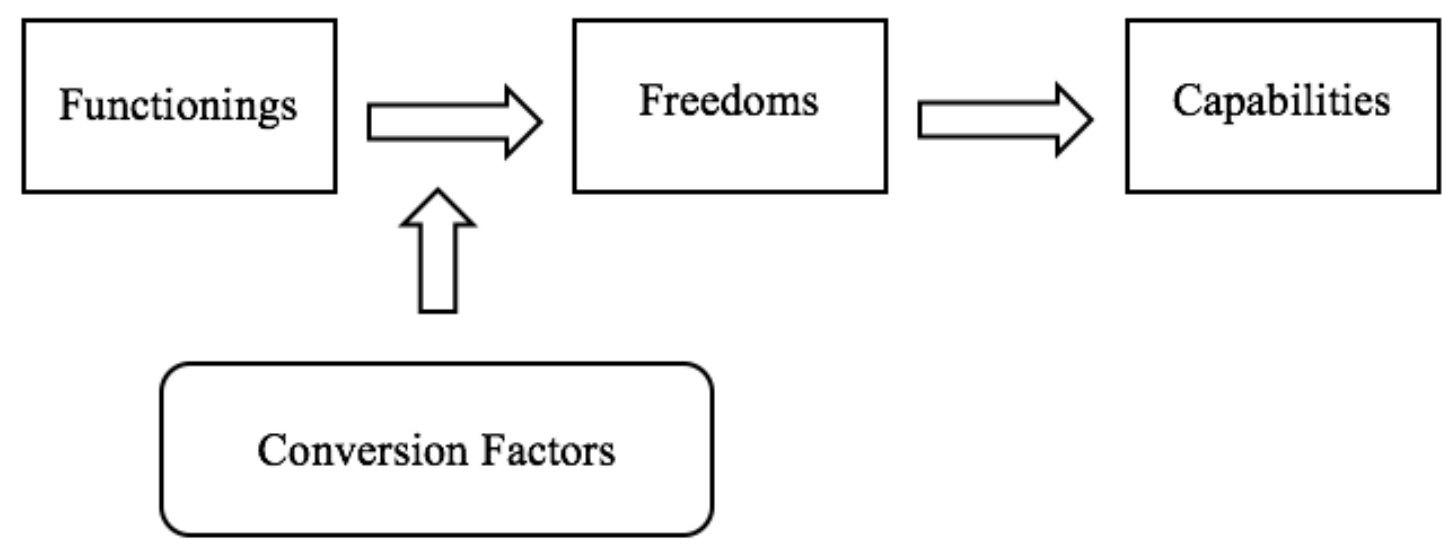

Figure 1. Simplified visual interpretation of Capabilities Approach

Summary of the Capabilities Approach. The Capabilities Approach is a normative framework that evaluates individual well-being and social arrangements based on what people are able to do and be in society (Robeyns, 2006). "The key idea of the Capability Approach is that social arrangements should aim to expand people's capabilities - their freedom to promote or achieve what they value doing and being" (Alkire \& Deneulin, 2009, p. 31). Sen placed emphasis on freedom and a person's ability to achieve what s/he values and has reason to value (Sen, 1999). Nussbaum further developed the Capabilities Approach by examining specific entitlements. The Capabilities Approach seeks to expand freedoms, therefore, by removing the different types of obstacles to freedoms in an individual's life (Sen, 1999). Freedoms and positive societal arrangements increase the presence of meaningful life opportunities. The presence of these opportunities facilitates what one is able to be or do (Robeyns, 2005). Negotiating or overcoming these obstacles to freedom allows an individual more choices and thus improves his/her quality of life by living the kind of life he or she values. 
Key components of the Capabilities Approach include functionings, freedoms, and capabilities. Functionings are a person's individual accomplishments (Robeyns, 2017). Functionings are classified as either "beings," psychological conditions or states of mind, or "doings," activities (Alkire, 2002a; Robeyns, 2011; Sen, 1999). Freedoms act as the basic building blocks of one's life (Sen, 1999). The Capabilities Approach recognizes process freedoms and opportunity freedoms (Sen, 1999). Process freedoms are one's ability to act according to what matters to an individual, and whether such freedom actually exists in society (Sen, 1999). Opportunity freedoms are one's real opportunities to achieve a valued functioning, based on societal norms and culture (Robeyns, 2011; Sen, 1999). Greater freedom enhances one's ability to succeed and to influence aspects of life one values and has reason to value (Sen, 1999). The ability to act upon one's functionings is a central process of development. Capabilities are what someone can actually do in society. Capabilities "describe the real actual possibilities open to a person" (Alkire, 2005, p. 2) and are a person's ability to achieve something. Overall, the Capabilities Approach embraces the notion that "people should be equal with respect to...freedom" (Gasper, 2007, p. 337) and pursue that which they value and have reason to value, the ultimate goal of which is increasing well-being.

\section{Strengths of the Capabilities Approach}

The Capabilities Approach is lauded for several strengths. One strength is the approach's flexibility and adaptability to different fields (Clark, 2005a, 2005b). By providing a framework that lends itself to adaptation across many disciplines, researchers can build upon the Capabilities Approach and apply it in different ways to different disciplines (Clark, 2005a, 2005b). Sen (1999) advocates that the approach is well suited 
to find solutions for novel challenges, and does not require a consensus amongst industry experts in order to succeed. This is a problem solver's approach.

Sen encourages practitioners to take initiative and make aspects of the Capabilities Approach their own. Alkire (2002a) supports this rationale, as she argues Sen's approach allows development practitioners to work on pressing issues without needing a consensus on fundamentals. Instead of creating consensus or waiting until a clear picture was established, Sen primarily focused attention to the fact that economic approaches alone are insufficient to truly define development and one's well-being. Alkire (2002a) saw the Capabilities Approach as a way to work on solutions to novel issues.

Another strength of this approach is the emphasis on personal well-being and individualistic functionings/capabilities. Functionings and capabilities belong to the individual (Robeyns, 2003). They are neither part of the economic marketplace nor part of the state. Robeyns (2003) believes including nonmarket or noneconomic aspects of well-being "will reveal complexities and ambiguities in the distribution of well-being that an analysis of income or wealth alone cannot capture" (p. 66). These additional indicators can reflect on aspects of inequality other than income. For example, economic indicators of well-being cannot account for societal deprivation of freedom or inequality in gender, race, or sexual orientation. Each of these factors has the potential to negatively impact well-being by preventing individuals from pursuing or achieving their passions even though neither concept is factored into economic analysis. Deprivation of a capability may be just like preventing someone from achieving a fundamental entitlement granted to him or her as a human being (Nussbaum, 1997, 2003, 2011). 
Inequality in development is not a binary concept. It is impacted by many aspects. For example, someone may suffer discrimination or hardship due to their age, gender, race and socio-economic status, which are all further impacted by a society's values that blend diversity and freedom. However, no one component of that person is responsible for all of his/her hardship. Thus, using capabilities will give a much richer and complete picture of well-being than the limited scope of economic indicators.

A third strength of the Capabilities Approach lies in its inclusiveness (Robeyns, 2003). Sen's framework intrinsically acknowledges the importance of diversity within the realm of development. Diversity exists at all levels: race, age, ethnicity, gender, sexuality, geographic location, disability, economic status, culture, and a litany of other classifications (Robeyns, 2003). Each different segment of the world may view resources, functionings, and freedoms differently. Each variation is a lens that impacts one's respective viewpoint (Robeyns, 2003). Robeyns (2003) provides a quote from Sen (1992, p. xi) to illustrate this point: "[h]uman diversity is not a secondary complication (to be ignored or to be introduced 'later on'); it is a fundamental aspect of our interest in equality." Finally, as part of keeping the Capabilities Approach relatable to as many frameworks and disciplines as possible, Sen does not provide a definitive list of capabilities (Alkire, 2002a; Clark, 2005a; Nussbaum, 2011; Sen, 1999). The principle reason for this omission is because, by not establishing a fixed list, individuals can select the capability list themselves, weighing each capability based on their personal value judgments as well as societal influences (Clark, 2006). One's values are impacted by the range of factors that makes each person unique, which incorporates race, age, ethnicity, gender, sexuality, attitudes, belief systems, geographic location, disability, economic 
status, culture and other aspects into the decision-making process of which capabilities to include.

From a general perspective, Sen's approach has been hailed as broadening development into a process that is people-centric (Clark, 2005a). This emphasis on people's functionings and freedoms as opposed to economic considerations recognizes the uniqueness and diversity of human-beings. In essence,

[t]he capability approach [sic] is a proposition, and the proposition is this: that social arrangements should be evaluated according to the extent of freedom people have to promote or achieve functionings they value. If equality in social arrangements is to be demanded in any space - and most theories of justice advocate equality in some space - it is to be demanded in the space of capabilities (Alkire, 2005, p. 122).

Sen's approach is not one size fits all; it embraces variability as a central component of the widely-adaptable framework. Once the building blocks of life are provided such as basic economic opportunities, political liberties, social entitlements, adequate health and basic education, people can achieve the various things a person may value doing and being (Sen, 1999). However, the Capabilities Approach is not development. As Robeyns (2017, p. 20) said, let us not forget that the capability approach is a tool and not an end in itself; we should master it as well as we can, perhaps also as efficiently as we can, and then move on to use it in the work that really matters. 


\section{Criticisms of the Capabilities Approach}

While some praise the Capabilities Approach for its adaptability, others view that as a primary weakness of the theory. Some argue its breadth and multi-dimensional aspect prevents the approach from possessing practical and operational significance within development (Sugden, 1993). Because it lacks a foundational focus or a fixed list of capabilities, other practitioners must add dimensions to the Capabilities Approach. Adding to the Capabilities Approach's framework may take away from the approach's effectiveness or actually injure the framework. For example, Robeyns (2003) notes that if another framework paired with the Capabilities Approach is deficient, "racist, homophobic, sexist, ageist, Eurocentric, or biased in any other way, capability evaluation will be accordingly affected" (p. 67). Robeyns (2003) suggested that coupling the Capabilities Approach with an underlying framework that is sexist can injure or reduce a person's set of capabilities.

Beyond a theoretical or philosophical standpoint, criticism exists concerning how one utilizes, implements and evaluates development issues through the Capabilities Approach. The approach is somewhat ambiguous, which can make applying and operationalizing it difficult (see Gasper, 2007). A researcher seeking to utilize the Capabilities Approach may not understand a number of the concepts. The practitioner may wonder:

[d]oes the capability approach [sic] provide adequate direction regarding (i) how to identify valuable capabilities; (ii) how to make strategic economic decisions that weight and prioritize capabilities; (iii) what to do when value judgments 
conflict; and (iv) how capability sets may be measured, such that one can evaluate changes brought about by economic initiatives? (Alkire, 2011, p. 11)

Some critics recommend that identifying valuable capabilities may improve the Capabilities Approach (Nussbaum, 2011; Qizilbash, 2011). However, experts disagree whether or not recognizing a universal list of capabilities applicable to all individuals regardless of context is appropriate under the Capabilities Approach. This disagreement is discussed in the next section.

\section{Central Capabilities}

Sen and Nussbaum are divided over whether there is a set of universal capabilities (which Nussbaum labels as "central capabilities") and the methodology for selecting those capabilities. Although a list of universal capabilities that all people must enjoy exists, it is unclear whether they will still differ depending on the context specific situation. Nussbaum (2011), who applies a social justice lens to the Capabilities Approach, identifies her ten central capabilities.

1. Life. Being able to live to the end of a human life of normal length; not dying prematurely, or before one's life is so reduced as to be not worth living.

2. Bodily health. Being able to have good health, including reproductive health; to be adequately nourished; to have adequate shelter.

3. Bodily integrity. Being able to move freely from place to place; to be secure against violent assault, including sexual assault and domestic violence; having opportunities for sexual satisfaction and for choice in matters of reproduction.

4. Senses, imagination, and thought. Being able to use the senses, to imagine, think, and reason - and to do these things in a "truly human" way, a way 
informed and cultivated by an adequate education, including, but by no means limited to, literacy and basic mathematical and scientific training. Being able to use imagination and thought in connection with experiencing and producing works and events of one's own choice, religious, literary, musical, and so forth. Being able to use one's mind in ways protected by guarantees of freedom of expression with respect to both political and artistic speech, and freedom of religious exercise. Being able to have pleasurable experiences and to avoid nonbeneficial pain.

5. Emotions. Being able to have attachments to things and people outside ourselves; to love those who love and care for us, to grieve at their absence; in general, to love, to grieve, to experience longing, gratitude, and justified anger. Not having one's emotional development blighted by fear and anxiety. (Supporting this capability means supporting forms of human association that can be shown to be crucial in their development.)

6. Practical reason. Being able to form a conception of the good and to engage in critical reflection about the planning of one's life. (This entails protection for the liberty of conscience and religious observance.)

7. Affiliation. (A) Being able to live with and toward others, to recognize and show concern for other human beings, to engage in various forms of social interaction; to be able to imagine the situation of another. (Protecting this capability means protecting institutions that constitute and nourish such forms of affiliation, and also protecting the freedom of assembly and political speech.) (B) Having the social bases of self-respect and nonhumiliation; being 
able to be treated as a dignified being whose worth is equal to that of others. This entails provisions of nondiscrimination on the basis of race, sex, sexual orientation, ethnicity, caste, religion, national origin.

8. Other species. Being able to live with concern for and in relation to animals, plants, and the world of nature.

9. Play. Being able to laugh, to play, to enjoy recreational activities.

10. Control over one's environment. (A) Political. Being able to participate effectively in political choices that govern one's life; having the right of political participation, protections of free speech and association. (B) Material. Being able to hold property (both land and movable goods), and having property rights on an equal basis with others; having the right to seek employment on an equal basis with others; having the freedom from unwarranted search and seizure. In work, being able to work as a humanbeing, exercising practical reason and entering into meaningful relationships of mutual recognition with other workers (Nussbaum, 2011, pp. 33-34).

Although Sen agreed that capabilities must be identified and ranked from trivial to fundamental, he argued that problems exist with creating a list of fundamental capabilities. The issue was less about creating a list, but rather the perspective being used in creating that list:

The problem is not with listing important capabilities, but with insisting on one predetermined canonical list of capabilities, chosen by theorists without any general social discussion or public reasoning. To have such a fixed list, emanating 
entirely from pure theory, is to deny the possibility of fruitful public participation on what should be included and why (Sen, 2004, p. 77).

Sen went on to say, "public discussion and reasoning can lead to a better understanding of the role, reach and significance of particular capabilities (Sen, 2004, pp. 80).

Clark (2005a) noted that although Nussbaum stated her list of central capabilities is subject to constant scrutiny and revision, no categories had been added or deleted since the list's inception. Further, a central list of valuable functionings or capabilities based through the lens of a North American philosopher seemed paternalistic (Clark, 2002, 2005, 2005b, Stewart, 2001). Clark (2005a, p. 7) also noted that Nussbaum's book Women and Human Development, which trumpeted central capabilities, was based on two "brief field trips to India." Nussbaum's brief time in the developing world appeared to color some critics' viewpoint of the list, perhaps making it a starting point for discussions in each individual society, based on unique factors and values, as opposed to a definitive and final list (Clark, 2005a; Gasper, 2004). While criticisms of and disagreements within the Capabilities Approach exist, the Capabilities Approach encouraged other disciplines to adapt key components of the framework to innovate within their respective fields. While not perfect, this emphasis on innovation has led to operationalization of the Capabilities Approach in many different ways.

\section{Operationalizing the Capabilities Approach}

Scholars seeking to implement the Capabilities Approach begin with a hypothesis that this framework is applicable to their respective discipline. Thus, those seeking to apply the Capabilities Approach are searching for a method of operationalization. Operationalization is the process of transforming a theory or hypothesis so it can be 
applied in a discipline to obtain practical value (Comim, 2001). To operationalize a hypothesis is to add enough specifics to the theory so it can be utilized in the field (Alkire, 2001). Based on the outcome of the attempt, one can determine whether the hypothesis is applicable.

The Capabilities Approach is intentionally incomplete to be more easily operationalized to other disciplines (Alkire, 2001, 2002a, 2003; Comim, Qizilbash \& Alkire, 2008). Incompleteness is divided into two categories: fundamental and pragmatic (Alkire, 2003; Sen, 1999). Fundamental incompleteness is "the ideas of well-being and inequality may have enough ambiguity and fuzziness to make it a mistake to look for a complete order of either" (Alkire, 2003, p. 15). Pragmatic incompleteness is "to use whatever parts of the ranking we manage to sort out unambiguously, rather than maintaining complete silence until everything has been sorted out and the world shines in dazzling clarity" (Alkire, 2003, p. 15). In other words, there is no need for all aspects of an approach to become clear before a practitioner can begin applying the Capabilities Approach to another discipline.

Comim (2001) suggests that the operationalization process consists of four sequences or alternatives. They are as follows: “(i) theoretical inclusion: elaboration of theoretical concepts...; (ii) measurement: transformation of these theoretical concepts into empirical variables; (iii) application: use of these variables in qualitative empirical analysis; (iv) quantification: use of these variables in quantitative empirical analysis" (p. 1).

Ample literature exists concerning the theoretical underpinnings of the Capabilities Approach: functionings, freedoms, and capabilities (Alkire, 2002a; 
Nussbaum, 2000, 2011; Sen, 1985, 1989, 1999, 2005). In addition to the foundational concepts, practitioners must understand that the diversity of the world's population may change the implications of the approach from person-to-person, society-to-society and culture-to-culture (Comim, 2001). Therefore, understanding local context is important. Once theory is understood, operationalizing focuses on measurement utilizing empirical measures.

For Comim's (2001) second recommended step of changing theoretical concepts into empirical variables, literature on empirical data and the Capabilities Approach often equates operationalization with measuring functionings, freedoms, and capabilities (Chiappero-Martinetti \& Roche, 2009). Empirical measures may vary when applying the Capabilities Approach to other disciplines such as education or health. Sen (1992) understood that creating appropriate measurements may be a challenge to operationalization because of the nebulous nature of capabilities:

...the capability set is not directly observable, and has to be constructed on the basis of presumptions...Thus, in practice, one might have to settle often enough for relating well-being to the achieved - and observed - functionings...(when the presumptive basis of such a construction would be empirically dubious) (p. 52).

As Sen alluded to, obtaining empirical data that is readily observable may be difficult. A researcher must decide which elements of well-being to measure, whether it will be qualitative or quantitative, and what unit of analysis (households, individual, population subgroups) to use in the analysis (Chiappero-Martinetti \& Roche, 2009). The researcher should also decide whether to focus on measuring capabilities, functionings, freedoms, or some combination, and whether data of specific functionings will be combined together 
or kept separate (e.g. aggregated or disaggregated) (Burchardt \& Vizard, 2011).

Researchers must also decide whether to collect their own data or use previously collected data.

Once transforming theoretical concepts into variables, part three of Comim's approach suggests that researchers begin exploring the Capabilities Approach in a qualitative research setting. When collecting data, a researcher may do so through primary analysis. Chiappero-Martinetti and Roche (2009) defined primary analysis as involving fieldwork for directly collecting data so as to address a specific research question. Data may be collected through interviews and field observations for qualitative empirical analysis.

When collecting data, Robeyns (2003) suggested that researchers should identify a list of valuable capabilities, and decide whether to focus on broader or narrower functionings. However, debate exists concerning whether a list of substantive freedoms and opportunities must be developed as a means of operationalization (Burchardt \& Vizard, 2011). While Alkire (2003) chose to operationalize the Capabilities Approach according to a set of central elements, practitioners may also operationalize the Capabilities Approach by using local factors as the basis of capability selection. In this regard, the approach responds to a specific societal context because the Capabilities Approach recognizes that everybody will not have the same goals and aspirations.

The final stage of Comim's suggested approach to operationalization is quantitative analysis. For a quantitative empirical analysis, researchers may use their own datasets or datasets that are readily available such as population censuses, Human Development Reports or the HDI to generate quantitative data. Researchers may generate 
data through multivariate studies incorporating factor analysis, principal component analysis, regression, and fuzzy sets in order to identify and measure elements of functioning and capabilities (Chiappero-Martinetti, 2009; Comim, 2001).

Fuzzy set theory is a technique that analyzes continuous and ordinal variables simultaneously, and is generally used in the Capabilities Approach for micro-level analysis of well-being (Chiappero-Martinetti, 2009). Sen also provided multiple equations to calculate aspects of well-being (Anand, Hunter, Carter, Dowding, Guala, \& Van Hees, 2009; Sen, 1985). Other measurements exist, including empirical studies using descriptive statistics, case study approaches for descriptive data and other theoretical/methodological applications (Comim, 2001). These different approaches generate data as part of the operationalization process.

\section{Capabilities Approach Operationalized in Different Disciplines}

One chief strength of the Capabilities Approach is its ability to be adapted, applied to various disciplines, and improved through that process. Practitioners from diverse disciplines have utilized approaches grounded in Sen's or Nussbaum's concept of the Capabilities Approach. This section provides discussion on how the Capabilities Approach was applied to various disciplines such as education, health and disability, economics, environmental refugees (Kim, 2012), self-determination of indigenous people (Murphy, 2014), intergenerational justice (Gutwald et al., 2014), and the tourism industry (Croes, 2012). Thus, this framework has a wide-ranging appeal for application. 


\section{SDP Defined}

\section{Sport}

The United Nations (2003) defines sport broadly. Sport includes all physical activity that contributes to physical fitness, mental well-being and social interaction (United Nations, 2003). Sport also includes play, organized sport at both the casual or competitive level, and all indigenous sports or games (United Nations, 2003). Haudenhuyse, et al. (2012) refer to sport as acting in a leisure context, also falling in line with the United Nations' broad definition. Further, Darnell and Black (2011) link sport to the concept of physical activity. While the United Nations and other scholars broadly defined sport, Coakley (2014) took a narrower approach. Coakley $(2014$, p. 6) defined sport as "physical activities that involve challenges or competitive contests. They are usually organized so that participants can assess their performances and compare them to the performances of others or to their own performances from one situation to another." Therefore, the concept of what is sport varies.

\section{Development in Sport Context}

While sport is broadly defined to include aspects beyond strict competition (Levermore \& Beacom, 2009; United Nations Inter-Agency Task Force on Sport for Development and Peace, 2003; United Nations Office of Sport for Development and Peace, 2014), the term “development” has many different meanings within various contexts of SDP (Hartmann \& Kwauk, 2011). Gilbert and Bennett (2012) provided a definition of development, which was allowing individuals to "lead long and healthy lives, to be knowledgeable, to have access to the resources needed for a decent standard of living and to be able to participate in the life of the community" (p. 5). 
From an SDP perspective, the definition of development is also multidisciplinary, cutting across areas such as economics, sociology, political science, and sport management. Development may refer to the process of economic modernization, liberalization of societal norms, cultivation of political institutions, or even increased administrative expertise within the realm of sport management. Development, in an SDP context, refers to a scientific approach towards modernization trying to improve the "life chances" of those that a program serves (Levermore \& Beacom, 2009, p. 7). Some using SDP have attempted to improve a person's life chances by using sport, play, and/or physical activity to increase a person's skills, including but not limited to their educational, cultural or social skills. However, it is this development through sport that allows the "use sport as a vehicle to achieve a range of other social, economic and political objectives" (Levermore \& Beacom, 2009, p. 8).

\section{Peace}

Peace, the final element of SDP, is also a dynamic concept with varying definitions. A nation cannot truly begin to prosper from the benefits of development without first achieving peace and stability within its borders. However, as Wilson (2012, p. 12) states, two types of peace exist: (a) negative peace - which solely consists of "the absence of war," and (b) positive peace - "situations where various forms of equality and equity - related to economic, social, cultural, and political rights - have been approached." When comparing negative and positive peace, the main difference is that while direct violence or war is not present, negative peace is a society that still contains aspects of structural violence such as "poverty, discrimination and denial of economic, 
social, and political equality" (Jeong, 2000, p. 24-25). Therefore, peace is a complex concept that may be difficult to identify as a singular notion.

Gilbert and Bennett (2012) found it difficult to find a specific definition for peace. However, they settled on a broad definition describing peace as a "process-oriented pattern of the international system, which is marked by decreasing violence and increasing distributive justice" (Gilbert \& Bennett, 2012, p. 6). This definition classified peace not as a static state, but rather as something dynamic process. Therefore, as Jeong (2000) posited, peace can both be a literal definition of the absence of war or something more aspirational, such as making positive steps toward increasing safety and justice.

\section{Education}

Scholars applied the Capabilities Approach to education in a number of ways. Some scholars utilized a more abstract approach while others used the framework in a more practical manner. Saito (2003) examined the relationship between Sen's approach to well-being and education. Saito (2003) found that education can play a role in exercising a person's capabilities. This meant that the Capabilities Approach can be theorized to education. As part of this examination, Saito (2003) posited that one may use the HDI to operationalize the Capabilities Approach in education. As mentioned before, the HDI measures relative levels of human development, including educational attainment (Saito, 2003). Saito (2003) suggested using HDI in conjunction with exploring how human development impacts education. Thus incorporating HDI into education is critical (Saito, 2003).

Teaching plays a role in exercising capabilities (Saito, 2003). McLean and Walker (2012) sought to apply the Capabilities Approach in higher education in South Africa by 
exploring how capabilities and human development relate to professional education in South African Universities. The authors created an index: the "Public-Good Professional Education Index" (p. 588). The index was utilized to generate theory and empirical data from five university-based education departments at three universities in South Africa (McLean \& Walker, 2012).

Through interviews, the authors created an innovative professional capabilities index by combining the Capabilities Approach theory, theories from other disciplines, and data collected through a series of meetings and workshops with university departments. The research by McLean \& Walker (2012) generated four non-hierarchical key meta functionings: “(1) recognize the full dignity of every human being, (2) act for social transformation and to reduce injustice, (3) make sound, knowledgeable, thoughtful, imaginative professional judgments, and (4) work with others to expand the comprehensive capability of people living in poverty" (p. 588). The findings created four functionings that, if applied, may improve education and quality of life within South Africa.

Lambert, Solem, and Tani (2015) illustrated the widely adaptive nature of the Capabilities Approach by applying it to geography education. The authors were motivated by the perceived difficulties of communicating the value of geography in the 21 st Century (Lambert et al., 2015). Specifically, the authors sought to explore the value of studying geography in primary and secondary school from the perspective of capabilities and human development (Lambert et al., 2015). The goal was to understand whether human development diminished when the study of geography was absent or poorly provided in a student's education (Lambert et al., 2015). 
For this study, the authors incorporated a pilot phase (Lambert, Solem, \& Tani, 2013 ) that adapted three of Nussbaum's (2000) capabilities. The three capabilities were slightly modified to include a geography element (Lambert et al., 2015). The authors asked whether geography can:

“(1) Promote individual autonomy and freedom and the ability of children to use their imagination and to be able to think and reason? (2) Help young people identify and exercise their choices in how to live, based on worthwhile distinctions with regard to their citizenship and to sustainability? (3) Contribute to understanding one's potential as a creative and productive citizen in the context of the global economy and culture?" (Lambert et al., 2015, p. 729).

Although this program (called GeoCapabilities) was ongoing, it hoped to utilize the Capabilities Approach as a means of framing "localized 'curriculum thinking' in geography" (Lambert et al., 2015, p. 9). The researchers found that teaching geography encourages students to develop a deeper understanding of the world, gain greater awareness of those who live on the planet, and think differently about the issues that confront the world (Lambert et al., 2015). These findings mean that enhanced geography skills can lead to enhanced capabilities.

Based on calls to reexamine assumptions within the field of special education and disability, Terzi (2005) used the Capabilities Approach to reframe the concept of disability in education. Terzi (2005) theorized the Capabilities Approach's foundational underpinnings of justice and equality made it well-suited as a framework for special education and disability. Terzi (2005) argued that current understanding of special needs was based only on two factors: one's individual factors and social factors around that 
person. Instead of using this as the basis for special needs, Terzi (2005) suggested utilizing the Capabilities Approach to re-conceptualize special needs according to the individualistic aspects of the Capabilities Approach and the emphasis on social arrangements and the responsibilities society has to the individual. Terzi’s (2005) theoretical article noted that the Capabilities Approach was a fundamental framework for "reconceptualizing impairment and disability within the capability approach" (p. 453). Terzi (2005) concluded that reframing disability through the Capabilities Approach can change how one views what is a disability and encouraged using this framework to understanding disability that is based in terms of justice. This is important because it changed the dominant view of how society understood the concept of a disability in special education, from focusing on individual and social factors, to now focusing on functionings and social arrangements.

\section{Health}

Disciplines in health also utilize the Capabilities Approach. Dubois and Trani (2009) applied the Capabilities Approach framework to disability as a way of assessing an individual's capability. A case study was carried out in Afghanistan as part of a national disability survey of randomly selected households that measured detailed capabilities and focused on freedom dimensions (Dubois \& Trani, 2009).

The authors believed the Capabilities Approach offered a conceptual framework to study disability because it looked at the "range of possibilities from which he/she may choose these specific functionings" (Dubois \& Trani, 2009, p. 198). A disability was defined as "a lack of capability, due to restriction in the range of opportunities available in a given context" (Dubois \& Trani, 2009, p. 198). The authors argued that the 
Capabilities Approach decreased the consequences of disability because it allowed individuals with disabilities to choose from a great variety of opportunities due to the emphasis on equality (Dubois \& Trani, 2009).

The authors operationalized the Capabilities Approach by creating an analytical method using several steps (Dubois \& Trani, 2009). The first step was to estimate a person with a disability's freedoms and functionings. The second step consisted of a comparative analysis of people with and without disabilities concerning their achievements and freedoms to achieve (Dubois \& Trani, 2009). The third and final step of the approach was monitoring any changes in the condition of individuals living with a disability (Dubois \& Trani, 2009). The authors also developed measurements to measure functionings and estimate freedoms (Dubois \& Trani, 2009).

After creating 12 variables, with 40 response categories concerning an individual's personal demographics, social characteristics, and basic capabilities, the authors analyzed the data collected from the Afghanistan survey (Dubois \& Trani, 2009). One of the 12 categories was whether or not the person was disabled. Their analysis illustrated a "clear distinction between the situation of men and women in regard to basic capabilities in Afghanistan," with positive traits clustering around men and negative traits clustering around women (Dubois \& Trani, 2009, p. 207). The lowest performing subjects in this analysis were clusters of disabled women. Based on this data, the authors were able to create models that addressed disability research based on the Capabilities Approach (Dubois \& Trani, 2009).

Similarly, Simon, Anand, Gray, Rugkasa, Yeeles, and Burns (2013) created and utilized a multi-dimensional instrument as part of operationalizing the Capabilities 
Approach to apply to mental health research. The authors carried out the study as part of a program that served individuals with mental illness. Their research focused on identifying capabilities areas most impacted by mental illness and their measurements of well-being along with socio-demographic and clinical factors (Simon et al., 2013).

Building off the prior work of Anand, Hunter, Carter, Dowding, Guala, and Van Hees (2009), the authors sought to continue operationalizing the Capabilities Approach to the mental health discipline by identifying direct measurements of capabilities from survey data to produce new capabilities measurements (Simon et al., 2013). After developing the survey instrument and measurement scale by adapting part of a prior instrument and developing new measurements, the authors surveyed a sample of individuals with mental disabilities. The authors obtained data concerning health-related categories identified as quality of life, social functioning, and capability domains (Simon et al., 2013). They were thus able to develop a questionnaire that applied the Capabilities Approach to health outcome measurement for mental health patients' measured capabilities. The instrument could be utilized to determine as outcome measures for health-related quality of life and social functioning (Simon et al., 2013).

Kinghorn, Robinson, and Smith (2015) also utilized the Capabilities Approach in the area of chronic pain (Kinghorn, Robinson, \& Smith, 2015). In the qualitative study, fifteen subjects were recruited from a local pain management clinic to be part of a focus group and were asked to list any abilities, freedoms, activities, or roles they felt were valuable and contributed to a good quality of life (Kinghorn, et al., 2015). The respondents then were asked if their pain restricted their ability to partake in activities on that list (Kinghorn et al., 2015). The authors followed up focus groups with individual 
interviews.

After analyzing the data, the authors identified the following eight capabilities: (a) love and social inclusion, (b) enjoyment, (c) respect and identity, (d) remaining physically and mentally alive, (e) interdependence and autonomy, (f) societal and family roles, (g) physical and mental well-being, and (h) feeling secure about the future (Kinghorn et al., 2015). The authors used the results from the qualitative work to create a questionnaire, which "could then be used in evaluating both health and non-health interventions targeted at those with chronic pain" (Kinghorn et al. 2015, p. 910).

Greco, Skordis-Worrall, Mkandawire, and Mills (2015) utilized the Capabilities Approach to assess the quality of life for women in rural Malawi. The authors assessed well-being through developing a quality of life measure via the selection of relevant capabilities. As part of this health-based intervention, the authors used 15 focus group discussions comprised of a total of 129 women to explore relevant aspects of quality of life within rural Malawi. The findings helped to provide a complex picture of quality of life and well-being.

The authors analyzed the data to formulate a list of capabilities based on the responses concerning “someone living a 'good life' as a person that enjoys different states of "beings and doings"' (Greco et al., 2015, p. 71). After discussing the general meaning of a "good life," the authors analyzed and grouped the answers into a set of six main capability dimensions, each with sub-level dimensions (Greco et al., 2015). The levels and sublevels provided by Greco et al., 2015, (p. 72) were as follows:

- Physical strength

○ Being able to do physical work 
○ Having enough food to eat

○ Being able to avoid diseases

○ Being able to space births

- Inner wellbeing

- Having peace of mind

○ Having control over personal matters

○ Being free from oppression

- Living without shame

○ Having knowledge

○ Having good conduct

- Household wellbeing

- Living free from domestic violence

○ Having control over money

- Living in a decent house

○ Being able to take care of children and husband

- Being able to educate the children

- Community relations

- Feeling safe and comfortable in the village

- Being able to join community groups

- Avoiding social exclusion and discrimination

○ Being respected

○ Being able to access services

- Economic security 
$\circ$ Owning assets

- Being able to access business opportunities

○ Being able to rely on safety nets

○ Being able to cope with shocks

- Happiness

○ Being satisfied with life

○ Being happy

The findings portrayed the complex notion of women in rural Malawi concerning life and well-being (Greco et al., 2015). The results communicated that women spend a great deal of time concerned with physical and mental well-being, which in addition to the absence of sickness, also referred to the ability to work and create resources to support the family (Greco et al., 2015). Further, women lacked control over reproductive choices, which impeded their ability to achieve their own concept of a "good life" (Greco et al., 2015). The authors also noted that the results from their study aligned with many of Nussbaum's central capabilities (Greco et al., 2015; Nussbaum, 2003). This study illustrated how the Capabilities Approach may be operationalized to include indicators for well-being that measure quality of life. In practice, the results demonstrated the dimensions that impacted quality of life. Well-being was shaped not by just basic material needs but was "also highly dependent on complex feelings, relations and social norms" (Greco et al., 2015, p. 75). Here, one complex feeling was being in control of your own reproductive choices, and not leaving that decision to someone else. This was a social need as opposed to a physical aspect of life. Other dimensions that may impact 
quality of life are the freedom to own a business or the need to be respected. Thus, these needs go beyond the physical, and are more complex from a societal standpoint.

\section{Economics}

The discipline of economics contains studies attempting to apply or operationalize the Capabilities Approach. Schischka, Dalziel, and Saunders (2008) utilized a case study method to apply the Capabilities Approach to poverty reduction in a low-income neighborhood in a city within New Zealand and a project for women in a Samoan village. The authors drew five themes from their New Zealand case study, which focused on a governmental community garden program in a low-income area (Schischka et al., 2008). The focus group illustrated that participants felt a number of their life choices had improved because of the program (Schischka et al., 2008). They are as follows: "(1) the ability to learn and apply more gardening skills; (2) the ability to have social contact and be part of the community; (3) the ability to lead healthy lives; (4) the ability to have increased self-confidence and status; and (5) the ability to earn future income" (Schischka et al., 2008, p. 236). The second case study concerned women's interest in business program in Samoa. Program participants learned about micro-finance. Through 13 focus groups, participants reported the following new capabilities:

(1) The ability to generate cash income from local sources. (2) The ability to support the family. (3) The ability to make handicrafts for sale. (4) The ability to revive traditional crafters. (5) The ability to contribute to the local church and community. (Schischka et al., 2008, p. 240).

Schischka et al. (2008) praised using the focus group method as part of the Capabilities Approach because it helped facilitate reflective participation. The authors felt that both 
case studies helped participants discover that in addition to learning new skills, they also discovered they also had potentially valuable capabilities they had not previously discovered until now (Schischka et al., 2008). Thus, these case studies showed that "human development is not restricted to giving people new capabilities or access to extra material goods. Rather, development is also a process in which people come to recognize valuable capabilities they already have" (Schischka et al., 2008, p. 243).

Alkire and Santos (2014) presented another study operationalizing the Capabilities Approach through the multidimensional poverty index, a measurement system based off the Capabilities Approach. Recall that Sen (1999) advocated for measurement of well-being through capabilities instead of economic-based approaches due to the failure of monetary measurements to provide the entire picture. Alkire and Santos' (2014) study used three separate data sources on health, which incorporated (a) the United Nations' Millennium Development Goals, and (b) core functionings related to poverty measurements from over 100 developing nations. Alkire and Santos (2014) utilized the data set to create an internationally comparable poverty measure using a direct measurement method. Findings using the multidimensional poverty index included global poverty estimates, 1.67 billion people in the developing world living in acute poverty, distribution of global poverty, 49\% living in South Asia, 27\% in Sub-Saharan Africa, and poverty's intensity, most nations high in poverty correlated with high rates of poverty intensity (Alkire \& Santos, 2014). The author maintained that the results are credible due to the extensively robust analysis (Alkire \& Santos, 2014). Therefore, this meant that a capability-based approach to poverty reduction was operationalized and 
yielded reliable data through statistical analysis. From a practical standpoint, Alkire and Santos (2014) presented a direct method to measure poverty in over 100 nations.

The approach to multidimensional poverty utilized by Alkire and Santos (2014) seems to be gaining traction. Wagle (2014) operationalized the multidimensional poverty index approach utilized by Alkire and Santos (2014) to capture various achievement indicators that made up an individual's well-being and used the scale to measure multidimensional poverty within the United States. Wagle's (2014) results showed that "significantly larger numbers of households were deprived on economic and especially relational resources than on inner capabilities, with Blacks, Hispanics, and American Indians falling consistently behind" (Wagle, 2014, p. 237).

\section{Summary of operation in education, health, and economics.}

Scholars applied the Capabilities Approach in various ways. Saito (2003) examined the relationship between Sen's approach to well-being and education. McLean and Walker (2012, p. 588) created the "Public-Good Professional Education Index," utilized to create theory and empirical data from five university-based education departments at three universities in South Africa. The findings created four functionings that may improve education and quality of life in South Africa. Lambert et al. (2015) studied geography in primary and secondary school from the perspective of capabilities and human development. Terzi (2005) used the Capabilities Approach to reframe the concept of disability in education.

In the health discipline Dubois and Trani (2009), using a case study approach, applied the Capabilities Approach framework to disability as a way of assessing an individual's capability. They operationalized the Capabilities Approach by creating an 
analytical method using several steps: (a) estimate a person with a disability's freedoms and functionings, (b) perform a comparative analysis of people with and without disabilities concerning their achievements and freedoms to achieve, and (c) monitor any changes in the condition of individuals living with a disability (Dubois \& Trani, 2009). The authors also developed measurements to measure functionings and estimate freedoms (Dubois \& Trani, 2009). The authors were able to create models that addressed research on people with disabilities based on the Capabilities Approach (Dubois \& Trani, 2009).

Simon, et al. (2013) operationalized the Capabilities Approach to provide outcome measurements in the health discipline by creating a multi-dimensional instrument for mental health research. This research focused on identifying capabilities most impacted by mental illness and their measurements of well-being along with sociodemographic and clinical factors (Simon et al., 2013). Kinghorn, et al. (2015) also performed a qualitative study to operationalize the Capabilities Approach in the health discipline. Greco, et al. (2015) utilized the Capabilities Approach to assess the quality of life for women in rural Malawi through the selection of relevant capabilities. The results demonstrated that well-being is shaped not just by basic material needs but "also highly dependent on complex feelings, relations and social norms" (Greco et al., 2015, p. 75).

In economics, multiple researchers attempted to operationalize the Capabilities Approach. Schischka et al. (2008) utilized a case study method to apply the Capabilities Approach to poverty reduction in a low-income neighborhood in a city in New Zealand and a project for women in a Samoan village. The authors praised the Capabilities Approach because it helped facilitate reflective participation. The case study illustrated 
that development is "a process in which people come to recognize valuable capabilities they already have" (Schischka et al., 2008, p. 243). The Capabilities Approach has also been used to examine poverty reduction. Alkire and Santos (2014) operationalized the Capabilities Approach through the multidimensional poverty index, using three separate data sources on health, which incorporated (a) the United Nations' Millennium Development Goals, and (b) core functionings related to poverty measurements from over 100 developing nations. An internationally comparable poverty measure was created and the findings included global poverty estimates, distribution of global poverty, poverty's intensity, numbers of the poor and the deprived non-poor, and what deprivations the poor experience (Alkire \& Santos, 2014). A capability-based approach to poverty reduction was operationalized and yielded reliable data through statistical analysis. Wagle (2014) operationalized the multidimensional poverty index approach to capture various achievement indicators that make up an individual's well-being and used the scale to measure multidimensional poverty within the United States. The results illustrated that multidimensional poverty is an issue for both the Global North and Global South.

\section{Sport for Development and Peace}

Sport for Development and Peace (SDP) is not a new phenomenon. The roots of the modern SDP movement are traceable back to the late 19th century where, as part of the colonization process, socialization and development was often accomplished through sport (Cavallo, 1981; Kidd, 2008; MacAloon, 2006; Pitter \& Andrews, 1997). These early goals and ideals of SDP still exist today. The use of sport for socialization and development creates a language that is understood by virtually all cultures across the 
world, and has the power to mobilize populations in a variety of situations (Kleiner, 2012).

Development through sport has experienced several phases. The first phase involved 'recreation' interventions that focused on working and middle-class populations in the US, and used sport in colonialist efforts to civilize foreign populations during the late 19th century (Giulianotti, 2011; Kidd, 2008, p. 371; Levermore \& Beacom, 2009). This first phase also included the "playground movement" in the early 20th century, which was a demand by the working-class population to be given safe spaces where they could enjoy recreation activities (Darnell, 2010). The second phase arose during the mid to late 20th Century, where the focus shifted to Global North nations engaging Global South nations during an era that shunned colonialism in favor of scaling down imperialism (Kidd, 2008). Finally, the current era of development through sport has seen considerably increased attention as governments phased out international SDP programs in the late 20th Century, leaving a void for non-governmental entities to enter the field (Schulenkorf, et al., 2015). This ushered in the age of neo-liberalism development where private industry filled the void left by government (Wilson, 2012).

The evolution of SDP was characterized by rapid expansion in developing nations (Levermore \& Beacom, 2009). National leaders have utilized sport diplomacy to gain different perspectives or build common understandings with other nations concerning political issues (Kleiner, 2012). Non-government organizations like UNICEF look to sport to help spread their respective messages and achieve desired results (Kidd, 2008). Athletes and managers in sport-focused organizations have performed acts such as raising money for charitable causes that are in the public interest or public good. These acts 
involving sport led to the creation of "sport for development," a new concept that allowed others to utilize a vehicle: development through sport (Kidd, 2008).

Providing a short and concise definition for SDP is difficult because the term refers to varying types of activities. The concept of SDP is inclusive and crossdisciplinary, so practitioners and academics define SDP differently. One accepted way to define SDP is an approach where organizations utilize sport as a vehicle or a hook for broad, sustainable interventions with various goals in mind (Hartmann \& Kwauk, 2011; Kidd, 2008; Schulenkorf et al., 2016). Other practitioners might limit the definition to programs focusing on social change, peace, or economic development (Wilson, 2012). Regardless of definition, the field of SDP is expanding. Each element of SDP is defined in the subsequent section.

\section{History of SDP}

SDP, in its earliest forms, was used as a socialization tool. Giulianotti, (2011, p. 209) characterized sport as a "highly important socio-cultural and political-ideological tool in shaping Global North-South relations." Colonializing powers used sport to civilize indigenous populations in foreign lands, encouraging them to assimilate into the colonializing nation's culture thereby destroying aspects of the local culture (Giulianotti, 2011; Wilson, 2012). Multiple colonizing nations would utilize this approach as they made their way through the world.

SDP's focus would change during the 1940s to early 1990s, as the Global North's colonization efforts faded. During this phase, nations turned to sport for more nationalistic reasons and to assist disadvantaged communities throughout the world (Kidd, 2008). Developing nations were able to secure funding for sport-infrastructure 
projects and athlete training (Giulianotti, 2011). As part of helping these less developed nations within the Global South, Global North nations provided assistance such as increased aid, improved infrastructure, and other business/economic opportunities. As part of this process, however, Global North countries were also able to craft relationships with the Global South that saw developing nations increasingly become more dependent on aid (Levermore \& Beacom, 2009). This relationship of dependency helped foster unequal economic and power relations between Global North and Global South nations, leading to further marginalization of the developing world (Levermore \& Beacom, 2009).

The current era of SDP has witnessed a reduction in government sport-based development efforts in favor of neo-liberalism. Neo-liberalism is "an ideological approach that advocates for private businesses to come up with market-driven solutions for social, cultural, political, and other public policy matters" (Wilson, 2012, p. 76). This rationale advocates for decreased governmental interventions so that the open market can operate freely and come up with solutions for issues in the SDP field (Darnell, 2010). For example, as outlined by Wilson (2012), the Susan G. Komen Race for the Cure is a private business that raises money for treating breast cancer, an illness affecting a large number of people. Historically, the government raised money to fund breast cancer research. However, in an era of shrinking government spending where governments spend less funds on fighting diseases such as breast cancer, Susan G. Komen has stepped into this role traditionally filled by government to address this public policy matter.

Another such private actor is Olympic speed skater Johann Koss. Koss has been a driving force within the current SDP era (Kidd, 2008). Looking for a way to give back to the sport community, Koss worked in conjunction with the Lillehammer Winter Olympic 
Games Organizing Committee and several international charities to create a sports-based program called Olympic Aid (Kidd, 2008). The goal of the organization was to provide sports-humanitarian assistance (Kidd, 2008). After first providing solely monetary support, Olympic Aid moved on to conduct its own programs under the name "Right to Play" (Kidd, 2008). Today Right to Play operates on almost every continent, providing interventions involving sport on topics such as education, health, and peace-building (Right to Play, 2015).

\section{SDP Theoretical Frameworks}

Various historical theoretical frameworks have historically guided SDP programs such as Right to Play. Well designed and well-managed programs can typically help bring about positive outcomes (Welty Peachey, 2015). In the pursuit of pairing programs with the appropriate framework, SDP scholars and practitioners have utilized SDPspecific theory as well as theory from outside the SDP field (Schulenkorf \& Spaaij, 2015). Many frameworks exist. In an integrated literature review of 294 SDP publications collected between 2000 and 2013, Schulenkorf et al. (2016) found that 143 articles used a conceptual focus. Schulenkorf and Spaaij (2015) provided a possible rationale for the variety of frameworks used in SDP, as opposed to one SDP-specific theory, stating that "given the breadth and diversity of SDP...it is unrealistic to expect that one single SDP theory can encompass all relevant and potential significant aspects of the field" (p. 72). Instead, they suggested looking to parent disciplines from other fields and using theory that respects local program context and includes "local voices" when designing programs (Schulenkorf \& Spaaij, 2015, p. 74). 
Given the diversity and growth of SDP programs, the use of unique SDP theories and theories borrowed from other disciplines as frameworks is unsurprising. The duration of this section highlights several popular frameworks used in recent SDP studies. Sugden (2010, p. 267) developed a sociological framework he termed as a "critical left-realist approach" to aid in the use of sport in peace-building efforts within divided societies. Sugden (2010) focused on using sport as a mechanism to create a "ripple effect" that goes from the center of a program involving divided societies and then influences the events taking shape around the program by transcending social and political context to impact people who are not taking part of the events on the pitch. This ripple effect would then potentially create an organic network for people to develop relationships at the individual, community, and institutional levels (Sugden, 2010). He then applied the approach to several of his prior peace-building programs.

Massey, Whitley, Blom, and Gerstein (2015) applied theories from several disciplines to create a framework for SDP programs that, like Sugden (2010), attempted to facilitate an impact beyond an individual level. Massey et al. (2015) explored the use of systems theory and structural, attitudinal, and transactional (SAT) theory to facilitate a more holistic approach to SDP. Systems theory relates to interconnectedness of various pieces that create a result within a system (Massey et al., 2015; Ricigliano, 2012). SAT theory focuses on seven interrelated domains - governance, security, economy, human rights, social services, environmental/natural resources, the media, and civil society - as structural domains that meet society's basic needs from a structural, attitudinal, and transactional perspective (Massey et al., 2015; Ricigliano, 2012). First, the authors evaluated SDP-specific approaches such as those that focus on changing individual 
behavior (Lyras \& Welty Peachey, 2011) or methods that are not linked with societal structures (Schulenkorf, 2012). Because these approaches functioned solely at an individual level, Massey et al. (2015) questioned whether meaningful change could occur without examining how society impacted programming. In other words, more context was needed.

Massey et al. (2015) suggested that SDP practitioners integrate SAT theory as part of developing programs that were more in tune with what was happening in society. The authors felt this approach would account for factors occurring not only at the individual level, but also at the meso and macro levels. This meant programs could use SAT theory to be aware of other key aspects of society such as relationships and social systems in the community or other societal-based structures. SDP would not look at sport as a way to solve a societal issue, but instead use it as part of understanding the environment in which the program operates. An SDP program could discover the contextual issues that are unique to the local population, and focus on how it can "influence the attitudinal and structural outcomes" of those involved (p. 27). In other words, sport can be used as part of a holistic process to understand the context in which a program operates.

Massey et al. (2015) highlighted the importance of developing a context-specific theory for change. However, while using a systems theory or SAT theory would help provide more rigorous program planning and incorporate local context, challenges using this framework exist. Massey et al. (2015) acknowledge that a program must dedicate substantial time and resources to properly use this framework from a planning perspective. However, this is sometimes inconsistent with the funding and operational 
realities of the SDP field. In other words, money may be scarce and/or funding agencies may come with a tight project timeframe/agenda that prevents programs from conducting sound theoretical analysis to help understand context. Despite these difficult realities, Massey et al. (2015) encouraged those in different academic disciplines to work together to develop and implement holistic SDP programs.

Another framework that attempts to incorporate holistic a context into an SDP program is postcolonial theory. Darnell and Kaur (2015) used postcolonial theory as an SDP program framework as a way for practitioners to avoid looking to sport as a panacea for the world's problems. SDP postcolonial theory was used as a guiding framework to illuminate (a) sport's role as a mechanism to establish social hierarchies and relations of societal dominance, (b) understand how the use of sport is interpreted in a particular social and political context, and (c) that sports can be a forum that either preserves dominant social structures or challenges traditional social structures (Darnell \& Kaur, 2015). When executing SDP programs, Darnell and Kaur (2015) cautioned that practitioners should not oversimplify the complexity that development through sport embodies. Instead, "development is best viewed as embedded in historical, social, political, and economic relations and structures, structures that both produce and constrain the ideologies, viewpoints and actions of stakeholders" (Darnell \& Kaur, 2015, p. 15). Darnell and Kaur (2015) further suggested that scholars who use postcolonial theory in SDP must understand the importance of integrating the framework into the local historical and social context of the community where the program takes place. This framework highlights the importance of respecting local context, values, and history when building a program. 
Another theory from an outside discipline used in SDP programs, one that implicitly highlights the importance of understanding local values, is contact theory (Allport, 1954). This framework has been applied to a diverse group of SDP programs including conflict resolution and gender-based conflict (Lecrom, \& Dwyer, 2013; Lyras $\&$ Hums, 2009). Contact theory is premised on the hypothesis that facilitating meaningful contact between a diverse group of stakeholder groups may reduce hostility between them, defeat stereotypes, and facilitate positive attitudes between the groups (Allport, 1954). Because participating in sport may at times facilitate camaraderie between diverse groups through shared experiences, it is a logical to utilize Contact theory as a framework with SDP.

Baker, Baker, Atwater, and Andrews (2015) paired contact theory with an empowerment evaluation model to assess the effectiveness of a sports diplomacy initiative. Baker et al. (2015) analyzed 520 respondents who took part in a government sponsored sport diplomacy program, which lasted 39 months. The authors collected both qualitative and quantitative data using a pre-test/post-test survey. Three discussion points emerged from their findings: “(a) program objectives were effectively implemented creating positive change among participants, (b) change was equitably distributed among participants, [and], (c) the evaluation model was appropriate" (Baker et al., 2015, p. 65). The authors concluded that the study's findings supported the hypothesis based on Allport's contact theory that extended contact between two stakeholder groups through a grassroots sports diplomacy program would create increased positive change (Baker et al., 2015). However, these findings were limited to the short term. 
While some SDP scholars have suggested that academics apply theory from other fields to SDP (Schulenkorf \& Spaaij, 2015), a limited amount of SDP-specific theory exists. Chalip (2006) developed social leverage theory, the process of leveraging good will out of an event for other purposes, as a means to take advantage of the unique elements presented by sport. Chalip (2006) identified the phenomenon of communitas, or the sharing of intimacy within a group, that allows those who participate in a sport event to form relationships that span age, gender, and social class in a manner that may not had been possible but for that sport event. Chalip (2006, p. 123) suggested that programs could harness the social leverage created through communitas by taking advantage of "that post-event euphoria" that comes from these events and cultivate community development and social initiatives.

Welty Peachey, Borland, Lobpries, and Cohen (2015) explored leveraging SDP programming to create communitas of those connected to the event known as Street Soccer, USA. Using Chalip's (2006) social leverage framework and a qualitative methodology, the researchers interviewed participants and coaches from several Street Soccer, USA tournaments about their experiences (Welty Peachey et al., 2015). The authors also used field observations from the events for triangulation. Using social leverage theory and social capital theory, the researchers discovered that communitas emerged at the events, fostering social opportunities for those involved. This led to social interaction and leveraged the event into an opportunity to contribute to social good with the potential outcome for creating social capital (Welty Peachey et al., 2015). It was unclear, however, what approach would then be used to accomplish that social good. 
Building off Chalip's (2006) introduction of an SDP specific framework and call to use sport as an opportunity to contribute to social good, Lyras and Welty Peachey (2011) developed sport-for-development theory (SFDT) in an attempt to bridge the gap between theory and practice within SDP the field. SFDT is based on Allport's (1954) contact theory involving meaningful interactions between different stakeholder groups and potentially removing barriers between groups. SFDT embraces "non-traditional sport management practices through an interdisciplinary framework, blending sport with cultural enrichment" (Lyras \& Welty Peachey, 2011, p. 313). The approach contains what are referred to as five building blocks: "(a) impacts assessment, (b) organisational [sic], (c) sport and physical activity, (d) educational, and (e) cultural enrichment" (Lyras \& Welty Peachey, 2011, p. 313). The elements of SFDT "describe and explain the conditions under which sport researchers and practitioners can more effectively design and assess sport for social change initiatives" (Lyras \& Welty Peachey, 2011, p. 313). These conditions should also be fostered from a micro, meso, and macro level of society, (e.g. the individual, community, and collective levels of society) (Lyras \& Welty Peachey, 2011).

After setting out the five building blocks of SFDT, the authors articulated how the framework could be used in several SDP programs they were affiliated with - The Doves Project and the World Scholar-Athlete Games (Lyras \& Welty Peachey, 2011). Lyras and Welty Peachey (2011) suggest that this framework can be used to examine programs from a micro, meso, and macro levels to uncover factors that encourage and discourage positive social change. This means viewing issues from a personal (e.g. psychological), community (e.g. how people treat each other and what a community may value), and 
societal (e.g. what policies and structures exist in society) can help identify nuanced aspects that may impact change.

Lyras and Welty Peachey (2011) argue that SFDT seeks to better understand the conditions and processes by which sport can work to resolve challenges throughout the world using local context. Further, SFDT embraces the incorporation of outside theories such as resource dependency theory and institutional theory, among others to use sport to solve challenges (Lyras \& Welty Peachey, 2011). However, Lyras and Welty Peachey (2011) also cautioned that researchers and practitioners must also be aware of the various underlying challenges that are part of the issue that is the target of the program. Researchers and practitioners should thus understand the complexity of the various social and political challenges that may exist in the society where they operate. Therefore, considering a program's local context is important for SFDT to a program's success.

Marshall and Barry (2015) applied SFDT as a specific model to evaluate the Kicking AIDS Out Network. The researchers interviewed practitioners affiliated with the network to identify what each person thought was the most important part for meeting an SDP program's objectives. Marshall and Barry then compared subjects' answers with the elements identified in Lyras and Welty Peachey's (2011) SFDT model - (a) impacts assessment, (b) organizational, (c) sport and physical activity, (d) educational, and (e) cultural enrichment (Lyras \& Welty Peachey, 2011, p. 313). The researchers' intent was to explore the applicability of the SFDT model to what the Kicking AIDS Out Network programs used in different countries (Marshall \& Barry, 2015). Of the 21 reported responses, the most popular elements were identified as skills training, local youth 
leaders, participation and involvement, and program design. The authors grouped the five most popular results into two categories: capacity and sport.

Marshall and Barry felt the results fit within the SFDT framework at different categories within the theory. For example, 11 results such as skills training, participant and involvement, and funding were mapped to the organizational component of SFDT while seven responses, including local Youth Leaders, sports activities, and program delivery fell into the sport element of SFDT. The authors also reviewed the results from a macro, meso, and micro standpoint. The results illustrate that SFDT may be applicable to different types of programs. Marshall \& Barry (2015) suggested that SFDT be used in conjunction with theories from various disciplines due to sport's interdisciplinary manner. The researchers further suggested that future studies involving SDP should explore different perspectives of stakeholders and individuals involved of SDP projects.

In addition to the SFDT framework introduced by Lyras and Welty Peachey (2011), Schulenkorf (2012) created a sport-for-development (S4D) framework intended to "guide the strategic investigation of sport and event projects and their contribution to creating inclusive social change, enhancing local capabilities and achieving overall community empowerment” (p. 7). This framework focuses on cultivating an external change agent, for example a program from the Kicking AIDS Out Network, that takes part in the program and works as a facilitator alongside members of the targeted community to help create change. Once the community is able to make change on its own, the change agent withdraws (Schulenkorf, 2012).

The framework consists of three related areas: sport event management (planning, organizing, and conducting the project), facilitating opportunities for social experiences 
to facilitate positive intergroup behavior, and directing the social impacts toward longterm social outcomes (Schulenkorf, 2012). This three-step process creates a holistic approach that can guide SDP programs in its planning, implementation and evaluation processes (Schulenkorf, 2012). However, S4D theory has been criticized for its heavy dependence on an outside change agent to facilitate community-wide change (Massey et al., 2015). Further, because S4D theory does not take a multi-level approach that views a program from a micro, meso, and macro level viewpoint, the approach may be less successful in facilitating successful programs because of the limited focus (Massey et al., 2015).

Taken together, this section demonstrates the diversity of frameworks that are used in evaluating SDP. The common usage of these myriad of frameworks reflects what Schulenkorf et al. (2016) refers to as an ongoing debate concerning whether SDP "as a field of study is 'ready' for - and indeed worthy of - its own theories or if the trend of 'borrowing and applying theories and frameworks from parent disciplines... will continue in the future" (p. 35). While frameworks from other disciplines have traditionally dominated SDP (Schulenkorf et al., 2016; Schulenkorf \& Spaaij, 2015), SDP-specific theory primary based on contact theory and contextual considerations is also finding its way into the field (Chalip, 2006; Lyras \& Welty Peachey, 2011; Marshall \& Barry, 2015; Schulenkorf, 2012; Welty Peachey et al., 2015). However, given its varied contexts and complexities, SDP still lacks theory that can serve as a guiding model for those at the practitioner level as well as academics and policy makers to design and implement programs (Welty Peachey, 2015). Welty Peachey (2015), as guest editor of an International Journal of Sport Management and Marketing special issue focusing on 
generating SDP theory, even went so far as to ask in his introduction of the issue, "whether or not there can be an overarching theory of SDP given the varied contexts associated with the field, and cultural complexities that must be addressed" (p. 2).

If such a theory exists, it would likely contain many of the common elements of the frameworks used in SDP. Two common refrains from these frameworks are as follows: (a) the need for academics and practitioners to work closely within the local communities they seek to operate (Schulenkorf \& Spaaij, 2015), and (b) that a program should be conceptualized at the micro, meso, and macro levels (Lyras \& Welty Peachey, 2011; Marshall \& Barry, 2015; Massey et al., 2015). This common emphasis within the literature on working closely within the local communities and conceptualizing a program at an individual, community, and societal level, coupled with the call for SDP researchers to continue creating theory that is flexible enough to accommodate the varied and interdisciplinary nature of SDP programs provides a justification for exploring the Capabilities Approach as a potential framework for SDP (Lyras \& Welty Peachey, 2011; Massey et al., 2015; Schulenkorf et al., 2016; Schulenkorf \& Spaaij, 2015; Welty Peachey, 2015).

\section{SDP Program Characteristics}

Sport, development, and peace are linked together to help allow individuals and entities become positive agents of change in society (Coakley, 2011). By combining these elements together into a sport-based approach, SDP programs cover a spectrum of activities related to goals that address important societal issues (Coakley, 2011). The very nature of sport creates an inherent belief that it can be used as a development tool (Hartmann \& Kwauk, 2011). While sport-based programs last for differing time 
durations, whether it be something short-term or long-term, (see World Health Organization, 2007), each event utilizes the SDP framework to improve society. Sport-based interventions utilize various frameworks. However, Kidd (2008) suggested categorizing sport-based interventions into three broad categories. The categories, although related in some regard, have different characteristics. The first category includes traditional sport development projects that emphasize basic sports coaching, and focus also on building sport infrastructure and providing sports equipment (Coalter, 2010; Kidd, 2008). The second category of sport developmental interventions centers around humanitarian-based assistance (Coalter, 2010; Kidd, 2008). These types of programs focus on attending the needs of refugees or other need-based populations by providing supplies and critical services. Finally, the third type of sport-based intervention concerns an individual's and community's development through sport (Coalter, 2010; Kidd, 2008). These programs concentrate on the human development side of development to help increase well-being and meaningful choices in life.

Levermore (2008a) theorized that sport could be used as a vehicle for developmental purposes to reach communities that might be difficult for traditional development programs to reach. Although scant scholarship existed at the time of Levermore's (2008a) research concerning the potential viability of sport to act as an engine for development, Levermore theorized that sport could be used as a tool in an array of ways to foster development.

As part of evaluating whether SDP could be used as a potential development tool, Levermore (2008a, 2008b) provided a comprehensive review of what SDP programs existed. After the review, Levermore (2008a, 2008b) sorted each program into six 
identified clusters. The clusters were (a) conflict resolution and intercultural understanding, (b) building physical social, sport and community infrastructure, (c) raising awareness, particularly through education, (d) empowerment, (e) direct impact on physical and psychological health, as well as general welfare, and (f) economic development/poverty alleviation (Levermore, 2008a). These clusters illustrated how sport was emerging to assist with the goals of development in various ways.

Levermore (2008a) noted that while many of these clusters overlapped, each cluster related to specific types of programs. In the first cluster, programs often used sport to ease tensions caused by ethnic, racial or similar differences. Another common program example within the conflict resolution and intercultural understand cluster was programs that sought to build social cohesion in societies. The second cluster, building physical social, sport and community infrastructure, consisted of hosting sports events where money was raised to build new facilities, roads or meet other needs of a city or region, perhaps while also adding new jobs. Levermore (2008a) indicated that FIFA and similar organizations could play a role in this second cluster.

The third cluster related to raising awareness about important issues, whether they have to do with health (e.g. HIV/AIDS) or education. The fourth cluster, empowerment, was somewhat closer to the awareness cluster. Empowerment and awareness go hand in hand, as Levermore (2008a) suggested that programs could use empowerment to educate traditionally disadvantaged communities. One example provided was programs with a gender equity objective (Levermore, 2008a). The fifth cluster was improved physical and psychological health. Here, an organization might create programming targeting physical activity as a means to encourage exercise, healthy eating habits and the like. In the final 
cluster, economic development/poverty alleviation, one example given was working with the World Bank or similar entities to encourage awareness about banking services. Programs could also educate participants about micro-finance. Each identified cluster reflected the diversity of SDP programs, and the lack of standardization of organizations and their programming.

Although Levermore (2008a, 2008b) observed in his review that a large number of SDP organizations existed, he also noticed that there was a gap in critical evaluation of SDP programs. This lack of critical literature created a tension between SDP organizations and the NGOs/corporations they sought work with as partners (2008b). Levermore (2008b) cautioned that the desire of SDP organizations to quickly raise funds and execute programming in the field could injure the effectiveness of the organization, impair its long-term organizational strategy, and actually marginalize the people the program/NGO/corporation sought to help. Levermore (2008b) suggested that SDP programs should use a theoretical framework that utilized a holistic approach to understanding the local population. Levermore (2008b) concluded his review by stating that additional critical literature needed to evaluate SDP as an approach before it would be embraced by traditional development institutions.

Levermore (2008a, 2008b) identified theoretical challenges involving SDP and stated that additional studies needed to take place before it could be considered a potential engine for development. Scholars heeded Levermore's (2008a, 2008b) call for increased SDP research using different evaluative theoretical frameworks. Since Levermore's call for more scholarship back in 2008, SDP studies have increased (Levermore, 2011). In 2011, Levermore revisited the topic of SDP programming and 
again highlighted the need for programs to use a theoretical framework that rejected using a top-down approach and instead utilize context-specific programming. This would hopefully reduce a program's susceptibility to developing "a rigid mentality" (Levermore, 2011, p. 341). As part of this study, Levermore (2011) interviewed several prominent SDP programs concerning each organization's monitoring and evaluation methods. While such measures existed, Levermore (2011) called upon researchers and others working in the field to further explore evaluative components of SDP programs.

\section{United Nations Working Groups}

The United Nations played a significant role in SDP by assisting researchers with applying theoretical concepts to SDP programming. This relationship between the United Nations and SDP was paved in 2003, when the United Nations Inter-Agency Taskforce on SDP authored a report exploring the potential contributions sport can make toward achieving the United Nations Millennium Developmental Goals. The seminal finding in this report was "that well-designed sport-based initiatives are practical and cost-effective tools to achieve objectives in development and peace. Sport is a powerful vehicle that should be increasingly considered by the United Nations as complementary to existing activities" (United Nations Inter-Agency Task Force on Sport for Development and Peace, 2003, p. v).

In addition to again highlighting the unique benefits sport offers to development efforts, the authors also arranged SDP into five thematic groups (United Nations Office of Sport for Development and Peace, 2011). The groups were (a) sport and child and youth development, (b) sport and gender, (c) sport and peace, (d) sport and persons with disabilities, and (e) sport and health (United Nations Office of Sport for Development and 
Peace, 2011). Each thematic group was composed of UN member state delegates and other individuals, who may had been representatives of the UN system, academia, civil society, private sector, sports organizations and non-governmental organizations (United Nations Office of Sport for Development and Peace, 2011). Each group provided assistance to SDP practitioners to help implement policies that used the potential of sport to help achieve the Millennium Development Goals (United Nations Office of Sport for Development and Peace, 2011). These positive findings from the United Nations InterAgency Taskforce on SDP paved the way for future theoretical and practical research under the thematic group headings created in the report.

\section{Sport and Child \& Youth Development}

The first thematic working group is Sport and Child \& Youth Development (United Nations, n.d.). Sport-based interventions targeting children and youth boast many benefits. Programs involving youth provide individuals with a safe and supportive environment to help facilitate opportunities to learn and acquire skills. In the context of marginalized populations, these programs may help children cope with or improve their circumstances (Haudenhuyse, et al., 2012). Youth sport programs have explored issues concerning social norms and culture (Hartmann \& Massoglia, 2007), social relationships created as part of participating in sport (Fry \& Gano-Overway, 2010), and the physical, mental and socio-physiological benefits of sport in development (Coalter, 2007). Sport, therefore, has become a popular conduit for youth-based programs.

When studying sport and youth-based development programs, its level of success is contingent on a number of factors specific to the type of sport, those participating, the social, cultural aspects of the program, and the participants' specific experiences 
(Catalano, Berglund, Ryan, Lonczak, \& Hawkins, 2004; Coakley, 2002; Kane \& LaVoi, 2007; Weiss, 2008). Therefore, the success of each program involving sport and youth is contingent on specialized factors. Haudenhuyse et al. (2012) collected data from a boxing program located in Belgium to gain insight into how sport is delivered to and experienced by socially vulnerable youth. The authors collected information through focus groups and in-depth interviews with program participants, coaches, and other key individuals (Haudenhuyse, et al., 2012). The study's first author made 20 total field visits over a sixmonth period - nine visits were focused on boxing session observations and the remaining visits were dedicated to surveys, interviews, and focus groups. Thirty-five individual interviews were conducted (youth $=15$, coaches $=13$, key individuals $=7$ ), four focus groups occurred (coaches $=5$ participants, youth $=5$ participants, head coaches and coordinator $=2$ participants, project managers from program locations $=2$ participants). Data were then compiled and managed via NVivo 8.0 to interpret the results.

The concept of cultural capital was important to this study. Cultural capital, in the study's context, was possession of cultural qualifications that helped individuals get ahead in society (Haudenhuyse, et al., 2012). Cultural capital also included possessing societally desirable traits like knowledge, style, and taste (Haudenhuyse, et al., 2012). The results of that study illustrated the importance of the program's environment, teaching approach, and the necessity of cultural capital when attempting to create broad outcomes for socially vulnerable youth (Haudenhuyse, et al., 2012). It is important to generate an environment where socially vulnerable youth are able to be safe and experience feelings of success (Haudenhuyse, et al., 2012). 
Organizers and coaches emphasized creating a climate in which participants feel successful and respected, and fostering an environment where youth feel emotionally and physically safe (Haudenhuyse, et al., 2012). Socialization into accepting authority was also a key finding. The study's themes linked program instructions to participants abiding by the rules of established, mainstream society (Haudenhuyse, et al., 2012). Creating an environment where feeling safe and welcomed was viewed as a priority. Highlighting the importance of social interactions, coaches and participants were encouraged to engage in direct contact with each other. Instead of focusing solely on competition, coaches also tried to link boxing with the socialization process. The program also highlighted the importance of coaches having some commonalities with the participants, as a coach's background impacts the level of cultural capital or clout with the participants (Haudenhuyse, et al., 2012).

Taken together, the findings have specific meaning when working with socially vulnerable youth. Youth participating in programs like this one should not be viewed as potential talent for sport, but rather as individuals in need of broad developmental support through voluntary engagement (Haudenhuyse, et al., 2012). Further, the findings seem to support the notion that a traditional competitive club-based sport model is not ideal when working with a population such as socially vulnerable youth (Haudenhuyse, et al., 2012).

Burnett (2001) examined the social impact of sport and sport-based interventions in the Australian-South African Sport Development Programs Super Kidz and Playsport. She made the assessment according to social impact assessment paradigms. Four programs used as part of the study were located in urban areas, and three programs were located in rural areas. The questionnaire sample included 29 presenters or teachers, 96 
adult representatives of the household, and 11 other stakeholders. A random sample of 40 pre-intervention individuals and 70 post-intervention participated in focus groups participants (Burnett, 2001).

As a result of the participatory study, Burnett (2001) found several core themes concerning the individual in a social context. The researcher uncovered themes that included biographical and social issues within the community, ways in which problems were addressed, networks and supportive structures within the community, and factors influencing sports participation, such as norms and values, expectations, preferences, likes and socialization (Burnett, 2001). Poverty of the sample was a main theme. Burnett (2001) found that the chronic experience of poverty and lack of resources resulted in specific behavior patterns such as violent behavior. Furthermore, a majority of parents had relatively low education levels and were apathetic towards being involved in their children's' schooling (Burnett, 2001). The schools also lacked proper resources.

From a community perspective, the author found that households held the "educational" values of sport (Burnett, 2001). Sport kept children busy and taught them discipline, provided avenues to achieve good health and physical fitness, develop social skills such as comradely and leadership (Burnett, 2001). The households also viewed participating in sport as a coping mechanism, something that could make important contributions such as reducing crime (Burnett, 2001). Sport was viewed as a mechanism for social control and discipline (Burnett, 2001). The interviewees viewed sport as helping with the following outcomes, in order or prioritization: (a) development of a person, (b) cooperation, (c) a method of support of one another, (d) building character, (e) to accept losing, (f) coping with life, (g) to compete with one another, and (h) to 
experience winning as an individual (Burnett, 2001). Therefore, the subjects valued sport in many contexts and capacities. Taken together, Burnett's (2001) study found that sport and SDP programs were a great resource for the community.

Burnett (2013) used a qualitative study to examine both the quality of life and community development of participants in a youth development program that used football coaching to build operational capacity. The researcher used focus groups and structured interviews with 21 program managers, 51 program participants, and 51 others defined as family members and close friends (Burnett, 2013). Another 231 individuals participated in 36 focus group sessions for triangulation purposes (Burnett, 2013). Those facilitating the program asked questions about participant experiences as the beneficiaries of the program and also how the program contributed to any changes in their own lives (Burnett, 2013). The author used a Sport for Development Impact Assessment Tool as part of the research framework.

Burnett (2013) found that four indicators played an influential role in how youth are incorporated as part of social and economic development in community-based organizations. The four factors were: (a) training and delivery, (b) socio-economic empowerment, (c) utilizing youth to increase institutional capacity and sustainability, and (d) recognizing that youth are the drivers of social change (Burnett, 2013). The program sought to train 1,000 youth in the program's curriculum. It also focused on providing participants the knowledge necessary to implement the program once properly trained (Burnett, 2013). In exchange for training, coaches would receive financial compensation and access to food, thus participating in the program was very popular for those needing additional compensation and nourishment (Burnett, 2013). 
A common form of motivation for participants in one segment of the program was an opportunity to access scholarship resources to complete their schooling (Burnett, 2013). Part of the program was dedicated to providing training that would improve participants' chances of finding long-term employment (Burnett, 2013). Lack of education was an issue, however. Focus group sessions illustrated that most participants did not complete their education or have post-graduation qualifications. Therefore, many interviewees felt trapped into a coaching role because they lacked the financial means to go back to school. The scholarships served as a way to empower individuals seeking to restart or complete their education and training to develop employable skills. The results acknowledged that youth contribute to a program's sustainability and generally recognized that youth drive social change; therefore, empowering this demographic was important (Burnett, 2013). The findings illustrated that this program was a significant force that offered sport for development of youth and participants in the African nations through community-based drivers of behavior change (Burnett, 2013).

Kay (2009) examined the benefits that children and youth obtain by participating in sport programs. The program examined in this study utilized sport as a means of working with youth in severely disadvantaged communities. Educational and community services professionals who believed in the role that sport played in their profession staffed the program (Kay, 2009). The research questions investigated the types of benefits gained in this intervention and how the participating youth and staff working the program believed that sport played a role in the process (Kay, 2009). The program studied was located in Delhi, and conducted netball-led interventions with the goal of empowering young women to become both leaders and social activists in their local communities 
(Kay, 2009). Topics covered in the intervention included health, socialization and economic issues. Thirty-nine individuals participated in the study's data collection, which consisted of discussion groups and individual interviews.

The results showed that the sport program offered specific benefits to address issues within the participants' lives. Participants noted during interviews that they encountered limited expectations about being a young female. The program utilized sport to address the educational and social problems participants encountered through modules that both educated and empowered the youth (Kay, 2009).

Programs involving sport and youth have explored a variety of social issues. Sport has been used to help with socialization of vulnerable youth (Haudenhuyse, et al., 2012). Sport has also been used to socialize youth into accepting the rules of mainstream society (Haudenhuyse, et al., 2012). Sport can be used as a coping mechanism for social control as well as a way to educate youth about society (Burnett, 2001). Youth can also use sport to improve their self-confidence and drive social change (Burnett, 2013; Kay, 2009). However, the success of sport-based youth development programs depends on a number of factors involving the sport, who is participating, and the social, cultural, and prior experiences of the participants (Catalano et al., 2004; Burnett, 2008, 2013; Coakley, 2002; Kane \& LaVoi, 2007; Weiss, 2008).

\section{Sport and Gender}

The second thematic working group created by the United Nations Sport for Development and Peace International Working Group was Sport and Gender (United Nations Office of Sport for Development and Peace, 2011). Sports-based interventions

encourage discourse concerning gender equity in sport and equality, not just within sport 
but also in society (Swiss Academy of Development). Absence of interaction between men and women can create prejudice and conflict (Lyras \& Hums, 2009). Different interventions can be utilized to combat this issue, including those that use intergroup contact theory to demystify and de-stigmatize the other gender (Allport, 1954; Lyras \& Hums, 2009). Females participating in physical activities, sport, and play, derive many benefits including physical health, mental health, educational and intellectual development, reproductive health, and social inclusion, all within the context of experiencing a "fun factor" (Swiss Academy of Development, 2005; World Health Organization, 2004). Thus, myriad programs focus on varied gender-related outcomes using sport, physical activity or play.

Practitioners may develop gender-based interventions to address cultural norms that injure one gender's personal growth and socialization. For example, girls standing on the sideline of a field watching boys play does not necessarily indicate girls lack an interest in participating in that sport (Swiss Academy of Development, 2005). Instead, girls might be constrained by a cultural expectation. There may be a price to pay, however, for not adhering to this norm. Failing to conform to socially and culturally expected norms creates safety concerns in certain settings or may lead to other serious consequences with family or create societal friction (Swiss Academy of Development, 2005).

When dealing with gender and sport, cultural norms may impact each gender's ability not only to utilize sport, but also influence rights in other societal matters. However, sport participation does have its benefits. Sport-related activities may provide females with benefits such as access to public space, facilitating an opportunity for group 
gatherings and growing social networks, meeting with peers and discussing problems or other matters of importance (Swiss Academy of Development, 2005). Through sportbased interventions focusing on gender, programs can help individuals claim their own space, provide structure, educational lessons, safety, role models, and incentives to create meaningful outcomes to those they serve (Swiss Academy of Development, 2005).

Hancock, Lyras and Ha (2013) provided a comprehensive review of the trends in SDP programs targeting girls and women. Each program was located by using four different SDP databases, yielding 376 usable programs. The authors sought to answer the following four questions: what SFD programs exist for girls and women? What sports and activities are utilized? What are the major program objectives and intended impacts? What global patterns exist (Hancock et al., 2013)? Utilizing a framework of SDP theory and the program objectives created by the United Nations, the researchers identified the patterns used in sports/activities, the programs' objectives, and intended impacts by using a content analysis (Hancock et al., 2013).

After going through the coding process, the researchers separated the usable programs into the following areas: (a) individual development (i.e. self-efficacy, skill development) -109 programs, (b) social integration and the development of social capital - 54 programs, (c) promotion of gender equity - 49 programs, (d) health promotion and disease prevention -44 programs, (e) communication and social mobilization - 39 programs, (f) other programs whose objectives were not previously identified by the United Nations Office of Sport for Development and Peace - 30 programs, (g) equipment and facilities -21 programs, (h) economic development -19 programs, (i) peace-building and conflict prevention/resolution - 10 programs, and (j) 
post-disaster trauma relief and normalization of life - five programs (Hancock, et al., 2013).

Hancock et al. (2013) found that many programs utilized similar content. Programs often created programming related to health education matters such as maternal health, HIV/AIDS, alcohol/drug abuse and nutrition, social inclusion topics related to equality and breakdown stereotypes and the personal development of those who attended the programs such as increasing leadership skills and self-esteem. Nearly two-thirds of programs utilized social inclusion as a means to recruit participants. Another 99 programs used sport as a hook in the recruitment process while 61 programs planned to use sport as a diversion to accomplishing intended intervention outcome.

After completing their content analysis, Hancock et al. (2013) concluded that international governing bodies such as the UN as well as governing bodies like the IOC and FIFA support the use of sport-based programs focusing on development and empowering females. Based upon the number of programs using sport as a tool for social development and/or socialization, one may conclude that social inclusion is an important intervention topic globally. The authors argued that social inclusion programs are important because they "offer a safe sporting environment, which allows girls and women the freedom to socialize and express themselves through movement and physical activity...[thus social inclusion programs are]...particularly important in communities with strict cultural or religious practices" (Hancock et al., 2013, p. 20).

One issue identified from the content analysis of the 376 programs was the trend that they were gender specific (Hancock et al., 2013). Of the majority of programs identified, $77 \%$ were reserved to only females. This invites discussion as to whether 
programs covering gender-related issues should be separate or integrated interventions (Hall, 2010). Sport-based interventions concerning gender do not want to see an escalation of social divisions between genders. Hancock et al. (2013) therefore agreed with Lyras and Hums (2009) and suggested utilizing Allport's (1954) intergroup contact framework to encourage an inclusive setting. The authors concluded by positing although more research is needed, the programs, objectives and intended impacts identified within the content analysis and "the abundance of policy supporting sport and women's development is a step forward in the quest for global gender equity and the achievement of various Millennium Development Goals" (Hancock et al., 2013, p. 22).

Hayhurst (2013) explored a NGO corporately-funded program in Eastern Uganda that focused on gender issues in the developing world. The program used a sport, gender and development martial arts program to address the marginalization of girls in Uganda (Hayhurst, 2013). Through this approach, the program sought to advance the health and educational levels of participants, cultivate their self-respect, and improve gender relations within the local community (Hayhurst, 2013). In short, the program existed to combat the marginalization females faced and address the inequalities that women faced in Uganda. Hayhurst's (2013) study utilized 35 semi-structured in-depth interviews, and also relied on document analysis and studying the participants. Interviews with each individual lasted from 35 minutes to 120 minutes, were digitally recorded, transcribed verbatim, entered into NVivo 8, and then coded using notes (Hayhurst, 2013).

The results showed that the young women who participated in the sport, gender, and development intervention were deeply influenced by the martial arts program's model (Hayhurst, 2013). Martial arts acted as both a self-defense mechanism and a say no 
to sex mechanism for the girls. Overall, the results revealed many positive outcomes of the martial arts program. The program "increased the young women's confidence, challenged gender norms, augmented their social networks, improved their physical fitness and was useful for providing them with employment opportunities" (Hayhurst, 2013, p. 8). Several girls interviewed repeatedly credited martial arts as building their confidence to refuse sexual relations and assert their opinions on decisions that directly impacted their lives.

There were also negative impacts. The program "also attempted to 'govern' their sexuality and sexual relations with boys and men by promoting individual avoidance and encouraging the use of self-defense strategies against potential abusers" (Hayhurst, 2013, p. 8). Young women, through the program, were disciplined to hold back their sexuality, using it as a sense of empowerment to match the physical power they had to fight back against others (Hayhurst, 2013). Therefore, the treatment of female sexuality may be an issue.

This successful martial arts program may have had the effect of creating change agents. Hayhurst (2013) argued that this girl-focused sport, gender, and development program built self-esteem, confidence, self-responsibly and encouraged women to become social change agents to address potential resistance from family or the community at large concerning female participation in matters not traditionally reserved to their gender roles. Despite having these new tools, girls still needed to successfully navigate the structural inequities embedded in the local community culture that foster female marginalization. Practitioners must gain a better understanding of the burdens 
placed on young women who are charged with being change agents so that they can avoid additional marginalization and receive support (Hayhurst, 2013).

Be (2014) researched the various elements of the program Moving the Goalposts (MTG), an organization that used football and peer education to empower/foster leadership development within Kenyan girls. MTG combined football with peer-led health education as a means to help encourage leadership in their participants (Be, 2014). Be (2014) also sought to identify which program elements contributed to the growth of leadership characteristics. Be (2014) utilized a combination of in-depth interviews, participant questionnaires, field observations, and digital story scripts in gathering information from the 88 participants.

Be (2014) found that MTG changed community altitudes concerning stereotypical gender norms and that program participants displayed a perceived change in their confidence and communication skills. Many participants stated that they increased their courage and confidence because of the program. They also considered themselves as being good role models now (Be, 2014). Peer education sessions created awareness about individual rights, how those rights may be violated, and the need to protect those rights (Be, 2014). Leaders produced by MTG also gained enough courage to readily disagree with traditional cultural beliefs that stigmatized unmarried women, women who wore shorts or other non-traditional clothing or carried themselves in a manner that would be traditionally perceived as arrogant $(\mathrm{Be}, 2014)$. The MTG participants were empowered to lead, stand up for their rights and become change agents within their community.

The results of Be's (2014) findings speak to the power of sport to be used in the context of gender studies. Sport was a tool for developing girl leaders within the local 
Kenyan community when a close relationship between the target group and the local community exists (Be, 2014). However, sport cannot be just a main component of the activity, but rather as an entry point into the discussion of female empowerment $(\mathrm{Be}$, 2014). Furthermore, a successful program must offer a safe environment with multiple paths for development if it seeks to modify traditional gender norms and create leaders within developing nations (Be, 2014).

Samie, Johnson, Huffman, and Hillyer (2015) utilized a case study approach to analyze data collected from a US Department of a State-supported initiative known as the Global Sports Mentoring Program (GSMP). The aim of the study was to collect information concerning the participants' experiences and perceptions of empowerment, agency, and voice. The GSMP was a month-long program where women from the sport industry living in emerging nations were paired with female sports industry professionals from the United States or the purpose of mentorship. These international emerging leaders experienced an educational curriculum intended to "expose, equip, empower and entrust" them with both life skills and knowledge so as to assist in the process of reexamining the social world they experience as women (Samie et al., 2015, p. 923). The program also focused on empowerment. Multi-cultural staff was used in the program to reduce neo-colonialism and other biases. The researchers focused on participants' perceptions and experiences of female empowerment as conveyed by the emerging leaders before and during their participation in the 2012 and 2013 educational component of the GSMP.

The authors sampled 27 women attending the GSMP from 27 countries (Samie et al., 2015). The participants differed in social, personal and political backgrounds, as well 
as age, socioeconomic status, religion and ethnicity. Video and telephone interviews were conducted in English before the subjects participated in the Global Sports Mentoring Program. Semi-structured face-to-face interviews occurred midway through the program. Data were then analyzed for patterns and themes.

The results illuminated participants' sentiments on their experiences with empowerment, agency, and voice. All participants expressed that they felt empowered as a result of their current positions as educated, accomplished women. Two-thirds of the emerging leaders believed that even though they subjectively believed they were responsible for their own power, their respective family and partners also were credited with helping create opportunities for their own empowerment (Samie et al., 2015). There were also issues with resistance to power. Many participants' experiences with power involved their struggle to resist the power of others in their lives to be able to make their own decisions, instead of being granted power. This constant resistance negatively impacted some participants' desires or ability to work for the betterment of women, even though they associated women's lack of power in society with a lack of education or appropriate knowledge (Samie et al., 2015).

A major emerging theme from mid-program interviews concerned how the initial perceptions of participants concerning empowerment were broadened (Samie et al., 2015). Emerging leaders developed a more sophisticated understanding of the dynamics that go into empowerment, oppression and inequality as it related to people, communities, societies and structure and agency (Samie et al., 2015). The study also illustrated the struggles that exist concerning adult female empowerment in the sportslandscape. 
Although different sport-based programs involving gender exist, many focus on encouraging discussion about equality, combating gender norms, promoting inclusion, and individual skill development (Hancock et al., 2013; Swiss Academy of Development, 2005). Youth-based programs often focus solely on females (Hancock et al., 2013), and empowerment is an important aspect of many programs (Be, 2014; Samie et al., 2015). Sport can also be used as vehicle to improve self-confidence and encourage participants to become social change agents (Be, 2014; Hayhurst, 2013).

\section{Sport and Peace}

The third thematic group is the Sport and Peace working group. Sport's universal language allows it to be a tool in defusing tension caused by intergroup conflict (Levermore, 2008a). Conflict is a part of life, but it is often times made worse when a conflict is caused by the characteristics an individual cannot change. Researchers and practitioners have used sport to elevate or address conflicts based on race, citizenship, national identity, sex, sexual orientation, or disability (Hoglund \& Sundberg, 2008; Schulenkorf, 2010; Schulenkorf, Sugden, \& Burdsey, 2014; Sugden, 2006, 2010, 2015). Sport-based interventions help illustrate to these seemingly different groups that they have much more in common than previously thought and can melt away barriers (Hoglund \& Sundberg, 2008; Schulenkorf, 2010; Schulenkorf, et al., 2014; Sugden, 2006, 2010, 2015).

Multiple examples illustrate how sport is utilized to promote conflict resolution and or intercultural understanding. Traditionally, practitioners or scholars seeking to use SDP in this capacity established programs in regions where violence was prevalent. A popular example of using sport for peace and intercultural understanding is soccer in the 
Middle East. Sugden (2006, 2010) and Schulenkorf and Sugden (2011) evaluated an intervention that used soccer to break down barriers between Palestinian and Israeli communities. The program, Football4Peace, sought to promote a dialogue between these two groups, using soccer as the activity to bring people together but then transition to activities away from the pitch (Sugden, 2006). Children participating in Football4Peace were not the sole target (Sugden, 2006). Adults facilitating activities and parents were also viewed as key targets (Sugden, 2006).

Sugden (2006) interviewed local coordinators, coaches, children, parents, and volunteers helping to facilitate the Football4Peace program. Those participating were Jewish or Arab. Through semi-structured interviews and observations, Sugden (2006) found that as the program grew, it promoted awareness of both sides in a distinctive cultural context. Jewish Israelis gained awareness of Arab Israelis and vice versa. The intervention became a meaningful opportunity to promote a dialogue among young people (Sugden, 2006).

There were some problems, however. At times, adults participating in the intervention focused too much on winning the on-pitch activities (Sugden, 2006). Neutrality of the adults also was an issue at times. Sugden (2006) further pointed out that a program's chance at success was bolstered if the leaders and volunteers both had a shared commitment to the project's underlying principles and values. Through this process, Sugden (2006) concluded that significant sociopolitical issues must be considered when engaging in this type of intervention. Although criticism exists concerning this type of program, the Football4Peace initiative was a modest attempt to implement a program defusing conflict within a divided society (Sugden, 2006). 
Schulenkorf and Sugden (2011) again examined the Football4Peace intervention, this time focusing on the management and implementation strategies utilized to deliver inter-community sport interventions within societies in conflict. The data for this study were gathered through observational research and semi-structured focus groups with volunteer coaches participating in the program (Schulenkorf \& Sugden, 2011). The authors found that, from an implementation perspective, the coaches experienced issues with local support staff who were not trained according to the Football4Peace method and did not understand the underlying driving program values such as trust, responsibility, and inclusion (Schulenkorf \& Sugden, 2011). Despite these issues, the international coaches facilitating the intervention believed that Football4Peace was a promising step towards intercommunity development and that the program should grow and be leveraged (Schulenkorf \& Sugden, 2011).

Several themes emerged through this study. The first theme focused on building the capability of local volunteers. In order to fulfill their roles as supporting change agents in the programs, local volunteers should be included in briefings and strategic preparation during the pre-project phase and not on an ad hoc basis (Schulenkorf \& Sugden, 2011). Second, the commitment and leadership of key individuals is critical in achieving positive outcomes. "This research showed that not sport per se, but the active involvement of passionate community leaders and change agents makes a strong contribution to positive intergroup development, cooperation and inclusive change" (Schulenkorf \& Sugden, 2011, p. 251). Further, the "conditions (e.g. downplay of competition and the focus on social values) and context of the event (e.g. combination of foreign expert and community support) are important success factors" when trying to 
diffuse an intervention initially filled with tension (Schulenkorf \& Sugden, 2011, p. 251). A final key theme that arose from this study was that program organizers must include the local community when engaging in strategic planning in order to grow and leverage individual projects (Schulenkorf \& Sugden, 2011). This means that a program's success is also based on its ability to be inclusive and gain the support of individuals other than program participants.

Football4Peace is a program often studied in sport for development and peace. This specific program has been in existence since 2001 and has experienced multiple cycles. Each time Football4Peace was examined, the authors used semi-structured interviews, journaling, and observations to gather information. Often, the children were satisfied with the intervention and became more comfortable with the out-group (Schulenkorf, et al., 2014). At times, however, organizers experienced issues with adults criticizing the program and its aims (Schulenkorf, et al., 2014). Ultimately the authors found that, although sport was inherently neutral (Sugden, 2010), when a program was locally grounded through key stakeholders and carefully planned and professionally implemented, it could create a modest impact toward promoting conflict resolution and peace (Sugden, 2010).

Another program falling into the conflict resolution and cultural understanding cluster is the Intercultural Sport Meeting (ISM) Event, which was the focus of Schulenkorf's work (2010). Utilizing 31 semi-structured interviews with Sinhalese, Tamil, and Muslim international event stakeholders participating in the ISM, Schulenkorf (2010) created an in-depth case study to examine whether social change developed because of this event. The overall goal was to investigate the role, if any, sporting events 
played in facilitating the reconciliation and movement toward social change in the various divided communities of Sri Lanka.

Schulenkorf (2010) found that the ISM enabled participants to experience the different groups directly through contact for the first time in their lives. Another interesting finding was that participants were very friendly with each other and did not disrespect each other's ethnicity (Schulenkorf, 2010). Individuals mixed beyond their social identities, which helped create emotional bonds with members from out-groups. At times, participants completely forgot about any differences in nationalities (Schulenkorf, 2010).

Taken together, these findings suggested that, under specific conditions and if strategically designed, sport events allowed the establishment of friendships and the creation of inclusive social identities along national lines, organizational lines, common interests, and imagined factors in bonding with others (Schulenkorf, 2010). Because of the program, pride developed as being part of a new group called "Imagination" that was composed of Sinhalese, Tamil, and Muslim communities, creating an imagined group (Schulenkorf, 2010, p. 288). This led to participants feeling a part of "something larger" than themselves (Schulenkorf, 2010, p. 289). The ISM created an opportunity for disparate groups to come together and contribute to positive social change (Schulenkorf, 2010). While this event was successful, and sport was a good starting point to serve as a catalyst for social change and community development, Schulenkorf (2010) cautioned that sport must be integrated into a larger agenda supported by both society and the governing political institutions to make a significant contribution toward promoting cultural understanding and providing reconciliation or peace in divided societies. 
Lecrom and Dwyer (2013) also examined sport's use in intercultural understanding. The authors evaluated a program designed to promote intercultural understanding between the United States and China. The program, Developing and Improving Synergies in Chinese and United States Soccer (DISCUSS), was a two-way coaching exchange program that took place in $2010-11$. The authors specifically evaluated the participants' cultural awareness and understanding of the United States through sport. They were interested in how Chinese participants' impressions of the United States and Americans changed because of this exchange program (Lecrom, \& Dwyer, 2013). The authors were also interested in knowing what role soccer and soccerrelated programming played in influencing a participant's cultural awareness and understanding (Lecrom, \& Dwyer, 2013).

Utilizing Intergroup Contact Theory (Allport, 1954), the authors focused on 12 Chinese participants taking part in the program. The authors found that, due to the program, the participants (a) experienced a changed impression of people in the United States and their society, (b) a changed view of interest in soccer in the United States, and (c) a perspective that sport and coaching reflected a culture of people in the United States being more passionate about soccer (Lecrom, \& Dwyer, 2013). By viewing the culture directly instead of through a filter, participants gained a differing perspective.

The authors concluded DISCUSS organizers succeeded in creating an environment optimal for creating relationships and improving understanding (Lecrom, \& Dwyer, 2013). Their findings provided additional support that SDP and sport diplomacy promote cultural understanding (Lecrom, \& Dwyer, 2013). This work further supports the proposition that sport can serve as a vehicle to educate others in matters of cultural 
understanding and awareness, further reinforcing the "plus-sport" approach to utilizing sport in development (Lecrom, \& Dwyer, 2013). The authors viewed this case study as giving additional weight to the argument that sport can play a significant role in development (Lecrom, \& Dwyer, 2013).

Practitioners and scholars have applied sport to cultural understanding and conflict resolution involving the cessation of war and violence (Dyck, 2011). One such examination was Dyck's (2011) case study of the use of sport in the Sierra Leone postcivil war disarmament, demobilization, and reintegration (DDR) intervention by the United Nations. Dyck (2011) specifically researched how ex-youth combatants, camp administrators, and caregivers perceived the role and significance of sporting activities in interim care centers or DDR camps. The study used an in-depth case study of 13 semistructured interviews of Sierra Leonean child soldiers' experiences in sport during their time at DDR camps to gain a greater understanding of the micro-level dynamics of sport in DDR processes (Dyck, 2011). Dyck (2011) also interviewed four adult camp administrators and caretakers as part of this case study.

Dyck (2011) found that using sport as part of the DDR process helped researchers to understand the nuanced forms of violence former child soldiers experienced and the healing process of youth combatants during the integration process. Several important findings emerged. They were as follows: (a) the main benefit of using sport in the DDR camps was that it helped facilitate the gradual decrease in levels of direct violence among male youth combatants, (b) the interactions on the football pitch between DDR youth and local community teams helped to reestablish relationships between former youth soldiers and the various communities, (c) sports facilitated the building of social networks among 
the youth that could be nurtured and utilized in other respects, and (d) sport was a helpful tool to distract former child soldiers from the psychological trauma of their former lives (Dyck, 2011).

Taken together, these findings illustrate sport's potential to serve as a tool to address psychological trauma. Here, that trauma stemmed from being forced into servitude as a child soldier. Sport in this intervention served as one of the many activities aimed at supporting the DDR approach in transitioning participants back into society. Although not the focal point, sport played a supporting role working in synergy with other rehabilitation programs such as vocational training and psychological counseling (Dyck, 2011). Thus, if used effectively, Dyck's (2011) research supports the argument advanced by Schulenkorf (2010) that sport works as a component within a broad range of rehabilitation and developmental activities within the development process.

Hoglund and Sundberg (2008) reviewed sport and conflict in the context of South Africa's post-apartheid era. They attempted to answer the question of whether and in what manner sport can serve as a tool for conflict reconciliation and social cohesion (Hoglund \& Sundberg, 2008). The authors identified methods by which sport was being used for peace building: (a) the national level, (b) the community level, and (c) the individual level (Hoglund \& Sundberg, 2008). By working within these levels, practitioners could utilize several sets of factors to deliver social change (Hoglund, \& Sundberg, 2008). The first set of factors related to how specific initiatives were designed, who comprised the target groups, what activities were planned and what leadership team was in place (Hoglund \& Sundberg, 2008). The second set of factors related to culture and required practitioners to know specifics about the target groups and what type of 
group interaction would be most successful (Hoglund \& Sundberg, 2008). The third set of factors examined the context of the nations in which the reconciliation sport initiatives took pace (Hoglund \& Sundberg, 2008). For instance, in South Africa, the context was racial quotas. This mechanism may vary in other nations due to changing context (Hoglund \& Sundberg, 2008). Hoglund and Sundberg's (2008) findings are important because they again illustrated the importance of local context in sport-based interventions.

Schulenkorf and Edwards (2012) examined whether intercommunity sport events could create a positive social outcome within ethnically divided communities within Sri Lanka. As part of this, the authors conducted two focus groups and 35 in-depth interviews with Sinhalese, Tamil, Muslim and international event stakeholders. The authors found that peace and reconciliation events were achieved by starting with the youth, which then generated additional social benefits (Schulenkorf \& Edwards, 2012). The youth can provide a pathway to reach their friends, but also individuals from other age groups and a wider community and build a positive community (Schulenkorf \& Edwards, 2012).

The authors' findings further suggested that those organizing events and the communities that host them should focus strategically on children as catalysts for change (Schulenkorf \& Edwards, 2012). Further, fostering a mutual understanding and appreciation of different ethnicities and cultures may be achieved by increasing the frequency of ethnically mixed team sport activities (Schulenkorf \& Edwards, 2012). Providing event-related sociocultural opportunities, combining large-scale events with regular sport-for-development programs, and engaging in social, cultural, and political 
events leverages the potential to increase a community's capacity (Schulenkorf \& Edwards, 2012). These findings show that sport, when utilized with other strategies and tactics, contribute to a local community's capacity building and can also impact the wider community (Schulenkorf \& Edwards, 2012).

Sport's ability to communicate across language and cultural barriers has made it a popular method for staging peacebuilding programs. Intergroup Contact Theory is one method that has been used to break down barriers between two groups (Allport, 1954; Lecrom, \& Dwyer, 2013). Sport has been used to defuse conflict between groups by finding common ground (Levermore, 2008a). Sport has also been utilized as a supporting tool to address psychological trauma (Dyck, 2011). Any program aimed at resolving conflict must address the unique sociopolitical issues surrounding the participants and other stakeholders (Sugden, 2006). Further, programs should focus on building the capacity of local volunteers and members of the local community should be involved in the planning process (Schulenkorf \& Sugden, 2011). Accounting for a program's local context is important for success (Hoglund \& Sundberg, 2008).

\section{Sport and Persons With Disabilities}

The Sport and Persons With Disabilities Thematic Group was the fourth group to be activated by the United Nations Sport for Development and Peace International Working Group. A disability is one's individual difference in appearance, structure, functioning, and performance that is often perceived as being undesirable in society (Goffman, 1963; Sherrill, 1997). Participating in physical activity, however, provides a person with a disability the opportunity to counter negative self-perceptions that may exist due to society's restrictive treatment of individuals with disabilities (Blinde \& 
McClung, 1997). It is also noteworthy that Silva and Howe (2012) suggested that adapted physical activity as part of sport and play may benefit from incorporating the Capabilities Approach to aid in development. Therefore, this prior research may illustrate the potential of the Capabilities Approach relative to disability and sport.

Pensgaard and Sorensen (2002) proposed a model to empower those with disabilities through a sport context. This model for empowerment of people with disabilities through sport accounted for both individual and situational factors (Pensgaard $\&$ Sorensen, 2002). The model included moderators (age of onset of disability, gender, and type of disability) and mediators (individual level: achievement goals, identity, and self-efficacy; empowerment at the group level, motivational climate, group identity, and collective efficacy; and societal level: the cultural context and political efficacy) (Pensgaard \& Sorensen, 2002). These different moderators and mediators worked differently from group-to-group. Each moderator and mediator impacted whether a person with a disability was empowered or disempowered in a sport context (Pensgaard $\&$ Sorensen, 2002). Therefore, the effectiveness of empowerment through sport was moderated and mediated by one's internal factors and the external, situational, environment.

Goodwin, Thurmeier, and Gustafson (2004) studied the phenomenon of disability and the metaphors commonly associated with disability (e.g. fear, illness, survival, and empowerment) that young adults with physical disabilities faced. Goodwin et al. (2004) also explored the moderating influence that physical activity had for the meanings of those metaphors. The authors used purposeful sampling to conduct 14 semi-structured interviews with individuals with disabilities (seven male; seven female) aged 14-24 about 
their sport, physical activity, or similar experiences. The authors identified three themes: (a) don't treat me differently, (b) managing emotions, and (c) physical activity balances perceptions (Goodwin et al., 2004).

For don't treat me differently, participants described encountering "metaphorical descriptions [such as being viewed as always needing help, even if that is not the case, or being pitied as someone in a wheelchair because the wheelchair is viewed as a symbol of tragedy] and resulting stigmatization of dependency, pity, and social rejection" (Goodwin et al., 2004, p. 387). For example, when asked to respond to this metaphor of dependence, one subject expressed frustration when members of the public offer to help her with an activity she could do by herself (Goodwin et al., 2004). Another subject showed his distaste for the cliché image of people with disabilities not being able to do for themselves, so he would try to demonstrate his independence in public (Goodwin et al., 2004). For the theme of managing emotions, the participants seemed to be comfortable with themselves and the direction their life was heading (Goodwin et al., 2004). The final theme, physical activity balances perceptions, was important because it illustrated how physical activity "provided opportunities for the participants to come to know themselves better while also giving others an opportunity to see them outside of the illness metaphor" (Goodwin et al., 2004, p. 392).

Within the setting of adapted physical activity, participants did not have to deal with answering questions, making others feel comfortable, or manage the perceptions of others (Goodwin et al., 2004). Physical activity also offered an opportunity for others to view individuals with disabilities bucking the stereotypical view of weakness or dependency. Instead, these individuals appeared to be "healthy, vibrant, and able" 
(Goodwin et al., 2004, p. 393). The results were important because they illustrated the positive impact physical activity and direct contact had with other people had on the attitudes participants held for themselves (Goodwin et al., 2004). Thus, engaging in a setting with physical activity appeared to have a moderating impact on the validation these young people gave to the messages and perceptions received from members of the general public. Instead these individuals, through the context of physical activity, fashioned an empowering self-definition different from the traditionally experienced perceptions of weakness and dependency.

Empowerment in disability was also studied from a quantitative perspective. Riggen and Ulrich (1993) studied matters of empowerment by exploring the benefits athletes (Special Olympians) with cognitive disabilities gained related to feelings of selfworth and self-perceptions of competence in social and physical realms through sport participation. Participants were separated into two groups: a group composed solely of athletes with a disability and one that was integrated using participants with and without disabilities. The study sought to explore the benefits athletes with a disability received by participating in a traditional separated Special Olympics program versus a unified program, which was integrated with both athletes with a disability and athletes without a disability (Riggen \& Ulrich, 1993). Special Olympics participants were also compared with athletes with a disability who did not participate in the program.

A sample of 75 participants was divided into three equal groups: unified, separated, and non-sport (Riggen \& Ulrich, 1993). The authors found significant differences in self-perceptions and increases in basketball performance for individuals who took part in the Special Olympics (Riggen \& Ulrich, 1993). However, there was a 
lack of significant improvement in pre-test/post-test scores in overall self-perception for the Special Olympic groups (Riggen \& Ulrich, 1993). The unified group reported a greater increase in self-concept following program participation than non-unified and non-sport groups (Riggen \& Ulrich, 1993). The findings suggested that the organization and implementation of both the traditional and unified programs did not result in anticipated gains in multidimensional self-concept.

McConkey, Dowling, Hassan, and Menke (2013) also studied unified sport and evaluated the outcomes concerning the processes that were perceived to enhance social inclusion. The specific study objective was to describe factors that contributed to promoting social inclusion in the Youth Unified Sports Program of the Special Olympics (YUSP) from the viewpoint of different stakeholders (McConkey et al., 2013). The YUSP creates teams where players with intellectual disabilities are paired with players without intellectual disabilities of similar skill for the purposes of training and competition, and learning life skills (McConkey et al., 2013). The authors conducted individual and group interviews with athletes, partners, coaches, parents and community leaders, completing a total of 40 participants for each of the five countries where the program operated (McConkey et al., 2013). The interviewers sought to understand the participants' experiences in YUSP and perceptions regarding what improved or hindered social inclusion (McConkey et al., 2013).

Based on these qualitative methods, the authors identified four thematic processes across all countries: (a) the personal development of athletes and partners, (b) the creation of inclusive and equal bonds, (c) the promotion of positive perceptions of athletes, and (d) building alliances within local communities (McConkey et al., 2013). Every study 
participant confirmed that unified sports resulted in greater social inclusion of the athletes, not only due to continuously engaging with coaches and partners for training and competitions, but also in terms of shared activities away from the sports field (McConkey et al., 2013). The results illustrated that unified sport helped promote social inclusion of persons with disabilities (McConkey et al., 2013), and may be helpful in the SDP context as well.

Sit, Lindner, and Sherrill (2002) examined sport participation outside of physical education classes of Chinese children with disabilities attending special schools. The research questions sought to discover how frequently children with disabilities engaged in sport, whether children with disabilities participated as members of sport clubs and, if so, which type of sports, and what were the motives of the children with disabilities who participated in sport, withdrew, or chose not to participate in sport (Sit et al., 2002)? The sample consisted of 237 children, aged from nine to 19 , who attended one of 10 special schools in Hong Kong (Sit et al., 2002). Each participant had responded to a questionnaire on sport participation and the researchers also conducted individual personal interviews with participants (Sit et al., 2002).

The results illustrated that boys were significantly more active than girls and that gender stereotyping impacted the actual choice of girls with disabilities to participate in sports (Sit et al., 2002). Further, the authors found that subjects' choices and participation patterns differed by disability, with those with mental disabilities and visual impairments participating less than those with hearing impairments or nervousness (Sit et al., 2002). The results demonstrated that disability type was more related to a child's level of participation in recreation/physical activity or sport rather than gender (Sit et al., 2002). 
Thus, sport-based practitioners must be cognizant of these differences when planning programs.

Physical activity allows someone with a disability an opportunity to counter negative self-perceptions that may exist due to society (Blinde \& McClung, 1997). Whether a program is successful in using sport, play, or physical activity to help improve empowerment depends on a variety of factors that act as mediators and moderators (Pensgaard \& Sorensen, 2002). Sport, play, and physical activity offer participants an environment where they can be themselves without having to deal with elements of the outside world that are uncomfortable (Goodwin et al., 2004). Using sport, play, or physical activity in a program involving disability can promote social inclusion, help change perceptions about how others perceive a person with a disability and help empower someone with a disability (Goodwin et al., 2004; McConkey et al., 2013; Riggen \& Ulrich, 1993; Sit et al., 2002).

\section{Sport and Health}

The final thematic group is Sport and Health. Generally speaking, sports-based programs have been praised for their ability to help participants receive physical, psychological and general welfare benefits (Levermore, 2008a). The World Health Organization (2003) also trumpets the direct health benefits of sports-based programs, including physical activity, improved diet, discouragement of drugs, alcohol and tobacco, and capacity-building benefits of socialization. Sport also encourages participants to learn attributes such as teamwork, self-discipline and sportsmanship (Hartmann \& Kwauk, 2011). The inherent benefits of participating in sport are vast.

Many programs incorporating sport and health focus on combatting devastating 
diseases such as HIV/AIDS. One reason behind utilizing sport in HIV/AIDS prevention programs is based on the notion that sport can provide an attractive and convenient platform to disseminate health information, and that it can help encourage the development of necessary life skills that create knowledge, influence attitudes, behavioral intentions, and actual behavior (Koss \& Alexandrova, 2005). Therefore, multiple studies on sport and health use sport as an entry point to address HIV/AIDS prevention.

Clark, Kaufman, Friedrich, Ndlovu, Neilands, and McFarland, (2006) evaluated a school-based program that utilized soccer and professional soccer players to prevent HIV in Zimbabwe adolescents. Focusing on 12 to 14-year olds from four local schools, the authors collected information on participants' HIV-related knowledge, attitudes and intended behaviors through a quasi-experimental design study using both experimental and control groups (Clark et al., 2006). The researchers focused on participants' HIV/AIDS knowledge, attitudes, and intentions, collecting both qualitative and quantitative data using a pre-test and post-test design. Data were collected twice immediately after, and five months after, the two-week intervention (Clark et al, 2006). The program featured HIV/AIDS curriculum developed through several HIV/AIDS prevention organizations, including the Center for Disease Control and Prevention. In addition, the program enlisted the help of several professional soccer players (Clark et al., 2006). The program incorporated the specific HIV/AIDS curriculum created by Grassroots Soccer, a non-profit created by one of the researchers, and included interactive games delivered to four classrooms at each of four schools (Clark et al, 2006). The control group was comprised of the pre-existing HIV/AIDS content of the general health education curriculum in four other classrooms (Clark et al, 2006). 
The authors found differences between intervention and control student responses to the quantitative pre-test and post-test surveys (immediately post-program, and five months after the program concluded) (Clark et al, 2006). Those participating in the treatment group were led by local professional soccer players executing the Grassroots Soccer curriculum. The control group was taught the standard curriculum. The researchers found that the treatment group demonstrated significantly higher levels of belief in condom effectiveness, social support, and awareness of HIV prevention services and lower levels of stigma about condom usage in preventing HIV immediately postintervention (Clark et al, 2006). In contrast, students in the control group showed little or no change in responses to these items during the same time (Clark et al, 2006). The general positive results of the program suggested that the two-week intervention significantly improved students' HIV related knowledge, attitudes, and intended behaviors, and thus may had been an effective approach for practitioners wanting to implement health-based education programs using sport as a hook.

Building off Clark et al.'s (2006) success, Kaufman, Welsch, Erickson, Adams, and Ross (2012) implemented a similar HIV/AIDS awareness and prevention program in the Dominican Republic. Seeing that previously studies have only taken place in SubSaharan Africa, the authors applied Clark's Grassroots Soccer curriculum to the Futbol Para la Vida (Soccer for life) program (Kaufman et al., 2012). The authors conducted 397 structured interviews with 140 adolescents from six migrant settlements before, immediately after, and four months following 10-hour interventions using the Grassroots Soccer curriculum (Kaufman et al., 2012). Data was coded, aggregated into composite scores, and analyzed using logistic regression, adjusting for baseline differences as well 
as age, sex, community, and descent. The authors observed significant differences between groups receiving treatment and those who did not concerning HIV-related knowledge, reported attitudes, and reported communication. These differences were still significant four months after the intervention (Kaufman et al., 2012).

Like Clark et al. (2006), Kaufman et al.'s (2012) study demonstrated strong evidence of the Futbol Para Vida program's effect on HIV-related knowledge, reported attitudes, and reported communication. The treatment group performed higher than the control group on every indicator post-program, and also more effectively retained the information on post-testing (Kaufman et al., 2012). These results are important because they once again suggest that sports-based interventions can play a valuable role in HIV prevention efforts for adolescents in different parts of the world, including the Caribbean (Kaufman et al., 2012).

Maro, Roberts, and Sorensen (2009) investigated the effectiveness of an ongoing HIV/AIDS education intervention program targeting at-risk youth using a sport context. The researchers also sought to determine the program's efficacy with peer coach intervention through sport. The quasi-experimental study recruited 764 participants whose average age was 13.6 years and randomly grouped them into two treatment groups and two control groups (Maro et al., 2009). The two treatment groups used peer coaches conducting AIDS education. One treatment group used sport and the other group did not use sport (Maro et al., 2009). The two control groups were comprised of one group who received traditional AIDS education in school, and a second group of children who received no education at all. The program lasted for eight weeks (Maro et al., 2009). 
Once again, the results indicated that the program using sport was more effective in conveying HIV prevention knowledge, cognitions and perceived behaviors than the control groups (Maro et al., 2009). Further, participants in the experimental group using sport were significantly more likely than those in school who received AIDS education through the traditional education to report reliably higher levels of condom use and HIV knowledge, and more positive beliefs about and perceived control of preventing HIV infection (Maro et al., 2009). The findings illustrated that using peer coaches and soccer to educate adolescents was an effective method to communicate knowledge about HIV/AIDS and safe sex practices. It proved more reliable than the other approaches, and may serve as an approach to reduce AIDS risk in Africa, specifically adolescents.

Delva, Michielsen, Meulders, Groeninck, Wasonga, Ajwang, Temmerman, and Vanreusel (2011) surveyed 454 youth of the Mathare Youth Sport Association (MYSA) and 318 non-MYSA members in Kenya to assess participants' sexual behavior. MYSA incorporated a sport-based curriculum into its HIV/AIDS prevention and awareness program called the Movement Games, where knowledge was conveyed through sport and play (Delva et al., 2011). While sport was the major component of the project, books and videos about sexual and reproductive health issues were available along with a peer counselor and local volunteers to give advice (Delva et al., 2011). The authors collected data through a self-administered questionnaire consisting of closed-ended questions in English. The questionnaire asked about access to knowledge about HIV/AIDS, attitudes and perceptions toward HIV/AIDS, sexual behavior, sexual intentions, social capital and perceptions of body and health (Delva et al., 2011). 
The results from 772 useable questionnaires (454 MYSA; 318 control) were analyzed (Delva et al., 2011). The researchers found that MYSA members were more likely than non-MYSA members to use condoms during the first sex act. MYSA participants also scored higher (23.2\%) for consistent condom use with the current/last partner versus $17.2 \%$ among the non-member group (Delva et al., 2011). The results illustrated no significant differences between MYSA and non-MYSA members concerning their attitudes toward risk avoidance, subjective beliefs on virginity and responsibility, and behavioral intentions regarding using a condom and faithfulness to a partner. Further, other than MYSA members being more likely to use condoms in certain situations, the authors' analysis indicated that the sexual behavior of MYSA and nonmembers did not significantly differ (Delva et al., 2011). This study illustrated that significant outcomes do not always occur when utilizing sport-based interventions for health, specifically HIV/AIDS awareness.

Sports-based programs generally provide participants with opportunities to receive physical, psychological and general welfare benefits (Levermore, 2008a). Aside from trumpeting the various benefits of sport-based programs, many SDP programs target combatting diseases such as HIV/AIDS because sport is a convenient platform to disseminate health information, which can encourage the development of positive life skills (Koss \& Alexandrova, 2005). Programming using sport as the hook can improve effectiveness of health interventions (Clark et al, 2006; Kaufman et al., 2012; Maro et al., 2009). However, significant outcomes do not always occur when using sport-based interventions for health, specifically HIV/AIDS awareness (Delva et al., 2011). 
Summary of United Nations Working Groups. In 2003, the UN Inter-Agency Taskforce on SDP authored a report on how sport could help achieve the United Nations Millennium Developmental Goals and created five thematic groups: (a) sport and child and youth development, (b) sport and gender, (c) sport and peace, (d) sport and persons with disabilities, and (e) sport and health (United Nations Sport for Development and Peace International Working Group, 2008). Each group was composed of UN member state delegates and individuals with specialized knowledge (United Nations Office of Sport for Development and Peace, 2011).

Sport and Child \& Youth Development was the first thematic working group activated. Sport-based interventions targeting children and youth provide participants with a safe and supportive environment to help facilitate opportunities to learn skills, and to be socialized into society (Burnett, 2001; Haudenhuyse, et al., 2012). The success of sport-based youth development programs depends on a number of factors specific to the type of sport, the participants and their specific experiences, and the social, cultural aspects of the program (Burnett, 2008, 2013; Catalano et al., 2004; Coakley, 2002; Kane \& LaVoi, 2007; Weiss, 2008). A traditional competitive club-based sport model is not ideal when working with socially vulnerable youth (Haudenhuyse, et al., 2012). While sport can be viewed as a coping mechanism, it can also be viewed as a mechanism for social control and discipline (Burnett, 2001; Haudenhuyse, et al., 2012).

The Sport and Gender working group was the second group to be activated. Females participating in physical activities, sport, and play, derive many benefits including physical health, mental health, educational and intellectual development, reproductive health, social inclusion, personal empowerment, and leadership skills all 
within the context of experiencing a "fun factor" (Be, 2014; Samie et al., 2015). Girls could be constrained, however, by cultural expectations. Intergroup contact theory can be used to combat conflict between men and women (Allport, 1954; Lyras \& Hums, 2009).

The Sport and Peace thematic working group was activated in 2011. Sport's universal language allows it to be a tool in defusing tension caused by intergroup conflict (Levermore, 2008a). Practitioners have used sport to address a variety of conflicts to break down barriers between the two sides (Hoglund \& Sundberg, 2008; Schulenkorf, 2010; Schulenkorf et al., 2014; Sugden, 2006, 2010, 2015). SDP has been used in sport diplomacy to promote cultural understanding and, as part of a treatment protocol, to address psychological trauma (Lecrom, \& Dwyer, 2013). Any program aimed at resolving conflict must account for unique sociopolitical issues surrounding the participants and include local stakeholders in the planning process (Hoglund \& Sundberg, 2008; Schulenkorf \& Sugden, 2011; Sugden, 2006).

The Sport and Persons with Disabilities Thematic Group was the fourth group to be activated. Participating in physical activity provides a person with a disability the opportunity to counter negative self-perceptions that may exist in society (Blinde \& McClung, 1997). Mediators and moderators help determine whether a program using sport, play, or physical activity to help improve empowerment is successful (Pensgaard \& Sorensen, 2002). Sport, play, and physical activity can serve as a refuge for those with disabilities, and also offer an opportunity to counter common stereotypes (Goodwin et al., 2004). Unified sport helps promote social inclusion of persons with disabilities (McConkey et al., 2013).

Sport and Health was the final thematic group. Sports-based programs have 
received praise for their physical, psychological and general well-being benefits (Levermore, 2008a). Many programs incorporating sport and health focus on combatting diseases by providing health information (Koss \& Alexandrova, 2005). While some sport and health programs have succeeded in improving the effectiveness of health interventions (Clark et al, 2006; Kaufman et al., 2012; Maro et al., 2009), significant outcomes do not always occur (Delva et al., 2011).

\section{Criticisms of Sport-Based Interventions}

Sport itself has been praised for its seemingly inherently beneficial qualities (Coalter, 2010; Kidd, 2008). However, sport itself is neither inherently positive or negative (Coakley, 2011; Hums \& Wolff, 2014; Kidd, 2008; Sugden, 2010). Despite this conclusion, some believe that sport can solve complex issues and act as a panacea to cure all the world's ills (Coalter, 2010; Kidd, 2008; Sugden, 2015). This belief, and criticism from scholars concerning this conviction, is discussed below.

\section{Sport Evangelists}

SDP utilizes sport as a means of addressing or solving a variety of social issues.

However, viewing sport as the definitive solution to challenges may also be problematic. Prior literature identified the phenomenon of the "sport evangelist," which is a person who utilizes sport as a panacea for addressing myriad of issues (Coalter, 2007;

Giulianotti, 2004). Sport evangelists

view sport in essentialist terms and assume that it inevitably leads to multiple forms of development, including remediation for individuals perceived to need reformative socialization and revitalization for communities perceived to need an infusion of civic awareness and engagement. Sport, therefore, is viewed as an 
effective activity for solving problems and improving quality of life for individuals and society alike (Coakley, 2011, p. 307).

Sport evangelists' use of sport often falls into one of the following three categories: (a) personal character development, (b) reforming vulnerable or at-risk populations, and (c) creating social capital intended to lead to career success and civic engagement (Coalter, 2007). Claims made by sport evangelists about the power of sport are categorized into specific categories: (a) the Fertilizer Effect (Coakley, 2011; Coalter, 2007) (b) the Car Wash Effect (Coakley, 2011; Hartmann, 2001, 2003; Hartmann \& Depro, 2006; Hartmann \& Massoglia, 2007), and (c) the Guardian Angel Effect (Coakley, 2002, 2011; Coalter, 2007). Each category contains beliefs about the innate characteristics of sport.

The Fertilizer Effect refers to beliefs that participating in sport positively impacts a child's development because of the inherent physical, mental, and psychological benefits (Coakley, 2011; Coalter, 2007). For example, sport evangelists argue that participating in sport builds a child's self-confidence, positive body image, and overall character (Coakley, 2011; Coalter, 2007). As Coakley (2011) states, the Fertilizer Effect is based on the notion that, if properly cultivated through sport, one's character and potential will grow in ways society views as positive. This notion concerning the natural character benefits of sport influences educational policy decisions and public policy decisions (Coakley, 2011).

The Car Wash Effect (Coakley, 2011; Hartmann, 2001, 2003; Hartmann \& Depro, 2006; Hartmann \& Massoglia, 2007) refers to sport evangelist claims concerning the transformative effect of sport for 'at-risk' youth. Specifically, the claims made concerning the Car Wash Effect focus on: (a) the ability of sport to provide a refuge for 
youth to go in the form of an adult-controlled space instead of remaining on the street in an uncontrolled environment, (b) sport gives children and youth adult role models to follow, emulate, and serve as mentors, (c) the structure that sport provides, and (d) sport's intrinsic ability to teach participants societal values such as respecting authority, selfcontrol and conforming to society's rules. Often, the Car Wash Effect is associated with rehabilitating, cleansing or washing away character issues so that youth can become conforming members of mainstream society. In other words, the Car Wash Effect is about washing away elements that traditional dominant society views as deviant.

The Guardian Angel Effect (Coakley, 2002, 2011; Coalter, 2007) claims that those who participate in sports will form integral personal relationships, which will lead to social engagement. Specifically, the experiences and relationships built through sport create physical capital, which can then be utilized to obtain social and cultural capital, encourage individuals to pursue education, assists in forming a person's social networks and encourage individuals to look beyond sport for life ambitions (Coakley, 2002, 2011; Coalter, 2007). The Guardian Angel Effect will guide youth in acceptable directions as dictated by dominant societal norms and position them for success oriented (Coakley, 2011, Wilson, 2012).

A foundational element of each sport evangelist claim is that participating in sport gives participants vital life lessons that each individual must process on his/her own and apply to his/her respective life (Coakley, 2011). Although not exclusively utilized by the community as a whole, this approach is commonly used in the United States and private enterprises primarily funded by North American and the Northern European entities (Coakley, 2011). The claims of sport evangelists have created a justification for sport- 
related program and secured funding at local and national levels. (Kay \& Bradbury, 2009). In fact, even when the programs repeatedly fail, these programs have avoided a critical examination and survived on the general assumption that sport is inherently good and thus good for those who participate in the program (Coakley, 2011). Instead, blame falls to other individuals whose "inferred character flaws or defective social and cultural backgrounds" are blamed as the reason for the failure of others to understand and benefit from the lessons of sport (Coakley, 2011, p. 309).

\section{Evidence-Based Criticisms}

With the field of SDP being relatively young, sports-based interventions have drawn substantial criticisms. Sport can potentially reinforce hegemonic values concerning the Global North and Global South. Sport-based interventions that are poorly conceived, executed and/or dominated by the external funding sources may compromise a program's mission or effectiveness (Lindsey \& Grattan, 2012; Nicholls, et al., 2010). Critical scrutiny of SDP programs at times brings into question the actual beneficiaries of sportbased programs and whether this approach should be integrated into a boarder development framework (Darnell \& Black, 2011; Levermore, 2008; Spaaij \& Jeanes, 2013; Sugden, 2015). The following examples illustrate several criticisms of sport-based interventions.

Hayhurst (2009) undertook a development policy discourse analysis, reviewing six key SDP policy documents. She chose these documents because they helped to form SDP policy discourse from 2003 to 2008, a year before the study's publication. Another important distinction concerning these policy documents is that three were produced by the United Nations, with three created by the United Nations Sport for Development and 
Peace International Working Group, as part of guiding SDP program policy. Hayhurst (2009) utilized a theoretical framework that combined postcolonial theory and actororiented sociology to critically analyze these SDP policies.

The results of Hayhurst's (2009) study led to three critical findings. She found that (a) SDP policies were unclear, convoluted, and underpinned by an increasingly political and inefficient system; (b) sport-based inventions were driven by political agendas and the interests of donors, UN agencies, and NGOS that rendered two-thirds of the world as passive recipients of SDP with polices akin to developmental assimilation; and (c) SDP policy models were wedded to the increasingly neoliberal character of development interventions. Hayhurst (2009) argued that the examined policies were grounded in hegemonic concepts and that non-governmental organizations controlled key decisions within the field. This could result in inconsistent policy development within SDP.

Hayhurst made several recommendations. She recommended that "future research on SDP should be informed by anthropological perspectives that aim to uncover how those on the 'receiving end' of SDP policies are affected and challenged by taking up the solutions and techniques prescribed to them" (Hayhurst, 2009, p. 223). Further, Hayhurst (2009) argued that researchers should seek to uncover "how power relations, authority and influence are embedded in the social process of policy-making" of SDP programs (p. 223). Critically researching underpinning aspects such as power relations and the hegemonic aspects of SDP could help practitioners address these issues. Hayhurst's recommendations would prove to be accurate, as subsequent critical SDP studies would identify issues involving programs lacking local context. 
While Hayhurst (2009) explored challenges to SDP programs from a macro perspective, Darnell (2010) utilized a micro viewpoint. Darnell (2010) explored the underlying ideologies of development and social change that anchored SDP practices by interviewing 27 young individuals who interned as project managers during a Commonwealth Games Canada. The results indicated interns often viewed sport in the context of development from a political perspective, which Darnell (2010) viewed as a hegemonic, class-based ideology. The interns relied on their prior positive experiences involving sport, which in turn embodied neoliberalism and hegemony as part of their participation in the Commonwealth Games Canada. The results of the study showed that even with good intentions, traditional notions of sport like teamwork and socialization were susceptible to a hegemonic or neo-liberal development vision (Darnell, 2010).

Whereas Hayhurst (2009) and Darnell (2010) explored the theoretical underpinning of SDP that demonstrated hegemonic trends, Nicholls, Giles, and Sethna (2010) examined another often-criticized aspect of SDP programs: evidence of success. According to the authors, "[a]cademics and development agencies in the Global North have consistently had the privilege of shaping what sport for development is and what constitutes relevant and valid evidence of its success" (Nicholls et al., 2010, p. 250). Thus, the authors sought to explore why contributions by SDP practitioners in the Global South were being devalued and asked more general questions about what constituted legitimate evidence or knowledge when evaluating SDP programs. Utilizing a Foucauldian framework (Foucault, 1980), which offered a foundation to examine power relations within SDP, the authors conducted 17 semi-structured interviews with practitioners that supported a popular SDP methodology. Using a snowball sampling 
technique, the authors interviewed leaders from organizations participating in the Kicking Out AIDS program. The participants offered a wide range of perspectives: funders, policy-makers, and practitioners. Semi-structured interviews lasted between 45 minutes to two hours. Interviews were then transcribed, verified, and analyzed for themes using NVivo.

The results spanned four themes that built the perception of a " 'lack of evidence' of the effectiveness of sport for development" (Nicholls et al., 2010, p. 255). The first four themes were as follows: (a) "barriers to the co-creation of knowledge," (b) "the politics of partnership," (c) “donor-driven priorities and top-down approaches," and (d) "calls for more research" (Nicholls et al., 2010, p. 255). The results indicated that program policy decisions were often made by individuals who were not on the ground but instead were "detached" from the day-to-day operation of the program (Nicholls et al., 2010, p. 255). This arrangement of having policy makers away from the program created a disconnect for those in the field attempting to implement policy, as no link existed between what was going on at the grassroots level and the policy level (Nicholls et al., 2010).

Often both donors and policy makers were part of the Global North and located off-site, but their cooperation was necessary for a program's existence. Nicholls et al. (2010) argued that program recipients and grassroots practitioners (typically from the Global South), became dependent on funders and policy makers, thus creating the opportunity for inherently unequal power relations and colonizing tendencies. Further, by partnering with Northern donors, the funders dominated the process, thus muting the program implementers' value and creating a paternalistic relationship between the two 
groups (Nicholls et al., 2010). Strategies were donor-driven, with top down approaches, and questions arose of what counted of evidence to support and document a program's work. This undercurrent of marginalization created unequal power dynamics and may had seriously affected the SDP organization and undermined the partnership.

After identifying multiple criticisms based on power theory, Nicholls et al. (2010) proposed several recommendations. Although the marginalization of practitioners is unintentional, parties should make efforts to recognize that local knowledge is valid and plays a vital role in shaping SDP policy. This is because,

if practitioners do not feel that their experiences are reflected or that they have opportunities to challenge mainstream representations of their experiences, then it becomes critical to re-examine the discourses that are shaping the sport for development policy creation process and how they can be modified to make room for alternatives (Nicholls et al., 2010, p. 260).

Further, donors, academics, and practitioners should work together to facilitate research that can meet multiple needs in the co-production of knowledge. By doing so, the concept of what constitutes SDP and evidence of program success can be discovered and perhaps address the issues identified by Nicholls et al. (2010).

The concept of what constitutes evidence of success relates to criticisms SDP programs face concerning monitoring and evaluation. Challenges exist in how to measure and document outcomes to highlight a program's effectiveness (Coalter, 2010; Hartmann \& Kwauk, 2011; Hayhurst, 2009). While evidence of success is important for both practitioners and donors, the data must also be reliable. With reliable data, practitioners can receive funding and donors can justify their investment. Thus, Kay (2012) examined 
issues surrounding monitoring and evaluation systems established by donors to evaluate the impact of SDP programs a donor supports. While Kay (2012) perceived that people working in SDP view monitoring and evaluation as less than intellectually exciting, these systems play a major role in creating a hierarchical donor-recipient relationship (Kay, 2012).

Limiting emphasis on monitoring and evaluation may arise from insufficient resources for research, which leads to lowered methodological rigor. Further, monitoring and evaluation procedures are often shaped by funders' requirements. For example, outside funders may require the use of a form that the program is unfamiliar with, which may cause confusion or ambiguity to occur in monitoring and evaluating the program (Kay, 2012). Kay (2012) identified several factors that can improve critical monitoring and evaluation. Kay (2012) emphasized the need for external accountability, meaning that donors "should also be accountable to recipients, e.g. for the processes through which decisions made about allocations of funding to programmes" (p. 896). This would create program accountability for both funders and practitioners. Further, it is important to note that context matters. Monitoring and evaluation should promote involving local stakeholders in the decision-making process concerning program performance targets and about procedures and mechanisms related to monitoring. Kay (2012) also argued that monitoring and evaluation systems must provide timely and relevant information that has the potential to focus on local learning. Making these changes may reduce funding agencies' influence on programs' monitoring and evaluation. 


\section{Power Relations Criticism}

Another area of criticism related to monitoring and evaluation is questions concerning proof that SDP programs effectively meet proposed objectives. Burnett (2015) critically evaluated the trajectory, challenges, and future for understanding sport's role in the areas of peace and conflict resolution. After tracing SDP's proliferation back to the early 2000's efforts of the UN, governmental entities, and NGOs, Burnett (2015) identified criticisms concerning the field, highlighting the opportunity for unequal power relations based on the Global North-Global South dynamic. Burnett (2015) identified the specific challenge of donors searching for proof of program success while fostering hegemonic practices and neoliberal agendas.

Burnett (2015) recommended that future SDP research should address the need to incorporate local voices into SDP. This research approach would create a holistic and contextual understanding of SDP and the development process. Interestingly, Burnett (2015) advocated for collaboration between scholars from diverse disciplines to create meaningful insights within SDP. Burnett (2015) referenced a "call for Global South Agency," and that

researchers need to address the complexity of contextual poverty, power structures and struggles in order to ensure praxis and theory building in innovative and strategic ways. It is possible that Sport for Development might infiltrate a wide range of associative knowledge domains; but, with its current political profile, it constitutes a movement with praxis which critical scholars, as agents of change, regard as being especially significant (p. 389). 
Burnett's suggestion focused on working with a wide range of disciplines and utilizing local perspectives as part of building agency within the Global South. This urging seems consistent with Burnett's (2009) observation that SDP is based on multidisciplinary frameworks and diverse disciplines. Burnett's $(2009,2015)$ observations suggest that the Capabilities Approach may serve as a possible theoretical framework to address the criticisms levied against SDP concerning the need for including local perspectives and using interdisciplinary frameworks.

Further illustrating Burnett's (2015) point, Schulenkorf, et al. (2014) examined the lessons learned from 13 Football 4 Peace projects from the perspective of local stakeholders such as volunteers, community members, organizers, and coaches. Using an exploratory framework, the authors conducted 30 semi-structured interviews and held two focus groups with local stakeholders about their Football 4 Peace experiences. Interview data were coded for themes and supported by comprehensive field notes.

The results showed that differences existed between how local stakeholders viewed the underlying program methods versus program planners. The findings also illustrated that elements of the program's success were influenced by whether organizers had ties to the local community, thus highlighting the importance of including local perspectives into the geopolitical and cultural environment in which SDP programs operate (Schulenkorf et al., 2014). Schulenkorf et al. (2014) argued that their findings "demonstrated the need for reflexivity, openness and the importance of continual dialogue between participants, local staff and project organizers" (p. 384-385). Program members external to the local environment "need to be willing and able to transfer responsibilities to the locals facilitating a 'bottom-up' management approach" and, "[i]n 
return, local community leaders need to be ready and prepared to shoulder such responsibility" (Schulenkorf et al., 2014, p. 385). This should aid in community empowerment and accountability.

Spaaij and Jeanes (2013) echoed the calls to put the local community's needs over the agendas of the outside agencies involved in the SDP program. Instead of using a prepackaged SDP curriculum that may promote western values and not fit the needs of the local community, practitioners should engage the entire local community to understand their needs before designing a program. Spaaij and Jeanes (2013) suggested that SDP programs should spend time in the community and research the knowledge, social situations, and vocabulary of the groups that they are working with. This way, the organization can help recipients with the things or goals that they care about. The approach suggested by Spaaij and Jeanes (2013) is similar to the Capabilities Approach. Specifically, both approaches emphasize local context, focusing on the community, and building local agency to achieve individualized goals that are important to the local population.

Another benefit of focusing on the local community when planning a program is that it builds a better understanding of local society. Sometimes, local society is nuanced, and an organization using a cookie-cutter approach may miss these differences. Hartmann and Kwauk (2011) suggested that implementing more critical frameworks into SDP also helps to discover differences in a local population that are difficult to identify.

Incorporating local context also addresses Levermore's (2011) criticism concerning SDP program evaluative frameworks. One may presume that SDP programs are inherently positive (Coalter, 2010). However, "simply recognizing or bestowing rights to sport 
participation may do little to support persons and communities in the struggle against the broader social and political inequality that prevented their participation in sport in the first place" (Darnell, 2012, p. 37).

Participating in sport alone is not enough to cause social change (Coalter, 2006, 2010). SDP scholars and practitioners should utilize local perspectives as part of an effort to empower those within the Global South to live what they individually believe are meaningful lives (Burnett, 2015; Hartmann \& Kwauk, 2011; Spaaij \& Jeanes, 2013). However, despite the need for a successful SDP program to be community focused, many SDP programs continue to be dominated by external funders with little regard for local voices (Kidd, 2011). To strengthen the potential effectiveness of sport-based interventions, additional research must occur concerning which programs are successful and what aspects makes them successful (Hartmann \& Kwauk, 2011).

One research approach to examining SDP programs is through well-being. Svensson and Levine (2017) suggested that SDP should be examined through alternative frameworks to gain a more complete understanding. They further suggested that the Capabilities Approach can promote a greater understanding of SDP from a theoretical, policy, and practitioner perspective. Svensson and Levine (2017) suggested that future research could consider different interpretations of the Capabilities Approach and its usefulness as well as its limitations for enhancing knowledge of SDP. Darnell and Dao (2017) also argued in favor of experimenting with the Capabilities Approach in the SDP field.

Summary of Criticisms of Sport-Based Interventions. Sports-based interventions have drawn substantial criticisms. While sport itself has been praised for its 
argued inherently beneficial qualities, (Coalter, 2010; Kidd, 2008; Sugden, 2015), sport itself is neither inherently positive or negative (Coakley, 2011; Hums \& Wolff, 2014; Kidd, 2008; Sugden, 2010) and can potentially reinforce hegemonic values concerning the Global North and Global South. Sport evangelists have looked to sport as a cure-all for solving a variety of issues. Sport evangelists have made claims related to sport's ability to provide participants with physical, mental, and societal benefits to justify this belief (Coakley, 2011).

Hayhurst (2009) reviewed six key SDP policy documents and criticized the policies from a planning, executing, and evaluation perspective. Nicholls et al. (2010) examined why contributions by SDP practitioners in the Global South were being devalued. Using semi-structured interviews, the researchers found that program recipients and grassroots practitioners (typically from Global South) became dependent on funders and policy makers (typically from the Global North), creating opportunities for inherently unequal power relations and colonizing tendencies. To resolve these issues, Nicholls et al. (2010) suggested donors, academics, and practitioners should recognize that local knowledge plays an important role in programs and work together to facilitate research that meets multiple needs in the co-production of knowledge. Kay (2012), when researching issues surrounding monitoring and evaluation systems in SDP programs, emphasized the need for external accountability, meaning that donors "should also be accountable to recipients, e.g. for the processes through which decisions made about allocations of funding to programmes" (p. 896). In terms of improving SDP programs, Burnett (2015) recommended that future SDP research should incorporate local voices. These voices should create a holistic and contextual understanding of SDP and the 
development process. Programs should work with a wide range of disciplines and utilize local perspectives as part of building agency within Global South.

Spaaij and Jeanes (2013) reaffirmed calls to put the local community's needs over the agendas of the agencies involved in the SDP program. Practitioners should engage the entire local community to understand their needs before designing a program. Needs could be identified by spending time in the local community. Spending time with the local community builds understanding of what is important to the locals, which is what should be emphasized. Svensson and Levine (2017) suggested that alternative frameworks should be used to examine SDP and that the Capabilities Approach was uniquely suited to address the criticisms that scholars have levied against SDP.

\section{Summary of Literature Review}

Development is an evolving phenomenon traditionally thought of as the process of improving a person's overall quality of life (Alkire \& Deneulin, 2009). Approaches to development take different forms, whether based on maximizing access to financial resources and commodities, maximizing happiness, or maximizing freedom (Sen, 1985, 1999). One such approach is Human Development Theory, which views development as a holistic process aimed at achieving well-being (Haq, 1995). Human Development Theory defines development as the process of enlarging a person's choices so that people can lead long, healthy, and creative lives (Haq, 1995). Human development seeks to expand a person's choices in all areas of life; not just economics but also cultural, social, political, and other aspects that lead to enriching a person's quality of life and finding well-being (Alkire \& Deneulin, 2009; Haq, 1995). Human development is people-centric and thus, fundamentally, a process helping individuals to achieve what is valuable for 
them at a specific moment in time (Alkire \& Deneulin, 2009). People need the freedom to be educated, and basic entitlements like freedom of expression to improve their lives (Alkire \& Deneulin, 2009). Quality of life can be improved by negotiating barriers and hindrances that people face so that they have the freedom to choose among different ways of living (Alkire \& Deneulin, 2009, Sen, 1985). This emphasis on removing obstacles to an individual's freedoms and opportunities in life led to the creation of the Capabilities Approach, a normative framework that assesses well-being as part of facilitating the objectives of Human Development Theory.

The Capabilities Approach assesses and evaluates individual well-being and social arrangements based on what people are able to do and be in society (Robeyns, 2006). This framework emphasizes a person's freedom and ability to achieve what s/he values and has reason to value (Alkire, 2005; Nussbaum, 2003; Robeyns, 2005; Sen, 1999, 2005). Key components include functionings, freedoms, and capabilities (Alkire, 2005; Nussbaum, 2003; Robeyns, 2005; Sen, 1999, 2005). Functionings are the achievements people value and have reason to value within the context of societal norms (Robeyns, 2005). Freedoms act as the basic building blocks of one's life. A freedom is only possible if a process exists to allow for actions and decisions and if people are given actual opportunities to exercise those freedoms (Sen, 1999). Capabilities are achieved functionings and "describe the real actual possibilities open to a person" and may range in complexity (Alkire, 2005, p. 2). The Capabilities Approach is lauded for is flexibility and emphasis on personal well-being and individualistic functionings/capabilities, as functionings and capabilities belong to the individual (Clark, 2005a, 2005b; Robeyns, 2003). 
Sen's framework intrinsically acknowledges the importance of diversity within the realm of development. Diversity exists at all levels, and different areas of the world may view resources, functionings, and freedoms differently (Robeyns, 2003). Thus, a lens that incorporates local contexts and nuanced considerations is required to identify relevant functionings, freedoms, and capabilities. Sen's approach is not one size fits all; it embraces diversity as a central component of the widely-adaptable framework. Once the basics of life such as basic economic opportunities, political liberties, social entitlements, adequate health, and basic education, are present, people can achieve that which they value and have reason to value (Sen, 1999). Criticism exists that the Capabilities Approach's breadth and multi-dimensional aspects prevent it from possessing practical and operational significance within international development (Sugden, 1993). However, the Capabilities Approach has been operationalized in other disciplines including education (Lambert et al., 2015; McLean \& Walker, 2012; Saito, 2003; Terzi, 2005), health (Dubois \& Trani, 2009; Greco, et al., 2015; Kinghorn, et al., 2015; Simon, et al., 2013), and economics (Alkire, 2014; Alkire \& Santos, 2014; Schischka et al., 2008; Wagle, 2014).

SDP is rooted in late 19th century where sport was often used as part of the socialization and development processes of colonialization (Cavallo, 1981; Kidd, 2008; MacAloon; 2006; Pitter \& Andrews, 1997). In recent years, sport has gone through a rapid expansion involving governments, NGOs and athletes (Kidd, 2008; Kleiner, 2012; Levermore \& Beacom, 2009). The concept of SDP is inclusive and cross-disciplinary, so its definition may vary. One popular way to define SDP is as an approach utilizing sport 
as a vehicle or a hook for broad, sustainable interventions with various goals in mind (Hartmann \& Kwauk, 2011; Kidd, 2008; Schulenkorf et al., 2016).

Sport, development, and peace are all defined very broadly. The UN embraced sport as a development tool, and created international working groups for (a) sport and child and youth development, (b) sport and gender, (c) sport and peace, (d) sport and persons with disabilities, and (e) sport and health (United Nations, 2015). Prior studies utilized SDP as a framework and focused on each thematic group as the program's focus.

The very nature of sport creates an inherent belief that it can be used as a development tool (Hartmann \& Kwauk, 2011). Viewing sport as the definitive solution to challenges, however, may also be problematic. Prior literature identified the phenomenon of the "sport evangelist" who utilizes sport as a panacea for addressing myriad of issues (Coalter, 2007; Giulianotti, 2004). SDP as a field has received substantial criticism as reinforcing hegemonic values between the Global North and Global South. Traditional SDP strategies were criticized as attempts to maintain control and conformity over populations (Spaaij \& Jeanes, 2013).

Critical scrutiny of SDP programs at times reveals programs being dominated by Global North donors, and bringing into question evidence of program success, whether the voices of local stakeholders are heard, who actually benefits from sport-based programs and whether this approach should be integrated into a boarder development framework (Burnett, 2015; Darnell \& Black, 2011; Levermore, 2008; Nicholls et al., 2010; Spaaij \& Jeanes, 2013; Sugden, 2015). Elements of an SDP program's success may be influenced by whether organizers had ties to the local community, highlighting the importance of including local perspectives (Schulenkorf et al., 2014). Donors must be 
“willing and able to transfer responsibilities to the locals facilitating a 'bottom-up' management approach" and, "[i]n return, local community leaders need to be ready and prepared to shoulder such responsibility” (Schulenkorf et al., 2014, p. 385). Program agendas must include the voices of local stakeholders. Power must rest with the local program, not the external donor. SDP educators should not utilize a pre-packaged curriculum but instead strive for an individualized method that facilitates local voices (Spaaij \& Jeanes, 2013). Educating through sport "can enhance the capacity of the SDP sector to" help participants pursue the lives they wish to live (Spaaij \& Jeanes, 2013, p. 454). Program administrators should spend time in the community researching the knowledge, social situations, and vocabulary of the groups with which they work (Spaaij \& Jeanes, 2013). Svensson and Levine (2017) suggested that the Capabilities Approach was uniquely suited to address the criticisms that scholars have levied against SDP. 


\section{CHAPTER III}

\section{METHODOLOGY}

SDP is becoming increasingly more popular as a development tool. The principle of SDP is attractive: using sport/play/physical activity as the hook to engage participants' interest in conjunction with other program elements intended to address a variety of social issues. Yet questions concerning SDP's effectiveness and relevance remain. SDP programs receive criticism from planning, implementation, and monitoring/evaluation standpoints. Critical scholars have called upon SDP practitioners to utilize an alternative guiding framework that identifies the needs of the local population participating in the program and place those needs ahead of the interests of other parties involved. An alternative framework should be used to reflect this encouraged approach, and one such framework may be the Capabilities Approach (Darnell \& Dao, 2017; Rossi, 2015; Svensson \& Levine, 2017).

\section{Purpose}

The purpose of this study was to explore what role does an SDP program play in participants achieving their capabilities. This purpose was chosen for two reasons. First, the literature criticized SDP program effectiveness from a planning, execution, and evaluation standpoint. Second, when designing programs, critical scholars have called for the use of alternative theoretical frameworks that respect a program's local context and to incorporate local stakeholders' viewpoints into the planning process (Schulenkorf \& 
Spaaij, 2015). If the Capabilities Approach can help facilitate inclusion of local context and demonstrate that SDP programs play a crucial role in improving a participant's wellbeing, it could serve as a guiding framework to improve SDP programs. Further, Svensson and Levine (2017) believe the Capabilities Approach can promote a greater understanding of SDP from a theoretical, policy, and practitioner perspective. Svensson and Levine (2017) encouraged future research to consider the varying perspectives of the Capabilities Approach and its usefulness in enhancing SDP knowledge. This study sought to take this recommended step and explore a case involving SDP and the Capabilities Approach.

\section{Research Questions}

This study was guided by an overarching research question: what role does Youth Odyssey play in participants achieving their capabilities? The following three research questions assist in answering the aforementioned question and address the purpose of the study:

RQ1: What functionings are being supported by Youth Odyssey?

RQ2: How does Youth Odyssey help remove barriers for participants?

RQ3: What capabilities are Youth Odyssey creating for its participants?

\section{Research Design}

This study used a qualitative research design. A qualitative study was chosen because I sought to explore components of the Capabilities Approach in an SDP program case setting. A qualitative research approach is appropriate when someone wants to conduct research with the intent of exploring a problem or issue to gain a complex understanding of the phenomena (Creswell, 2013; Patton, 2014). This approach explores 
an issue and develops a detailed understanding of the central phenomenon of interest (Creswell, 2015). This study used exploratory questions to investigate an unexplored phenomenon of what role an SDP program plays in participants achieving their capabilities.

Qualitative research has common characteristics. First, qualitative research occurs in a natural setting, meaning a researcher goes out into the field to experience the problem or issue being studied under real-life conditions (Creswell, 2013, 2014; Miles, Huberman \& Saldaña, 2014). Patton (2014) encourages researchers to go into the natural environment of those being researched so that investigators can observe participants in action to gain a greater understanding of the phenomenon. Second, qualitative research is intended to provide a holistic account of a phenomenon and allow researchers an opportunity to reach a complex picture of what is being studied (Marshall \& Rossman, 2011). Third, qualitative research involves emergent design. Emergent design means that part of the research plan may change or a new idea may emerge during the study (Patton, 2014). These basic characteristics of qualitative research allowed me to immerse myself in the field to explore what role an SDP program plays in participants achieving their capabilities and answer the three research questions.

Qualitative research is guided by various assumptions. Although these assumptions may remain hidden, they act as a lens that frames a study (Patton, 2014). Although other interpretative frameworks exist, I adopted a social constructivist framework. I chose to use social constructivism as the qualitative research design framework because it captures the complexity of the data collected in qualitative research. Social constructivism is human-focused and honors the belief that people 
construct multiple realities through their interactions with others and their lived experiences (Creswell, 2013; Gergen \& Gergen, 2008; Glesne, 2016). This makes reality more complex as both the researcher and participants co-create the data (Creswell, 2013). In social constructivism, everyone is seeking to understand the world in which he or she lives and works (Creswell, 2013). For social constructivists, reality is subjective with multiple interpretations; there is no one absolute meaning (Patton, 2014). All concepts of reality are socially constructed and the meaning of this subjective reality is created through interactions with others. Therefore, a person's history and cultural norms impact the reality that is created (Creswell, 2013). Many different stakeholders are involved in an SDP program, and brings their unique life experiences and backgrounds to their involvement, which means their perceptions and understandings of the program will differ from one another. Since the Capabilities Approach emphasizes respecting these differences, it was appropriate to pair the Capabilities Approach and social constructivism together.

Social constructivism holds certain beliefs. Multiple realities exist and are created through the lived experiences and interactions the study participants have with other people (Creswell, 2013). Reality is co-created by the group being studied and the researcher; each person's beliefs should be honored (Creswell, 2013). Because human beings construct their own reality, a researcher heavily relies on the views of the participants who are the research's focus (Creswell, 2013). Social constructivism uses an inductive research method through emergent design to understand the phenomena in the context of the study (Creswell, 2013; Patton, 2014). Researchers ask subjects broad, open-ended questions so that "participants can construct the meaning of a situation, a 
meaning typically forged in discussions or interactions with other persons" (Creswell, 2013, p. 25). Common methods of data collection include interviews, observations, and document analysis (Creswell, 2013). Multiple perspectives are collected to understand the perceived realities of study participants and the researcher (Guba \& Lincoln, 2013; Patton, 2014). This study collected different types of data from multiple individuals who have constructed unique realities, which means they may perceive an SDP program differently than others. Each reality, and each person's values, are to be respected. Respect for individualism is an important feature of the Capabilities Approach and defines social constructivism.

Social constructivism was an appropriate framework because it embraces the belief that people view reality differently (Creswell, 2013). Different social groups construct their own reality and have different reasons for participating in an SDP program (Patton, 2014). An SDP program is made up of a diverse range of stakeholders, including program participants, employees, volunteers, board of directors, donors, and third parties such as parents/legal guardians. Each group has constructed a different reality that influences their reasons for being involved with an organization. Therefore, to accomplish the purpose of this study, I must understand the different realities that exist within a program setting.

The Capabilities Approach also recognizes the importance of individuality (Sen, 1999). Having been created as a theoretical framework to help people achieve well-being, the concepts of functionings and capabilities implicitly acknowledge that multiple realities exist. A person may find happiness by creating a reality that radically differs from the reality of another person; however, each reality and its values are to be honored 
(Creswell, 2013). Therefore, it is up to the researcher to capture these different realities using an interpretative framework that accounts for these nuances. Capturing and honoring these different realities is important.

\section{Case Study Design}

To conceptualize the Capabilities Approach and investigate what role an SDP program plays in participants achieving their capabilities, I chose to use a case study research design. A case study is "an empirical inquiry that investigates a contemporary phenomenon (the "case') in-depth and within its real-world context" (Yin, 2014, p. 16). In other words, an investigator examines a bounded system over time using data collection (Creswell, 2013; Miles et al., 2014). A bounded system is a focus of the case that is limited to a time and place being studied (Creswell, 2013; Patton, 2014). A case is a person, organization event, or other social phenomenon with a temporal and special condition (Patton, 2014; Yin, 2014). This methodology involves collecting multiple types of data, such as interviews, observations, and documents as part of developing a description of the case and the case's themes (Creswell, 2013).

Case studies are an appropriate qualitative research approach when the main purpose of a research project is exploratory and calls for collecting a diversity of data to gain an in-depth understanding of the case (Creswell, 2013; Marshall \& Rossman, 2011; Yin, 2014). A case study was the proper methodological approach because it provided an opportunity to explore what role an SDP program plays in participants achieving their capabilities in a real-world setting through collecting in-depth data. Using a case study approach, I collected multiple types of data on functionings and capabilities to understand different perspectives related to SDP and the Capabilities Approach. A case study's 
emphasis on in-depth understanding through collecting multiple forms of data was also consistent with the objectives of social constructivism, this study's chosen research design.

A case study can be used for exploratory purposes (Yin, 2014). Questions involving how, why, and what are likely to lead to a case study (Yin, 2014). For the purposes of this study, a single instrumental case study was used. A single, instrumental case study is a case that is studied because the researcher is interested in a phenomenon bounded in a specific time and space (Bloomberg \& Volpe, 2016; Edwards \& Skinner, 2009). In this study, a single, instrumental case study approach was chosen because it focused solely on one case seeking to explore how a social phenomenon exists in the real world through in-depth description using multiple types of data (Bloomberg \& Volpe, 2016; Edwards \& Skinner, 2009, Yin, 2014).

\section{Sample Organization}

A case study must include a unit of analysis, which in this case was a single SDP organization. The participating organization for this study was selected according to a purposeful sampling technique (Creswell, 2014). Purposeful sampling involves intentionally selecting an information-rich case (Patton, 2014). According to Patton (2014), an information-rich case refers to a case where the researcher can learn a great amount of detail related to the purpose of the study. In purposeful sampling, participants are selected for a specific purpose (Rossman \& Rallis, 2011). Here, that specific purpose was to explore what role an SDP program plays in participants achieving their capabilities. 
The sample organization was selected based on specific criteria (Patton, 2014). The selection criteria included the following four elements: (a) organized as a 501(c)(3) non-profit organization, (b) consistently operating for at least ten years, (c) uses sport, play, or physical activity as part of its programming, and (d) has a mission statement consistent with the goals of SDP. If an organization has been in operation for at least a decade, as a non-profit, and has a stated mission consistent with the goals of SDP, this helps to bolster the likelihood a diversity of data exits to provide an in-depth and rich understanding of the case. In short, by meeting these criteria, such a sample organization would be an appropriate partner for the study.

Based on these criteria, I identified multiple organizations. Ultimately, Youth Odyssey was selected because it matched the selection criteria and offered me the broadest access to stakeholders and organizational data. I was granted entrée to the organization without limitations, thus spending prolonged time in the field with different organizational stakeholders and receiving access to other types of data. Youth Odyssey had requested I provide feedback on my study once completed, which I was happy to give as reciprocity for the access.

Youth Odyssey is a 503(c)(3) non-profit organization created in 1997, located in Corpus Christi, Texas (Youth Odyssey, n.d.a). Youth Odyssey was created with the express intent of "address[ing] the rising tide of juvenile crime and violence" in the Corpus Christi area (Youth Odyssey, n.d.a, para. 1). The organization's mission statement is as follows: "Youth Odyssey is a 501 (c)(3) nonprofit on a mission to provide at-risk youth, ages 10-17, with positive youth development through adventure programming" (Youth Odyssey Mission, n.d.b, para. 1). The organization's internal 
documents defined "at-risk youth" as "a young boy or girl who struggles in school, home, or in their social circles in one way or another" (Youth Odyssey History, Regular and Short Narratives, n.d., p. 1). Adventure programming is consistent with the customary definition of sport (Darnell and Black, 2011; United Nations, 2003). Therefore, based on the selection criteria, Youth Odyssey fit the selection criteria.

Over time, Youth Odyssey strengthened its connection to the local community. In 2003, it began working with local youth agencies through referrals and, because of its success with these youth agencies, Youth Odyssey now works with a range of organizations all over southeastern Texas. Youth Odyssey offers a range of play, recreation, and adventure activities year-round as part of building, what it terms, "basic, yet vital life skills (communication, teamwork, problem-solving, goal-setting, leadership, and trust)" that blends traditional programming focusing on at-risk youth with adventure wilderness activities (Youth Odyssey, n.d.b, para. 2). At the time of the case study, Youth Odyssey had four full-time employees, headed by an executive director, and was overseen by a seven-member board of directors. Therefore, Youth Odyssey's mission, structure, longevity, and integration with the local community made it an appropriate SDP organization to exhaustively explore the nuances of SDP and the Capabilities Approach.

\section{Curriculum}

Youth Odyssey's program was organized into the following levels: (a) portable team challenges, (b) ropes course sessions, (c) an adventure wilderness trip, and (d) graduation. Portable team challenges took place at select public housing communities, local 
middle schools, and a local homeschooling association. These sessions lasted for a maximum of two hours, depending on the program.

At portable team challenges, participants engaged in a variety of games and activities, intended to teach what Youth Odyssey called basic life skills, focusing on communication, teamwork, or problem-solving (Youth Odyssey, 2014). Each activity also included a debrief that employees, called facilitators, used to reinforce the preceding lesson's important takeaway. Select participants were invited to attend a ropes course, Youth Odyssey's second level, located approximately 30 minutes outside of Corpus Christi. Youth Odyssey took care of all costs. Here, the curriculum shifted to goal-setting, leadership and trust (Youth Odyssey, 2014). The final substantive programming was the camping trip. These invited participants were driven by Youth Odyssey directly from their respective school to a camp site located several hours outside of town. Participants spent the weekend camping, hiking, and doing other outdoor activities. On Sunday, the group packed up and headed back to Corpus Christi. Following a successful trip, the participant graduated from Youth Odyssey (Youth Odyssey, 2014).

During the camping trip and, to a certain extent, the ropes course, participants are required to make decisions on their own without much input from facilitators (Youth Odyssey, 2014). Completing these tasks is intended to be challenging. These challenging activities are an opportunity for participants "to reach beyond the typical, the normal, and experience the unique as they attempt to utilize new skills, apply these skills to new problems and situations, and internalize how their efforts helped achieve their goals" (Youth Odyssey Soft Skills Manual, p. 2). 
Youth Odyssey also offered a Youth Leadership program (Youth Odyssey, 2014). The Youth Odyssey website described this as "a closed program where youth are selected based on attendance, internalization of skills, and good decision making" (Youth Leadership Program, n.d., para. 1). The program provided select youth Odyssey participants with exclusive benefits and opportunities beyond what was normally offered through traditional programming. According to the Youth Odyssey website, Youth Leaders assisted program staff and eventually started leading activities and demonstrations for the other youth participants. Youth Leaders were expected to attend each stage of Youth Odyssey programming, assist the facilitator, and serve as exemplars for others to follow. In exchange for these duties, Youth Leaders had access to exclusive camping trips, educational opportunities, and other benefits.

\section{Access and Entry}

Qualitative researchers may encounter issues concerning access and rapport with subjects (Welty Peachey \& Cohen, 2016). Therefore, to gain access to potential research participants, I took several steps (Creswell 2013). First, I called the number listed on Youth Odyssey's website and the executive director answered the phone call. After an introductory phone call, I sent the executive director a letter of proposal for a strategic partnership (see Welty Peachey \& Cohen, 2016). I and the executive director then met via Skype to formally discuss a strategic partnership. After this meeting, the executive director received permission from Youth Odyssey's board of directors to approve the strategic partnership and granted me access to the organization. After receiving approval from Youth Odyssey, I submitted a case study research proposal to the University of Louisville Institutional Review Board and received approval to conduct the study. 


\section{Data Collection}

A rigorous case study involves collecting multiple sources of data so a researcher can gain an in-depth understanding of the phenomenon being studied as part of an emergent case study design (Creswell, 2013; Patton, 2014; Yin, 2014). Expansive data collection is important so the researcher can provide a holistic analysis of the case through triangulation (Creswell, 2013; Yin, 2014). Therefore, I collected multiple types of data in order to answer the study's questions. This data included semi-structured interviews, direct observations in the form of field notes, and documents/artifacts that were relevant to Youth Odyssey.

\section{Semi-structured interviews}

I developed two semi-structured interview protocols to use as part of the study (Appendix A). Interviewees belonged to one of the following two groups: employees, or parents/legal guardians. These two groups were likely to yield information rich interviews due to their close proximity to Youth Odyssey and/or its participants. Therefore, these interviews seemed likely to assist me in understanding these perspectives concerning what role Youth Odyssey's programming plays in participants achieving their capabilities. Interview questions were derived from relevant literature that related to challenges SDP organizations encountered and studies exploring/explaining the elements of the Capabilities Approach. The interview protocols contained open-ended questions that was separated into the following sections: (a) subject's background and preliminary questions, (b) what capabilities are Youth Odyssey creating for its participants, (c) what functionings are being supported by Youth Odyssey, and (d) how does Youth Odyssey help remove barriers for participants? 
Prior to conducting interviews, I pilot tested the semi-structured interview protocols. The pilot participant was an SDP practitioner who worked in an adaptive sport NGO and was familiar with the topic of the study. The pilot interview assisted me in refining the interview questions' clarity and scope of inquiry to better answer the research questions posed in this current study (Yin, 2014). After completing the pilot interview, I refined and finalized the semi-structured interview protocols. The two semi-structured interview protocols listed in Appendix A include the changes made because of the-pilot test and used in this study. I also created a research grid that offered an overview of how each question from the interview protocols related to the three primary research questions (Appendix B).

After revising the interview protocols, I conducted interviews with members from each group. Interviews with employees and parents/legal guardians were conducted so I could understand the different perspectives and realities of each group to gain a greater understanding of what role Youth Odyssey's programming plays in participants achieving their capabilities (Creswell, 2013; Yin, 2014). I chose to interview employees and parents/legal guardians and to exclude Youth Odyssey participants because they were unlikely to understand my questions related to functionings, barriers, and capabilities. Further, parents/legal guardians and employees were better positioned to evaluate and answer whether or not the needs of Youth Odyssey participants were being met.

I used a snowball sampling technique to locate information-rich cases (Patton, 2014). Creswell, (2015, p. 209), defines snowball sampling as "a form of purposeful sampling that typically proceeds after a study begins and occurs when the researcher asks participants to recommend other individuals to be sampled." Through these interviews, I 
could understand how subjects constructed reality (Patton, 2014). Prior to the interview, each participant was given an informed consent agreement to review and sign (Appendix C). Interview data was collected until the point of saturation, the point where interviews stopped yielding new data (Creswell, 2013; Patton, 2014) or up to 20 interviews total. Each interview lasted approximately 60 to 90 minutes, with an average time of 42 minutes. To enhance accuracy, each interviewee granted me permission to use a digital device to record the interviews (Yin, 2014). I also took notes during the interviews to help formulate questions for future interviews. To maintain privacy, a system of coded pseudonym identifiers was used and this information was stored in a spreadsheet separate from the interview transcripts, manuscript, and other documentation. The interviews were transcribed and compared with the audio recording to ensure accuracy.

\section{Direct observations (field notes)}

I collected direct observations in the form of field notes using a field note observations template sheet (Appendix D). The goal of observational data is to describe the setting in-depth and provide detail of the observed setting (Patton, 2014). Direct observation from the field is an integral aspect of qualitative research, as qualitative takes place in a natural setting and a researcher may be able to obtain data through that would not be possible through an interview (Patton, 2014). So, in order to gain credible data, qualitative researchers must go into the setting (Creswell, 2013). The goal of the direct observations was to provide a rich description of what is taking place in the naturalistic environment, and provide additional context for the other data collected to determine whether the data is consistent. 
I was granted access to observe multiple settings, including employee meetings and the locations where programming took place, which enhanced the quality of the data collected. Having been granted access to Youth Odyssey, I was an insider-observer and was thus able to interact with others while observing (Patton, 2014). This insider access helped to produce an accurate portrayal of the case being studied (Yin, 2014). At times during field observations, I used analytical memos and jottings to capture data. Thus, in the process of engaging in direct observations, there needed to be a certain amount of flexibility to learn about the case.

\section{Artifacts}

Artifacts were also collected. Artifacts refer to material that reflects the culture of an organization or internal documents written by the organization for various uses (Patton, 2014). They may consist of mission statements, corporate filings, legal documents (i.e. bylaws), operations manuals, organizational brochures, and the like that provide a glimpse into the organization. While an artifact may not hold much meaning to an outsider, it may have an entirely different meaning to insiders (Glesne, 2016). When reading an artifact, one attempts to understand the stories that it embodies (Glesne, 2016). These artifacts were reviewed for the purposes of data triangulation and to gain a more in depth, holistic understanding of the case.

\section{Documents}

Finally, documents relevant to the case study were collected (Yin, 2014). Documents take many different forms and are an integral part of data collection (Yin, 2014). Documents refer to both the information that a case organization puts out (e.g. information on its website, social media, press releases, brochures, etc.) as well as 
documents written by third party organizations about the case organization (e.g.

newspaper articles, Facebook commenters). One of the most important uses of documents in a case study is that they can augment and corroborate evidence that was collected via other sources (Yin, 2014). Therefore, documents can help to verify or contradict other evidence collected in a case study.

\section{Data Analysis}

The purpose of case study analysis is to obtain a comprehensive and in-depth understanding of the case (Patton, 2014). Consistent with a social constructivist framework, data analysis of the case study used an inductive theoretical approach. Inductive analysis is "data-driven analysis" (Bloomberg \& Volpe, 2016, p. 190). In inductive-driven studies, researchers build theory from data so the data can "speak for themselves” (Bloomberg \& Volpe, 2016, p. 190-1991). Induction differs from a deductive-driven approach, which is a theory-based approach (Bloomberg \& Volpe, 2016). Since the purpose of the case study was to explore what role an SDP program plays in participants achieving their capabilities, uncovering data that made sense of the research questions were important. When analyzing qualitative data, Yin (2014) recommends that the researcher start making sense of the data by searching for patterns, concepts, or insights that look promising. Yin (2014) also suggests using analytic memos when beginning to analyze data. Patton (2014) views well-constructed case studies as being holistic and context sensitive. Therefore, as part of this process, I broke the data analysis stage into three stages as suggested by Patton (2014): assemble the raw case data, construct a case record, and organize the data into a case study narrative. This was all done in order to obtain a deeper understanding of the phenomenon being studied. 
In the first stage, where raw data is assembled, I began by transcribing each interview. Each interviewee was given a pseudonym. I used NVivo, a qualitative software program, as part of the organizational process. Each interview was uploaded into NVivo and included the interviewee's pseudonym and the date of the interview. NVivo also allowed for annotating on the interview transcript. Next, field notes were created from jottings after leaving the field. I then uploaded the jottings into my computer. Where required, I expanded my jottings shortly after uploading them to provide a more accurate and vivid description of the field. Artifacts and documents were also reviewed in this stage.

Once interview transcripts and field note were inputted and organized, I read each transcript and field note observation several times to become familiar with the data. The data was then coded using exploratory coding to make preliminary code assignments (Miles et al., 2014). A code in qualitative research is usually a word or phrase that summarizes or captures the essence of a larger portion of data (Saldaña, 2013). According to Rossman and Rallis (2011, p. 282), "coding is the formal representation of categorizing and thematic analysis." When coding, the goal is to reduce data without losing any of its meaning and capturing the significant issues or ideas (Saldaña, 2013). Through coding, a researcher can develop themes and theory, and thus can begin to understand a phenomenon.

For this study, coding was divided into first cycle and second cycle coding. During first cycle coding, multiple coding methods were used (descriptive coding, in vivo coding, and provisional coding) as a means to begin making sense of the data (Creswell, 2013). After initial coding, data was again coded through second cycle coding using, 
axial coding to gain a more holistic understanding of the case (Saldaña, 2013). In second cycle coding, codes were reconfigured and/or reorganized to further explain the data (Miles et al., 2014). Some codes were reframed or combined, while other codes were excluded. The author also used constant comparative analysis, the systematic examination and refining of data in emergent concepts (Patton, 2014), to compare the resulting data with what the I discovered through field observations, document analysis and reviewing artifacts.

I went out of my way to frequently journal as a way to contemporaneously capture my data analysis thought process and strategies. Further, through this process, I made use of memoing as a means to capture my rationale for coding decisions. Journal entries and memos sometimes also reflected my thoughts that took place during this process. This was all done to remain reflexive during the data analysis process.

Once the raw case data was created, I further reduced and organized the data as part of the final case study narrative (Patton, 2014). Data was sorted out, patterns were found, and data was organized to help explain the phenomenon (Yin, 2014). In this phase, data was also condensed and edited into a manageable form (Patton, 2014). In the final stage, a case study narrative was written. The case study was the final, readable, descriptive picture of the phenomenon, which investigated what role an SDP program plays in participants achieving their capabilities (Patton, 2014).

\section{Researcher Reflexivity}

With most any qualitative research study, the researcher must understand his or her biases regarding the topic of focus and try to limit these biases from interfering with the study. This is important because the researcher is the principle instrument that 
captures data from the participants. Limiting a researcher's biases is accomplished through reflexivity. Reflexivity, quite simply, is the process of reflection (Patton, 2014). A researcher goes through this process to reflect about how his or her personal background, upbringing, culture, and other experiences impact his or her own perspective. That way, a researcher can be aware so that bias does not shape the direction of a study or interpretation of data (Creswell, 2013).

Bracketing is part of the reflexivity process. Moustakas (1994) refers to this process as epoche. In this process, the researcher engages in self-examination to identify and set aside any preconceived beliefs to the fullest extent possible (Creswell, 2013). Through this process, a researcher will hopefully be able to identify potential biases and adopt a fresh perspective toward the phenomenon being studied. Although Moustakas (1994) believes that some phenomena are "unbracketable" because of one's own life experiences that are too deep-rooted in a person, he still argues that bracketing is achievable.

Bracketing was important for this case study because it may make a difference in what and how one sees, hears and/or views things (Moustakas, 1994). As part of the bracketing process, I explored my potential biases, such as understanding my position of privilege as a doctoral student from the Global North who is learning about SDP from a critical perspective. To better bracket, I examined potential biases and prior opinions by writing in a reflexive journal. Reflection is an important aspect of the bracketing process, as it encourages an openness of one's perception and to avoid prejudgment (Moustakas, 1994). Through using a reflexive journal, a researcher can discuss their own thoughts, assumptions, perceptions, frustrations, and evaluations concerning a study (Lindlof, 
1995). I also went through my own personal written reflection debrief after every field observation session to supplement the reflexive journal. By reflecting, a researcher may become more mindful of and receptive toward unfamiliar or new ideas (Moustakas, 1994). Thus, in order to become more aware of potential biases and minimize their influence on decisions, I wrote in a reflexive journal before, during, and after data collection efforts.

\section{Quality of Findings}

\section{Trustworthiness}

Trustworthiness of the research refers to whether one believes in the claims that a study has advanced (Marshall \& Rossman, 2011). This question concerns issues about the validity, reliability, objectivity, and generalizability about a study. In qualitative research, the goal of trustworthiness is to create results that are "worth paying attention to" (Lincoln \& Guba, 1985, p. 290). According to Lincoln and Guba (1985), the four concepts of trustworthiness are credibility, transferability, dependability, and confirmability.

\section{Verification (credibility)}

Credibility, also known as internal validity, examines whether a researcher's finding is interpreting the credible data conception as drawn from the participants' original data (Lincoln \& Guba, 1985). In other words, credibility refers to the accuracy of the phenomenon being described. For this study, credibility was enhanced by prolonged time in the field with the phenomenon being studied as part of the case. I also collected multiple types of data, in hopes of using triangulation to increase the validity of the data collected (Yin, 2014). Specific to interviews, I enhanced the accuracy of the interviews 
by using a recording device, which was transcribed and then reviewed for accuracy, and by taking notes during the interview. I also received confirmation from the participants that the transcribed interview was accurate and conformed with what they had said during the interviews. I also informally conferred with several SDP experts as part of the confirmation process concerning the credibility of the data. This informal feedback confirmed that the data collected conformed with their understanding of the SDP field. My use of constant comparative analysis aided in strengthening validity. Finally, I also used member checks to confer with others in the field that the collected data was accurate (Lincoln \& Guba, 1985).

\section{Transferability}

Transferability, also known as external validity, refers to whether the findings apply beyond the current study and its participants. In other words, transferability examines whether or not outside researchers are able to understand and transfer my study's findings to other studies (Lincoln \& Guba, 1985). A researcher can meet this threshold by providing sufficient detail in the study that readers can assess whether transferability exists. I attempted to provide a thick description to allow readers to transfer the information for this study to other settings to determine whether the findings are transferrable due to shared characteristics of each study (Erlandson, Harris, Skipper, \& Allen, 1993). Further, I am willing to provide other researchers with the data analysis documents by making these documents available so that transferability can be confirmed. My analytical memos and journaling may also help others with transferability. 


\section{Dependability and conformability}

Dependability, or how reliable the data is, concerns the quality of the data collected analyzed. In this case, I was able to bolster transferability through providing a thick description of the phenomenon through 43 separate field observation entries, 20 interviews, and a multitude of artifacts and documents. Dependability refers to the trackability of any changes in the study's data over time. Researchers seek to bolster dependability because qualitative research is emergent and the study may change over time. Further, as another form of dependability, this study's dependability relied on external auditing in the form of the dissertation committee's examination of my methodology.

Finally, confirmability addresses whether I considered the potential subjectiveness of the findings, as it may relate to the trustworthiness of the data (Lincoln $\&$ Guba, 1985). To account for confirmability, I attempted to limit any biases through the epoche and bracketing process. This also involved writing into a reflexive journal, providing a personal written reflection debrief after every field observation session. I also created an audit trail so that independent researchers can make their own conclusions about the data that emerged from the study.

Summary of the method. This study explored the Capabilities Approach as a theoretical framework as it applies to an SDP program. It was guided by an overarching research question of what role an SDP program plays in participants achieving their capabilities? The research questions focused on Youth Odyssey's role in creating capabilities, supporting functionings, and removing barriers. A qualitative research 
design was used because the study was exploratory in nature (Creswell, 2013; Patton, 2014).

Qualitative research occurs in a natural setting, is intended to provide a holistic account, and involves emergent design. A social constructivist framework was used to capture the complexity of the research subject and that people construct multiple realities and each reality is to be respected (Creswell, 2013). Respect for individualism is a defining feature of both the Capabilities Approach and social constructivism. Since SDP programs involve different stakeholders, and each stakeholder experiences differ from one another, it was appropriate to pair the Capabilities Approach and social constructivism together.

A case study design was used for the study. A case study involves collecting multiple types of data to develop an in-depth understanding of the case (Creswell, 2013). A case study was the proper methodological approach because it provided an opportunity to explore what role an SDP program plays in participants achieving their capabilities in a real-world setting and collect in-depth data. A case study must include a unit of analysis, which was a single SDP organization. I used purposeful sampling to locate the participating organization - Youth Odyssey. I made contact with the organization, met with the executive director, and secured entre, access and cooperation through its board of directors. Semi-structured interviews, direct observations in the form of field notes, and relevant documents/artifacts that were collected in the study.

The case study used an inductive theoretical approach for data analysis. Coding was divided into first cycle and second cycle coding. Patterns were found and data was organized to help explain the phenomenon (Yin, 2014). The data was organized and 
analyzed so that a case study narrative was written, which provided an in-depth understanding of the case. I used bracketing and journaling for reflexivity. 


\section{CHAPTER IV}

\section{FINDINGS}

SDP has become a popular approach to development, due to the inherent attractiveness of using sport, play or physical activity as a vehicle to facilitate opportunities for social change. However critical scholars remain skeptical of SDP's effectiveness, particularly programs premised on the belief that sport serves as a remedy for all of society's problems, or that operate according to values that are out of step with program participants' ideals (Coakley, 2011; Coalter, 2010; Darnell, 2007; Hayhurst, 2013). Properly conceptualized theories that can accommodate the varying objectives of SDP programming while also addressing the criticism are essential.

Critical scholars suggested pursuing a framework that utilizes a more holistic approach that is locally grounded and listens to the individual voices of those they wish to serve (Hayhurst, 2013; Spaaij \& Jeanes, 2013). SDP practitioners must develop tools for program design and evaluation that are sensitive to local context, values, and voices; the Capabilities Approach may provide a model to achieve this goal. Therefore, the aim of this study was to apply the Capabilities Approach in evaluating what role an SDP program, Youth Odyssey, plays in participants achieving their capabilities. This study was guided by an overarching research question: what role does Youth Odyssey play in participants achieving their capabilities?

The following three research questions assist in answering the aforementioned question and address the purpose of the study: 
RQ1: What functionings are being supported by Youth Odyssey?

RQ2: How does Youth Odyssey help remove barriers for participants?

RQ3: What capabilities are Youth Odyssey creating for its participants?

This chapter is organized into three sections: (a) recap of study sources, (b) introduction of the setting, and (c) findings derived from the data for each research question.

\section{Study sources}

This study used multiple sources as part of an emergent case study design (Creswell, 2013; Patton, 2014; Yin, 2014). Interviews, field observations and document/artifacts provided a holistic analysis of the case through triangulation (Creswell, 2013; Yin, 2014). Each type of data played a role in this study in order to answer the research questions. Please see Table 3, for a summary of study data sources.

\section{Interviews}

The case study yielded 21 interview subjects. Every interviewee was an adult who had a connection with Youth Odyssey, whether it was a parent, guardian, or employee. Four interviewees were employees, and 17 were parents or guardians. Two of the parents interviewed were also former Youth Odyssey participants who now have children of their own taking part in the organization. The average interview time was 42 minutes, with a minimum of 22 minutes and a maximum of 78 minutes. Table 1 contains each employee's pseudonym, relationship with Youth Odyssey, age, ethnicity, gender, and years spent working at Youth Odyssey. Table 2 contains information about the parents or guardians, including their pseudonym, age, ethnicity, children involved with Youth

Odyssey, Diverse perspectives provided by semi-structured interviews and other forms of data unearthed a conceptualization of the role Youth Odyssey played in achieving 
participants' capabilities (in other words, how the elements of the Capabilities Approach materialized in an SDP setting).

\section{Demographics}

Every interview subject provided demographic information. Four Youth Odyssey employees were interviewed - two males and two females. The average Youth Odyssey employee interviewee age was 29.5 , with 20 being the youngest and 39 being the oldest. All four (100\%) of the employees self-identified as white. The average time spent working at Youth Odyssey was 4.1 years, with a low of less than a year and a high of 10 years. Seventeen parents or guardians were also interviewed - three males and 14 females. The average parent or guardian age was 43 , with 24 and 60 being the youngest and oldest subjects, respectively. Ten participants (59\%) self-identified as white, five participants (29\%) as Hispanic, one person (6\%) as Chicano, and one (6\%) participant chose not to self-identify as any ethnicity. Parent or guardian interviewees most commonly had one child enrolled in Youth Odyssey, with an average enrollment of 1.4 participants. Each parent had been involved with Youth Odyssey for an average time of 4.5 years, although one person's 17-year relationship with the organization skewed the data. Omitting this number lowered the average time to 3.9 years. The presented demographic information provides a snapshot of the study's interviewees.

\section{Table 1}

List of Youth Odyssey Employee Interview Subjects

\begin{tabular}{cccccc}
\hline Pseudonym & $\begin{array}{c}\text { Relationship with } \\
\text { Youth Odyssey }\end{array}$ & Age & Ethnicity & Gender & $\begin{array}{c}\text { Years with Youth } \\
\text { Odyssey (years) }\end{array}$ \\
\hline Sam (E1) & Staff member & 20 & White & M & $<1$ \\
& & \multicolumn{2}{c}{173} & &
\end{tabular}




$\begin{array}{cccccc}\text { Kira (E2) } & \text { Staff member } & 25 & \text { White } & \text { F } & 1.5 \\ \text { Jake (E3) } & \text { Staff member } & 34 & \text { White } & \text { M } & 4 \\ \text { Kathryn (E4) } & \text { Administrator } & 39 & \text { White } & \text { F } & 10\end{array}$

Table 2

List of Youth Odyssey Parent Interview Subjects

\begin{tabular}{cccccc}
\hline Pseudonym & Age & Ethnicity & Children & $\begin{array}{c}\text { Years with Youth } \\
\text { Odyssey }\end{array}$ & Notes \\
\hline Alexis (P1) & 46 & White & 1 & 1 & \\
Alice (P2) & 55 & Hispanic & 2 & 3 & \\
Alonzo (P3) & 36 & Hispanic & 1 & 5 & \\
Brian (P4) & 34 & Chicano & 4 & 2 & \\
Carol (P5) & 39 & White & 1 & 1 & \\
Danielle (P6) & 34 & Hispanic & 2 & 5 & \\
Emily (P7) & 24 & Hispanic & 1 & 6 & \\
Jennifer (P8) & 47 & N/A & 1 & 6 & \\
Leah (P9) & 35 & White & 1 & 5 & \\
Lucy (P10) & 60 & White & 1 & 4 & \\
Lynn (P11) & 59 & White & 2 & 5 & \\
Mark (P12) & 56 & White & 2 & 17 & \\
Michelle (P13) & 42 & White & 1 & 2 & \\
Maria (P14) & 40 & White & 1 & 2 & \\
Patty (P15) & 35 & Hispanic & 1 & 5 & \\
Rachel (P16) & 41 & White & 3 & 1 & \\
Shannon (P17) & 43 & White & 1 & 6 & \\
& & & & & \\
\hline
\end{tabular}

\section{Direct Observations}

I collected direct observations in the form of field notes throughout the study.

Field observations served as an integral aspect of understanding Youth Odyssey's approach because they took place in the study's natural environment. I made 43 separate field observation entries as part of building a thick description of the phenomenon. Observations ranged from portable team challenges in community (community programs 
A, B, and C), middle school (middle schools A, B, C, D, E, F, and G), and home school (home school programs A, and B) settings, to the ropes course, to employee and board meetings, and other settings. Time in the field varied, the average time spent was 103.5 minutes per field observation. Each field observation often ended with a debrief between facilitators, Youth Leaders, and myself, as well as my personal debrief once I exited the field, returned to my vehicle and filed out my field notes to more vividly reconstruct what I witnessed.

Field-observations yielded useful data for this case study. Because I was granted access to virtually any setting I requested, this data collection technique led to understanding the observed phenomenon in numerous environments and contexts. Further, each facilitator debrief and personal debrief helped to capture the authentic happenings in the field contemporaneously. Therefore, field observations and debriefs were very helpful in making sense of what I had observed and how this data fit within the larger case.

\section{Artifacts}

Artifacts are internal administrative documents as well as material that reflects an organization's culture (Patton, 2014). Artifacts can be diverse, and this case study was no exception. I reviewed Youth Odyssey's mission statements, select corporate filings, board of director minutes, executive director reports, bylaws, skills manuals, strategic plans, select program reports, select contracts/memos of understanding, surveys/handouts for participants, budgets, grant reports, organizational curriculum, and policies and procedures. 
Each artifact held significance for Youth Odyssey. Executive director reports, which were distributed to Youth Odyssey's board of directors, set the agenda and included information about different matters to be discussed during the meeting. They also provided a recap of the last meeting, and therefore were a unique window into the organization. Program reports also were helpful, as they were narratives written by facilitators that provided their perspective on the progression of select programs. Many of these artifacts were helpful with providing additional triangulation for data analysis.

\section{Documents}

Like artifacts, Youth Odyssey personnel allowed me to review any document I wished. Documents include information an organization releases to the public such as what it puts on its website, social media, or traditional methods, as well as any documents an outside party publishes concerning Youth Odyssey. For the purposes of this study, I analyzed Youth Odyssey's social media documents, mass emails to individuals who registered with the organization, fundraising communications, and information on its official website (e.g. about the organization, employee biographies, programs offered, resources, testimonials). I also reviewed promotional materials such as information listing Youth Odyssey's goals, statistics it collected illustrating participant success, traditional print advertisements and brochures, a Youth Odyssey promotional video, Youth Odyssey letters to parents/guardians, and hard copy fundraising promotions/communications. This information was used similarly to artifacts, to provide additional triangulation for data analysis. Table 3 displays a summary of the data sources collected in this study.

\section{Table 3}

Summary of data sources collected. 


\begin{tabular}{|c|c|c|}
\hline Type & Description & $\begin{array}{l}\text { Number } \\
\text { of items }\end{array}$ \\
\hline Interviews & $\begin{array}{l}\text { Semi-structured interviews with Youth Odyssey employees } \\
\text { and parents/guardians of Youth Odyssey participants. Total } \\
\text { interview time was } 14.7 \text { hours, average interview lasted } 42 \\
\text { minutes. }\end{array}$ & 21 \\
\hline $\begin{array}{l}\text { Direct Observations } \\
\quad \text { (Field Notes) }\end{array}$ & $\begin{array}{l}\text { Granted access to observe Youth Odyssey programming at a } \\
\text { variety of locations that varied by group and activity. Helped } \\
\text { to provide a thick description of the phenomenon. Total time } \\
\text { in the field was } 74.13 \text { hours, average field observation lasted } \\
103.5 \text { minutes. Holistic account of time observing } \\
\text { phenomenon where it took place. }\end{array}$ & 43 \\
\hline Artifacts/Documents & $\begin{array}{l}\text { A variety of information that was both private and publicly } \\
\text { available. Provided more data for triangulation purposes. }\end{array}$ & 116 \\
\hline
\end{tabular}

\section{INTRODUCTION OF THE SETTING}

Youth Odyssey served as the focus for the case study. The mission of Youth

Odyssey is to provide at-risk youth with positive youth development by using adventure programming. Youth Odyssey provides financial resources and opportunities for participants to enjoy a variety of activities, while also teaching lessons using the organization's core curriculum. This curriculum is divided into six core values: communication, teamwork, problem-solving, goal-setting, leadership, and trust. These items have been Youth Odyssey’s six core skills since its founding in 1997.

\section{Participant recruitment}

Many interviewees were eager to enroll their children in Youth Odyssey because of the entertainment aspect. Alonzo (P3), representing several parents, simply said, "We didn't want [our son] to be at home bored." Several parents were motivated to enroll their children because it took them away from indoor activities such as computers and video games. Mark (P12), who has been involved with Youth Odyssey for 17 years and currently serves as a board member, said he enrolled his children because "I didn't want them to get 
stuck playing video games and sitting inside." Instead, he wanted his two girls to "know and love the outdoors."

Other parents gravitated toward Youth Odyssey because of what it provided participants. A few parents, such as Danielle (P6) and Emily (P7), specifically enrolled their children because it offered them unique experiences that were normally unaffordable. Leah (P9), as a former participant herself, tied several motivations together by saying Youth Odyssey “actually shows you that there's so much more you can do than just sit at home and be on a phone, or be on the video game or out in the street getting in trouble." Once a program was established and populated with participants, facilitators spent the first few sessions playing games and creating a fun atmosphere. However, as the program continued, it shifted to focus more on the Youth Odyssey's targeted skills as opposed to solely fun. Games essentially became rewards for good behavior and attendance.

\section{Introduction of select interviewees}

Though 17 parents or guardians were interviewed and the results include data from every interviewee, Chapter 4 will commonly highlight experiences from seven parents that captured the essence of Youth Odyssey. These select interview subjects included Brian (P4) and Leah (P9), who both participated in Youth Odyssey as adolescents and chose to enroll their youngsters in the organization now that they were are a parent. They provided unique child and adult perspectives for this study. Mark (P12) also brought a different viewpoint, as he has been associated with Youth Odyssey for over 17 years. His roles included a parent with two children who became Youth Leaders and graduated to volunteers. He currently serves as a board member, and owns a company that financially supports Youth Odyssey through donations. Alice (P2), Carol, (P5), Emily (P7), and Maria 
(P14), all provided diverse perspectives. Table 4 provides a list of these select interviewees'

respective motivations for enrolling their children in Youth Odyssey.

Table 4

Parent motivations to enroll participants into Youth Odyssey

\begin{tabular}{|c|c|c|}
\hline Pseudonym & Initial motive to enroll & Representative Quote \\
\hline Alice (P2) & $\begin{array}{l}\text { Improve leadership } \\
\text { skills. }\end{array}$ & $\begin{array}{l}\text { I felt that he needed some direction with his whole life, and } \\
\text { he needed to become more of a leader than a follower (p. 1). }\end{array}$ \\
\hline Brian $(\mathrm{P} 4)$ & $\begin{array}{l}\text { Wanted to help his son } \\
\text { get over his fear of } \\
\text { heights and to have new } \\
\text { experiences. }\end{array}$ & $\begin{array}{l}\text { I told my son, you know, I said, “Look," I said, “These } \\
\text { people will help you with your confidence,” I said, "I } \\
\text { promise you that.” I said, "You have a fear of heights," I } \\
\text { said, “They will help you get over it.”... I said, "You'll see } \\
\text { places of the state that you haven't seen before." (p. 6). }\end{array}$ \\
\hline Carol (P5) & $\begin{array}{l}\text { Wanted to build her } \\
\text { daughter's confidence. }\end{array}$ & $\begin{array}{l}\text { My daughter tends to become a shy and people pleaser, so I } \\
\text { really wanted her to be in the group where she could work on } \\
\text { communication and teamwork and just kind of built } \\
\text { confidence (p. 1). }\end{array}$ \\
\hline Emily (P7) & $\begin{array}{l}\text { Making friends and } \\
\text { safety. Said her daughter } \\
\text { liked the activities } \\
\text { offered by Youth } \\
\text { Odyssey. }\end{array}$ & $\begin{array}{l}\text { Just the fact that she was able to hang out with friends after } \\
\text { school in a safe place and, everything was free } \\
\text { (laughs)... } \\
\text { just because of all the activities that they had after school and } \\
\text { she just wanted to be involved in stuff like that (pp. 1-2). }\end{array}$ \\
\hline Leah (P9) & $\begin{array}{l}\text { Though she could gain } \\
\text { life skills. }\end{array}$ & $\begin{array}{l}\text { I thought it's good life skills, it's good coping mechanism } \\
\text { skills (p. 2). }\end{array}$ \\
\hline Mark (P12) & Outdoor activities. & $\begin{array}{l}\text { I grew up with horses and in the country, and I wanted that } \\
\text { for my girls. I didn't want them to get stuck playing video } \\
\text { games and sitting inside, and all the things that we do, you } \\
\text { know, going camping, you know. Having two daughters - I } \\
\text { was in the boy scouts, but this kind of filled that void that I } \\
\text { saw in raising them and having them know and love the } \\
\text { outdoors (pp. 1-2). }\end{array}$ \\
\hline Maria (P14) & $\begin{array}{l}\text { Opportunity for her } \\
\text { daughters to mentor } \\
\text { other children. }\end{array}$ & $\begin{array}{l}{[\mathrm{T}] \text { he reason that it was appealing to us, is because there was }} \\
\text { an opportunity for my daughters to be involved in a } \\
\text { mentorship for other kids. (p. 1). }\end{array}$ \\
\hline
\end{tabular}




\section{RQ1: What functionings are being supported by Youth Odyssey?}

Functionings are what a person manages to accomplish during his or her life (Robeyns, 2017). These are activities and behaviors a person values and has reason to value (Robeyns, 2005). "In other words, functionings are valuable activities and states of being that make up people's well-being" (Alkire \& Deneulin, 2009, p. 31). Because functionings are defined within the context of the individual's life experiences and desires, they differ in complexity (e.g. being employed versus having a job that one finds rewarding, being reasonably nourished versus being able to eat at restaurants, and access to a mode of transportation versus owning a reliable automobile). Thus, since an achievement may be limited or unconstrained in scope, a great degree of variability exists in functionings.

Functionings will differ from person-to-person; further, the existing social structures a person lives in can impact functionings (Robeyns, 2011, 2017). In this study, one relevant social structure was society's notion that young people need supervision. This supervision came via Youth Odyssey and the life skills programming offered to the local community. Youth Odyssey's programming was organized around six life skills: communication, teamwork, problem-solving, goal-setting, leadership, and trust. When discussing Youth Odyssey's life skills development programming, parents and staff (those responsible for providing the supervision) both indicated that these skills represented valuable achievements and would be beneficial for youth development. Because children were constrained by the decisions parents/legal guardians made on their behalf, the program participants were required to work within these social structures. Four major themes reflecting functionings emerged from this study. The themes that 
emerged were (a) being more comfortable and capable in social settings and interactions, (b) using logical reasoning and analytical skills, (c) being part of community, and (d) doing new activities and experiences. These themes are presented in Table 5.

Table 5

Summary of supported functionings themes

RQ1: What functionings are being supported by Youth Odyssey

Theme 1: Being more comfortable and capable in social settings and interactions

Theme 2: Using logical reasoning and analytical skills

Theme 3: Being part of a community

Theme 4: Doing new activities and experiences

\section{Theme 1: Being more comfortable and capable in social settings and interactions.}

Many parents explained that they wanted Youth Odyssey to help their children learn behaviors related to socialization. The hope was that participants would use Youth Odyssey as a resource to become better at using their social skills in public such as at school. Youth Odyssey supported this by making participants feel more comfortable and capable in social settings and interacting with others as they led activities focused on strengthening certain social skills. Moreover, staff interviews, field observations, and organizational documents illustrated the ways and reasons that Youth Odyssey supported participants in becoming more comfortable and capable interacting with others in social settings as a functioning.

Jake (E3) felt Youth Odyssey’s socialization-heavy curriculum helped participants to become an "even more awesome version" of themselves as they went 
through their process of becoming more comfortable in social settings and interacting with others. Alice (P2), agreeing with Jake, commented on how she had "noticed a big change" in her son's level of comfort socializing with others since joining Youth Odyssey, and that he was having more positive social interactions with others. Youth Odyssey provided social resources to participants in the form of its social structures and curriculum that facilitated a space to practice socialization skills. Through this practice, participants achieved being more comfortable and capable in social settings and interactions using their social skills. The most commonly discussed and observed ways that Youth Odyssey supported participants to become more comfortable and capable in social settings and interactions with others related to communication, leadership, and teamwork.

\section{Communication}

Each facilitator began making participants more comfortable and capable in social settings by starting his/her respective portable team challenge focusing on communication. Kira (E2) reasoned that communication was a fundamental building block of nearly all the Youth Odyssey experiences that participants enjoyed. Naturally, then, she felt facilitators ought to start by seeking to cultivate this behavior. "[I]f you have bad communication, you're not gonna have a very good game, and so any single game that you choose, whether it be Tic-Tac-Toe, Tag, or whatever, you're gonna have to be communicating with somebody." In other words, if a participant communicates poorly, it will inhibit his/her ability to effectively participate in future activities because each one involves communication. Kira's quote demonstrates her belief that if a person cannot effectively communicate, it will inhibit his/her ability to feel more comfortable 
interacting with others in social settings. Communication games targeted a range of different ways to help a person become more comfortable communicating with others. Some games prevented participants from communicating verbally while others required children who were less talkative to speak up. In this sense the curriculum facilitated recognition of a variety of communication types, and participants became more comfortable by working on their communication skills in different ways.

Nearly every interviewee, parent or staff, suggested that Youth Odyssey's games and activities helped participants improve their communication skills. Leah (P9), both a parent and former participant, was particularly passionate and outspoken concerning the program. Her praise focused on her own experience becoming more comfortable and capable in social settings interacting with others through communication. She said:

I was a very secluded child. I didn't talk to anybody...[Through Youth Odyssey, I] learned how to open up and be more punctual [sic] when it came to conversations and doing things, and I wasn't left behind so much...I learned how to cope with people and conversate [sic] [with] different people...

The comment that she "wasn't left behind so much" is particularly striking, since it potentially evokes both the specific idea that she accomplished being more capable interacting with others in different social settings, and the broader idea that she was no longer "left behind" in her social development.

Similarly, Carol (P5) felt her son became more confident and adept at using his communication skills during social interactions through his Youth Odyssey experience. Carol explained that her son "always had a hard time sounding out sounds in sixth-grade. He didn't want to talk to anybody." Instead of being self-assured and meaningfully 
interacting with others, her son "[made] grunts and he wanted no one to hear him talk." However, her son's verbal and communication skills transformed once he began taking part in Youth Odyssey. "He was talking more to his friends, he was more on his phone talking to his friends, you know, and they would come over to see him." Through the communication skills he gained, Carol's son has become more confident and capable in social settings and interactions.

Field observation notes from Middle Schools A, B, C, D, E, and F, as well as community programs $\mathrm{A}, \mathrm{B}$, and $\mathrm{C}$, reflected that communication was the first skill featured in portable team challenges. Specifically, the first activity in portable team challenges consistently involved public speaking. Virtually every field observation on location during a portable team challenge, regardless of facilitator or setting, began with facilitators asking participants to speak, one-by-one, about their day to the group. This, however, created stress for some participants, as reflected in comments by Rachel (P16), who said her daughter “doesn't like the first 10 minutes of Youth Odyssey...because they're made to speak in front of people, and that makes her very, very nervous." Rachel (P16) went on to note, however, that repetition of this activity caused her daughter to practice outside of Youth Odyssey, thereby making her be more comfortable and capable in social settings and interactions.

\section{Leadership}

Youth Odyssey programming also commonly employed activities targeting leadership as part of helping participants become more comfortable and capable in social settings and interactions. Sam (E1) felt that Youth Odyssey helped guide participants "down a path to learn better what leadership is" through its programming. Meanwhile, 
Brian (P4), as both a parent and former Youth Odyssey participant, spoke with passion of the leadership skills he achieved as an adolescent through his Youth Odyssey camping trip and other outdoor activities.

To be able to be placed in a position of a leader, there's no way to replicate that, without actually doing it. You know, you can go to all the leadership schools you want, all the leadership courses, until you're actually placed as a leader inside somewhere where you're actually, given a task, given an objective, and you're told to accomplish this, that's when you really start learning the true qualities of being a leader. That's where you really start learning.

Switching his perspective from that of a participant to that of a parent with a son in the program, Brian (P4) noted that his son, "always had a little bit of leadership potential, you could see it, but he was always kind of shy going about it." He went on to say that, even though his son had attended leadership camps, "it's just never the same as actually being put in place in charge of a group. So by giving him that opportunity to be in charge [of Youth Odyssey activities]...that experience, you know, it - to me that's something that you can't even pay to get."

Other data supported Brian's thoughts on how Youth Odyssey strengthened children's' leadership skills as part of helping participants become comfortable and capable in social settings and interactions. For instance, Youth Odyssey's soft skills manual listed "create strong leaders in every group" as a goal. Field observation notes captured scenes from various portable team challenges and ropes courses where facilitators orchestrated activities heavily related to leadership. In one case, Kira (E2) 
required a group of approximately 10 participants to link legs and walk in unison past a marker located about 50 feet away without becoming untangled or falling. It was a task that would had been difficult to accomplish without a leader to organize the group. Without prompting, one of the older participants spoke up and took on a leadership role, allowing the group to complete the task.

Alice (P2) credited Youth Odyssey with vastly improving her son's leadership skills. She felt that activities such as the one above "instill with [the participants] what good leadership is, what makes a good leader, how to lead other students to make the right choices." She also appreciated the amount of control the youth have during certain activities. She liked that facilitators "actually tell the kids, you know, we're going to step back. You'll be the [leaders].",

Direct observations in the field showed mixed results when it came to using leadership as part of helping participants in becoming more comfortable and capable in social settings and interactions. Sometimes no student took a leadership role when one was needed, and the group faltered as a result. This was an organic process. Overall, however, observations suggested that Youth Odyssey programming supported participants' successful efforts to learn about leadership, when it was appropriate or even necessary to be a leader, as well as when it was best to defer to others who have taken on that role. All of these different scenarios may had helped participants to become more comfortable and capable in social settings and interactions.

\section{Teamwork}

Youth Odyssey used activities focusing on practicing teamwork to help support participants become more comfortable and capable interacting with others in social 
settings. Many parents sought out Youth Odyssey so that their children would become better at collaborating with others in group settings. Jennifer (P8), Lucy (P10), and Carol (P5) all brought their children to Youth Odyssey in hopes they would learn to work better with others. Carol (P5) said her daughter needed to learn about "working together [with others]...that's how the world is when you have to work with people, and all different kinds of people." Carol's comment was referencing social structures that often require citizens to work alongside others in groups to solve issues, whether it be at school or work. Thus, practicing teamwork supports participants being more comfortable and capable in social settings and interactions with others. Similarly speaking to social structures, Rachel (P16) said, we can work together as a team, like, around our house but it's different when you have people that, maybe, you're not as comfortable with because you don't know them. I think teamwork is one of the big things that I've seen with Youth Odyssey.

Rachel's (P16) comment refers to the difficulty of feeling comfortable working in a group with others if one is not used to the experience. Youth Odyssey supported participants becoming more comfortable and capable in social settings and interactions through repeating activities where teamwork and groupwork were required. One approach that Shannon (P17) referred to as, teaching participants how to "handl[e] situations," was by having to work together with other children they did not previously know. This required participants to interact with unfamiliar people and, in the process, become comfortable with the task. 
Several interviewees described how many Youth Odyssey activities incorporated teamwork. Maria (P14) noted that often, "the kids are broken down into small groups and they're working together, they're doing a lot of team building, teamwork." Emily (P7) explained that for participants to succeed at their various objectives, "they have to depend on each other." Leah (P9) agreed with Emily that teamwork is required to succeed at the activities. For example, when describing the camping trips, Leah (P9) said, "there's a job to do during the whole entire camping trip, you have to look out for each other, you have to take care of one another." To accomplish these various tasks, participants must be comfortable and capable interacting with each other. Lynn (P11) observed her children "helping each other" during Youth Odyssey programming. "You don't see them moping around," as opposed to outside of Youth Odyssey, where Lynn's children used teamwork less. Lynn credited Youth Odyssey's programming with helping develop her children's teamwork skills. Brian (P4), having taken part in Youth Odyssey as an adolescent, provided a unique perspective when it came to Youth Odyssey and teamwork. He said participants "learn to work as a team, to want to work as a team." This desire indicates that children become more comfortable and capable in social settings and interactions.

Documents and field observations also triangulated teamwork. The Youth Odyssey manual discussed the importance of teamwork and why facilitators were to incorporate teamwork into portable team challenge lessons as one of the organization's six core life skills (Youth Odyssey, 2015). The manual contained information the facilitators could use as part of introducing the concept of teamwork, why it was important, and steps to build teamwork within a group. Field observations noted games where the participants' success was based on whether or not they worked together as a 
team. In addition to portable team challenges, field observations from the ropes course provided examples of participants progressively becoming more comfortable completing activities that required teamwork on the low elements.

\section{Theme 2: Using logical reasoning and analytical skills.}

Youth Odyssey supported participants using logical reasoning and analytical skills. Alice (P2) felt Youth Odyssey helped participants learn "how to make [the] right choices" by having them do activities requiring use of logical reasoning and analytical skills to succeed. Social institutions and social norms are societal structures that allow for youth to use their logical reasoning and analytical skills as part of a making decisions in life. Youth Odyssey provided a forum for participants to practice and achieve doing these activities. Facilitators routinely used activities that tested participants' goal-setting skills and problem-solving abilities. These attributes were prominently represented in the data collected to facilitate participants' use of logical reasoning and analytical skills.

\section{Goal-setting}

Youth Odyssey games, activities, and debriefs almost always included a goalsetting component to facilitate a participant's logical reasoning and analytical skill development. Kathryn (E4) said part of Youth Odyssey's core programming was teaching participants "why it's important to set goals." Leah (P9) reflected on watching her daughter's improved goal-setting skills, saying “before she was in this program she didn’t even realize how to make a goal and stick with it. It was just, 'oh I want to do this,' and then five minutes later she forgot all about it." Since enrolling, Leah reported that Youth Odyssey facilitators have "taught her how to stay on track" by setting and keeping goals. 
Kira (E2), during an interview, recounted how she emphasized the importance of goal-setting to participants by comparing the process to planning for a marathon. "Say I wanted to run a marathon, that's 26.2 miles, do you think I would do a very good job in that marathon if I were to run it tomorrow?" When the participants responded "no," Kira solicited reasons as to why not. The children said, "you need to practice" or, as Leah said, one needs "endurance." She also related training for a marathon to training to succeed in school: studying, showing up to class, and performing well in class. Kira's example of why setting goals should be similar to training for a marathon was intended to cause participants to think logically about their desired goals and analyze the needed steps to accomplish them.

Other triangulating data in the form of field observation notes demonstrated the importance of goal-setting in Youth Odyssey programming. For example, during one field observation at the ropes course, the youth were tasked with completing a difficult challenge involving a tire swing to dismount in an area with several small rings that could not accommodate the entire group. The group had set an ambitious goal and, after they failed, Jake commented that the group had "bit[ten] off more than you can chew." Jake encouraged the group to set a more realistic goal, having never attempted the activity before. During a different field observation at a portable team challenge, Kira (E2) also stressed the importance of goal-setting when attempting to complete a difficult activity for the first time. Kira explained to the group that it is unrealistic to set a goal that exceeds reasonable expectations when attempting a difficult task for the first time. Both facilitators' points to their respective group was to think more logically and set a more 
realistic goal when trying a challenging activity for the first time. Goal-setting was also prominently discussed in the Youth Odyssey manual.

\section{Problem-solving}

Youth Odyssey facilitators routinely presented groups with different challenges to solve. Sometimes the activity involved use of limited resources, physically challenging barriers, or limits on communication. Regardless, once providing the parameters, facilitators normally stood back to let the group work through the challenge, typically saying very little until the post-activity 'debrief.' Carol (P5) was particularly enthusiastic about this aspect of Youth Odyssey's approach:

I think [what makes Youth Odyssey unique is] the way its run...nobody's telling them what to do, they are given a task like "you guys have to figure out how to accomplish it." I think that's cool that the kids have to think about things. They have to figure things out on their own.

Facilitators did not normally assist the youth, which meant they needed to use their own logical reasoning and analytical skills to solve the issue, or fail the challenge. Carol (P5) felt her daughter "really enjoys" the problem-solving aspect of the program. Rachel (P16) said her son also "loves to take a challenge and figure out how to accomplish the task set at hand...because he gets to challenge himself."

As part of encouraging participants to use their logical reasoning and analytical skills, facilitators required children to take ownership of activities and would not intervene unless they encountered significant difficulties. Carol (P5), again enthusiastic about the analytical aspect of Youth Odyssey, said "I love [that participants] have to figure it out themselves, [Kira is] there for support but she does not cheat (e.g. assist 
participants when they are stuck).” By requiring children to take ownership of group challenges, Youth Odyssey promoted participants' use of their logical reasoning and analytical skills.

Field observations also triangulated the theme of participants going through their problem-solving process as part of using their logical reasoning and analytical skills. Facilitators assigned games that frequently included a wrinkle to highlight a specific challenge such as restricting communication, limiting a person's senses, or restricting mobility. Participants needed to use analytical skills to accomplish tasks such as those.

For example, one game required participants to solve a puzzle by traversing a specific path on a block of carpet squares that had been predetermined by the facilitator. Participants did not know the pre-determined route, so a wrong turn meant everyone had to go back to carpet square one. Ultimately the group devised their own analytical process, adopted their own strategies and worked together as a team to solve the puzzle. During the debrief, Kira asked the group "how do you think you worked together in the activity?" One participant said "100" while another guessed "90." Kira rewarded the group with a perfect score, praising them and saying "you didn't get upset or lose your cool. It was all part of the problem-solving process."

The Youth Leader also praised the participants for solving the puzzle, recapping the process they used to identify the problem and then to come up with a plan. The Youth Leader asked the group what their first step was in the problem-solving process. One participant shouted out, "identify the problem;" and another youth said, "come up with a plan.” The Youth Leader prompted the group further, asking, “what was your plan?” A participant replied by saying the group's approach was, "memorize the steps [in the 
puzzle]." The Youth Leader expanded on the group's problem-solving process: "[y]our method was you knew where to start, and used trial and error. If it [one person's step] doesn't work, you tried something new. You did a great job."

\section{Theme 3: Being part of a community.}

Youth Odyssey participants experienced being part of a community. Children accessed social structures available to them through Youth Odyssey that they used to be part of a community. To create community, facilitators established trust among participants and facilitators, and promoted a positive environment. Jake (E3) said, through this approach, participants let their guard down to "be more of themselves."

\section{Trust}

Kathryn (E4) was empathic when she underscored the importance of establishing trust. She said, “[p]arents, guardians, [and] schools are entrusting their kids to us, ok?” If facilitators are unable to gain their trust, then "we have no business working with [the] kids." Jake (E3) explained that some children came from circumstances where "they've been let down a lot in the past" by adults they trusted and may be hesitant to trust someone for fear of being disappointed again. Similarly, Kira (E2) said, "[t]hese kids aren't used to people, one, being there for them, and, two, consistently being there for them." Therefore, they felt, facilitators needed to overcome the previous negative experiences some participants had with adults in positions of power and gain their trust if they wanted to support participants achieving being part of a community. Without trust, participants would be less likely to take part in the community that Youth Odyssey wanted to build. 
Interviews with parents illustrated that facilitators cultivated trust with participants, which was required for them to be part of a community. Brian (P4), the former participant and parent of a current participant, described Youth Odyssey as a group of people "that genuinely cares about you." Jennifer (P8) believed her daughter felt Youth Odyssey was a place where "you can do whatever you want to do and be whatever you want to be;" this supported Jake's (E2) comment about participants being "more of themselves" at Youth Odyssey. Emily (P7) said her daughter looked at Youth Odyssey as more than an extracurricular activity; facilitators and participants were "almost like a second family." This reference to family supports the notion that Emily's daughter felt she was a part of the Youth Odyssey community.

Interviews with two former participants who are now parents of children in Youth Odyssey also spoke about trust's role in the process of being part of a community. Brian (P4) suggested that Youth Odyssey also taught participants "to trust each other." Leah, (P9), another former participant and parent, spoke to the same point in more detail, saying that Youth Odyssey provided her daughter with ...people she can confide in. People she can trust. People that she feels are reliable. There's not too many people in this world that you can actually confide in anymore. And that is one thing that she loves the most about it.

Field observation notes also illustrated that Youth Odyssey prioritized creating trust between facilitators and participants. A new employee orientation at Youth Odyssey's headquarters captured Jake (E2) explaining that all Youth Odyssey employees and volunteers were required to pass a background check. He also said that employees and volunteers sometimes were subject to additional security screening, depending on 
their level of involvement in programming. This underscored the importance trust played in helping create a community.

\section{Positive environment}

Generating positivity also contributed to being part of a community. Leah (P9) called it "the energy and the vibe of the positive reinforcement [that her daughter derived] from everybody else there." Many field observations captured Jake (E3) going out of his way to generate a positive environment for those in attendance. He explained why he did it by saying, "people need that positive encouragement that we provide for them, [at Youth Odyssey], we try to work with them for a sense of belonging." A sense of belonging seems like being part of a community for those involved. Sam (E1) provided further support for Jake's (E3) statement, saying, "all [participants] want is to know they've done something good. [Participants] don't hear lot of, 'I believe you would be good at this,' or 'I think that you did a great job here.'” Sam (E1) believed providing participants with the reassurance that a facilitator had faith in them was important for building a positive environment as part of being a part of a community.

Triangulating data also illustrated Youth Odyssey's emphasis on creating a positive community. One particularly meaningful interaction between Jake and a participant while at the ropes course stuck out (see Appendix E, Field Note 20). The group was about to tackle their first high element of the afternoon. One participant, however, appeared to be nervous about climbing the high element and only ascended several steps up before saying he wanted to come back down. Instead of admonishing him or providing negative reinforcement, Jake praised the participant and said he was proud of him. Other participants complimented the person as he came back down and/or 
gave him a high five, taking their lead from Jake's comments. In that moment, that participant appeared to be uplifted by the positive environment and community that they all shared, which was nurtured by Jake.

\section{Theme 4: Doing new activities and experiences.}

Youth Odyssey supported doing new activities and experiences. Participants partook in a diversity of experiences as well as experiences that were non-routine. Youth Odyssey championed new experiences, which parents appreciated. Youth Odyssey's programming facilitated participants with access to a number of resources that allowed them to achieve accomplishing new activities and experiences beyond what was commonplace for adolescents. For example, in addition to the portable team challenges, Youth Odyssey attendees provided the resources for children to participate in summer camps, travel to a ropes course which included both low and high elements, hiking, kayaking, canoeing day trips, snorkeling, scuba diving, and weekend camping trips throughout the state and region. Youth Odyssey also offered participants opportunities to engage in community service activities. Participating in these new activities and experiences would be unlikely to occur without Youth Odyssey's involvement.

Participants did things that was fun and outside the norm of their daily lives. Many interviewees felt the organization facilitated new experiences that participants just would not typically encounter. Carol (P5) explained that without Youth Odyssey, "I never would have been able to [provide my daughter]" with the experiences Youth Odyssey offered. Many parents felt the scope of experiences available to their children came with a message best said by Jake (E3), that these experiences helped participants understand "there is more out there" for them to explore. Jake (E3) also felt these 
experiences could serve as a lifeline to children who feel "trapped in their own neighborhoods," as many do not leave their familiar surroundings. Jake (E3) felt that participants "seeing that there is more outside Corpus, or even sometimes more outside Texas, gave them something else to look towards," but achieving these experiences was only possible because of Youth Odyssey's involvement.

Brian (P4) recounted a memorable experience from his time as a Youth Odyssey participant that reinforced Jake's (E3) comment about seeing that there is more beyond Corpus Christi. His vivid description encapsulated why unique experiences were important achievements. Brian (P4) said his first unique experience as a Youth Odyssey participant was an excavation site about an hour away from town. During the process, the facilitator began teaching the group about "the history of where we were at. That's when we started realizing that, at the time it was like, 'man, this is so cool."” Brian (P4) also appreciated that Youth Odyssey provided him everything necessary to achieve this experience; "they let us use sleeping bags, they gave us everything we needed, down to the camp soap."

These new experiences helped Youth Odyssey personnel facilitate experiences that transcended everyday life for participants. Although Sam (E1) felt that many participants initially attended solely because they "want something to do," Youth Odyssey was different because it met participants" "desire to explore, that desire to do something that isn't just the normal everyday grind," suggesting that these were truly new experiences for participants.

Comments from parents confirmed Sam's (E1) suggestion. For instance, Emily (P7) noted that "[my daughter] was very persistent about enrolling just because of all the 
activities that they had after school and she just wanted to be involved in stuff like that." Michelle (P13) also said her daughter was the one who insisted on joining Youth Odyssey. 'I said, '[w]ell tell me about [the program],' and she really didn't know what to tell but, in the beginning, and she said, "it's just where we learn to do things, and how to be." Michelle's (P13) comment on learning "to do things, and how to be," connects to the new achievements that Youth Odyssey made possible for participants.

Additional secondary data reinforced the importance of giving participants new activities and experiences. The preamble of Youth Odyssey's training manual stated that the goal for programming was for participants "to reach beyond the typical, the normal, and experience the unique as they attempt to utilize new skills" and to learn while doing (Youth Odyssey, 2015, P. 2). Further, Youth Odyssey's slogan was “[o]pening minds and expanding horizons," a reference to the benefits of supporting new experiences (Youth Odyssey, 2016). The Youth Odyssey manual also expressed the importance of providing non-routine experiences, as it was critical element of Youth Odyssey lesson plans.

\section{Summary}

In this study, (a) being more comfortable and capable in social settings and interactions, (b) Using logical reasoning and analytical skills, (c) being part of a community, and (d) doing new activities and experiences emerged as themes. Participants became more comfortable and capable in social settings and interactions, principally by participating in communication, leadership, and teamwork activities. These behaviors help participants to navigate social situations and perform better in institutional settings such as school or, eventually, the workplace. Participants used their logical reasoning and analytical skills (e.g. goal-setting and problem-solving behaviors) through activities 
based on Youth Odyssey's core curriculum. By building trust amongst each other and fostering a positive environment, programming also helped to create a community that participants could be a part of. Participants also took part in a diversity of non-routine activities and experiences. Giving children these experiences helped them to understand that there was more for them to experience than their everyday lives.

\section{RQ2: How does Youth Odyssey help remove barriers for participants?}

The Capabilities Approach is concerned with expanding people's meaningful opportunities to improve their quality of life and pursue achievements that they value (Alkire \& Deneulin, 2009; Robeyns, 2017). Increased freedom means more opportunities to exercise one's agency and take control over one's life (Sen, 1999). Conversely, Sen (1992) viewed a lack of freedom and real opportunities to improve one's quality of life as barriers. Therefore, increasing one's process freedoms (the political structures that allow for agency to pursue functionings) and opportunity freedoms (the social system allows this agency to pursue functionings) are instrumental to lessening barriers in a person's life that prevent pursuing and achieving a functioning that s/he values (Taylor, 1979). Once barriers are negotiated, a person's real freedom to achieve a functioning (e.g. do something or be something) without being limited, their capabilities, means s/he has agency to pursue one's passions.

Although barriers are not an explicit element of the Capabilities Approach framework, they relate to its concepts of freedom and conversion factors. A conversion factor, recall, is defined as a person's ability to convert a resource into functioning (Robeyns, 2017). Conversion factors vary according to an individual's biological 
attributes, social context, and living environment, and may prevent a person from turning resources into functionings. In other words, a barrier may relate to a person being unable to read (e.g. a personal characteristic), one's marginalized social standing in society (e.g. a societal characteristic), and/or living in a rural community without access to clean drinking water or internet (an environmental characteristic). The proceeding examples of barriers, to some extent, may operate similarly to a conversion factor, because it inhibits an individual's freedom and/or ability to turn a resource into a functioning. A person may experience difficulty performing well in school if $\mathrm{s} /$ he cannot read, is a member of a marginalized group of society, is chronically absent from school because of illness from unclean drinking water, and does not have access to internet to perform homework. Thus, although I am not arguing that barriers and conversion factors are the same, Youth Odyssey's work to negotiate barriers participants face to give them the freedom to achieve functionings may relate to the Capabilities Approach framework.

Youth Odyssey participants faced multiple barriers including financial, educational, emotional, and social obstacles. The nature of the reality in which participants and their families lived, including their socioeconomic and cultural surroundings, dictated many of these barriers and the ease (or difficulty) of their removal. Each of these barriers limited his or her freedom and opportunity to achieve functionings (Sen, 1999). The data regarding how Youth Odyssey helped reduce barriers for participants coalesced into three themes: (a) reflecting positive role models and social behaviors, (b) emphasizing personal growth and confidence, and (c) countering difficult home or environmental influences. These themes are listed in Table 6.

\section{Table 6}




\section{Summary of participant barriers theme}

RQ2: How does Youth Odyssey help remove barriers for participants?

Theme 1: Reflecting positive role models and social behaviors

Theme 2: Emphasizing personal growth and confidence

Theme 3: Countering difficult home or environmental influences

\section{Theme 1: Reflecting positive role models and social behaviors.}

As a former Youth Odyssey participant who is familiar with the communities and social contexts from which many current Youth Odyssey participants live, Brian (P4) spoke to the barriers that many Youth Odyssey participants face. "Most of them come from single parent families," he said. "Father might not be in the picture, mother might not be in the picture." Brian's (P4) description suggested that some participants lacked consistent supervision and the presence of steady, positive adult influences. Youth Odyssey administrator Kathryn (E4) agreed, saying many Youth Odyssey participants lacked "positive role models. Someone to encourage them, and to challenge them, and not to punish them every time they make a mistake." Not having the consistent positive influence of a parent, guardian or some other role model at home meant a participant would miss out on learning about social behaviors expected in society. A youth would not know how to act in public or what was acceptable behavior in social settings.

In addition to the lack of positive role models, data from field observations suggested that negative role models factored in the lives of many Youth Odyssey participants. For example, during one field observation, a facilitator recounted a conversation she had with a participant about his disruptive behavior. The participant said he acted the way he did because his friend taught him that "bullies are cool" and he "has to be tough." Another field observation, this time from a program meeting, captured Kira 
(E2) as she explained to co-workers that some parents tell their children, "[d]on't let someone punch you, just punch them back." This a message that directly conflicts with Youth Odyssey's lessons. Youth Odyssey facilitators attempted to negotiate the barriers of absent or inconsistent adult role models and the disruptive influences from peers by providing positive role models and demonstrating acceptable social behaviors. This occurred through both facilitators and Youth Leaders serving as role models, as well as establishing consistent standards of accountability and rewards in line with relevant social structures.

\section{Role models and acceptable social behaviors}

Data offered support that Youth Odyssey's programs provided positive role models and demonstrated acceptable social behaviors. Jake (E3) clearly viewed it as part of his job to act as the missing role model, "a constant figure. I'm someone who shows up every week that they can depend on.” Kira (E2) agreed with Jake (E3) and suggested that participants "can see me or [Jake] or other mentors and other children as something to aspire to" as models of how participants are expected to function in and the various social norms related to society. Youth Odyssey, in turn, executed programming that provided participants with positive reinforcement in the form of facilitators and Youth Leaders. These tactics created opportunities for participants to learn preferred social behaviors.

Youth Odyssey facilitators adopted a surrogate role as a participant's exemplar to provide youth with positive adult role models. This was intended to provide examples of society's expectations for how participants are to behave. Kathryn (E4) said a facilitator's role was to "help [participants] become productive members of [the] community, of 
society." Sam (E1) agreed, suggesting that the goal was to help each participant become "a good member of society, and a good functioning human being." Thus, facilitators sought to positively influence participants.

This positive influence began by facilitators establishing expectations for participants. Kira (E2) explained her expectations to participants on the first day of her portable team challenge at Middle School E: "[s]tep one is showing up to the program. Step two is being nice. Step three is being respectful.” Facilitators also commonly stressed continued attendance, good behavior, and keeping up one's grades while a part of Youth Odyssey. Youth Leaders served as a role model for younger children. Kira (E2) mentioned that many newer participants wanted to be Youth Leaders, suggesting that the position was an influential one among them. Brian (P4) recalled believing during his time as a participant that Youth Leaders were "the coolest people in the world cause they're like - they know everything." Kira (E2) viewed the Youth Leaders as a way for participants to see their peers modeling acceptable behavior, "[doing] all [the] things that we talk about, and doing it really well."

As noted, being a Youth Leader was a sought-after position. Kira (E2) said, "I've had so many members of Youth Odyssey come up wanting to be a Youth Leader...they get really excited and they will be like 'how do I become one?"' When a participant expressed interest, Kira would explain the expectations they need to conform with in order to be considered. "'Well, you need to be showing up and participating and having a good attitude and be able to get others on task and kind of set yourself apart in a leadership way." Participants needed to emulate the role models of Youth Odyssey in 
order to be considered for this sought-after position, hopefully internalizing the behavior that was expected.

Alice (P2) explained that her son has become a Youth Leader by modeling his behavior after Jake. She witnessed a change in the way "he carries himself" once emulating Jake. She felt Jake "did a great job" with her son, saying "he's been such a good mentor...I think it's what he needed.” The Youth Odyssey training manual served as a triangulating data point, as it encouraged facilitators to "[b]e a model for the group" (Youth Odyssey, 2015, p. 11), and that "[i]nstructors should model and promote appropriate behavior" for participants to follow (Youth Odyssey, 2015, p. 23). A program report from Community Program A detailed how a Youth Leader had "become a role model for some of the other kids" at the program (Community Program, 2016, p. 1). Youth Odyssey corporate records from 2013 also noted a comment from Jake (E2) praising the Youth Leaders because they were "serving as great role models for the youth in the program" (Youth Odyssey Board of Directors Meeting Minutes, 2013, p. 2). This triangulating data supported the finding that facilitators and Youth Leaders served as positive role models for participants.

\section{Accountability and rewards}

A significant finding related to accountability and rewards. Although Youth Odyssey attempted to reflect positive role models and social behaviors by implementing consistent practices of accountability and rewards for participants, each facilitator had their own approach to accountability and rewards that appeared to be inconsistent with each other. No data emerged illustrating that Youth Odyssey had an official organizational policy when it came to accountability and rewards, as the organization's 
policies and procedures manual was silent on this topic (Youth Odyssey Policies and Procedures Manual, 2005), apparently leading to facilitators using an ad hoc approach. During portable team challenges, each facilitator had a different method to dealing with a non-conforming participant; therefore, disruptive participants were likely to receive different treatment based on the facilitator present. Kira (E2) routinely used a "three strikes and you're out" approach.

I'll take them off to the side - I don't like call them out in front of everybody and like scold them, I'll take them off to the side and I'm like, "look, you had three opportunities to get it together and today wasn't your day, I'm sorry.

The three strikes rule meant Kira gave a person two warnings, and then disciplined the participant after a third occurrence. Usually the consequence was dismissing the disruptive individual from the day's activities. Kira (E2) took steps not to embarrass the participant, but instead respectfully told him or her why she was excluding the person from the day's activities. Kira (E2) also made sure the participant knew he or she could return with a "clean slate" the following day and try again.

While Kira (E2) followed her "three strikes" approach, Jake (E3) exhibited less consistency. Jake explained that he is sometimes soft on a disruptive participant because he "sees something" in that Youth Odyssey member, that "something is going on" in the person's life. Sometimes Jake (E3) gave multiple warnings to a participant, or chose not to dismiss a disruptive participant at all; other times he immediately dismissed participants for poor behavior. One time, at Community Program C, Jake even attempted to discipline a group of participants by asking them to take deep breaths to settle down. His approach appeared to change based on program location, and he seemingly imposed 
stricter penalties at community programs than at middle school or home school programs. Occasionally Jake (E3) raised his voice, which seemed to startle participants since his normal demeanor was clam, soft spoken, and affable. This inconsistent ad hoc approach suggested that facilitators were not contributing to negotiating social barriers through consistent supervision and the presence of steady, positive adult influences to demonstrate acceptable social behaviors.

Youth Odyssey facilitators rewarded and incentivized good behavior with invitations for innovative programming. Participants who did not meet expectations would miss out on these rewards or incentives. Data from former participants confirmed the positive impact of some of Youth Odyssey's expectations and rewards. Brian (P4) described how he changed his own behavior as a teen participant, due to the high expectations his facilitators set and Youth Odyssey's consequences for failing them: It really kept me off the streets. Normally I'd be with my cousins or with my neighborhood friends and doing not so legal things. My friends would tell [me], "oh you know, hey, there's going to be a party," or "[h]ey we're going to go do this.” And I would say, “Nah, man I can't. I'm going to go with Youth Odyssey this weekend." [And they would say], "you're going with that group again?" "Yeah man, I'm going to go." "Man, come on, man, we're going to do this." I was like, “Uh, I don't [want to] mess it up man because, if I mess up, they're going to kick me out for a while."

Brian (P4) struggled with succumbing to his peers' influences to do "not so legal things." However, Brian concluded that missing out on the rewards of participating in Youth Odyssey because he violated the organization's rules was more important to him than 
heeding calls from his peers. Thus, he chose to respect Youth Odyssey's rules as a condition of affiliation, meaning he stayed out of trouble to avoid the consequences.

Jake explained why Brian's (P4) was so committed to following Youth Odyssey's rules. He said, "[participants] have to show us that they are mature enough, and that they've learned enough" to merit the continued rewards. Sam (E1) recounted an example where a participant had not been rewarded with a trip because of his behavior. He said, "there was a kid who had been acting up" and was not invited to the ropes course, which upset the participant.

I was like, “look, I know you're upset about this, I know you know you're just trying to be funny and you don't mean anything bad by it but, first impressions and impressions in general are important, your actions define how people perceive you.

Sam's statement reinforced the importance of a participant's actions, the value of the reward, and there are consequences for actions. In this case the consequence meant no invitation to the ropes course.

\section{Theme 2: Emphasizing personal growth and confidence.}

Some participants were hesitant to embrace new experiences, or challenge

themselves, which caused them to miss opportunities for personal growth. Mark (P12), a Youth Odyssey Board Member and longtime volunteer, suggested participants experienced a fear of failure or being vulnerable. Mark (P12) explained this fear of failure or being vulnerable could be an "emotional fear [such as] opening up and being able to talk to someone about what you truly feel about things," or something more specific like "the fear of heights." Fear of being vulnerable operated as a barrier at times 
because some participants avoided taking on new challenges that may had led to personal growth or an increase in confidence. Therefore, Youth Odyssey attempted to diminish participants' fear of being vulnerable, first, by establishing trust as a foundation for relationships between facilitators and participants; and second by encouraging participants out of their comfort zone. Once trust was established, the organization pushed participants to get out of their comfort zones to face their fears. Mark (P12), when describing this approach, felt participants were given the opportunity to gain "the confidence to do something you never thought you would be able to do." Sam (E1) felt these opportunities allowed participants to grow in a way that "sticks with you, and changes you for the rest of your life, and impacts you in a positive way."

\section{Establishing trust as a foundation for relationships}

Data revealed that Youth Odyssey emphasized personal growth and confidence by establishing trust as a foundation for relationships between participants and facilitators. Sam (E1) explained why some participants experienced trust issues. He said, "maybe they've been let down a lot in the past and, it's difficult for them to [trust] others." Sam felt his role was "to regain a lot of that [lost] trust" and show participants that it was ok to put your trust in facilitators. Leah (P9), a former participant, felt Youth Odyssey succeeded in gaining her daughter's trust by creating "almost like a family setting" between facilitators and participants. Lynn (P11) noted that her children trusted Jake, saying that "his word is gospel to them." Building trust was important because it enabled participants to experience positive relationships with adults and peers.

Brian (P4), a former participant, explained that building trust between him and Youth Odyssey occurred quickly. Initially, he said, he was skeptical of the organization's 
motives. By end of his first weekend camping trip, trust began to develop. He learned that all the organization wanted to do was "give kids a better chance." Brian said "about a few months in, I trusted them with my life. I mean, I spent Thanksgiving with them instead of my family..." This illustrated how quickly Brain (P4) and Youth Odyssey facilitators established a relationship based on trust.

Brian (P4) further suggested that Youth Odyssey was able to build trust because it accepted participants for who they were. There were no preconditions and participants did not have to do anything to be accepted into the group. "You know, just be you, and they accept you." Kira (E2) had a similar viewpoint as Brian, but from a facilitator's perspective. She explained, "I don't know how much control [participants] have in their everyday personal lives and how much is dictated by a parent or a teacher or somebody else." So, as part of building a supportive environment based on trust, Kira (E2) felt Youth Odyssey "gives [participants] a chance to really become themselves, instead of having maybe to walk on eggshells."

\section{Getting participants out of their comfort zone}

After establishing trust, data also confirmed Youth Odyssey helped participants overcome their fears by pushing them to get out of their comfort zones. Jake (E3) described this aspect of Youth Odyssey programming as "taking [participants] out from what they always did and giving them new things so they will have new experiences and new knowledge from outside their normal community.” Patty (P15) framed Youth Odyssey's approach as asking participants to "try something new," while Maria (P14) described it as asking participants to "push yourself." Rachel (P16) put it this way: "I don't want my daughter to be an introvert her whole life. I want programs that can pull 
her out of her comfort zone and help her to grow." Getting participants out of their comfort zones was part of the confidence-building process.

Youth Odyssey's programming routinely placed participants in situations that lacked the comfort of the familiar. Emily (P7) felt her daughter "was very shy" before enrolling, but Youth Odyssey's programming placed her daughter in situations that removed her from her comfort zone. Emily said, because the participants "have to depend on each other [when they go camping,] it forced her [daughter] out of her shell so she could talk to other people." According to Brian (P4), this was a typical story. He suggested that, over time, as participants embraced new situations, "[y]our perception on reality starts to change [and] you start to realize that you're worth a little bit more [and] other people see." Similarly, according to Alice (P2), as participants are pushed into unfamiliar situations, they grow from learning to deal with unfamiliar situations. Through this process, and showing their vulnerability, "they find their strength within themselves."

Some interviewees talked about how their children embraced new challenges. For instance, Rachel (P16) recounted a related anecdote concerning the ropes course. "I thought for certain that only one of my children would actually participate in that ropes course. I really thought that they would back out and completely not do it once they saw what they were supposed to do." Rachel expressed disbelief, however, that her children participated. She said, "they did it, and they were scared, but they were able to overcome [their anxiety] and they actually completed the whole course." Rachel was surprised by the result, that her children took the opportunity.

Triangulating data confirmed that Youth Odyssey's curriculum relied on pushing participants to get out of their comfort zone. Youth Odyssey's employee manual 
highlighted the importance of getting participants outside of their comfort zone, stating "challenge and adventure activities provide the opportunity for participants to push past their own comfort zones (physically, emotionally, intellectually, spiritually)" (Youth Odyssey Soft Skills Manual, 2015, p. 2). Field notes and documents (see Appendix E, Table 9, Table 10), particularly from the ropes course observations, also provided affirmative support of the role physical challenges played in getting participants away from their comfort zones and providing the real opportunity personal growth.

Although Youth Odyssey programming created an opportunity for participants to experience growth and gain confidence through their efforts, facilitators would not force participants to face their fears. "Everyone moves at their own pace," according to Mark (P12). "No one is forced to do anything that they don't want to do." Kira (E2) explained that, "giving [participants] freedom to make that decision [to face their fears] for themselves is something that they need, but it's also a trust thing, that they can trust us." Therefore, participants must have trust that facilitators will help them face their fears, but also respect their limits. Kira continued, "some of our activities are really hard [and] you have the kids that shut down, 'this is hard I'm done,' then you have the kids who are like, 'This is hard, we can do it." These decisions relate to how far a participant is willing to push themselves to face their fear.

Mark (P12) also felt Youth Odyssey was a place where participants "can say what they feel, they can have emotion.” For Mark (P12), who has been involved with Youth Odyssey for over 17 years, learning how to express one's own emotions meant “breaking down that wall and allowing those kids to have the freedom to say what they mean and 
what they feel and not have the fear that they're going to be reprimanded for that." Thus, facilitators helped participants to face their own fears, at their own pace.

Other data illustrated how facilitators helped participants face their fears as part of emphasizing an individual's personal growth and confidence. Kira (E2) explained that she told a participant with anxiety about an activity, "[y]ou don't have to do anything you don't want to do, we're going to encourage you to go as far as you're comfortable going. We're not going to force you." During another field observation at the ropes course, I observed Jake recognize that a participant had faced his fear of heights. This participant had advanced only a few steps up the phone pole before coming back down. Jake praised him for pushing himself out of his comfort zone. This observation showed that participants had the real opportunity to grow and build their confidence.

\section{Theme 3: Countering difficult home or environmental influences.}

Although each Youth Odyssey participant was different, most employees and multiple parents discussed challenges participants faced relating to a difficult home life and environmental influences. Jake (E3) noted that participants "have to deal with the issues that are going on here [in the Corpus Christi community]. With the higher amount

of drug use and teen pregnancy and people leaving school; and it is something they swim upstream against." Kathryn (E4), who has spent over 10 years working within this community, explained that "crime [and] violent behavior is higher in [this] county than most of Texas and most of the nation." She suggested that some participants believed incarceration was an inevitable part of their futures, reasoning, "[w]ell, my mom and dad went to prison so I'm probably going to go to prison too." Lack of parental attention was another common issue. Jake (E3) suggested that some parents were too busy to notice 
what was going on in their children's lives, while others were unreliable. Brian (P4), a former participant, explained that growing up, "my dad was still in and out of my life." He believed that his father did not care about him and knowing that "kills your confidence."

Multiple facilitators suggested that a non-traditional family structure or difficult home life could had negatively impacted a participant's development. A difficult home life, according to Leah (P9), led her to run away as a child, be placed on juvenile probation and finally be referred to Youth Odyssey. Maria (P14) mentioned her niece's difficult home life. "[S]he's orphaned, her mother passed away when she was one, and her father abandoned her." Maria further explained.

She's living with my mom who's in her sixties and she's working full-time now that she has her and...they don't live in [the] best neighborhood...so there's gang violence and...they had drive-bys by their house and others - my mom, they had talked about kids that are not very nice and, you know, there's bullying going on, and so she's definitely affected by her environment.

Leah (P9) felt that participants' difficult family setting caused them to get in trouble. However, she felt that most of the children who misbehaved were "misunderstood, as opposed to troublemakers." Leah (P9) said "society does not know how to deal with them, so they are shunned or pushed aside and they get forgotten about." These difficult home or environmental influences amounted to barriers participants had to overcome.

Youth Odyssey recognized these difficult home or environmental barriers in the development of their programming. The data revealed three distinct strategies associated with Youth Odyssey programming to address these barriers. These strategies included, 
(a) creating a safe environment (physical and emotional), (b) adapting programs to meet the individual needs of the participants, and (c) ensuring their programs were affordable and accessible.

\section{Creating a safe environment}

Kathryn (E4) explained that the organization focused on "at-risk kids, the kids that are underprivileged, underserved," as part of countering difficult home or environmental influences. Kira (E2) understood that Youth Odyssey's program was intended for participants "who might not be around necessarily positive environments at home, [and] to tell them Youth Odyssey is a safe place. They can come here and they can do our activities, and have fun while also making friends." Data revealed Youth Odyssey created a safe physical environment as well as an environment providing emotional support and safety as well. For example, Carol (P5) agreed with Kira (E2), calling Youth Odyssey a place for her daughter to "have a good time." Emily (P7) also agreed with Kira (E2), and she also focused on safety, saying Youth Odyssey was a "safe place" for her daughter to be with friends after school. Kathryn (E4) said "[w]e promise two things in Youth Odyssey: emotional safety and physical safety. And those are things that a lot of our kids don't get in their regular home lives on a regular basis."

Each participant was unique and therefore it could not be assumed that he or she lived in a safe space. For example, in reference to the environmental influences her son grew up around, Patty (P15) said "I didn't want [my son] to be on the streets and getting in trouble. I needed him to have an after school activity [because t]here's a lot of kids out there causing trouble" in her neighborhood. Since joining Youth Odyssey, her son was "not out there [on the streets] getting in trouble, he's [at Youth Odyssey] doing 
something," thus giving him real opportunity to be in a safe space. Brian (P4) explained that, at Youth Odyssey,

...it's like you're a normal kid. You're not a kid that's worried about getting shot, you're not a kid that's worried about getting jumped, you're not kid that's worried about if you're still going to, you know, have a place to live for the month. You know, you're - you're just a kid.

Brian's (P4) quote illustrates that even if that was not their normal environment, participants could come to Youth Odyssey to experience a safe physical and emotional space.

Triangulating data in the form of field observation notes and documents confirmed that no significant physical safety issues occurred during portable team challenges or more advanced programming. At the ropes course, facilitators highlighted Youth Odyssey's clean safety record (Field Note 20, 2017). Direct observations confirmed participants received detailed instructions on the use of equipment proper climbing and spotting techniques, and they learned the signals to use to help keep one another safe during the belaying process (Field Note 20, 2017; Field Note 36, 2017). Youth Odyssey also had equipment and clothing available onsite at the ropes course to provide to participants who became cold (Field Note 36, 2017). Documents showed that Youth Odyssey had put in place policies and procedures regarding incident reporting and when to call emergency services (Youth Odyssey Policies and Procedures Manual, 2005). Data also confirmed facilitators were all trained in first aid (Field Note 20, 2017). These efforts made Youth Odyssey a physically safe environment (see Appendix E). 
In addition to a safe physical space, data illustrated that Youth Odyssey also supported an environment providing emotional safety. Brian (P4) felt Youth Odyssey gave participants "a place to vent, and to talk about life in general." Kathryn (E4) explained that many participants were afraid to face a parent at home because of the possible consequences. "[I]f they mess up, who knows how their parents are going to react." However, at Youth Odyssey, "if you mess up, we are not going to lambast you...it's a safe place.” Kira (E2) agreed, saying Youth Odyssey created an environment that gave participants "a chance to actually relax and be a kid, make mistakes."

In addition to creating an emotionally safe and relaxed environment, Kathryn (E4) stressed that facilitators sought to further cultivate a safe space by building an emotional bond with participants. "We are actually interested in [participants'] lives, not just surface level stuff, we get deep with the kids." She went on to expand on the importance of being engaged in participants" lives because "[t]hey know that somebody cares and that somebody believes in them." Brian (P4), having been a former participant, supported Kathryn's assertion that facilitators create an emotional connection as part of a safe emotional space. "[T] hey believed in me when a lot of people [in his life] wouldn't of [and were] somebody that genuinely cares...they want to see you succeed." Lynn (P11), having been involved with Youth Odyssey as a parent for over five years, brought a different perspective. She complemented facilitators, saying, "I've never seen such just utmost patience, understanding, compassion, empathy, and they're able to take the worst situation and just make it a good-go for everybody." This data helped illustrate the safe emotional space Youth Odyssey created for participants. 
Other data located in Appendix E supported the finding that Youth Odyssey prioritized creating physical and emotional safety. The Youth Odyssey manual cited fostering an "atmosphere of trust, safety and respect between participants and instructors" as an objective of programming (Youth Odyssey Soft Skills Manual, p. 23). Further, field observations illustrated that Youth Odyssey fostered physical and emotional safety through facilitators' actions while on-site and their interactions with participants. For instance, I witnessed facilitators inspect participants' harnesses and safety equipment at the ropes course prior to allowing participants on any element (Field Note 20, 2017; Field Note 36,2017 ), and facilitators often walked the grounds before a portable team challenge. In terms of emotional safety, it was a common occurrence for facilitators to receive hugs and other signs of affection from participants. Notable occurrences often came at Home School Program A (Field Note 17, 2017). Hugs were such a common event that, while going over the Youth Odyssey policies and procedures handbook during a new employee orientation session, Kathryn explained that the organization's policy was to do side hugs and high fives - no direct hugging (Field Note 8, 2017). Maria (P14) summed it up by saying facilitators "created a relationship where the kids feel comfortable and safe."

\section{Adapting programs to the individual needs of participants}

Data revealed Youth Odyssey countered participants' difficult home or environmental influences by recognizing and adapting its programs based on participants' unique needs. Although the organization had materials describing the nature and goals of each program activity, facilitators delivered lessons in a flexible manner by respecting participants' feedback. "We don't really teach from a set curriculum," explained Sam 
(E1). “They don't give me a script, I'm not using someone else's words, [Jake (E3)] is not using someone else's words, when we do a game, or when we do an activity and we debrief on that game and we give insight." Kira (E2) explained that facilitators "are always adapting" a program to accommodate participants' needs. The feedback Kira (E2) received from her group dictated what she taught and how she taught the program for that day. Her lesson plan "changes every single time," and thus "every day, it's different with Youth Odyssey."

Facilitators recognized that participants come from different environments and are subjected to a variety of influences. Kathryn (E4) said "everyone is different." Thus, according to Kira (E2), "[t]he group dictates everything about the program...If the group just is not getting a concept, I'm not gonna hammer it down their throats." Instead, Kira (E2) said she will choose a different skill to focus on and return to the topic giving participants trouble at a later time. Programs were also adapted based on its location and makeup. Facilitators suggested a program's location (e.g. a community-based, middle school, or home school program) could impact the approach utilized by a facilitator. Field observations confirmed that participant feedback dictated the program's pace and that facilitators respected the feedback.

\section{Ensuring programs are affordable and accessible}

Data also revealed Youth Odyssey countered participants' difficult home or environmental influences by designing and delivering programs in an accessible and affordable manner. Some participants came from a family that lived on a tight budget or were unable to attend programming because the family lacked reliable transportation. Youth Odyssey made portable team challenges and other experiences accessible to 
participants by offering them at little to no cost and holding them in convenient locations such as schools or community developments. Making these opportunities accessible meant participants could progress through the program and unlock the other opportunities and experience something that would normally be unfeasible.

Sam (E1) compared the benefit of portable team challenges to his childhood experiences from the Boy Scouts, explaining that they were similar but that Youth Odyssey took care of the cost. "I paid thousands of dollars over the time I was in [the Boy Scouts]. This is free. I've never seen anything like it. They don't pay a dime, we pay for food, we pay for everything." Brian (P4) explained, that growing up as in a lowincome family, Youth Odyssey helped him overcome his difficult home life by giving him "the opportunity to go do what other kids do, go be a normal child... and go have fun, experience life..." For those where money was an issue, Youth Odyssey negotiated the financial barrier that prevented them from receiving an opportunity to experience what many normal, middle class children enjoyed.

Youth Odyssey raised funds through securing grants and donations to facilitate programming for participants who came from families that could not afford the program. Part of Kathryn's (E4) job was to apply for grants and solicit new avenues of funding. One such grant Youth Odyssey routinely obtained was a $\$ 40,000$ community youth development grant with the City of Corpus Christi to work with participants from certain at-risk zip codes (Field Note 8, 2017). In addition, Youth Odyssey ran its own fundraising campaign by partnering with the "Coast Bend Day of Giving." In 2016, Youth Odyssey raised $\$ 34,133.16$ through this event; in 2017 , that number jumped to \$42,617.55 (Day of Giving Results Are In, 2017). 
In addition to granting, Youth Odyssey routinely signed contracts to put on its programing. For instance, Youth Odyssey signed a memorandum of understanding to offer their community-based program and the middle school program for free (Memorandum of Understanding Between Youth Odyssey and Independent School District, 2016; Memorandum of Understanding Between Youth Odyssey and Home School Organization, 2016). This document, similar to those signed with other partner organizations where Youth Odyssey delivers programming, established the duties owed to each side, and the cost structure for the program (Memorandum of Understanding Between Youth Odyssey and Home School Organization, 2016). The school-based programs were paid for by the school district; however, for Youth Odyssey's homeschool program, the memorandum of understanding between the parties required participants to pay $\$ 20$ a month for the first youth, $\$ 15$ a month for a second youth, and $\$ 10$ a month for a third youth in the same family (Youth Odyssey/HUT Memorandum of Understanding, 2016). Other than these dues, participants across every program did not pay anything else for the opportunities that Youth Odyssey offered. Therefore, even for those participants who were required to pay, Youth Odyssey provided opportunities and experiences that far exceed the value of what was charged.

Data also identified the importance of reliable transportation to the accessibility and affordability of Youth Odyssey's programs. Some families lacked vehicles or the ability to transport their children. To remedy this, Youth Odyssey purchased a commercial van. Having its own vehicle allowed Youth Odyssey to transport participants out of Corpus Christi and South Texas to give them a different perspective. Sam (E1) highlighted transportation as an important way Youth Odyssey made programs 
accessible. Sam (E1) said "we come to them," which made participating in programming convenient. By having transportation available, several facilitators felt it lessened the likelihood of participants saying "no" and caused more children to sign up for Youth Odyssey.

\section{Summary}

This study identified (a) barriers that participants faced related to absent or inconsistent adult role models and the disruptive influences from peers, (b) barriers connected to a fear of failure or of being vulnerable, and (c) barriers related to a participant's difficult home or environmental influences. Youth Odyssey helped negotiate barriers participants faced related to a lack of role models or disruptive influences by reflecting positive role models and social behaviors through facilitators and Youth Leaders, who served as role models to positively influence participants. Facilitators and Youth Leaders also held participants accountable for their actions through consistent practices of accountability and rewards. Participants also faced barriers related to their personal growth due to a fear of failure or of being vulnerable. To diminish this barrier, facilitators established trust with participants as a foundation to build relationships together, giving facilitators the ability to push participants out of their comfort zone, to help them to face their fears. Youth Odyssey also countered difficult home or environmental influences that served as barriers by creating a safe physical and emotion space for participants, recognizing and adapting programs based on participants' unique

needs, and designed and delivered programming in an accessible and affordable manner. 


\section{RQ3: What capabilities are Youth Odyssey creating for its participants?}

Capabilities "are real opportunities for beings and doings" (Robeyns, 2017, p. 171). In other words, capabilities are a person's real freedoms or opportunities to accomplish an activity (raising children or driving in a car) or state of one's being (being nourished, being healthy, or choosing to fast) without being restrained or having to fight through obstacles (Robeyns, 2017). A person can actualize an activity or behavior if $\mathrm{s} / \mathrm{he}$ chooses to do so. A person has a meaningful choice as whether she chooses to pursue more complex aspects of life or chooses not to; the important aspect is that it is her choice. In other words, she possesses agency - the ability to accomplish what she values.

For example, a person can choose whether to have a child or refuse nourishment through fasting. In these examples, she is not unable to conceive a child or consume food. She possesses the freedom, the meaningful choice, whether or not to have a child or to eat a meal. Thus, capabilities can be more complex because a person has the real freedom and opportunity to pursue such a goal. The capabilities most commonly exhibited in Youth Odyssey materialized around cognitive and social skills. This appears appropriate, since Youth Odyssey as a program emphasized cognitive and social skills and thus it was likely the capabilities it created would be similar in nature. In this study, three classes of capabilities emerged: (a) Choice to exercise agency through increased self-awareness, self-reflection, and perceptions of self-determination, (b) Opportunity to hone social skills, and (c) having the freedom and ability to access support and resources. These themes are listed in Table 7.

\section{Table 7}




\section{Summary of created capabilities}

RQ3: What capabilities are Youth Odyssey creating for its participants?

Theme 1: Choice to exercise agency through increased self-awareness, self-reflection, and perceptions of self-determination

Theme 2: Opportunity to hone social skills

Theme 3: Having the choice to access support and resources

Theme 1: Choice to exercise agency through increased self-awareness, selfreflection, and perceptions of self-determination.

Participants could choose different opportunities that helped them develop a greater understanding of what was possible to do and be in life. Participants had a choice of whether or not they wanted to take part in opportunities that expanded their awareness of what was possible and discovering new passions. These opportunities were offered through Youth Odyssey's curriculum. Kathryn (E4) described these opportunities as “opening minds and expanding horizons.” Youth Odyssey’s goal, according to Kathryn (E3), was to "show them there is a bigger world out there and that whatever they want to do, whatever they want to accomplish in their lives, they can do it!” Through this awareness, children could increase the amount of control in their life.

This was a capability because Youth Odyssey participants could explore these different opportunities and reflect on what they offered. Ultimately it was each child's choice to further pursue these different opportunities. Alice (P2) believed Youth Odyssey helped her children become who they wanted to be because "they've learned to discover themselves. Their strengths, and they show them new experiences, so I think through this, they'll give them goals and things to set for them." Through this reflection, participants could learn about what was out there for them to do and accomplish. Then they had the 
choice of actualizing these options. Thus, as Alice said, participants are given the meaningful opportunity to take greater control of their respective lives. Youth Odyssey listened to what participants were interested in achieving, and then helped to create the ability to pursue and achieve what they valued.

Several parents believed Youth Odyssey helped to open participants' eyes. Maria (P14) felt Youth Odyssey helped her daughter realize that she was "capable of doing so much," and Lynn (P11) believed Youth Odyssey gave participants the real opportunity to realize "there's more past the point of their own nose." In other words, participants could use what was presented at Youth Odyssey to look beyond what was going on in their dayto-day lives, to become aware of what was out there. Youth Odyssey then, through its curriculum and approach, gave participants the choice to follow up on their curiosities. For Leah (P9), Youth Odyssey gave her daughter the real opportunity to "pursue what she wants to do, instead of hanging back and being scared to make that step forward." Leah's daughter had choice.

\section{Free to change perceptions of what is possible in life}

Through Youth Odyssey programming, participants became aware of new activities and accomplishments that they did not previously know was possible. As Kathryn (E4) said, Youth Odyssey provides different resources and perspectives that enable participants to re-evaluate what is possible in life. She said "we are asking questions; 'what do you want to do? How are you going to do this? Why are you doing this?' You know? And it gets them thinking." Kathryn hoped this line of questioning help participants to think "about their lives. 'What is it that I want to do? What do I want to accomplish? What is my purpose here?' And then, pointing them in the right direction, 
and giving them assistance if needed along the way," as part of providing participants with an opportunity to pursue and achieve the desired outcome. Participants became aware of these different opportunities, and could then reflect on what is possible and what they wish to pursue. Danielle (P6) felt Youth Odyssey gave her daughter "that freedom or that choice...[which] helped her see how much she can do...she's not limited." In other words, her daughter had a choice to change her perceptions of what was possible in life; she used Youth Odyssey to actualize an understanding that there were a range of potential things she could do and be, and that she could choose what opportunities to pursue.

Partaking in Youth Odyssey activities enabled participants to understand that the world was bigger than their home town. Brian (P4), as a former participant, credited Youth Odyssey for "let[ting] me know, 'man, there's so much more out there than just this town.' There's so much that I can see, so much that I can do, and I'm not limited [in what you can do]." Brian realized he had the real opportunity to do and be, to actualize different experiences he previously did not believe was possible. He said Youth Odyssey ...taught [me] you really can do a lot of stuff. You're not limited to what you think you can do, or you're not limited to what people tell you that you can do, you're not limited by what people tell you you're going to become just because of where you from.

Brian's quote captures the choice he had to act on what he valued; through Youth Odyssey, he discovered his own self-worth and agency. Kira agreed with Brian's statement about self-worth. She felt Youth Odyssey would be successful if participants "realiz[ed] that they are worth more and that they can do more."

\section{Real opportunity to explore new interests}


Youth Odyssey used portable team challenges, ropes course, and camping trip elements as a hook to kindle participants' interests in the organization and what it offered. Brian (P4) said "you don't know if you're gonna like camping until you try it." Lynn (P11), jokingly quipped that she was surprised by how much her daughter embraced Youth Odyssey's outdoor activities. She said her daughter, “our little priss [would], sit in a room play Barbie's, read. Who'd ever thought that she would put on a pair of hiking boots and go out, go brush stomping, camping, getting dirty, come home with dirt under her nails?" Although trying to be funny, Lynn illustrated an important point how participants could choose to meaningfully pursue new interests that they had not previously known about.

Jake (E3) discussed how providing a participant with the opportunity to try new things led to her exploring many new interests. Now in high school,

...she started up a whole bunch of clubs, she loves anime, she loves cosplay, she helps run a library club now, she puts on in December, they had like a winter formal that was Harry Potter themed that she helped put on.

Jake said her time in Youth Odyssey had "given her the ability to take her passions and show them to other people and find other people who are interested in them and then do more stuff." Fulfilling her passions started with what she learned at Youth Odyssey.

Documents such as Youth Odyssey training manuals and program reports detailed that participants were presented with opportunities to engage in different experiences outside of the three core stages of programming. Youth Odyssey intentionally allowed participants to select from a range of diverse programs, thereby providing children with opportunities to create an experience unique to their needs or interests. Youth Odyssey 
also routinely offered programs that included trips to a community garden, local farms, local kitchen, helping with community projects, surfing, kayaking, canoeing, snorkeling, scuba diving, rock climbing, and attaining a CPR certification. Participants had the choice of coming to Youth Odyssey for something as simple as the opportunity to occupy their free time at a portable team challenge to keep them from becoming bored or getting into mischief. However, children had more meaningful choices, such as the freedom to build outdoor skills or discover and develop their passions. These experiences, in addition to being novel, also gave participants the opportunity to envision new things they could be and do in life.

Triangulating data from field observation notes, documents, and artifacts also illustrated that participates increased their perceptions of self-determination through discovering new passions. For instance, an article posted on the Youth Odyssey website recounted a Youth Leader's experience with Majesty Outdoors. The goal of Majesty Outdoors, a nonprofit, was to give children from homes with a single mom memorable hunting or fishing experiences and mentor participants from a religious perspective (Youth Odyssey, 2017). Youth Odyssey and Majesty Outdoors formed a partnership to create an opportunity for those Youth Leaders who wished to participate in such activities. Children choosing to participate discovered new passions such as hunting, fishing, and spirituality. The interview indicated that the Youth Leader's experience with Majesty Outdoors sparked an interest in exploring his faith and to engage in personal reflection (Youth Odyssey, 2017). Each of these experiences opened new doors for participants to increase their perceptions of what was possible in their lives. 
Youth Odyssey's diverse range of experiences helped open a variety of doors for participants. They also served to kindle passions within participants. Jake (E3) felt these experiences helped participants understand that "there was more out there."

\section{Theme 2: Opportunity to hone social skills.}

Youth Odyssey created the choice for participants to hone their social skills through the organization's programming. Social skills referred to six values, communication, trust, problem-solving, teamwork, goal-setting, and leadership, which were taught through Youth Odyssey's programming. Participants could choose, once learning about these social skills, whether or not they would utilize them in their lives. For instance, Sam (E1) believed participants fostered the capability, meaning they would have the real opportunity, to become "successful adults" using their social skills. Sam (E1) referred to this as the meaningful opportunity participants will have in society to become "the leadership of tomorrow."

We're talking about junior high kids who are growing up to one day become responsible adults, and responsible parts of society, and we want to do our part to instill in them these basic core values that we think can help them be successful adults.

Parents and guardians also discussed how Youth Odyssey participants could choose to hone their social skills. Rachel (P16) explained that "Youth Odyssey definitely gives a wonderful opportunity for the kids in the home school group to get together and socialize." This opportunity is for participants to become progressively more sophisticated in their social skills development. 


\section{Opportunity to achieve more sophisticated teamwork, communication, and}

\section{problem-solving abilities}

Data indicated that participants were presented with the opportunity to improve their social abilities, most commonly those related to teamwork, communication, and problem-solving. Jake (E3) recalled a conversation with a parent that served as an example of participants whose chose to improve their social skills. In this story, the parent noticed that her three sons no longer fought as much after participating in Youth Odyssey for an extended time period. According to Jake (E3), the parent observed, " $[\mathrm{m}] \mathrm{y}$ boys used to fight all the time, but since being in your program, they wouldn't fight as much." Instead of fighting, the boys choose to "do a lot conflict resolution and talk to each other about what the problem is and then sort it out without throwing each other across the room." This may illustrate that the boys exercised an opportunity to hone their social skills after joining Youth Odyssey. In other words, they chose to use their social skills to resolve their conflict.

Another example of a participant who exercised her opportunity to become more sophisticated using communication and problem-solving skills was Michelle's (P13) daughter. Michelle (P13) recounted a story where the family went out to eat and her daughter was dissatisfied with her meal. Instead of staying quiet about this, which she historically did, Michele (P13) and her daughter "walked up there together and she asked, [after explaining the problem to the server] real nicely," and she got the order fixed. In this instance, Michelle's daughter chose to use her communication and problem-solving abilities to get her order changed, which she had not done before enrolling in Youth Odyssey, and it left an impression on Michelle. 
Other data also supported the interview findings. Program reports, short narratives of a program from a facilitator's perspective, provided a detailed window into a participants' development from beginning to end. It was common for these reports to document a group's progression, and customarily focused on participants' improvement throughout the program. Reports often detailed how participants developed their social skills. One 2016 program report from Middle School D written by Kira (E2) highlighted the progression of the group. Kira's (E2) report chronicled participants' development as they became more sophisticated at performing various social skills. She went on to say that a majority of the participants felt "they found their voice through Youth Odyssey. Most of them noted that communication skills and teamwork were the two big things they took away from the programs." As Kira (E2) noted, the participants gained the ability to pursue goals they valued - in this instance to hone their communication and teamwork skills.

Another example helped illustrate participants exercising their freedom and real opportunity to utilize their social skills. During a home school portable team challenge, Kira (E2) tasked a group of six females and two males to complete a challenge that involved everyone touching each other at the same time. After several unsuccessful attempts, the participants paused to discuss forming a strategy. Although they formed a coherent strategy, it failed. Kira (E2) stopped the group and asked them to think more strategically. Several participants chose to take a leadership role. The subsequent strategy led to the group quickly succeeding, to the surprise of Kira (E2). This observation illustrated that the group chose to exercise its ability to use problem-solving, 
communication, teamwork, and leadership skills to solve this game presented to them in the portable team challenge.

\section{Freedom to make meaningful personal changes through attaining social skills}

Data indicated that, once they became aware of new things they could accomplish, some children chose to become different people. Youth Odyssey played a role in some participants choosing to make meaningful personal changes in their lives because of their social skills. Jake (E3) felt that those children who chose to use their social abilities to make changes in their lives would become more successful people. To Jake (E3), those who did so "grow up and make good choices." They do "[t]hings that don't land them in jail, things that put them on a path to success, whatever version of success may be, things that contribute positively to their lives and others." Jake (E3) said some participants told him that "they are making better choices in life because of what they've done and seen in Youth Odyssey." Choosing to use these skills meant a participant would become more adept at navigating society and make changes in their lives.

Some parents also discussed recognizing changes in their children after participating in Youth Odyssey. Lynn (P11), similarly to Jake's comment about choices, focused on changes in the decision-making for her daughter. "I really noticed a great difference... [in my daughter]... since she started participating." Lynn (P11) felt her daughter "was always the follower, never the leader. And now she's a little more independent on her thought and action and, weighing things out more carefully before her responses." Alice (P2) also described the changes she witnessed in her son. She said before enrolling in Youth Odyssey, her son "was not as outgoing as he is, he was very 
shy. Now that boy won't stop talking, he's so confident, he knows what he wants." Alice (P2) said her son 'would always say 'whatever you want mom, whatever you want.' It was always whatever I want, but now he tells me what he wants now. He's becoming very assertive." Youth Odyssey seemed to play a role in some participants developing social skills and changing the way they thought and interacted with others.

Other participants chose to accept the opportunities Youth Odyssey provided. Brian (P4) explained that Youth Odyssey played an important role in changing his attitude and outlook on life. Promotional materials described stories about former participants' accomplishment after graduating from Youth Odyssey, crediting the person's growth at Youth Odyssey as the catalyst for success. Kathryn (E4) discussed a participant's growth from a troubled youth to one who become less angry and went on to a successful military career. She believed that Youth Odyssey played a role in the person's success. Kathryn (E4) also mentioned other examples of meaningful changes in participants because they chose to exercise the choice to develop their social skills through Youth Odyssey's programming:

Seeing kids go from quiet, young lady in sixth grade, whose seventh-grade brother overshadows her, not answering questions, to graduating second-incommand of her ROTC unit in high school. I've seen young ladies go from a flirtatious young woman in middle school and high school, having relationships left and right, to having a career as a medical assistant and making the most of her life, making better decisions for her life.

Triangulating data also illustrated participants who chose to utilize an opportunity to make meaningful changes through attaining social skills. For instance, a portable team 
challenge program report from middle school $\mathrm{F}$ written by Jake (E3) described his initial impressions of the group as "a little disjointed and all over the place." But over time the group chose to become more focused and accomplish the tasks. At another portable team challenge, this time middle school G, Kira (E2) wrote in her report that saw "growth in other kids who have become more outgoing, willing to participate and speak up with their ideas." These reports supported the interview data.

\section{Theme 3: Having the choice to access support and resources.}

Youth Odyssey played an important role in creating the choice for participants to access support and resources as part of belonging to the program. Danielle (P6) pointed out that participants had a choice and referred to it as a freedom. She felt Youth Odyssey provided participants with "the freedom to choose if [participants] can make certain events. It's not like it's a mandatory type of thing." Leah (P9), the former participant (P9) served as an example of a participant who chose to access Youth Odyssey's support and resources. She said, "it's awesome...I loved it, I always wanted to be there every weekend, I was gone. I never was home for the weekend, I always went on the camping and everything."

Leah (P9), a former participant, felt Youth Odyssey "gives you so many different opportunities to learn different things in life." She explained to her daughter the benefits she could choose to derive as a child and encouraged her daughter to participate. "All the activities to do...some of the things that we did, the camping, the trips to Goliad, all that, and I told her if she was interested then of course to go for it." Leah (P9) felt Youth Odyssey played an important role in giving her a real ability to achieve new states and 
experiences. "You get a lot out of it if you take what's given." As Leah emphasized, it was up to the participant to "take what's given;" this connoted choice.

While Leah (P9) was drawn to Youth Odyssey for monetary benefits, she felt her daughter primarily chose to attend because of the intrinsic aspects. She said her daughter is going through "certain situations" that are "really hard for her. This is where she's turned to, [Youth Odyssey], to release some her emotion, and...[she] takes it out on her ropes course...she's also finding peace in it to be able to get through what's bothering her." Building on Leah's example involving her daughter, Kira (E2) believed that Youth Odyssey gives participants the choice for "a mental escape" if a participant would rather be anywhere than home... [such as] at a ropes course, at a program or a camping trip."

Maria (P14) was grateful for the non-economic aspects of the organization. She felt participants could access emotional support. Maria (P14) said, "it's important to have people who are there supporting you, which Youth Odyssey, I know [does]. I mean, the way they build relationships with the kids it's...a lifelong friendship." Both Leah and Maria explained aspects related to Youth Odyssey playing a central role in giving participants the real freedom to access support and resources.

Although facilitators played a major role in creating the conditions necessary to give participants the choice of whether or not they wanted to access support and resources, others were also involved. Youth Leaders, board members, and partners outside of the organization also worked to create opportunities for participants to access, whether it was funding, specialized knowledge, or specialized access. In some cases, this support went so far as taking participants (usually Youth Leaders) on trips to far-away locations such as the Caribbean and/or receiving additional mentorship from Youth 
Odyssey facilitators and/or affiliated people/organizations. Having access to this support, in turn, created more life choices for participants because more opportunities that participants could meaningfully access if they wished.

\section{Creating a support system}

Youth Odyssey offered a support system that participants had the ability to access. For Jake (E3), support meant listening to participants so they knew "that there is someone out there who is interested in what they are doing." Sam (E1) believed Youth Odyssey's support system was intended to show participants "there's someone on your side, that you have someone who encourages you, who sees potential in you, wants to see you succeed, and is willing to apply effort and time to ensure the possibility of your success.” Brian (P4), as a former participant, was grateful for Youth Odyssey's support system and statements like Sam's (E1). He said, “it really helped to hear that [a facilitator] genuinely cares about you, genuinely tells you, 'hey, you're better than that."' Brian (P4) explained that he was constantly bombarded with negative influences growing up, and that having the choice to turn to Youth Odyssey for support improved his life - it saved him from going down a darker path.

Sam (E1) explained that he believed Youth Odyssey’s support system was important for participants like Brian (P4). When comparing two children - one that chose to participate in Youth Odyssey, and the other who did not - Sam (E1) explained, what I think separates the average everyday person who's not participating in this program, let's say specifically in this community, from someone who is [participating in Youth Odyssey], is that there is a group of people, being the people who work here, and the board that supports us and the donors that support 
us that are actively giving time, and putting in effort to make sure that you succeed. You have a support system, and I think that's a very important part, otherwise you doing it on your own.

Sam felt that others who do not participate in Youth Odyssey lacked the real freedom and opportunity to access a support system. Brian (P4), as someone who did not have support growing up, appreciated that participants did "not hav[e] to do anything to be accepted" into such a support system. Youth Odyssey gave participants the ability to feel accepted and supported, which they could achieve by joining in the program and following its rules.

Having the meaningful opportunity to access a supportive space resonated with Carol (P5). She said Youth Odyssey gave children "a place to come together, twice a month and have a good time, [and] be heard;" it was up to the kids to take advantage of this opportunity. Beyond simply being heard, Jennifer (P8) appreciated how facilitators "encourage[d] her" daughter. Jennifer (P8) recalled that one facilitator told her daughter "you can do whatever you want to do and be whatever you want to be." Thus, participants could have their ideas validated through the support system.

Some participants chose to participate in Youth Odyssey explicitly because of the group mentality. Emily (P7) said her daughter goes to Youth Odyssey programming because of "the mentorship part. She loves to work with the other kids." Brian (P4) said his son chooses to participate in Youth Odyssey because it means he is "being a part of a group that's bigger than him... it's bigger than you. It's not about you...it's about each other... You're there for each other." These quotes evidence that participants had a 
meaningful choice - that they exercised their agency to be a part of Youth Odyssey and achieve receiving mentorship and mentoring others.

Reinforcing the notion that Youth Odyssey created a support system for participants to access, Kathryn (E4) explained that participants could also access other benefits based on what s/he chose to embrace. Kathryn said if "an individual needs help with maybe resume writing, or they want to know more information about maybe being a contractor, then we will hook them up with one of our board members or a volunteer." That board member or volunteer would then tell the participant, “"ok this is the opportunities that you have for this line of work or for this passion." Thus, Youth Odyssey would provide more real opportunities for participants to actualize. Participants had the real opportunity to take greater control of their respective lives because Youth Odyssey listened to what participants were interested in achieving. Once knowing this, Youth Odyssey then helped to create the ability to pursue and achieve what participants valued by connecting them with others within the Youth Odyssey network would could help make their desires a reality.

Triangulating data such as field observations confirmed that Youth Odyssey provided participants could access a support system. A program report from Middle School D noted that participants "encourage[ed] one another to complete tasks." Youth Odyssey's training manual also encouraged facilitators to "reinforce positive behavior, create positive environments," and that "[e]veryone [in the group] works actively to set a supportive environment."

Other data also provided examples of participants having the choice to access resources based on their desires. During a field observation at an employee meeting, Jake 
(E3) discussed with Kira (E3) and Kathryn (E4) that he had asked Youth Leaders what they would like out of Youth Odyssey, at this point of their involvement. Jake explained that the list was as follows: (a) how to do taxes, (b) college prep, (c) how to fill out college applications, (d) how to apply for jobs, (e) how to fill out your resume, (f) how to find an apartment, (g) self-defense classes, (h) how to make money as a child, (i) ropes courses, (j) Job interview/application, (k) Buying a car, (1) Buying a home, (m) engineering, (n) cooking class, (o) budgeting, (p) house payments, and (q) gardening. The employees spent the rest of the meeting discussing how to integrate these ideas into future Youth Odyssey events.

\section{Financial benefits}

Youth Odyssey funded a range of opportunities that allowed participants to engage in new experiences that would not had been readily accessible These experiences helped to reinforce the different support aspects of Youth Odyssey, such as mentorship, stress release, and the Youth Leader Program. Jake (E3) said "we give them more opportunities to try things...just getting them more exposed to different things that they wouldn't normally do." Jake (E3) went through the list that, in addition to the ropes course, and camping portable team challenges, also included Youth Odyssey's summer camps. Youth Odyssey subsidized the costs of these activities either entirely or for the most part. It was up to the participant and the parent to decide whether to actualize the opportunity.

\section{Summary}

Based on interviews, observations, and documents, the data suggested Youth Odyssey created capabilities for participants that involved (a) the choice to exercise 
agency through self-awareness, self-reflection, and perceptions of self-determination, (b) the opportunity to hone one's social skills, and (c) having the choice to access support and resources. Facilitators helped participants expand their understanding of what was possible to do and be and uncovering new passions. Participants could then choose to hone their social skills through participating in Youth Odyssey's programming, and some participants chose to achieve meaningful changes in their lives due to their improved social skills. Youth Odyssey gave participants the choice to access support and resources that included physical/emotional/financial support and mentorship opportunities, which made up a support system for those who chose to attend.

\section{Summary of Results}

SDP has become a popular approach to development, however critical scholars remain skeptical of its effectiveness, or pairing it with the belief that sport can solve all the world's issues (Coakley, 2011; Coalter, 2010; Darnell, 2007; Hayhurst, 2013). Critical scholars suggested pursuing a framework that utilizes a more holistic approach that is locally grounded and listens to the individual voices of those they wish to serve (Hayhurst, 2013; Spaaij \& Jeanes, 2013). One possible framework is the Capabilities Approach. This case study included interviews, field observations and document/artifacts to holistically analyze what role an SDP program located in the Southern United States, Youth Odyssey, played in participants achieving their capabilities. Youth Odyssey was the focus for the case study.

In RQ1, which asked what functionings are being supported by Youth Odyssey, (a) being more comfortable and capable in social settings and interactions, (b) using logical reasoning and analytical skills, (c) being part of a community, and (d) doing new 
activities and experiences emerged as themes. For RQ2, which asked how does Youth Odyssey help remove barriers for participants, the study identified (a) barriers that participants faced related to absent or inconsistent adult role models and the disruptive influences from peers, (b) barriers connected to a fear of failure or of being vulnerable, and (c) barriers related to a participant's difficult home or environmental influences. Youth Odyssey helped to negotiate these barriers participants faced by (a) reflecting positive role models and social behaviors, (b) emphasizing personal growth and confidence, and (c) countering difficult home or environmental influences. Finally, in RQ 3, which asked what capabilities are Youth Odyssey creating for its participants, the data suggested Youth Odyssey created capabilities for participants that involved (a) the choice to exercise agency through self-awareness, self-reflection, and perceptions of selfdetermination, (b) the opportunity to hone one's social skills, and (c) having the choice to access support and resources. See Figure 2 for a flowchart of the Capabilities Approach in this case study

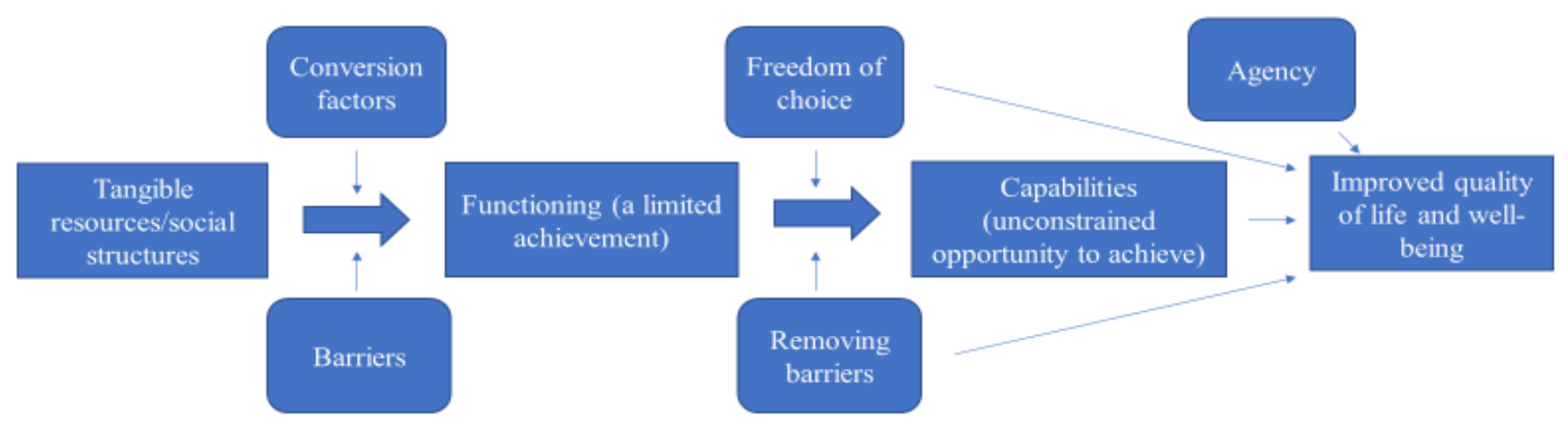

Figure 2. Flowchart of the Capabilities Approach based on case study 


\section{CHAPTER V}

\section{SUMMARY AND DISCUSSION}

SDP has become a popular approach to development due to the inherent attractiveness of using sport, play, or physical activity as a vehicle to facilitate social change. However, critical scholars remain skeptical of SDP's effectiveness, particularly programs that are premised on the belief that sport serves as a remedy for all of society's problems, or that operate according to values that are out of step with program participants' ideals (Coakley, 2011; Coalter, 2010; Darnell, 2007; Hayhurst, 2013). The field needs a theory that is well-suited to implement the wide-ranging objectives of the many SDP organizations and addresses criticisms that question the general belief that sport can be used as an effective tool to solve societal problems (Welty Peachey, 2015).

Critical scholars suggest pursuing a framework that utilizes a more holistic approach that is locally grounded and listens to the individual voices of those they wish to serve (Hayhurst, 2013; Spaaij \& Jeanes, 2013). Welty Peachey (2015) wondered whether an overarching theory of SDP exists that could account for the varied contexts associated with the field and its cultural complexities. SDP practitioners must develop tools for program evaluation and design that are sensitive to local context, values, and voices; the Capabilities Approach may provide such a model to achieve this goal. Svensson and Levine (2017) suggested, because it highlights understanding what is important to those in the local community, the Capabilities Approach could be explored as a framework to incorporate the suggestions made by critical scholars. Therefore, the 
purpose of this study was to apply the Capabilities Approach in exploring what role an SDP program located in the Southern United States, Youth Odyssey, played in participants achieving their capabilities. The following three research questions assist in addressing the purpose of the study:

RQ1: What functionings are being supported by Youth Odyssey?

RQ2: How does Youth Odyssey help remove barriers for participants?

RQ3: What capabilities are Youth Odyssey creating for its participants?

This chapter is organized into four sections: (a) summary of significant findings, (b) theoretical implications for SDP and the Capabilities Approach framework, (c) implications for SFD practitioners, and (d) directions for further research.

This study applied the Capabilities Approach to evaluate the role Youth Odyssey played in participants achieving their capabilities. The Capabilities Approach evaluates well-being by examining what people can do and be in society (Robeyns, 2011). The theory states that since people's beliefs and aspirations are unique, their interests will differ from person to person (Robeyns, 2011, 2017). The Capabilities Approach's key components in pursuing well-being are functionings, freedoms, and capabilities (Alkire, 2005; Robeyns, 2005; Sen, 2005). The preceding chapter presented the findings of this case study by organizing data into categories to produce a readable account of what took place. This chapter is designed to provide insights and help the reader understand what role Youth Odyssey played in helping program participants achieve their capabilities.

\section{Summary of Significant Findings}

This study resulted in three significant findings: (a) producing functionings and capabilities, (b) theorizing through the Capabilities Approach indicated that Youth 
Odyssey may had accounted for local context, and (c) these findings merit further studies operationalizing the Capabilities. The first finding relates to conceptualizing SDP using the Capabilities Approach as a theory. The study produced data that identified functionings and capabilities, two integral Capabilities Approach constructs, primarily related to socialization. Further, the study produced a list of identified capabilities that related to existing literature (Nussbaum, 2011). This was significant because the study was one of the first to apply the Capabilities Approach to SDP. This study also identified barriers impacted by Youth Odyssey programming. These barriers related to issues identified at the micro, meso, and macro levels (Lyras \& Welty Peachey, 2011; Marshall \& Barry, 2015; Massey et al., 2015). In other words, the challenges that participants faced could be differentiated by whether they were based off a person's personal characteristics (e.g. their health), the community in which he/she lived, or the societal norms that existed.

Second, examining how Youth Odyssey operated using the Capabilities Approach as a framework yielded data that indicated accounting for local context. If a program incorporated local context into a program, it may help identify the changing needs of the population the organization sought to serve (Spaaij \& Jeanes, 2013). Data also illustrated how Youth Odyssey helped mitigate barriers that participants faced through its programming to facilitate meaningful opportunities for participant agency. This finding is significant because it suggested Capabilities Approach, as a guiding framework, may be able to accommodate the variety of uses incorporating sport, play, physical activity, games and similar applications into a program as well as the interdisciplinary nature of SDP as a field (Welty Peachey, 2015). 
Third, since the study produced identifiable functionings and capabilities, these findings merit further studies operationalizing the Capabilities Approach as an evaluative framework in SDP. This further exploration is significant because it would also address the call by Svensson and Levine (2017) to consider different interpretations of the Capabilities Approach, including its usefulness and limitations. Through this process, we can advance our understanding of SDP knowledge by contributing to the literature and improving programs from a practical standpoint. Darnell and Dao (2017) also argued in favor of experimenting with the Capabilities Approach in the SDP field.

\section{Theoretical Implications for SDP and the Capabilities Approach Framework}

\section{Functionings Supported by Youth Odyssey Programs}

Functionings are a person's accomplishments that hold significance to that individual (Robeyns, 2005). Functionings are either states of mind (e.g. feeling wellrested) or activities (e.g. going to school or getting a diploma) that a person achieves (Alkire, 2002a; Robeyns, 2011; Sen, 1999). Since each person is different, and the context in which s/he lives their life, his or her functionings will also differ. This study identified a number of participant functionings, which fell into the following categories related to socialization: (a) being more comfortable and capable in social settings and interactions, (b) using logical reasoning and analytical skills, (c) being part of a community, and (d) doing new activities and experiences. These findings had theoretical implications for both SDP and the Capabilities Approach.

\section{Theoretical implications for SDP}

This study was consistent with prior studies that found SDP programs assisted with socialization for participants to become more effective at functioning in society. The 
findings were also consistent with prior studies indicating that sport was used as a mechanism for social control and discipline. Study results also supported previous research linking sport-based programs to build trust with and provide safe environments for participants. These implications are further discussed below.

This study expanded our understanding of SDP and youth socialization by identifying behaviors related to socialization. Prior SDP studies used sport as a hook to promote specific participant behavior (Hartmann, 2003; Hartmann \& Kwauk, 2011; Kidd, 2008; Schulenkorf et al., 2016). The data in this study identified youth socialization behaviors. Several interviewees believed that Youth Odyssey programming taught participants how to become more comfortable and capable in social settings and interacting with others as part of being a member of society. This finding is consistent with Haudenhuyse et al. (2012), who collected data from a European program that helped use boxing as part of the youth socialization process. The participants in the boxing program were socialized to accept the rules of mainstream society and recognize authority. Part of accepting authority included respecting adults (Haudenhuyse et al., 2012). In the present study, several interviewees believed Youth Odyssey's programming promoted behaviors similar to Haudenhuyse et al. (2012) as part of learning socialization skills that would help participants recognize authority. This in turn would help participants to better function in and accept the rules of society. Haudenhuyse et al. (2012) also found that the sports program steered participants into behaviors that would promote their acceptance of adult authority in society.

The study's findings were also consistent with Burnett (2001) who found that sport was used in part to help facilitate different socialization outcomes. Similarly, here, 
Youth Odyssey chose values for participants to emulate such as communication, teamwork, and leadership based on the organization's viewpoint as part of facilitating a socialization outcome. Youth Odyssey used portable team challenges to facilitate social skills and provide tools to participants that would make them function more effectively in society (Burnett, 2001). This finding supports Massey et al. (2015) who suggested SDP practitioners use an approach of developing programs to be in tune with navigating society. The findings were also consistent with Be (2014) who found a football and peer education program supported participants' socialization and communication skills, leading to increased confidence and communication skills. Thus, the current study's results expanded our understanding of sport and socialization consistent with previous SDP literature.

Another theoretical implication of this study was that promoting socialization behaviors were consistent with Burnett's (2001) finding that sport could be used as a mechanism for social control and discipline. Here, the behaviors that materialized under Youth Odyssey's supervision based on its life skills curriculum also predominately fell within socialization - being more comfortable and capable in social settings as well as being able to use logical reasoning. This was consistent with previous SDP literature that found that SDP programs used conflict resolution alternative as part of promoting cultural understanding and socialization (Hoglund \& Sundberg, 2008). Part of logical reasoning exercises and analytical thinking exercises included allowing participants to go through their own problem-solving process, including conflict resolution, which was also consistent with previous SDP literature (Schulenkorf \& Edwards, 2012). 
The current study's findings also supported Hancock et al. (2013) who commented that sport-based social inclusion programs provide a safe environment for participants to exercise their freedom to socialize and express themselves. The results indicated participants experienced being part of a community that also included elements of trust-building. Building trust and a positive environment showed that facilitators cared about participants and that participants could confide in the group members. Interactions through games and activities helped participants feel a sense of community. SDP researchers found that sport-based programs served as support structures within the community, which were factors that influenced member participation (Burnett, 2001). The findings in this study supported Burnett's (2001) assertion. This study's findings were also consistent with Be's (2104) finding that an environment based on trust was necessary for an individual's development. This finding furthered our understanding of SDP and trust-building as part of creating other outcomes.

Youth Odyssey's focus on diverse experiences presented a different finding from the previous literature. Although prior studies highlighted the importance of specific activities as part of a person's development and fitting into society (Hartmann \& Depro, 2006; Hayhurst, 2013), this was the first study that highlighted a diversity of experiences that also included non-sport activities such as camping, field trips, and community service as common program elements. These experiences were important because not only did they have the ability to keep participants away from bad influences, such as the purpose of "midnight basketball" (Hartmann, 2016), but also participants also discovered new passions outside of sport. These findings furthered our understanding of SDP through other non-sport activities. 


\section{Theoretical implications for the Capabilities Approach}

In this study, I identified specific functionings that Youth Odyssey supported. The study also was consistent with previous research that showed how discovering new activities could ignite a person's passions to further pursue this endeavor. Further, this study advanced our understanding of how behaviors and activities are understood related to children in a more specific context, rather than purely from abstract manner. The findings also related to SDP's search for a theory that prioritizes local context and could also accommodate the varied cultural complexities and contexts associated with the field.

I was able to identify specific behaviors and activities supported by Youth Odyssey. A fundamental aspect of the Capabilities Approach is widening a person's life choices (Sen, 1999), as increasing a person's life choices is a central part of improving one's well-being (Haq, 1995). The essence of the Capabilities Approach is widening what a person can do and be in life, meaning access to different experiences is paramount. This study was consistent with prior Capabilities Approach literature exploring how a program could ignite new passions within a participant through discovering new activities or pursuits (Fukuda-Parr, 2002). This finding supported arguments that the Capabilities Approach connects with what each person values, meaning the theory may be applied in different contexts and to each person in a unique manner based on what resonates with him/her (Clark, 2005a, 2005b; Robeyns, 2003; Sen, 1999).

The Capabilities Approach suggests individuals should engage in a diversity of experiences (Robeyns, 2003). This study identified a variety of activities that could lead to new opportunities for people to pursue as part of developing a life filled with pursuing choices that resonated with each particular person (Clark, 2005a; Robeyns, 2017). The 
Capabilities Approach is intentionally incomplete to be more easily operationalized to other disciplines (Alkire, 2001, 2002a, 2003; Comim, et al., 2008). However, operationalizing the Capabilities Approach to SDP can be somewhat confusing. This is consistent with Alkire (2011), who wrote about the difficulties researchers may encounter in trying to evaluate well-being through abstract constructions that make up the Capabilities Approach. In this study, rather than being fundamentally incomplete and making it impossible to understand what this theory looks like in an SDP setting, there was more of what Alkire (2003) called pragmatic incompleteness. In this instance, the theory is clear enough to continue exploring it in SDP.

Participants' needs, such as a safe space and resources to experience new activities, were met by what Youth Odyssey's programming provided. However, these needs differed by individual based on their own circumstances. One such need was being able to more efficiently navigate or function in society. These were meso-level or macrolevel needs, and were met by learning how to use social, logical reasoning and analytical skills. Previous attempts to conceptualize functionings at the micro-level were abstract (Kinghorn et al., 2015) or generalized (Greco et al., 2015). This study thus advanced our comprehension of identifying functionings in an SDP landscape in a more specific manner. Further, the study identified meso or societal-level constraints a manner similar to Schischka et al.'s (2008) descriptions. This study also advanced our understanding of the Capabilities Approach's application of understanding functionings as they relate to children at the micro level, which Shand (2014) described as limited, due to childhood being a time where most children lack agency. By identifying individual participant 
functionings, the study helped advance our understanding of the Capabilities Approach applied to children, specifically in an SDP context.

The findings also helped to respond to the literature critical of SDP questioning whether one theory could relate to the varied cultural complexities and contexts associated with the field (Welty Peachey, 2015). One suggestion was to conceptualize a program at micro, meso, and macro levels (Lyras \& Welty Peachey, 2011; Marshall \& Barry, 2015; Massey et al., 2015). The Capabilities Approach accounts for conceptualizing person, social, and societal issues that may impact how effectively a person utilizes a can achieve a behavior or activity. Thus, this study added to the body of Capabilities Approach knowledge by illustrating that the Capabilities Approach as an evaluative framework has the potential to account for the missing micro, meso, and macro (e.g. individual, community, and societal) elements identified by SDP critical scholars.

\section{How does Youth Odyssey help remove barriers for participants?}

Youth Odyssey's program helped negotiate barriers so participants could access certain resources and social structures offered by the organization and other aspects of society (Burnett, 2001; Hartmann \& Massoglia, 2007; Haudenhuyse, et al., 2012; Robeyns, 2011). This study identified multiple ways that Youth Odyssey helped mitigate barriers from participants' lives, which fell into the general categories of (a) reflecting positive role models and social behaviors, (b) emphasizing personal growth and confidence, and (c) countering difficult home or environmental setting. These findings had theoretical implications for both SDP and the Capabilities Approach.

Theoretical implications for SDP - removing barriers 
This study advanced our understanding of SDP's role in mitigating barriers involving social norms and culture as through modelling desired social behaviors well as those impacting each participant from an individual or community level. The findings also provided insight into how an SDP program can provide a detailed connection to local needs of those it serves by achieving positive outcomes through negotiating barriers. Study data also highlighted the importance creating trust plays as part of moderating the strength of barriers. These implications are further discussed below.

This study built on prior literature that found sport-based programming was used to reflect positive role models and socially desirable behaviors as part of negotiating participant barriers. Although Youth Odyssey's program encouraged participants to model desired social structures (Burnett, 2001; Haudenhuyse, et al., 2012), it also explored issues concerning social norms and culture (Hartmann \& Massoglia, 2007). This case study identified various barriers involving social norms and culture as well as described how Youth Odyssey reduced barriers based on each participant's needs. However, the organization also imposed its own social structures that were at times inconsistent when it came to participant discipline. These differing cultural norms may have functioned as a barrier between members of this community and mainstream society (Haudenhuyse et al., 2012; Hayhurst, 2013).

This study also advanced the SDP literature through evidence that it responded to local context (Burnett, 2015; Schulenkorf \& Spaaij, 2015). When children exhibited or expressed difficulty with a topic, the facilitators adapted the program to accommodate these issues. Further, facilitators understood that participants possessed their unique challenges based on the communities in which they lived or how they grew up. 
Levermore (2011) had highlighted the need for programs to use a less rigid theoretical framework that utilized context-specific programming. Facilitators communicated to me that many participants came from families and living environments where trust was an issue. Thus, this data indicated that facilitators understood there were differences between participants.

Several interviewees alluded to participants having experienced trust issues, including several former Youth Odyssey participants. Getting children to trust Youth Odyssey facilitators was a challenge at times. Some participants had been let down by adults in their lives, and facilitators identified this trust deficit. These differences merited different responses and approaches to programming. When executing programming, facilitators established trust as part of getting participants to move out of their comfort zone while always heeding the emotional limits of those they served. Therefore, it appears that Youth Odyssey did incorporate these local voices into its approach, as establishing trust became a foundation for creating relationships between participants and Youth Odyssey personnel. Data indicated that Youth Odyssey negotiated barriers associated with participants' difficult home life or environmental influences through fostering a safe environment, adapting programming based on the needs of participants, and providing resources to make sure programming was affordable and accessible. This finding was consistent with $\mathrm{Be}$ (2014), who found a successful program must offer a safe environment. This study also advanced our knowledge of SDP by identifying barriers that exposed at the micro, meso, and macro level. These different types of barriers according to different levels of society corresponded to two other theories used in SDP: SFDT (Lyras \& Welty Peachey, 2011) and SAT theory (Massey et al., 2015). 
Prior studies used sport-based programs to foster a community of trust between participants and facilitators (Burnett, 2001, 2013; Kay, 2009). This study furthered the SDP literature by being consistent with these previous studies, as it showed that Youth Odyssey strove to build an environment based on trust where participants could be themselves, and put trust in others (Darnell, 2010). Youth Odyssey helped construct an environment that communicated facilitators cared about those who participated, and that participants could develop confidence to be willing to try new things and leave their comfort zone. Facilitators also did not force participants to engage in activities that were uncomfortable. Although somewhat of a minor aspect of programming, it still seemed to be an important finding in light of criticism about the lack of SDP programs that incorporate feedback (Burnett, 2015). Youth Odyssey also provided financial resources and other assets to mitigate barriers children faced regarding a lack of resources to participate in various activities.

\section{Theoretical Implications for Capabilities Approach}

This study explored how Youth Odyssey helped negotiate barriers participants faced in their own lives, as part of expanding his or her life choices (Sen, 1999). The findings helped us to understand the different barriers participants face as identified through the Capabilities Approach. Data also illustrated how Youth Odyssey facilitators negotiated identified barriers, as theorized according to the Capabilities Approach. These implications are further discussed below.

This study explored how Youth Odyssey helped negotiate barriers for participants. Capabilities Approach scholars called upon people working in development to help reduce barriers to expand peoples' life choices (Sen, 1999), and this study further 
advanced how the Capabilities Approach can be used in conjunction with SDP to help identify and mitigate barriers. Alkire and Deneulin (2009) argued quality of life can be improved by easing barriers and hindrances that prevent a person from exercising freedom of choice and obstruct opportunities to live the lives a person values. One such barrier is a lack of meaningful opportunities in a person's life to pursue his or her passions. Sen (1992) viewed a lack of freedom as a barrier that limited quality of life. Reducing obstacles in a person's life and enlarging his or her choices is the basis of the Capabilities Approach.

This study provided data on barriers in the context of operationalizing the Capabilities Approach to an SDP program. Data illustrated that Youth Odyssey participants faced multiple barriers including financial, educational, health-related, emotional, geographical, and social obstacles. Each participant possessed different biological attributes, lived in their own social context, and faced different issues based on their respective living environments. Thus, this study helped us to understand through the Capabilities Approach the different barriers participants face. It also theorized how Youth Odyssey helped, through its tactics, to negotiate barriers as part of expanding peoples' freedoms, consistent with Sen's (1999) notion of development. The Capabilities Approach is designed to expand a person's life choices by removing obstacles that may impede one's ability to pursue meaningful functionings (Robeyns, 2005, 2017). Further, Human Development Theory defines development as a process of enlarging one's choices as part of living long, healthy, and creative lives (Haq, 1995, Ranis, Stewart, \& Ramirez, 2000). Mitigating barriers enlarges a person's life choices because they have more opportunities to pursue their passions, whether it is something as simple as riding a 
bike or more advanced such as studying engineering. But social constraints can derail these ambitions, thus serve as barriers.

Youth Odyssey's approach to designing and delivering programming in an adaptive, accessible and affordable manner as part of reducing participant barriers is also consistent with the Capabilities Approach. The purpose of development is to enlarge a person's life choices (Haq, 1995; Sen 1999). However, barriers to increasing life choices such as lack of access to resources may stunt development. Therefore, to counter a lack of equal access, Youth Odyssey provided participants with equitable access to financial resources and opportunities that were not normally present in their respective daily lives. This finding was consistent with Alkire and Deneulin (2009), who argued that some people needed to receive preferential treatment because of lived inequities.

Youth Odyssey designed and delivered affordable programming for participants and, if needed, provided its programs free of charge. Therefore, experiences that normally would had been too expensive or logistically impossible for participants became attainable. Through these experiences, Youth Odyssey provided new experiences, opened new doors, and expanded participants' horizons of what was possible to do and be in life (Sen, 1999). These opportunities and experiences showed participants there was more out there than what was present in their daily lives or, as one parent said, "there's more past the point of their own nose." Reducing these financial barriers provided opportunities for participants to pursue functionings of their choice, thus improving their life choices (Haq, 1995; Sen, 1999). For example, Brian (P4) and Leah (P9) both discussed at length how they discovered a love for camping because of Youth Odyssey. Patty (P15) and Alonzo (P3) also explained how their son was exposed to photography through Youth Odyssey 
and has become passionate about more seriously pursuing it as a profession. Thus, these findings were consistent with how Capabilities Approach scholars suggest the framework should be applied to other fields and advanced our understanding of applying the Capabilities Approach to SDP.

Youth Odyssey mitigated different obstacles in a participant's life and expanded what children could accomplish through increasing their opportunities (Robeyns, 2011). These findings were unique as the reviewed Capabilities Approach literature had not discussed programs that expended significant resources to provide opportunities for participants to obtain different types of experiences. However, previous studies had discussed programs that increased a participant's life choices (Haq, 1995; Schischka et al., 2008). These opportunities allowed participants to meaningfully explore new experiences that resonated with each person, consistent with literature (Robeyns, 2011, 2017; Sen, 1999). This made each functioning and capability individualistic (Frediani, 2010; Robeyns, 2003, 2005). Further, as part of the process, participants were provided personal agency to find and pursue their own passions to increase the real actual possibilities open to each participant (Alkire, 2005). Again, Patty (P15) and Alonzo’s (P3) son served as an example since he now wants to pursue a career in photography, something he knew nothing about before being exposed to it through Youth Odyssey.

\section{Capabilities Youth Odyssey created for its participants}

Capabilities are a person's real opportunities for what s/he can actually do and be in life, (Alkire, 2005; Robeyns, 2017). Actualizing a selected capability is based on meaningful choice; it is something readily available, meaning an individual does not have to fight past obstacles to realize the being or doing (Robeyns, 2017). Data from the study 
led to specific identified capabilities (see Appendix F). Each of these identified capabilities were placed in the following categories: (a) freedom to exercise agency through increased self-awareness, self-reflection, and perceptions of self-determination, (b) Opportunity to develop social skills, and (c) having the freedom and ability to access support and resources. These findings had theoretical implications for both SDP and the Capabilities Approach.

\section{Theoretical implications for SDP}

This study was consistent with Schulenkorf's (2012) S4D framework that sought to enhance participants' ability to facilitate social change and to feel empowered (Schulenkorf, 2012). The data also was consistent with prior studies that explored how meaningful opportunities and experiences fostered capabilities for a program's target population (Haudenhuyse, et al., 2012; Hayhurst, 2013). Some participants chose to continue attending Youth Odyssey and honing their social skills, eventually allowing them to make meaningful changes in their lives. This study found that Youth Odyssey provided participants with an opportunity to gain the choice to access monetary and nonmonetary resources that they may have lacked in their normal, day to day lives. By choosing to receive these resources, participants could seek their own meaning of success, make their own decisions, and become active participants in their lives. These implications are further discussed below.

This study materialized in a manner similar to Schulenkorf's (2012) S4D framework that sought to enhance participants' ability to facilitate social change and to feel empowered (Schulenkorf, 2012). Schulenkorf's (2012) S4D framework called for an external change agent to help communities engage in sustainable development. Here, that 
external change agent was Youth Odyssey. The study's findings illustrated that participants had real and meaningful choice to take advantage of opportunities presented to them via Youth Odyssey. Having the freedom to choose different opportunities that resonated with each person individually helped participants develop a greater understanding of what was possible to do and be in life. This freedom was consistent with prior literature that explored how meaningful opportunities and experiences fostered capabilities for a program's target population (Haudenhuyse, et al., 2012). This shared similarities with Hayhurst's (2013) study involving female participation in an Eastern Ugandan martial arts program, which suggested an outcome of participants gaining selfawareness, self-reflection, and perceptions of self-determination.

This study advanced the SDP body of knowledge by producing findings similar to previous studies that concluded sport-based programs have the potential to address or change social norms (Be, 2014; Burnett, 2013; Hayhurst, 2013). Youth Odyssey helped facilitate this change through the varied experiences it provided participants. Many of those interviewed in this study commented on how the diverse range of opportunities and experiences helped a participant to understand, as one facilitator said, "there was more out there" for them and self-reflect about what would capture their interest. Each opportunity served as a door that participants could open, and learn, as a parent said, "to discover themselves," empowering themselves in the process (Burnett, 2013). Giving participants meaningful choices also had the potential to empower a participant's agency to pursue what resonated with him or her individually (Kay, 2009).

In SDP, it was common for researchers to explore community and support issues. Be (2014) found that a sport-based program used peer education helped increase 
confidence, empowerment, and change social norms. Samie et al. (2015) found a program that paired women in the sport industry together, one from the developing world and one from a western nation, led to a positive mentor-mentee relationship. Hayhurst (2013) explored a martial arts program for girls that was a support system for participants that, among other benefits, increased participants' confidence, challenged gender norms, and enlarged participants' social networks.

The findings of this study suggested that some participants chose to adopt and use specific Youth Odyssey core values from its curriculum related to social skills. Some participants chose to continue coming to Youth Odyssey and working on refining their social skills, eventually becoming Youth Leaders. Not only did they serve as an example for younger children, data revealed that some Youth Leaders went on to make meaningful changes in their lives because of the social skills they chose to hone. Changes sometimes occurred in how they resolved conflict, worked towards new achievements, or took part in new activities. The choice was theirs.

Similarly, this study found that Youth Odyssey provided participants with an opportunity to gain the choice to access monetary and non-monetary resources that they may have lacked in their normal, day to day lives. Participants had the real freedom and opportunity to access these resources if they wished. Youth Odyssey provided participants with access to a support system, along with intangible and financial benefits that could be accessed. Some participants came from an unstable home environment that may have made accessing tangible and intangible resources difficult. Youth Odyssey gave participants the meaningful opportunity to take advantage of its network through subsidized trips and experiences as well as be a part of a group that provided emotional 
support, consistent with Burnett's (2001) finding. Further, as Haudenhuyse, et al. (2012) pointed out, some participants belonging to marginalized populations face challenges receiving support. In addition to providing financial support that may not had been available in the participant's life, emotional support was also a valuable aspect of the organization.

Youth Odyssey created an environment where participants could access support through facilitators who showed that they genuinely cared, listened to participants, and had a vested interest in their success. Several interviewees discussed how Youth Odyssey provided an opportunity for participants to release their emotional stress or emotionally recharge. The program also served as an opportunity for participants to find their success, whether educationally or socially, consistent with Kay's (2009) findings after examining a youth sport-based program. However, success would be achieved on the participant's own terms; this meant that a participant determined what s/he wanted to achieve and Youth Odyssey would help him/her pursue that goal (Spaaij \& Jeanes, 2013). Participants could seek their own meaning of success, make their own decisions, and become active participants in their lives. Thus, Youth Odyssey's approach was consistent with Levermore (2008a), who suggested that programs may use empowerment to educate traditionally disadvantaged communities

Data suggested that Youth Odyssey avoided the Fertilizer Effect because its curriculum was based on using games as a vehicle to target specific skills that would lead to increased participant choice of different things they could accomplish (Hartmann \& Kwauk, 2011; Samie et al., 2015). It should also be noted that the data suggests Youth Odyssey created opportunities to experience different aspects of life, not the inherent 
benefits of sport, thus perhaps avoiding criticism from the Car Wash Effect (Coakley, 2011; Hartmann, 2001, 2003; Hartmann \& Depro, 2006; Hartmann \& Massoglia, 2007). Sport was not viewed as a refuge for youth to seek to wash away socially undesirable behavior (Burnett, 2015; Hartmann \& Kwauk, 2011; Spaaij \& Jeanes, 2013). Instead, the focus was on learning different skills and trying activities/experiences unrelated to sport. This was also a unique contribution to the SDP literature.

The coupling of SDP and the Capabilities Approach can be further explored as a framework flexible enough to accommodate the varied and interdisciplinary nature of many different SDP programs (Massey et al., 2015; Schulenkorf \& Spaaij, 2015; Schulenkorf et al., 2016). This study conceptualized the different outcomes of Youth Odyssey programming through the Capabilities Approach. It operated to identify sportbased and non-sport-based capabilities. It also identified ways in which Youth Odyssey provided economic and non-economic resources to allow participants real opportunities to pursue a variety of activities and experiences. These benefits distinguished Youth Odyssey from other programs, and offering individualized opportunities based on a participant's interests also related to the agency and empowerment aspects of prior literature (Burnett, 2015; Samie et al, 2015; Sen, 1999; Spaaij \& Jeanes, 2013). This study also conceptualized SDP programming through different theoretical and methodological approaches, taking the next steps as suggested by Svensson and Levine (2017), as well as Darnell and Dao (2017). These were new contributions to the SDP literature.

\section{Theoretical Implications for Capabilities Approach}


Study data produced identifiable capabilities of Youth Odyssey participants. Identified capabilities fell into two groups: (a) those involving agency and (b) those related to resources. These groups of identified capabilities all materialized in a similar descriptive manner to previous studies, and shared similarities with Nussbaum's (2011) list of central capabilities. These implications are further discussed below.

One implication of this study was that the data produced identifiable capabilities of Youth Odyssey participants. Capabilities "are real opportunities for beings and doings" (Robeyns, 2017, p. 171) such as activities or a state of being a person can achieve at a moment in time. In other words, capabilities are what a person can accomplish without barriers preventing him or her from pursuing these opportunities. Most importantly, it is that person's choice what he or she decides to do. Data in this study illustrated that participants had the choice to try new activities and engage in new experiences, as part of widening their understanding of about what they could do and be (Robeyns, 2011; Sen, 1999). The identified capabilities listed in the study (see Appendix F) are presented similarly to those in Schischka et al.'s (2008) study operationalizing the Capabilities Approach to poverty reduction as well as Greco et al.'s (2015) use of the Capabilities Approach to assess the quality of life for women in rural Malawi.

The Capabilities Approach assesses quality-of-life by asking the question "what is each person able to do and to be" (Nussbaum, 2011, p. 18)? The present study furthered the Capabilities Approach literature by operationalizing it to SDP through conceptualizing capabilities. This study produced a list of capabilities, (see Appendix F), that helped provide context and examples of what participants could do and be. This list of capabilities responds to Robeyns (2003), who suggested that researchers should 
identify a list of valuable capabilities and decide whether to focus on broader or narrower functionings. This list also helps us to understand capabilities as applied to children, since the Capabilities Approach has not often been applied to children (Shand, 2014).

Nussbaum (2011) identified a list of central capabilities (life, bodily health, bodily integrity, senses, imagination and thought, emotions, practical reason, affiliation, other species' play, and control over one's environment). Although it was not possible to create a general list of capabilities from this one study, several specific capabilities were identified. One collection of capabilities was grouped under agency, in other words, a person's choice. Participants had the choice to exercise agency with new passions and interests, the freedom to engage in self-reflection, the opportunity to discover what they could do and be, the ability to engage in self-awareness, choice to change perceptions of what is possible to do in life, and the ability to think about aspects of life beyond the routine. Participants also had the freedom to make meaningful personal changes through attaining social skills.

The other major group of capabilities fell under the ability to access support and resources. Participants had the choice to attend Youth Odyssey as much as they wanted, had the choice of accessing resources as much as they wished, participants had the freedom to have a mental escape from daily life, participants had the ability to access non-monetary support, participants had access to a personal life coach. Participants possessed the ability to benefit from a supportive group, participants had the opportunity to be a part of a bigger group, participants had an opportunity to derive resources from a network, and participants possessed the choice to try new activities without paying for the cost. Data emerged that Youth Odyssey participants had the a meaningful opportunity to 
access a variety of support and resources. This finding directly relates to Haq's (1995) asserting that human development is grounded in equitable principles such as access to equal opportunities. If equitable access was not present, Alkire and Deneulin (2009) argued that accommodations should be made to facilitate access for those who were disadvantaged. Participants had the freedom and ability to receive support and resources, as part of gaining equitable access. This contributes to understanding SDP as operationalized through the Capabilities Approach.

These groups of identified capabilities all materialized in a similar descriptive manner as Schischka (2008), who reported skill-based capabilities and the ability to access resource-based capabilities. Greco et al. (2015) reported levels and sublevels of capabilities, including those relating to a community of support. These identified capabilities are intended to more accurately measure an individual's well-being than other approaches, such as focusing on economic indicators (Sen, 1985; 1999).

The study's identified capabilities shared similarities with Nussbaum's (2011) list of central capabilities. Capabilities falling into the agency grouping all related to Nussbaum's (2011) central capability of practical reason. Practical reason, number six on the list, is one's ability to form an understanding of what is good and to critically reflect on how one will plan his or her life (Nussbaum, 2011). Nussbaum's (2011) definition of practical reason is a person having the meaningful opportunity to plan one's life and pursue his or her passions. Hence the connection is to agency. Several identified study capabilities concerned the meaningful opportunity to use problem-solving and abilities to attain social skills. These capabilities connected to Nussbaum's fourth central capability: senses, imagination, and thought. This central capability is a person's ability to think and 
use his/her reasoning as part of being a human being (Nussbaum, 2011). Using problemsolving abilities and attaining social skills contribute to what makes a person human.

The final major group of identified capabilities shared similarities with affiliation, Nussbaum's (2011) seventh in the list. Nussbaum (2011) defined affiliation as socially interacting with others as well as recognizing and showing concern for other humans. Nussbaum (2011) also explained that affiliation is a person's ability to be treated with dignity as a person who is worth the same as others, which seems central to the intent Youth Odyssey. Please see Appendix F for a list of identified capabilities. The study's identified capabilities relating to activities also related to the central capability of play, the ability to engage in recreation (Nussbaum, 2011). Thus, by identifying a list of specific capabilities and explaining how they share similarities with Nussbaum's (2011) list of central capabilities, helps conceptualize and operationalize SDP through the Capabilities Approach as a framework as suggested by Comim (2001).

This study also advanced SDP under Human Development Theory, which is concerned with increasing a person's life choices (Haq, 1995) through a real opportunity to explore new interests inside and outside of sport. The findings are also consistent with one of the Capabilities Approach's strengths, a people-centric approach that is based on an individual's passions. Youth Odyssey provided participants with meaningful opportunities to pursue a variety of life choices. It was each participant's choice to pursue those opportunities. It should be noted that the benefits participants received were not purely through sport; instead, as told by Kathryn, Youth Odyssey provided participants with an opportunity to access diverse experiences to ascertain what they enjoyed and wanted to do with their lives. Once figuring that out, Youth Odyssey's network could 
help empower participants to exercise agency based on their passions. Thus, this study helped to provide an understanding of development from the Capabilities Approach standpoint which, as defined by Sen (1999), is concerned with enhancing a person's life by increasing their freedom to pursue a variety of experiences as part of exercising our own volitions.

Summary. The study's results were consistent with findings from much of the SDP literature that used frameworks unrelated to the Capabilities Approach and used sport as a hook to promote specific participant behaviors (Be, 2014; Burnett, 2001; Haudenhuyse et al., 2012). The data also illustrated that one outcome of Youth Odyssey's work was providing participants with a safe environment to exercise their freedom to socialize and express themselves, which supports Hancock et al.'s (2013) findings involving sport-based social inclusion programs. The findings also demonstrated how the ability to discern between personal, social, and societal issues may impact how effectively a person accomplishes an activity or experience. Development includes facilitating a person's ability to take part in a community, responding to calls for frameworks to analyze functionings at the micro, meso, and macro levels (Lyras \& Welty Peachey, 2011; Marshall \& Barry, 2015; Massey et al., 2015). Social structures were also found to play a role in a participant's achievements . However, a diversity of functionings specific to the case of Youth Odyssey were identified.

Youth Odyssey's program helped negotiate barriers so participants could access certain resources and social structures offered by the organization and other aspects of society. These barriers differed by a participant's unique factors, thus reflecting local context (Welty Peachey, 2015) and differences within a local population (Hartmann \& 
Kwauk, 2011). Facilitators respected the limits of those they served, as well as responded to the difficult home life and environmental influences participants experienced. As part of mitigating barriers, programming was designed and delivered in an adaptable, accessible and affordable manner consistent with the Capabilities Approach to increase the number of a person's meaningful opportunities.

Youth Odyssey created capabilities for participants based on building a person's agency. Participants possessed the freedom to pursue their passions through advancing their social and analytical/logical reasoning skills as well as providing opportunities for new experiences such as releasing stress or feeling emotionally supported. The resources were available, thus providing access (Alkire \& Deneulin, 2009); it was that person's choice to take advantage of the opportunity. Therefore, this approach was people-centric, a hallmark of the Capabilities Approach (Clark, 2005a; Robeyns, 2017). This capability, choice to exercise individual agency, reflected incorporating local voices into SDP (Burnett, 2015; Spaaij \& Jeanes, 2013). This advanced the literature regarding finding a framework able to incorporate the values of those they sought to serve and do so in a flexible manner. The study also yielded a list of identifiable capabilities that connected to Nussbaum's list of central capabilities. By identifying a list of specific capabilities and relating it to Nussbaum's (2011) list of central capabilities, it helps us to conceptualize and operationalize SDP through the Capabilities Approach as a framework as suggested by Comim (2001).

\section{Implications for SDP Practitioners}

This study can aid in how SDP practitioners approach programming from planning, execution, and evaluative standpoints (Hayhurst, 2009). Programs that do not 
use a system or framework to guide a program can lead to problems such as mission drift or compromising an organization's effectiveness. Critical scholars encourage SDP practitioners to understand the nuances of a program (Lyras \& Welty Peachey, 2011; Marshall \& Barry, 2015; Massey et al., 2015), as well as the local conditions in which a program operates (Burnett, 2015; Hayhurst, 2013; Marshall \& Barry, 2015; Spaaij \& Jeanes, 2013). The Capabilities Approach may help organizations with understanding and incorporating a program's nuances, as suggested by critical scholars. Therefore, the following are suggestions for an organization wanting to use the Capabilities Approach as a guiding framework for its program.

A person or organization, when seeking to create a new program, should begin by considering if there is anything about the people you want to help or where they live that makes them unique. In other words, ask yourself, "what makes this group of people special or different? Do they face any unique challenges?" An organization can start out using informal interviews with the target group or different stakeholders while building credibility. The questions should not be superficial. They should really touch on a person's or group's common beliefs, customs, and/or religious tenants. In addition, the physical and environmental aspects of where a program operates may create unique challenges (Lyras \& Welty Peachey, 2011; Marshall \& Barry, 2015; Massey et al., 2015). The more information showing how/why this group is different, the better. We are trying to identify specific impediments that are unique to those people your organization wants to help.

After considering these possibilities, the next step is to consider whether differences exist between those in the group of people the person or organization is 
seeking to help. It is quite possible that challenges people face may differ even if the two individuals seem similar. Therefore, it is up to a program to really spend time with getting to know the people who are likely participants in a program, so that we can understand what makes these people unique. Part of this process is making sure to incorporate policies so that organization employees regularly communicate with the target population and solicit their feedback (Spaaij \& Jeanes, 2013). This way, organization members can understand if the challenges of the group members are changing.

Although a program should continuously be communicating with its target group, it should also solicit other community stakeholders that are likely to play a role in the target population's development. This could be cultural, political, and religious leaders; any group likely to wield power or hold influence over the population. For this study, it was school administrators, parents of Youth Odyssey participants, Youth Odyssey volunteers, Corpus Christi city employees who had oversight over these public housing developments, as well as organizations within the Youth Odyssey network. These voices should had been included in the program's curriculum planning.

Once identifying what makes a group different and understanding whether different stakeholder groups play a role, we should now try to understand what challenges these individuals face that make life more difficult. Once having built up some rapport with the target population and stakeholders, an organization's employees should solicit feedback from these groups by asking questions about what make a person's life in the target group more difficult. You could use informal interviews, semi-structured interviews, or a questionnaire, depending on the situation and level of trust the 
organization's employees possess. Once enough data has been gathered to understand what difficulties exist, we can create strategies to lessen the challenge these obstructions create for a person.

Once these steps occur, the organization's employees have more insight into the unique challenges the target group faces, and other stakeholder groups are involved, a program should focus on helping participants accomplish his or her goals. Although this may seem a bit general, really we are asking the target population to identify and articulate what is important to him or her. In other words, we should find out answers to the following questions: (a) what is important to each person? (b) What does a participant want out of life? (c) Does each participant have any specific interests or passions? Once doing so, the program can respond by helping to make these interests, goals, or passions more attainable. This can be done only after understanding the nuances in which the program operates and working with stakeholders to help address these obstacles preventing the target population from pursuing these goals. Once that occurs, it is up to each participate to decide whether s/he wants to pursue this interest.

A program may have to set up some limitations and constraints on what it can help with, as not every goal will be reasonable. But keeping the communication loop with participants open is important. This is important because what we really care about is understanding what challenges participants face and what is important to them in terms of aspirations and opportunities for them to come true. This is a repetitive process, but we must continue to do it so we can create programming that effectively responds to these aspirations and challenges. 
In this study, evidence suggested that Youth Odyssey negotiated social and financial barriers participants faced, and helped to put them in a position where they could live new experiences and choose to pursue passions that piqued their interests. Data illustrated the progression of multiple participants who blossomed into individuals with a diversity of choices to follow their passions. However, there was also a lack of data that showed how Youth Odyssey continuously checked back in with participants and other stakeholders about the challenges its target population faced. The organization should had put in place policies and procedures for continuously incorporating participant feedback as part of changing its approach or curriculum based on the target group's evolving needs.

There were also some concerns. This was somewhat troubling, given the fact Youth Odyssey's curriculum had not been meaningfully modified since 1997 and it still uses the six life skills as the foundation of its program. I also did not see evidence that Youth Odyssey systematically solicited or incorporated stakeholder feedback as part of its program. I would suggest that any organization continuously use tools such as interviewing stakeholder groups and passing out surveys to continuously monitor whether it is effectively addressing its intended issues and that these parameters are actually what are important to those they are seeking to serve.

\section{Directions for Future Research}

This study adds to the limited literature exploring SDP using the Capabilities Approach. It theorized that Youth Odyssey should create functionings, capabilities, and remove barriers. The ability of the Capabilities Approach framework to account for local context, potentially understand SDP at different levels, and conceptualize individual well- 
being based on reducing barriers to foster meaningful choice raises the possibility for future SDP researchers to address various criticisms from critical scholars (Lyras \& Welty Peachey, 2011; Marshall \& Barry, 2015; Massey et al., 2015; Schulenkorf \& Spaaij, 2015).

Future researchers should continue to explore the Capabilities Approach as a framework to accomplish the goals of SDP practitioners and scholars. The most immediate future studies will continue operationalizing the Capabilities Approach by replicating this study in similar SDP contexts. Qualitative studies are not generalizable, meaning a gap in the literature remains. It is still not clear whether the Capabilities Approach is a suitable framework to address critical scholars' concerns about SDP or to incorporate local context as part of a program. Thus, I want to continue this line of study (Darnell \& Dao, 2017; Svensson \& Levine, 2017) and conduct similar studies involving SDP and the Capabilities Approach.

The next study will attempt to gain a greater understanding of functionings and capabilities as constructs in SDP. Both concepts can be abstract or ambiguous, which is a legitimate criticism of the Capabilities Approach (Gapser, 2007). Another subsequent potential study will focus on conceptualizing conversion factors. Conversion factors were not a research question in this study. Therefore, the study did not contribute to conceptualizing it in an SDP setting. Although this study researched how Youth Odyssey helped mitigate barriers for participants, and social, economic, and structural barriers were identified, conversion factors were not directly tested. Subsequent studies could also pair the Capabilities Approach with SDP settings different than the one involving Youth Odyssey. The goal of subsequent studies is to continue conceptualizing SDP through this 
alternative framework, which heeds suggestions by Svensson and Levine (2017) as well as Darnell and Dao (2017).

The goal of future research studies is to operationalize enough specifics of the Capabilities Approach to SDP using Comim's (2001) approach so it becomes a guiding model for practitioners, academics, and policy makers to design and implement successful programs (Welty Peachey, 2015). This approach should incorporate the voices of the population a program seeks to serve while also organizing it at the micro, meso, and macro levels (Lyras \& Welty Peachey, 2011; Marshall \& Barry, 2015; Massey et al., 2015). As Comim (2001) suggested, the stages for operationalizing the Capabilities Approach would likely include working through the theoretical concepts as applied to SDP, transforming theory to empirical variables (Sen, 1999), utilizing the variables as part of qualitative analysis, and finally repeat the process using quantitative analysis. Once established, future studies will involve use of the Capabilities Approach as the framework to connect diverse disciplines to create meaningful SDP discoveries (Burnett, 2015).

Additional future research will also focus on developing a Capabilities Approachbased monitoring and evaluation system for SDP programs. Outstanding challenges still exist in measuring and documenting outcomes to highlight an SDP program's effectiveness (Coalter, 2010; Hartmann \& Kwauk, 2011; Hayhurst, 2009). A monitoring and evaluation system using the Capabilities Approach could address these questions from SDP critical scholars (Kay, 2012). This monitoring and evaluation system would take advantage of metrics developed through operationalizing the Capabilities Approach to SDP. 
Another possible research opportunity involves identifying a list of fundamental capabilities for SDP programming. This idea is similar to Nussbaum's (2011) list of central capabilities that are universal among people throughout the world. However, this list would have to overcome the notion that capabilities are inherently individualistic (Robeyns, 2003). It should also be noted that Nussbaum listed play as one of her fundamental capabilities, which creates an apparent opportunity for developing a more direct connection between the Capabilities Approach and SDP. This opportunity to generate such a list of fundamental SDP capabilities may begin to evolve through repeated SDP studies using the Capabilities Approach.

\section{Conclusion}

This study explored what role an SDP program plays in participants achieving their capabilities. The findings add to the limited literature exploring SDP using the Capabilities Approach. It also highlighted the Capabilities Approach's potential ability to address the concerns of critical scholars regarding SDP from a planning, execution, and evaluation standpoint. It also served as one of the first studies to understand the role an SDP organization played in increasing the opportunities for an individual to achieve functionings, freedoms, and capabilities using qualitative data. 


\section{REFERENCES}

Alkire, S. (2001, June). Why the capability approach? Paper presented at the Conference on Justice and Poverty: Examining Sen's Capability Approach, Cambridge, England.

Alkire, S. (2002a). Dimensions of human development. World Development, 30(2), 181205.

Alkire, S. (2002b). Valuing freedoms: Sen's Capability Approach and poverty reduction. Oxford, England: Oxford University Press.

Alkire, S. (2003, September). The capability approach as a development paradigm? Paper presented at the International Conference on the Capability Approach, Pavia, Italy.

Alkire, S. (2005). Why the capability approach? Journal of Human Development, 6(1), 115-135. DOI: 10.1080/146498805200034275

Alkire, S., \& Deneulin, S. (2009). The human development and capability approach. In S. Deneulin \& L. Shamani (Eds.), An Introduction to the Human Development and Capability Approach (1st ed., pp. 22-48). Sterling, Virginia: Routledge.

Alkire, S., \& Santos, M. E. (2014). Measuring acute poverty in the developing world: Robustness and scope of the multidimensional poverty index. World Development, 59(7), 251-274. DOI: 10.1016/j.worlddev.2014.01.026 
Allport, G. (1954). The Nature of Prejudice. Cambridge, MA: Addison-Wesley Publishing Company.

Anand, P., Hunter, G., Carter, I., Dowding, K., Guala, F., \& Van Hees, M. (2009). The Development of Capability Indicators. Journal of Human Development and Capabilities, 10(1), 125-152. DOI: 10.1080/14649880802675366

Anand, S., \& Sen, A. (2000). Human development and economic sustainability. World Development, 28(12), 2029-2049.

Baker, R. E., Baker, P. H., Atwater, C., \& Andrews, H. (2015). Sport for development and peace: A program evaluation of a sport diplomacy initiative. International Journal of Sport Management and Marketing, 16(1/2), 52-70. DOI: http://dx.doi.org/10.1504/IJSMM.2015.074932

Be, M. (2014). The working elements of Moving the Goalposts: Football, peer education and leadership in Kenyan girls. Unpublished master's thesis, Utrecht University, Utrecht, Netherlands.

Blinde, E. M., \& McClung, L. R. (1997). Enhancing the physical and social self through recreational activity: Accounts of individuals with physical disabilities. Adapted Physical Activity Quarterly, 14(4), 327-344. DOI: https://doi.org/10.1123/apaq.14.4.327

Bloomberg, L. D., \& Volpe, M. (2016). Completing your qualitative dissertation: A road map from beginning to end (3rd ed.). Thousand Oaks, CA: Sage Publications, Inc.

Burchardt, T., \& Vizard, P. (2011). 'Operationalizing' the capability approach as a basis for equality and human rights monitoring in twenty- first- century Britain. 
Journal of Human Development and Capabilities, 12(1), 37-41. DOI:

$10.1080 / 19452829.2011 .541790$

Burnett, C. (2001). Social impact assessment and sport development: Social spin-offs of the Australia-South Africa junior sport programme. International Review for the Sociology of Sport, 36(1), 41-57. DOI: 10.1177/101269001036001005

Burnett, C. (2009). Engaging sport-for-development for social impact in the South African context. Sport in Society, 12(9), 1192-1205. DOI:

$10.1080 / 17430430903137852$

Burnett, C. (2013). GIZ/YDF and youth as drivers of sport for development in the African context. Journal of Sport for Development, 1(1), 4-14.

Burnett, C. (2015) Assessing the sociology of sport: On sport for development and peace. International Review for the Sociology of Sport, 50(4-5), 385-390. DOI: $10.1177 / 1012690214539695$

Catalano, R., Berglund, M., Ryan, J., Lonczak, H., \& Hawkins, J. (2004). Positive youth development in the United States: Research findings on evaluations of positive youth development programs. Annals of the American Academy of Political and Social Science, 591(1), 98-124. DOI: 10.1177/0002716203260102

Cavallo, D. (1981). Muscles and morals: Organized playgrounds and urban reform, 1880-1920. Philadelphia, PA: University of Pennsylvania Press.

Chalip, L. (2006). Towards social leverage of sport events. Journal of Sport and Tourism, 11(2), 109-127. DOI: http://dx.doi.org/10.1080/14775080601155126

Chiappero-Matinetti, E., \&. Roche, J. M. (2009). Facing trajectories from school to work: towards a capability-friendly youth policy in Europe. In H. U. Otto, R. Atzmüller, 
T. Berthet, L., Bifulco, J. M. Bonvin, E. Chiappero-Martinetti, V. Egdell, B. Halleröd, C. C. Kjeldsen, M. Kwiek, R. Schröer, J. Vero, M. Zielenska, M. (Eds.), Facing Trajectories from School to Work: Towards a Capability-Friendly Youth Policy in Europe. New York, NY: Springer.

Clark, D. A. (2002). Visions of development: A study of human values. Northampton, MA: Edward Elgar Publishing Limited.

Clark, D. A. (2005a). The capability approach: Its development, critiques and recent advances. In D. A. Clark (Ed.), The Elgar companion to development studies (pp. 32-45). Northampton, MA: Edward Elgar Publishing Limited.

Clark, D. A. (2005b). Sen's capability approach and the many spaces of human wellbeing. Journal of Development Studies, 41(8), 1339-1368. DOI: $10.1080 / 00220380500186853$

Clark, T. S., Kaufman, Z. A., Friedrich, G. K., Ndlovu, M., Neilands, T. V., \& McFarland, W. (2006). Kicking aids in Africa: Soccer players as educators in adolescent-targeted HIV prevention. Harvard Health Policy Review, 7(2), 62-71.

Coakley, J. (2002). Using sports to control deviance and violence among youths: Let's be critical and cautious. In M. Gatz, M. A. Messner, \& S. J. Ball-Rokeach (Eds.), Paradoxes of youth and sport (pp. 13-30). Albany, NY: State University of New York Press.

Coakley, J. (2011). Youth sports: What counts as “positive development?" Journal of Sport and Social Issues, 35(3), 306-324. DOI: 10.1177/0193723511417311 Coakley, J. (2014). Sports in society: Issues and controversies (11th ed.). New York, NY: McGraw-Hill Education. 
Coalter, F. (2007). Sport a wider social role: Whose Keeping the Score? London, England: Routledge.

Coalter, F. (2010). The politics of sport-for-development: Limited focus programmes and broad gauge problems? International Review for the Sociology of Sport, 45(3), 295-314. DOI: $10.1177 / 1012690210366791$

Comim, F. (2001, June). Operationalizing Sen's Capability Approach. Paper presented at the Conference on Justice and Poverty: Examining Sen's Capability Approach, Cambridge, England.

Comin, F., Qizilbash, M., \& Alkire, S. (2008). The Capability Approach: Concepts, measures and applications (1st ed.). Cambridge; England: Cambridge University Press. DOI: 10.1017/CBO9780511492587

Creswell, J. W. (2013). Qualitative inquiry and research design: Choosing among five approaches (3rd ed.). Thousand Oaks, CA: Sage Publications, Inc.

Creswell, J. W. (2014). Research design: Qualitative, quantitative, and mixed methods approaches (4th ed.). Thousand Oaks, CA: Sage Publications, Inc.

Creswell, J. W. (2015). Educational research: Planning, conducting, and evaluating quantitative and qualitative research (5th ed.). Noida, India: Pearson Education.

Croes, R. (2012). Assessing tourism development from Sen's capability approach. Journal of Travel Research, 51(5), 542-554. DOI: 10.1177/0047287511431323

Dang, A. T. (2014). Amartya Sen's capability approach: A framework for well-being evaluation and policy analysis? Review of Social Economy, 72(4), 460-484. DOI: $10.1080 / 00346764.2014 .958903$ 
Darnell, S. C. (2007). Playing with race: Right to Play and the production of whiteness in 'development through sport.' Sport in Society, 10(4), 560-579. DOI: $10.1080 / 17430430701388756$

Darnell, S. C. (2010). Sport, race, and bio-politics: Encounters with difference in "sport for development and peace" internships. Journal of Sport and Social Issues, 34(4), 396-417. DOI: 10.1177/0193723510383141

Darnell, S.C. (2012). Sport for development and peace: A critical sociology. London, England: Bloomsbury Academic.

Darnell, S. C., \& Black, D. R. (2011). Introduction: Mainstreaming sport into international development studies. Third World Quarterly, 32(3), 367-378. DOI: $10.1080 / 01436597.2011 .573934$

Darnell, S. C., \& Dao, M. (2017). Considering sport for development and peace through the capabilities approach. Third World Thematics: A TWQ Journal, 2(1), 23-36. DOI: $10.1080 / 23802014.2017 .1314772$

Darnell, S.C., \& Kaur, T. (2015). C.L.R. James and a place for history in theorizing 'sport for development and peace.' International Journal of Sport Management and Marketing, 16(1/2), 5-17. DOI 10.1504/IJSMM.2015.074919

Day of Giving Results are In! (n.d.). Retrieved from https://youthodyssey.com/2017/11/17/day-of-giving-results/

Delva, W., Michielsen, K., Meulders, B., Groeninck, S., Wasonga, E., Ajwang, P., Temmerman, M., \& Vanreusel, B. (2011). HIV prevention through sport: The case of the Mathare Youth Sport Association in Kenya. AIDS Care, 22(8), $1012-$ 1020. DOI: $10.1080 / 09540121003758606$ 
Desai, M. (1994). Measuring political freedom. In S. Fukuda-Parr \& A.K. Shiva Kumar (Eds.), Oxford handbook of human development: Concepts, measures, and policies (pp. 188-209). New Delhi, India: Oxford University Press.

Dubois, J. L., \& Trani, J. F. (2009). Extending the capability paradigm to address the complexity of disability. European Journal of Disability Research, 3(3), 192-218. DOI: $10.1016 / j$. alter.2009.04.003

Dyck, C. B. (2011). Football and post-war reintegration: Exploring the role of sport in DDR process in Sierra Leone. Third World Quarterly, 32(3), 395-415. DOI: $10.1080 / 01436597.2011 .573936$

Edwards, M. B. (2015). The role of sport in community capacity building: An examination of sport for development research and practice. Sport Management Review, 18(1), 6-19. DOI: 10.1016/j.smr.2013.08.008

Edwards, A., \& Skinner, J. (2009). Qualitative research in sport management. Burlington, MA: Routledge.

Erlandson, D. A., Harris, E. L., Skipper, B. L., \& Allen, S. D. (1993). Doing naturalistic inquiry: a guide to methods. Newbury Park, CA: Sage Publications, Inc.

Foucault, M. (1980). Power/knowledge: Selected interviews and other writings 19721977, Gordon, C. (Ed.). New York, NY: Pantheon Books.

Frediani, A. A. (2010). Sen's capability approach as a framework to the practice of development. Development in Practice, 20(2), 173-187. DOI: $10.1080 / 09614520903564181$

Fry, M., \& Gano-Overway, L. (2010). Exploring the contribution of the caring climate to 
the youth sport experience. Journal of Applied Sport Psychology, 22(3), 294-304. DOI: $10.1080 / 10413201003776352$

Fukuda-Parr, S. (2002). Rescuing the human development concept from the HDI: Reflections on a new agenda. In S. Fukuda-Parr \& A.K. Shiva Kumar (Eds.), Oxford handbook of human development: Concepts, measures, and policies (pp. 117-124). New Delhi, India: Oxford University Press.

Fukuda-Parr, S. (2003). The human development paradigm: Operationalizing Sen's ideas on capabilities. Feminist Economics, 9(2/3), 301-317.

Fukuda-Parr, S., Raworth, K. and Kumar, A, K. (2002). Using the HDI for policy analysis. In S. Fukuda-Parr \& A.K. Shiva Kumar (Eds.), Oxford handbook of human development: Concepts, measures, and policies (pp. 177-187). New Delhi, India: Oxford University Press.

Fukuda-Parr, S., \& Shiva Kumar, A.K. (2009). Forward. In S. Fukuda-Parr \& A.K. Shiva Kumar (Eds.), Oxford handbook of human development: Concepts, measures, and policies (pp. xxi-xxxi). New Delhi, India: Oxford University Press.

Gasper, D. (2004). The ethics of development: From economism to human development. Edinburgh, Scotland: Edinburgh University Press.

Gasper, D. (2007). What is the capability approach?: Its core, rationale, partners and dangers. Journal of Socio-Economics, 36(3), 335-359. DOI:

10.1016/j.socec.2006.12.001

Gasper, D. (2008). From 'Hume's Law' to problem-and policy-analysis for human development. Sen after Dewey, Myrdal, Streeten, Stretton and Haq. Review of Political Economy, 20(2), 233-256. DOI: 10.1080/09538250701819701 
Gergen, K. J., \& Gergen, M. M. (2008). Social Constructivism. In The Sage Encyclopedia of Qualitative Research Methods. (Vol. \#1\&2, pp. 816-820). Thousand Oaks, CA: Sage Publications, Inc.

Gilbert, K., \& Bennett, W. (2012). Sport, peace \& development. Champaign, Illinois: Common Ground Publishing, LLC.

Giulianotti, R. (2004). Human rights, globalization and sentimental education: The case of sport. Sport in Society, 7(3), 355-369. DOI: 10.1080/1743043042000291686

Giulianotti, R. (2011). Sport, peace-making and conflict resolution: A con-textual analysis and modeling of the sport, development and peace sector. Ethnic and Racial Studies, 34(2), 207-228. DOI: 10.1080/01419870.2010.522245

Glesne, C. (2016). Becoming qualitative researchers: An introduction (5th ed.). Columbus: OH: Pearson Education.

Goffman, E. (1963). Stigma: Notes on the management of spoiled identity. Englewood Cliffs, NJ: Prentice Hall.

Goodwin, D. L., Thurmeier, R., \& Gustafson, P. (2004). Reactions to the metaphors of disability: The mediating effects of physical activity. Adopted Physical Activity Quarterly, 21(4), 379-398. DOI: https://doi.org/10.1123/apaq.21.4.379

Greco, G., Skordis-Worrall, J., Mkandawire, B., \& Mills, A. (2015). What is a good life? Selecting capabilities to assess women's quality of life in rural Malawi. Social Science \& Medicine, 130, 69-78. DOI: 10.1016/j.socscimed.2015.01.042

Gutwald, R., Lebmann, O., Masson, T., \& Rauschmayer, F. (2014). A capability approach to intergenerational justice? Examining the potential of Amartya Sen's 
ethics with regard to intergenerational issues. Journal of Human Development and Capabilities, 15(4), 355-368. DOI: 10.1080/19452829.2014.899563

Hall A. (2010). The discourse of gender and sport: From femininity to feminism. Sociology of Sport Journal, 5(4), 330-340.

Hancock, M., Lyras, A., \& Ha, J. P. (2013) Sport for development programs for girls and women: A global assessment. Journal of Sport for Development, 1(1), 15-24.

Haq, M. U. (1995). Reflections on human development. New Delhi, India: Oxford University Press.

Hartmann, D. (2001). Notes on midnight basketball and the cultural politics of recreation, race, and at-risk urban youth. Journal of Sport and Social Issues, 25(4), 339-371. DOI: $10.1177 / 0193723501254002$

Hartmann, D. (2003). Theorizing sport as social intervention: A view from the grassroots. Quest, 55(2), 118-140. DOI: 10.1080/00336297.2003.10491795

Hartmann, D., \& Depro, B. (2006). Rethinking sports-based community crime prevention: A preliminary analysis of the relationship between midnight basketball and urban crime rates. Journal of Sport and Social Issues, 30(2), 180196. DOI: $10.1177 / 0193723506286863$

Hartmann, D., \& Kwauk, C. (2011). Sport and development: An overview, critique, and reconstruction. Journal of Sport \& Social Issues, 32(3), 284-305.

DOI: $10.1177 / 0193723511416986$

Hartmann, D., \& Massoglia, M. (2007). Re-assessing high school sports participation and deviance in early adulthood: Evidence of enduring, bifurcated effects.

Sociological Quarterly, 48(3), 485-505. DOI: 10.1111/j.1533-8525.2007.00086.x 
Haudenhuyse, R., Theeboom, M., \& Coalter, F. (2012) The potential of sports-based social interventions for vulnerable youth: implications for sport coaches and youth workers. Journal of Youth Studies, 15(4), 437-454.

https://doi.org/10.1080/13676261.2012.663895

Hayhurst, L. (2009). The power to shape policy: Charting sport for development and peace policy discourses. International Journal of Sport Policy and Politics, 1(2), 203-227. DOI: 10.1080/19406940902950739

Hayhurst, L. (2013). Girls as the 'new' agents of social change? Exploring the 'girl effect' through sport, gender and development programs in Uganda. Sociological Research Online, 18 (2), 8. DOI: 10.5153/sro.2959

Hoglund, K \& Sundberg, R. (2008). Reconciliation through sports? The case of South Africa. Third World Quarterly, 29(4), 805-818. DOI:

$10.1080 / 01436590802052920$

Hums, M., \& Wolff, E. (2014, April 2). Power of sport to inform, empower and transform. Huffington Post, retrieved from http://www.huffingtonpost.com/drmary-hums/power-of-sport-to-inform-

_b_5075282.html?utm_hp_ref=sports\&ir=Sports

Jeong, H. W. (2000) Peace and conflict studies: An introduction. Aldershot, England: Ashgate.

Kane, M., \& LaVoi, N. (2007). The 2007 Tucker Center Research Report, Developing physically active girls: An evidence-based multidisciplinary approach. Minneapolis: University of Minnesota Press. Retrieved from www.tuckercenter.org/projects/tcrr 
Kaufman, Z. A., Welsch, R. L., Erickson, J. D., Craig, S., Adams, L. V., \& Ross, D. A. (2012). Effectiveness of a sports-based HIV prevention intervention in the Dominican Republic: A quasi-experimental study. AIDS Care, 24(3), 377-385. DOI: $10.1080 / 09540121.2011 .608789$

Kay, T. (2009). Developing through sport: Evidencing sport impacts on young people. Sport in Society, 12(9), 1177-1191. DOI: 10.1080/17430430903137837

Kay, T. (2012). Accounting for legacy: Monitoring and evaluation in sport in development relationships. Sport in Society, 15(6), p. 888-904. DOI: $10.1080 / 17430437.2012 .708289$

Kay, T., \& Bradbury, S. (2009). Youth sport volunteering: Developing social capital? Sport, Education and Society, 14(1), 121-140. DOI: 10.1080/13573320802615288

Kidd, B. (2008). A new social movement: Sport and development and peace. Sport in Society, 11(4), 370-380. DOI: 10.1080/17430430802019268

Kim, K. (2012, March). The Capability Approach to environmental refugees. Paper presented at the Western Political Science Association annual meeting, Portland, OR.

Kinghorn, P., Robinson, A., \& Smith, R. D. (2015). Developing a capability-based questionnaire for assessing well-being in patients with chronic pain. Social Indicators Research, 120(3), 897-916. DOI: 10.1007/s11205-014-0625-7

Kleiner, M. (2012). Sport for development and peace. In K. Gilbert \& W. Bennett (Eds.) Sport, Peace \& Development (pp. 31-60). Champaign, Illinois: Common Ground Publishing, LLC. 
Koss, J. O., \& Alexandrova, A. (2005). Essay: HIV/AIDS prevention and peace through sport. Lancet, 366(Supp1. 1), S3-S4. DOI: 10.1016/S0140-6736(05)67820-8

Lambert, D., Solem, M., \& Tani, S. (2013). Geocapabilities: Toward an international framework for researching the purposes and values of geography education. Review of International Geographical Education Online, 3(3), 214-229.

Lambert, D., Solem, M., \& Tani, S. (2015). Achieving human potential through geography education: A capabilities approach to curriculum making in schools. Annals of the Association of American Geographers, 105(4), 723-735. DOI: $10.1080 / 00045608.2015 .1022128$

Lecrom, C., \& Dwyer, B. (2013). Plus-sport: The impact of a cross-cultural soccer coaching exchange. Journal of Sport for Development, 1(2), 1-16.

Levermore, R. (2008a). Sport: a new engine of development? Progress in Development Studies, 8(2), 183-190. DOI: 10.1177/146499340700800204

Levermore, R. (2008b). Sport in international development: Time to treat it seriously? Brown Journal of World Affairs, 14(2), 55-66.

Levermore, R. (2011). Evaluating sport-for-development. Progress in Development Studies, 11(4), 339-353. DOI: 10.1177/146499341001100405

Levermore, R., \& Beacom, A. (2009). Sport and development: Mapping the field. In R. Levermore \& A. Beacom (Eds.) Sport and international development (pp. 1-25). Basingstoke, England: Palgrave Macmillan.

Lincoln, Y. S., \& Guba, E. G. (1985). Naturalist Inquiry. Thousand Oaks, CA: Sage Publications, Inc. 
Lincoln, Y. S., \& Guba, E. G. (2013). The constructivist credo. Walnut Creek, CA: Left Coast Press, Inc.

Lindlof, T. R. (1995). Qualitative communication research methods. Thousand Oaks, CA: Sage Publications, Inc.

Lindsey, I., \& Grattan, A. (2012). An 'international movement'? Decentring sport-fordevelopment within Zambian communities. International Journal of Sport Policy and Politics, 4(1), 91-110. DOI: 10.1080/19406940.2011.627360

Lyras, A., \& Hums, M. (2009). Sport and social change: The case for gender equity. Journal of Physical Education, Recreation \& Dance, (80)1, 7-21. DOI: $10.1080 / 07303084.2009 .10598256$

Lyras, A., \& Welty Peachey, J. W. (2011). Integrating sport-for-development theory and praxis. Sport Management Review, 14(4), 311-326. DOI:

10.1016/j.smr.2011.05.006

MacAloon, J. (2006). Muscular Christianity in colonial and post-colonial worlds. International Journal of the History of Sport 23(5), 687-700. DOI: https://doi.org/10.1080/17460263.2013.825964

Maro, C. N., Roberts, G. C., \& Sorensen, M. (2009). Using sport to promote HIV/AIDS education for at-risk youths: an intervention using peer coaches in football. Scandinavian Journal of Medicine and Science in Sports, 19(1), 129-141. DOI: $10.1111 / \mathrm{j} .1600-0838.2007 .00744 . \mathrm{x}$

Marshall, S. K., \& Barry, P. (2015). Community sport for development: Perceptions from practice in Southern Africa. Journal of Sport Management, 29(1), 109-121. DOI: 10.1123/JSM.2012-0301 
Marshall, C., \& Rossman, G. B. (2011). Desiging qualitative research (4th ed.). Thousand Oaks, CA: Sage Publications, Inc.

Massey, W. V., Whitley, M. A., Blom, L., \& Gerstein, L. H. (2015). Sport for development and peace: A systems theory perspective on promoting sustainable change. International Journal of Sport Management and Marketing, 16(1/2), 1817-35. DOI: 10.1504/IJSMM.2015.074921

McConkey, R., Dowling, S., Hassan, D. \& Menke, S. (2013). Promoting social inclusion through unified sports for youth with intellectual disabilities: A five-nation study. Journal of Intellectual Disability Reseach, 57(10), 923-935. DOI: 10.1111/j.13652788.2012.01587.x

McLean, M., \& Walker, M. (2012). The possibilities for university-based public-good professional education: A case-study from South Africa based on the "capability approach.” Studies in Higher Education, 37(5), 585-601. DOI:

$10.1080 / 03075079.2010 .531461$

McNeil, D. (2007). "Human development": The power of the idea. Journal of Human Development, 8(1), 7-22. DOI: 10.1080/14649880601101366

Miles, M. B., Huberman, A. M., \& Saldaña, J. (2014). Qualitative data analysis: A methods sourcebook. Thousand Oaks, CA: Sage Publications, Inc.

Moustakas, C. (1994). Phenomenological research methods. Thousand Oaks, CA: Sage Publications, Inc.

Murphy, M. (2014). Self-determination as a collective capability: The case of indigenous peoples. Journal of Human Development \& Capabilities, 15(4), 320-334. DOI: $10.1080 / 19452829.2013 .878320$ 
Neumayer, E. (2001). The human development index and sustainability - a constructive proposal. Ecological Economics, 39(1), 101-114.

Nicholls, S., Giles, A. R., \& Sethna, C. (2010). Perpetuating the 'lack of evidence' discourse in sport for development: Privileged voices, unheard stories and subjugated knowledge. International Review for the Sociology of Sport, 46(3), 249-264. DOI: 10.1177/1012690210378273

Nussbaum, M. (1997). Capabilities and human rights. Fordham Law Review, 66(2), 273300.

Nussbaum, M. (1999). Women and equality: The capabilities approach. International Labour Review, 138(3), 227-245. DOI: 10.1111/j.1564-913X.1999.tb00386.x

Nussbaum, M. C. (2000). Women and human development: The capabilities approach. Cambridge; England: Cambridge University Press.

Nussbaum, M. (2003). Capabilities as fundamental entitlements: Sen and social justice. Feminist Economics, 9(2-3), 33-59. DOI: 10.1080/1354570022000077926

Nussbaum, M. C. (2011). Creating capabilities: The human development approach. Cambridge, Massachusetts: The Belknap Press of Harvard University Press.

Patton, M. Q. (2014). Qualitative Research and Evaluation Methods (4th ed.). Thousand Oaks, CA: Sage Publications, Inc.

Peercy, C., \& Svenson, N. (2016). The role of higher education in equitable human development. International Review of Education, 62(2), 139-160. DOI: $10.1007 / \mathrm{s} 11159-016-9549-6$ 
Pensgaard, A. M., \& Sorensen, M. (2002). Empowerment through the sport context: A model to guide research for individuals with disability. Adapted Physical Activity Quarterly, 19(1), 48-67.

Pitter, R., \& Andrews, D. (1997). Serving America's underserved youth: Reflections on sport and recreation in an emerging social problems industry. Quest, 49(1), 85-99. DOI: 10.1080/00336297.1997.10484225

Qizilbash, M. (2011). Sugden's critique of the capability approach. Utilitas, 23(1), 25-51. DOI: $10.1007 / \mathrm{s} 12232-011-0112-2$

Ranis, G., Stewart, F., \& Ramirez, A. (2000). Economic growth and human development. World Development, 28(2), 197-219. DOI: 10.1016/j.ecolecon.2007.05.011

Ricigliano, R. (2012) Making Peace Last: A Toolbox for Sustainable Peacebuilding, Paradigm Publishers, Boulder, CO.

Riggen, K. \& Ulrich, D. (1993). The effects of sport participation on individuals with mental retardation. Adapted Physical Activity Quarterly, 10(1), 42-51.

Right to Play. (2015). What we do. Retrieved from http://www.righttoplay.com/Learn/ourstory/Pages/What-we-do.aspx.

Robeyns, I. (2003). Sen's capability approach and gender inequality: Selecting relevent capabilities. Feminist Economics, 9(2-3), 61-92. DOI: $10.1080 / 1354570022000078024$

Robeyns, I. (2005). The Capability Approach: a theoretical survey. Journal of Human Development, 6(1), 93-114. DOI: 10.1080/146498805200034266

Robeyns, I. (2006). The Capability Approach in Practice. Journal of Political Philosophy, 14(3), 351-376. DOI: 10.1111/j.1467-9760.2006.00263.x 
Robeyns, I. (2011). The capability approach. In E. Zatla, U. Nodelman, C. Allen, \& J. Perry (Eds.), Stanford Encyclopedia of Philosophy (pp. 1-40). Stanford, CA: Stanford University.

Robeyns, I. (2017). Wellbeing, freedom and social justice: The Capability Approach reexamined. Cambridge, UK: Open Book Publishers.

Rossi, T. (2015). Expecting too much? Can indigenous sport programmes in Australia deliver development and social outcomes? International Journal of Sport Policy and Politics, 7(2), 181-195. DOI: 10.1080/19406940.2014.971125

Saito, M. (2003). Amartya Sen's Capability Approach to education: A critical exploration. Journal of Philosophy of Education, 37(1), 17-33. DOI: $10.1111 / 1467-9752.3701002$

Saldaña, J. (2013). The coding manual for qualitative researchers, (2nd ed.). Thousand Oaks, CA: Sage Publications, Inc.

Samie, S., Johnson, A., Huffman, A., and Hillyer, S. (2015) Voices of empowerment: Women from the global south re/renegotiating empowerment and the global sports mentoring programme. Sport in Society, 18(8) 923-937. DOI: $10.1080 / 17430437.2014 .997582$

Sanders, B. (2016). An own goal in sport for development: Time to change the playing field. Journal of Sport for Development, 4(6), 1-5.

Schischka, J., Dalziel, P., \& Saunders, C. (2008). Applying Sen's capability approach to poverty alleviation programs: Two case studies. Journal of Human Development, 9(2), 229-246. DOI: 10.1080/14649880802078777

Schulenkorf, N. (2010) Sport events and ethnic reconciliation: Attempting to create social 
change between Sinhalese, Tamil and Muslim sportspeople in war-torn Sri Lanka. International Review for the Sociology of Sport, 45(3), 273-294. DOI: $10.1177 / 1012690210366789$

Schulenkorf, N. (2012). Sustainable community development through sport and events: A conceptual framework for sport-for-development projects. Sport Management Review, 15(1), 1-12. DOI: 10.1016/j.smr.2011.06.001

Schulenkorf, N., \& Edwards, D. (2012). Maximizing positive social impacts: Strategies for sustaining and leveraging the benefits of intercommunity sport events in divided societies. Journal of Sport Management, 26(5), 379-390.

Schulenkorf, N., Sherry, E., \& Rowe, K. (2016) Sport-for-development: An integrated literature review. Journal of Sport Management, 30(1), 22-39. DOI: http://dx.doi.org/10.1123/jsm.2014-0263

Schulenkorf, N., \& Spaaij, R. (2015). Commentary: Reflections on theory building in sport for development and peace. International Journal for Sport Management and Marketing, 16(1/2), 71-77.

Schulenkorf, N., \& Sugden, J. (2011). Sport for development and peace in divided societies: Cooperating for inter-community empowerment in Israel. European Journal for Sport and Society, 8(4), 235-256. DOI: https://doi.org/10.1080/16138171.2011.11687881

Schulenkorf, N., Sugden, J. \& Burdsey, D. (2014). Sport for development and peace as contested terrain: Place, community, ownership. International Journal of Sport Policy and Politics, 6(3), 371-387. DOI: 10.1080/19406940.2013.825875 
Sen, A. (1981). Poverty and famines: An essay on entitlement and deprivation. Oxford, England: Oxford University Press.

Sen, A. (1985). Commodities and capabilities. New York, N.Y. Elsevier Science Publishing.

Sen, A. (1989). Development as capability expansion. Journal of Developmental Planning, 19, 41-58.

Sen, A. (1992). Inequality Reexamined. Cambridge, MA: Harvard University Press. Sen, A. (1997). Editorial: Human capital and human capability. World Development, 25(12), 1959-1961.

Sen, A. (1998). Human development and financial conservatism. World Development, 26(4), 733-742.

Sen, A. (1999). Development as freedom. New York, NY: Oxford University Press.

Sen, A. (2000). A decade of human development. Journal of Human Development, 1(1), 17-23. DOI: $10.1080 / 14649880050008746$

Sen, A. (2005). Human rights and capabilities. Journal of Human Development Journal of Human Development, 6(2), 151-166. DOI: 10.1080/14649880500120491

Sen, A. (2009). Forward. In S. Fukuda-Parr \& A.K. Shiva Kumar (Eds.), Oxford handbook of human development: Concepts, measures, and policies (pp. ix-xv). New Delhi, India: Oxford University Press.

Shand, W. (2014). Growing up on the street - Understanding the lives of street children and youth in Africa. In S. Ibrahim \& M. Tiwari (1st ed., pp. 73-92). Basingstoke, England: Palgrave Macmillan. 
Sherrill, C. (1997). Disability sport, identity, and involvement in sport and exercise. In K. R. Fox (Ed.), The physical self: From motivation to well-being (pp. 257-286). Champaign, IL: Human Kinetics.

Silva, C. F., \& Howe, P. D. (2012). Difference, adapted physical activity and human development: Potential contribution of capabilities approach. Adapted Physical Activity Quarterly, 29(1), 25-43. DOI https://doi.org/10.1123/apaq.29.1.25

Simon, J., Anand, P., Gray, A., Rugkasa, J., Yeeles, K., \& Burns, T. (2013).

Operationalising the capability approach for outcome measurement in mental health research. Social Science \& Medicine Social Science \& Medicine, 98(C), 187-196. DOI: 10.1016/j.socscimed.2013.09.019

Sit, H.P., Linder, K. J., \& Sherrill, C. (2002). Sport participation of Hong Kong Chinese children with disabilities in special schools. Adapted Physical Activity Quarterly, 19(4), 453-471. DOI: 10.1123/apaq.19.4.453

Spaaij, R., \& Jeanes, R. (2013). Education for social change? A Freirean critique of sport for development and peace. Physical Education and Sport Pedagogy, 18(4), 442457. DOI: $10.1080 / 17408989.2012 .690378$

Srinivasan, T. N. (1994). Human development: A new paradigm or reinvention of the wheel? The American Economic Review, 84(2), 238-243.

Sugden, J. (2006) Teaching and playing sport for conflict resolution and co-existence in Israel. International Review for the Sociology of Sport, 41(2), 221-240. DOI: $10.1177 / 1012690206075422$

Sugden, J. (2010). Critical left-realism and sport interventions in divided societies. 
International Review for the Sociology of Sport, 45(3), 258-272. DOI:

$10.1177 / 1012690210374525$

Sugden, J. (2015). Assessing the sociology of sport: On the capacities and limits of using sport to promote social change. International Review for the Sociology of Sport, 5O(4-5), 606-611. DOI: 10.1177/1012690214555166

Sugden, R. (1993). Review: Welfare, resources, and capabilities: A review of inequality reexamined by Amartya Sen. Journal of Economic Literature, 31(4), 1947-1962.

Svensson, P. G., \& Levine, J. F. (2017). Rethinking Sport-for-Development: The Capability Approach. Sport in Society. 20(7), 905-923. DOI:

https://doi.org/10.1080/17430437.2016.1269083

Swiss Academy of Development. (2005). Gender equity, sport and development: Working paper. Biel/Bienne, Switzerland: Meier, M.

Taylor, A. (1979). 'What's wrong with negative liberty?' In A. Ryan (Ed.), The Idea of Freedom (pp.175-193). Oxford: Oxford University Press.

Terzi, L. (2005). Beyond the dilemma of difference: The capability approach to disability and special educational needs. Journal of Philosophy of Education, 39(3), 443459. DOI: $10.1111 / \mathrm{j} .1467-9752.2005 .00447 . \mathrm{x}$

United Nations (n.d.) Sport and Child Youth Development Thematic Working Group. New York, NY. Retrieved from https://www.un.org/sport/sites/www.un.org.sport/files/ckfiles/files/Action\%20Pla n_Sport $\% 20$ and $\% 20$ Child\%20\%26\%20Youth\%20Development_FINAL_New.pd $\mathrm{f}$ 
United Nations. (1990). Human Development Report 1990. New York, NY: Oxford University Press.

United Nations. (2003) Sport for development and peace: Towards achieving the Millennium Development Goals. Report from the United Nations Inter-Agency Task Force on Sport for Development and Peace. New York, NY.

United Nations Inter-Agency Task Force on Sport for Development and Peace. (2003). Sport as a Tool for Development and Peace: Towards Achieving the United Nations Millennium Development Goals. New York, NY.

United Nations Office of Sport for Development and Peace. (2011). Achieving the objectives of the United Nations through sport. New York, NY.

United Nations Office of Sport for Development and Peace (2015). Annual Report 2014. New York, NY.

United Nations Office of Sport for Development and Peace (n.d.), Sport and Child \& Youth Development Thematic Working Group Action Plan 2010-2012. New York, NY.

United Nations Office of Sport for Development and Peace. (n.d.). Sport and Gender Thematic Working Group Action Plan 2011-2013. New York, NY.

United Nations Sport for Development and Peace International Working Group (2008). Harnessing the power of sport for development and peace: Recommendations to governments. New York, NY.

Vizard, P. (2006). The HDCA approach and human rights [White paper]. Human Development and Capability Association. Retrieved from https://hdca.org/?s2member_file_download=/HDCA_Briefing_HumanRights.pdf 
Wagle, U. R. (2014). The counting-based measurement of multidimensional poverty: The focus on economic eesources, inner capabilities, and relational resources in the United States. Social Indicators Research, 115(1). 223-240. DOI: $10.1007 / \mathrm{s} 11205-012-0216-4$

Weiss, M. R. (2008). "Field of dreams": Sport as a context for youth development. Research Quarterly for Exercise and Sport, 79(4), 434-449. DOI: $10.1080 / 02701367.2008 .10599510$

Welty Peachey, J. (2015). Introduction. International Journal of Management and Marketing, 16(1/2), 1-4.

Welty Peachey, J., Borland, J., Lobpries, J., \& Cohen, A. (2015). Managing impact: Leveraging sacred spaces and community celebration to maximize social capital at a sport-for-development event. Sport Management Review, 18(1), 86-98. DOI: http://dx.doi.org/10.1016/j.smr.2014.05.003

Welty Peachey, J., \& Cohen, A. (2016). Research partnerships in sport for development and peace: Challenges, barriers, and strategies. Journal of Sport Management, 30(3), 282-297. DOI: http://dx.doi.org/10.1123/jsm.2014-0288

Wilson, B. (2012). Sport \& peace: A sociological perspective. Don Mills, Ontario: Oxford University Press.

World Health Organization. (2003) Health and development through physical activity and sport. World Health Organization Noncommunicable Diseases and Mental Health Noncommunicable Disease Prevention and Health Promotion. Geneva, Switzerland. 
World Health Organization (2004). Girls' participation in physical activities and sports: Benefits, patterns, influences and ways forward. Geneva: Bailey, R., Wellard, I., \& Dismore, $\mathrm{H}$.

World Health Organization. (2007). Engaging men and boys in changing gender-based inequity in health: Evidence from programme interventions. Geneva: Barker, G., Ricardo, C., \& Nascimento, M.

Yin, R. K. (2014). Case study research: Design and methods (5th ed.). Thousand Oaks, CA: Sage Publications, Inc.

Youth Odyssey (n.d.a). History. Retrieved from http://youthodyssey.com/history.php Youth Odyssey (n.d.b). Our mission statement. Retrieved from http://youthodyssey.com/index.php

Youth Odyssey (2014). Normal program narrative [describes Youth Odyssey programs]. Hard copy on file with the author.

Youth Odyssey (2015). Soft skills manual [provides facilitators with comprehensive instruction on games and initiatives related to Youth Odyssey program]. Hard copy on file with the author.

Youth Odyssey (2017, January 20). Youth Odyssey Chris Takes a Walk on the Wild Side. Retrieved from https://youthodyssey.com/2017/01/20/chris-takes-a-walkon-the-wild-side/ 


\section{APPENDIX A: INTERVIEW PROTOCOLS}

\section{Employee Protocol}

\section{Preliminary Information for the Interviewer}

- Discuss informed consent with the interviewee.

- Confirm that interview can be stopped at any time if interviewee becomes uncomfortable.

- Confirm that interviewer is allowed to record interview.

- Explain that a pseudonym will be used to ensure anonymity

- Ask if interviewee has any questions before beginning. Ask and answer any questions.

- Thank the interviewee at the beginning and end of the interview.

\section{Subject background and preliminary questions}

1. Tell me about your experience with Youth Odyssey.

2. What drew you to Youth Odyssey?

PROBE

Why did you apply to be an employee?

3. Why do you think Youth Odyssey is important?

4. From your perspective, what is important to the children that participate in Youth Odyssey (Greco et al., 2015)?

\section{RQ 1: What capabilities are Youth Odyssey creating for its participants?}

5. What do you think participants gain by taking part in Youth Odyssey (Nussbaum, 2011, Sen, 1999)?

PROBES

What are the benefits (Schischka et al., 2008)?

What skills or knowledge have participants gained as a result of being a part of Youth Odyssey (Schischka et al., 2008)?

6. What does Youth Odyssey give to participants that they cannot get anywhere else (Clark, et al., 2006; Alkire, 2005)?

\section{PROBES}

What does Youth Odyssey do to give participants these unique skills?

What does Youth Odyssey do to give participants these unique experiences?

What does Youth Odyssey do to give participants these unique opportunities? 
7. Can you share an example of a time where, in your perception, Youth Odyssey helped a participant do something that $\mathrm{s} /$ he could not do before?

8. What can someone who participates in Youth Odyssey achieve that someone who does not participate in Youth Odyssey not achieve? (Nussbaum, 2011, Sen, 1999).

\section{RQ 2: What functionings are being supported by Youth Odyssey?}

9. What are some of the reasons why participants take part in Youth Odyssey (Kinghorn et al., 2014; Nussbaum, 2011; Sen, 1999)?

\section{PROBE}

From your perspective, what are some of the participants' needs from this program?

10. How does Youth Odyssey help participants discover their passions (Alkire \& Deneulin, 2009; Coakley, 2011; Hayhurst 2013)?

\section{PROBE}

From your perspective, what are some of the aspirations of Youth Odyssey participants?

11. How does Youth Odyssey help participants become who they want to be (Frediani, 2010; Goodwin et al., 2004; Kinghorn et al., 2014)?

12. How does Youth Odyssey help participants accomplish what they want to do in life (Frediani, 2010; Goodwin et al., 2004; Kinghorn et al., 2014)?

13. From your perspective, is there anything unique to living in South Texas that impacts the kids who participate in Youth Odyssey (Robeyns, 2011)?

\section{PROBE}

From your perspective, is there anything unique about the kids who participate in Youth Odyssey?

\section{RQ 3: How does Youth Odyssey help remove barriers for participants?}

14. From your perspective, what are the challenges that Youth Odyssey participants face living in South Texas (McLean \& Walker 2012; Terzi, 2005)?

a. Examples

i. Financial struggles (Schischka et al., 2008)

ii. Social issues (Be, 2014; Hayhurst, 2013)

iii. Educational challenges (Hayhurst, 2013)

iv. Health related issues (Kaufman et al., 2012)

\section{PROBES}

From your perspective, is there anything specific to the children who participate in Youth Odyssey that makes it more difficult for them to be successful in life (Robeyns, 2005, Sen, 1999)?

From your perspective, how does Youth Odyssey help participants overcome these challenges to success?

15. From your perspective, what does Youth Odyssey do to help overcome the challenges that participants face (McLean \& Walker 2012; Terzi, 2005; Sen, 1999)? 
16. How does living in Corpus Christi and the greater South Texas community Youth Odyssey impact participants (Alkire, 2011; Sen, 1999)?

\section{RQ 4: How does Youth Odyssey help participants improve well-being?}

17. What does Youth Odyssey do to improve the lives of participants (Alkire, 2002b; Nussbaum, 2001; Sen, 1999)?

PROBE

How does that improve the participant's life?

18. From your perspective how, if at all, have you seen Youth Odyssey change participants?

19. From your perspective how has, if at all, Youth Odyssey participants' ability to pursue their passions evolved through participating in programming (FukudaParr, 2002)?

\section{Parent/Guardian Protocol}

\section{Preliminary Information for the Interviewer}

- Discuss informed consent with the interviewee.

- Confirm that interview can be stopped at any time if interviewee becomes uncomfortable.

- Confirm that interviewer is allowed to record interview.

- Explain that a pseudonym will be used to ensure anonymity

- Ask if interviewee has any questions before beginning. Ask and answer any questions.

- Thank the interviewee at the beginning and end of the interview.

\section{Subject background and preliminary questions}

1. Tell me about your experience with Youth Odyssey.

2. What drew you to Youth Odyssey?

PROBE

Why did you choose to enroll your child in Youth Odyssey?

3. Why do you think Youth Odyssey is important?

4. From your perspective, what is important to your child about participating in Youth Odyssey (Greco et al., 2015)?

\section{RQ 1: What capabilities are Youth Odyssey creating for its participants?}

5. What do you think your child gains by taking part in Youth Odyssey (Nussbaum, 2011, Sen, 1999)?

PROBES

What are the benefits (Schischka et al., 2008)?

What skills or knowledge has your child gained as a result of being a part of Youth Odyssey (Schischka et al., 2008)? 
6. What does Youth Odyssey give to your child that $\mathrm{s} / \mathrm{he}$ cannot get anywhere else (Clark, et al., 2006; Alkire, 2005)?

\section{PROBES}

What does Youth Odyssey do to give your child these unique skills?

What does Youth Odyssey do to give your child these unique experiences?

What does Youth Odyssey do to give participants these unique opportunities?

7. Can you share an example of a time where, in your opinion, Youth Odyssey helped your child learn something that $\mathrm{s} / \mathrm{he}$ did not know before?

8. What can someone who participates in Youth Odyssey achieve that someone who does not participate in Youth Odyssey not achieve? (Nussbaum, 2011, Sen, 1999).

\section{RQ 2: What functionings are being supported by Youth Odyssey?}

9. What are some of the reasons why your child takes part in Youth Odyssey (Kinghorn et al., 2014; Nussbaum, 2011; Sen, 1999)?

PROBE

In your opinion, what does your child need from this program?

10. How does Youth Odyssey help your child discover his or her passions (Alkire \& Deneulin, 2009; Coakley, 2011; Hayhurst 2013)?

PROBE

What are your child's aspirations?

11. How does Youth Odyssey help your child become who he or she wants to be (Frediani, 2010; Goodwin et al., 2004; Kinghorn et al., 2014)?

12. How does Youth Odyssey help your child accomplish what he or she wants to do in life (Frediani, 2010; Goodwin et al., 2004; Kinghorn et al., 2014)?

13. From your perspective, is there anything unique to living in South Texas that impacts your child (Robeyns, 2011)?

PROBE

From your perspective, is there anything unique about the kids who participate in Youth Odyssey?

\section{RQ 3: How does Youth Odyssey help remove barriers for participants?}

14. From your perspective, what are the challenges that your child faces living in South Texas (McLean \& Walker 2012; Terzi, 2005)?

b. Examples

i. Financial struggles (Schischka et al., 2008)

ii. Social issues (Be, 2014; Hayhurst, 2013)

iii. Educational challenges (Hayhurst, 2013)

iv. Health related issues (Kaufman et al., 2012)

PROBE

How does Youth Odyssey help your child overcome these challenges to success? 
15. From your perspective, what does Youth Odyssey do to help overcome the challenges that your child faces (McLean \& Walker 2012; Terzi, 2005; Sen, 1999)?

16. How does living in Corpus Christi and the greater South Texas community Youth Odyssey impact your child (Alkire, 2011; Sen, 1999)?

\section{RQ 4: How does Youth Odyssey help participants improve well-being?}

17. What were your expectations when you enrolled your child into Youth Odyssey? PROBES

What additional benefits and opportunities did you think joining Youth Odyssey would provide your child?

How have your expectations been met or not met?

18. What does Youth Odyssey do to improve the lives of your child (Alkire, 2002b; Nussbaum, 2001; Sen, 1999)?

PROBE

How does that improve your child's life?

19. How has participating in Youth Odyssey changed your child?

PROBES

Does your child feel more fulfilled (Sen, 1985)?

Does your child feel greater achievement (Sen, 1985)?

How has your child's beliefs about what s/he can do and be in society changed as $\mathrm{s} / \mathrm{he}$ has spent more time participating in Youth Odyssey (Sen, 1999)?

20. How has, if at all, your child's ability to pursue his or her passions evolved through participating in Youth Odyssey (Fukuda-Parr, 2002)? 
APPENDIX B: RESEARCH QUESTIONS GRID

\section{Employee Protocol}

\begin{tabular}{|c|c|c|c|c|c|}
\hline & $\begin{array}{l}\text { RQ1: What } \\
\text { capabilities are } \\
\text { Youth Odyssey } \\
\text { creating for its } \\
\text { participants? }\end{array}$ & $\begin{array}{l}\text { RQ2: What } \\
\text { functionings } \\
\text { are being } \\
\text { supported by } \\
\text { Youth } \\
\text { Odyssey? }\end{array}$ & $\begin{array}{l}\text { RQ3: How } \\
\text { does Youth } \\
\text { Odyssey help } \\
\text { remove } \\
\text { barriers for } \\
\text { participants? }\end{array}$ & $\begin{array}{l}\text { RQ4: How does } \\
\text { Youth Odyssey } \\
\text { help } \\
\text { participants } \\
\text { improve well- } \\
\text { being? }\end{array}$ & $\begin{array}{l}\text { Preliminary } \\
\text { Question }\end{array}$ \\
\hline Q 1 & & & & & $\mathrm{X}$ \\
\hline Q 2 & & & & & $X$ \\
\hline Q 3 & & & & & $X$ \\
\hline Q 4 & & $X$ & & $X$ & $X$ \\
\hline Q 5 & $X$ & & & $X$ & \\
\hline Q 6 & $X$ & & & $X$ & \\
\hline Q 7 & $X$ & & & $X$ & \\
\hline Q 8 & $X$ & & & $X$ & \\
\hline Q 9 & $X$ & $X$ & & & \\
\hline Q 10 & & $X$ & & & \\
\hline Q 11 & & $X$ & $X$ & & \\
\hline Q 12 & & $X$ & $X$ & & \\
\hline Q 13 & & & $\mathrm{X}$ & & \\
\hline Q 14 & & & $\mathrm{X}$ & & \\
\hline Q 15 & & & $X$ & $X$ & \\
\hline Q 16 & & & $\mathrm{X}$ & & \\
\hline Q 17 & $X$ & & & $X$ & \\
\hline
\end{tabular}




$\begin{array}{llllll}\text { Q } 18 & \text { X } & & & \text { X } & \text { X } \\ \text { Q 19 } & \text { X } & \text { X } & X & X\end{array}$




\section{Parent/Guardian Protocol}

\begin{tabular}{|c|c|c|c|c|c|}
\hline & $\begin{array}{l}\text { RQ1: What } \\
\text { capabilities are } \\
\text { Youth Odyssey } \\
\text { creating for its } \\
\text { participants? }\end{array}$ & $\begin{array}{l}\text { RQ2: What } \\
\text { functionings } \\
\text { are being } \\
\text { supported } \\
\text { by Youth } \\
\text { Odyssey? }\end{array}$ & $\begin{array}{l}\text { RQ3: How } \\
\text { does Youth } \\
\text { Odyssey help } \\
\text { remove } \\
\text { barriers for } \\
\text { participants? }\end{array}$ & $\begin{array}{l}\text { RQ4: How } \\
\text { does Youth } \\
\text { Odyssey help } \\
\text { participants } \\
\text { improve well- } \\
\text { being? }\end{array}$ & $\begin{array}{l}\text { Preliminary } \\
\text { Question }\end{array}$ \\
\hline Q 1 & & & & & $\mathrm{X}$ \\
\hline Q 2 & & & & & $X$ \\
\hline Q 3 & & & & & $X$ \\
\hline Q 4 & & $\mathrm{X}$ & & $\mathrm{X}$ & $X$ \\
\hline Q 5 & $\mathrm{X}$ & & & $X$ & \\
\hline Q 6 & $X$ & & & $X$ & \\
\hline Q 7 & $X$ & & & $\mathrm{X}$ & \\
\hline Q 8 & $X$ & & & $\mathrm{X}$ & \\
\hline Q 9 & $X$ & $X$ & & & \\
\hline Q 10 & & $X$ & & & \\
\hline Q 11 & & $X$ & $X$ & & \\
\hline Q 12 & & $\mathrm{X}$ & $X$ & & \\
\hline Q 13 & & X & $\mathrm{X}$ & & \\
\hline \multicolumn{6}{|l|}{ Q 14} \\
\hline \multicolumn{6}{|l|}{ Q 15} \\
\hline Q 16 & & & $X$ & & \\
\hline Q 17 & $X$ & $\mathrm{X}$ & $\mathrm{X}$ & $X$ & \\
\hline
\end{tabular}




$\begin{array}{ccccc}\text { Q 18 } & \text { X } & & & \text { X } \\ \text { Q 19 } & \text { X } & \text { X } & \text { X } & \text { X } \\ \text { Q 20 } & \text { X } & \text { X } & \text { X } & \text { X }\end{array}$


APPENDIX C: INTERVIEW INFORMED CONSENT AGREEMENT

\section{Subject Informed Consent Document}

\section{Exploring sport for development and peace and the capabilities approach}

IRB assigned number:

Investigator(s) name \& address:
16.1048

Mary Hums, Ph.D.

Department of Health and Sport Sciences

HP/Studio Arts Room 107

University of Louisville

Louisville, KY 40292

Jeffrey Levine, J.D.

Department of Health and

Sport Sciences

HP/Studio Arts Room 110

University of Louisville

Louisville, KY 40292

Youth Odyssey

(248) 939-7864
Site(s) where study is to be conducted:

Phone number for subjects to call for questions:

\section{Introduction and Background Information}

You are invited to participate in a research study. The study is being conducted by Mary Hums, $\mathrm{PhD}$, and Jeffrey Levine, J.D. The study is sponsored by the University of Louisville, Department of Health and Sport Sciences. The study will take place at Youth Odyssey, located in Corpus Christi, Texas. Approximately 20 subjects will be invited to participate.

\section{Purpose}

The purpose of this study is to explore why people participate in, volunteer with, or otherwise become involved with Youth Odyssey. The study will also help us learn about 
the benefits people receive by being involved with Youth Odyssey programs and challenges people encounter by participating in Youth Odyssey programs.

\section{Procedures}

In this study, you will be asked to participate in a one-on-one interview about your experiences with Youth Odyssey. The interview will take approximately 60 to 90 minutes to complete. The study will take place from August 2016 to December 2016. Your participation in the study is voluntary. You may decline to answer any question that make you feel uncomfortable or may withdraw at any time, without penalty, if your participation makes you feel uncomfortable.

\section{Potential Risks}

There are no foreseeable risks other than possible discomfort in answering personal questions. Although, there may also be unforeseen risks.

\section{Benefits}

The possible benefits of this study include providing information about why people participate in Youth Odyssey and any challenges associated with participating in Youth Odyssey. The information collected may not benefit you directly. The information learned in this study may be helpful to others.

\section{Compensation}

You will not be compensated for your time, inconvenience, or expenses while you are in this study.

\section{Confidentiality}

Total privacy cannot be guaranteed. Your privacy will be protected to the extent permitted by law. If the results from this study are published, your name will not be made public. While unlikely, the following may look at the study records:

The University of Louisville Institutional Review Board and Human Subjects Protection Program Office.

\section{Conflict of Interest}

This study involves a conflict of interest because the investigator will be compensated for your participation in it. Please ask the investigator how the investigator will benefit by your participation in the study.

\section{Security}


Your information will be kept private by securing this information within in a locked office and on a password protected and encrypted computer.

\section{Voluntary Participation}

Taking part in this study is voluntary. You may choose not to take part at all. If you decide to be in this study you may stop taking part at any time. If you decide not to be in this study or if you stop taking part at any time, you will not lose any benefits for which you may qualify.

You will be told about any changes that may affect your decision to continue in the study.

\section{Contact Persons, Research Subject's Rights, Questions, Concerns, and Complaints}

If you have any concerns or complaints about the study or the study staff, you have three options.

You may contact the principal investigator at (502) 852-5908.

If you have any questions about your rights as a study subject, questions, concerns or complaints, you may call the Human Subjects Protection Program Office (HSPPO) (502) 852-5188. You may discuss any questions about your rights as a subject, in secret, with a member of the Institutional Review Board (IRB) or the HSPPO staff. The IRB is an independent committee composed of members of the University community, staff of the institutions, as well as lay members of the community not connected with these institutions. The IRB has reviewed this study.

If you want to speak to a person outside the University, you may call 1-877-8521167. You will be given the chance to talk about any questions, concerns or complaints in secret. This is a 24-hour hot line answered by people who do not work at the University of Louisville.

\section{Acknowledgment and Signatures}

This informed consent document is not a contract. This document tells you what will happen during the study if you choose to take part. Your signature indicates that this study has been explained to you, that your questions have been answered, and that you agree to take part in the study. You are not giving up any legal rights to which you are entitled by signing this informed consent document. You will be given a copy of this consent form to keep for your records.

\begin{tabular}{lll}
\hline Subject Name (Please Print) & Signature of Subject & Date Signed
\end{tabular}


List of Investigators:

Mary Hums, Ph.D.

Jeffrey Levine, J.D.
Phone Numbers:

(502) 852-5908

(502) 852-8286 
Field Notes Template

Youth Odyssey Project

Observation Site:

Location of researcher within site:

Time exited field:

Time entered into the field:

Subjects observed:

Activities Notes

\section{General Notes}


Analytical Memos 


\section{APPENDIX E: SUMMARY OF STUDY SOURCES}

Table 8

Summary of subject names, designation, interview, date, and time length.

\begin{tabular}{cccc}
\hline Subject Name & Interview Type & Date & Interview length (minutes) \\
\hline Sam & Employee & $12 / 15 / 2016$ & 66 \\
Kira & Employee & $1 / 5 / 2017$ & 71 \\
Jake & Employee & $1 / 6 / 2017$ & 49 \\
Kathryn & Employee & $1 / 13 / 2017$ & 48 \\
Alexis & Parent/Guardian & $1 / 31 / 2017$ & 25 \\
Carol & Parent/Guardian & $1 / 31 / 2017$ & 22 \\
Shannon & Parent/Guardian & $1 / 31 / 2017$ & 27 \\
Rachel & Parent/Guardian & $1 / 31 / 2017$ & 31 \\
Mark & Parent/Guardian & $2 / 3 / 2017$ & 49 \\
Michelle & Parent/Guardian & $2 / 6 / 2017$ & 38 \\
Jennifer & Parent/Guardian & $2 / 7 / 2017$ & 25 \\
Alice & Parent/Guardian & $2 / 8 / 2017$ & 32 \\
Lucy & Parent/Guardian & $2 / 8 / 2017$ & 37 \\
Danielle & Parent/Guardian & $2 / 9 / 2017$ & 43 \\
Maria & Parent/Guardian & $2 / 10 / 2017$ & 27 \\
Patty & Parent/Guardian & $2 / 11 / 2017$ & 43 \\
Alonzo & Parent/Guardian & $2 / 11 / 2017$ & 43 \\
Brian & Parent/Guardian & $2 / 13 / 2017$ & 78 \\
Lynn & Parent/Guardian & $2 / 13 / 2017$ & 49 \\
Leah & Parent/Guardian & $2 / 14 / 2017$ & 37 \\
Emily & Parent/Guardian & $2 / 20 / 2017$ & 32
\end{tabular}

Table 9

Summary of field observation notes

\begin{tabular}{cccccc}
\hline $\begin{array}{c}\text { Field } \\
\text { Note } \\
\text { Number }\end{array}$ & Date & Location & Subject & Hours & Minutes \\
\hline 1 & $12 / 7 / 16$ & Middle School A & Portable Team Challenge & 2 & 11 \\
2 & $12 / 8 / 16$ & Middle School B & Portable Team Challenge & 1 & 3 \\
3 & $12 / 12 / 16$ & Middle School C & Portable Team Challenge & 2 & 18 \\
4 & $12 / 12 / 16$ & Business Office & Youth Odyssey Board of & 0 & 22 \\
& & & Directors Meeting &
\end{tabular}




\begin{tabular}{|c|c|c|c|c|c|}
\hline 5 & $12 / 13 / 16$ & Middle School D & Portable Team Challenge & 2 & 46 \\
\hline 6 & $12 / 14 / 16$ & Middle School A & Portable Team Challenge & 2 & 23 \\
\hline 7 & $12 / 21 / 16$ & $\begin{array}{l}\text { Youth Odyssey } \\
\text { Headquarters }\end{array}$ & Meeting with administrator & 0 & 30 \\
\hline 8 & $1 / 3 / 17$ & $\begin{array}{l}\text { Youth Odyssey } \\
\text { Headquarters }\end{array}$ & New employee orientation & 1 & 57 \\
\hline 9 & $1 / 3 / 17$ & $\begin{array}{l}\text { Youth Odyssey } \\
\text { Headquarters }\end{array}$ & Program meeting & 0 & 36 \\
\hline 10 & $1 / 3 / 17$ & Community Program A & Portable Team Challenge & 1 & 48 \\
\hline 11 & $1 / 4 / 17$ & Business Office & $\begin{array}{l}\text { Youth Odyssey Board of } \\
\text { Directors Meeting }\end{array}$ & 1 & 13 \\
\hline 12 & $1 / 4 / 17$ & Community Program A & Portable Team Challenge & 2 & 0 \\
\hline 13 & $1 / 5 / 17$ & Community Program A & Portable Team Challenge & 2 & 7 \\
\hline 14 & $1 / 9 / 17$ & Community Program B & Portable Team Challenge & 0 & 43 \\
\hline 15 & $1 / 10 / 17$ & Community Program B & Portable Team Challenge & 1 & 52 \\
\hline 16 & $1 / 11 / 17$ & Community Program B & Portable Team Challenge & 2 & 0 \\
\hline 17 & $1 / 12 / 17$ & Home School Program A & Portable Team Challenge & 2 & 11 \\
\hline 18 & $1 / 12 / 17$ & Home School Program B & Portable Team Challenge & 1 & 40 \\
\hline 19 & $1 / 12 / 17$ & Community Program B & Portable Team Challenge & 1 & 5 \\
\hline 20 & $1 / 14 / 17$ & Youth Leader Cohort & Ropes Course Challenge & 2 & 42 \\
\hline 21 & $1 / 16 / 17$ & $\begin{array}{l}\text { Youth Odyssey } \\
\text { Headquarters }\end{array}$ & Program Meeting & 0 & 41 \\
\hline 22 & $1 / 16 / 17$ & Community Program B & Portable Team Challenge & 1 & 32 \\
\hline 23 & $1 / 17 / 17$ & Community Program B & Portable Team Challenge & 1 & 40 \\
\hline 24 & $1 / 18 / 17$ & Community Program B & Portable Team Challenge & 1 & 46 \\
\hline 25 & $1 / 19 / 17$ & Community Program B & Portable Team Challenge & 1 & 45 \\
\hline 26 & $1 / 23 / 17$ & Community Program B & Portable Team Challenge & 1 & 28 \\
\hline 27 & $1 / 24 / 17$ & $\begin{array}{l}\text { Youth Odyssey } \\
\text { Headquarters }\end{array}$ & Program Meeting & 1 & 15 \\
\hline 28 & $1 / 24 / 17$ & Community Program B & Portable Team Challenge & 0 & 58 \\
\hline 29 & $1 / 25 / 17$ & Community Program B & Portable Team Challenge & 1 & 40 \\
\hline 30 & $1 / 26 / 17$ & Home School Program B & Portable Team Challenge & 1 & 7 \\
\hline 31 & $1 / 26 / 17$ & Community Program B & Portable Team Challenge & 1 & 45 \\
\hline 32 & $1 / 31 / 17$ & Community Program C & Portable Team Challenge & 1 & 55 \\
\hline 33 & $2 / 1 / 17$ & Business Office & $\begin{array}{l}\text { Youth Odyssey Board of } \\
\text { Directors Meeting }\end{array}$ & 1 & 17 \\
\hline 34 & $2 / 1 / 17$ & Community Program C & Portable Team Challenge & 1 & 36 \\
\hline 35 & $2 / 2 / 17$ & Community Program C & Portable Team Challenge & 1 & 51 \\
\hline 36 & $2 / 4 / 17$ & $\begin{array}{l}\text { Portable Team Challenge } \\
\text { Participants and Youth } \\
\text { Leaders }\end{array}$ & Ropes Course Challenge & 6 & 19 \\
\hline 37 & $2 / 6 / 17$ & $\begin{array}{l}\text { Youth Odyssey } \\
\text { Headquarters }\end{array}$ & Directors Meeting & 1 & 7 \\
\hline 38 & $2 / 6 / 17$ & Middle School E & Portable Team Challenge & 1 & 56 \\
\hline 39 & 2/9/17 & Even Hall Ballroom & Youth Odyssey Fundraiser & 1 & 30 \\
\hline 40 & $2 / 13 / 17$ & Middle School E & Portable Team Challenge & 2 & 3 \\
\hline 41 & $2 / 14 / 17$ & Middle School F & Portable Team Challenge & 2 & 7 \\
\hline 42 & $2 / 15 / 17$ & Community Program C & Portable Team Challenge & 1 & 44 \\
\hline 43 & $2 / 16 / 17$ & Community Program C & Portable Team Challenge & 1 & 39 \\
\hline
\end{tabular}


Table 10

Summary of artifacts and documents

\begin{tabular}{|c|c|c|}
\hline Artifact/Document Name & Date & Description \\
\hline $\begin{array}{l}\text { Youth Odyssey History - } \\
\text { Regular and Short } \\
\text { Narratives }\end{array}$ & $7 / 1 / 2016$ & $\begin{array}{l}\text { Document provides expanded and abbreviated } \\
\text { narratives of Youth Odyssey's history and mission. }\end{array}$ \\
\hline $\begin{array}{l}\text { Youth Leadership } \\
\text { Program }\end{array}$ & n.d. & $\begin{array}{l}\text { Website contains information about Youth Odyssey's } \\
\text { Youth Leadership program. }\end{array}$ \\
\hline Youth Odyssey Goals & n.d. & $\begin{array}{l}\text { Short document lists Youth Odyssey's goals, } \\
\text { objectives and expected outcomes, and evaluation } \\
\text { tools. }\end{array}$ \\
\hline $\begin{array}{l}\text { Youth Odyssey Normal } \\
\text { Program Narrative }\end{array}$ & n.d. & $\begin{array}{l}\text { Lists Youth Odyssey's programs, and explains each: } \\
\text { Adventure Challenge Program (Portable Team } \\
\text { Challenges, Ropes Challenge Course, Adventure } \\
\text { Wilderness Trip, and Graduation Ceremony), Youth } \\
\text { Leader Program, and Summer Leadership Camps. }\end{array}$ \\
\hline $\begin{array}{l}\text { Youth Odyssey } \\
\text { Abbreviated Mission and } \\
\text { Statistics }\end{array}$ & 2015 & $\begin{array}{l}\text { Short version of organization's mission and data from } \\
2015 \text { regarding statistics gathered by organization. }\end{array}$ \\
\hline $\begin{array}{l}\text { Youth Odyssey } \\
\text { Testimonials }\end{array}$ & n.d. & $\begin{array}{l}\text { Provides testimonies from multiple participants and } \\
\text { parents regarding Youth Odyssey's programming. }\end{array}$ \\
\hline Youth Odyssey Fact Sheet & 2016 & $\begin{array}{l}\text { List Youth Odyssey's mission and other information } \\
\text { related to the organization, its objectives, results, and } \\
\text { programming. }\end{array}$ \\
\hline $\begin{array}{l}\text { Memorandum of } \\
\text { Understanding Between } \\
\text { Youth Odyssey and Home } \\
\text { School Organization }\end{array}$ & 2016 & $\begin{array}{l}\text { Memorandum established relationship and laid out the } \\
\text { rights/responsibilities between the parties concerning } \\
\text { the program. }\end{array}$ \\
\hline $\begin{array}{l}\text { Memorandum of } \\
\text { Understanding Between } \\
\text { Youth Odyssey and } \\
\text { Independent School } \\
\text { District }\end{array}$ & 2016 & $\begin{array}{l}\text { Memorandum established relationship and laid out the } \\
\text { rights/responsibilities between the parties concerning } \\
\text { the program. }\end{array}$ \\
\hline Grant Report & 2016 & $\begin{array}{l}\text { Reported general information of program for schools } \\
\text { that participated in the grant-supported program. }\end{array}$ \\
\hline $\begin{array}{l}\text { Program Report - } \\
\text { Community Program C }\end{array}$ & 2016 & $\begin{array}{l}\text { Provided overview, progression, highlights of two } \\
\text { participants' growth/changes, any program } \\
\text { issues/concerns, suggestions to improve future } \\
\text { programs at this location, and a conclusion on how } \\
\text { Youth Odyssey was able to make an impact during the } \\
\text { program. Some included survey data as well. }\end{array}$ \\
\hline
\end{tabular}




\author{
Program Report - \\ Community Program A
}

Program Report - Middle School F

Program Report - Middle School G

Program Report - Middle School A

Program Report - Middle School D

Program Report - Middle School E

Program Report - Middle School C

Program Report - Middle School B

List of Youth Leader Functionings
2016

Provided overview, progression, highlights of two participants' growth/changes, any program issues/concerns, suggestions to improve future programs at this location, and a conclusion on how Youth Odyssey was able to make an impact during the program. Some included survey data as well.

2015 Provided overview, progression, highlights of two participants' growth/changes, any program issues/concerns, suggestions to improve future programs at this location, and a conclusion on how Youth Odyssey was able to make an impact during the program. Some included survey data as well.

2016 Provided overview, progression, highlights of two participants' growth/changes, any program issues/concerns, suggestions to improve future programs at this location, and a conclusion on how Youth Odyssey was able to make an impact during the program. Some included survey data as well.

2016 Provided overview, progression, highlights of two participants' growth/changes, any program issues/concerns, suggestions to improve future programs at this location, and a conclusion on how Youth Odyssey was able to make an impact during the program. Some included survey data as well.

2016 Provided overview, progression, highlights of two participants' growth/changes, any program issues/concerns, suggestions to improve future programs at this location, and a conclusion on how Youth Odyssey was able to make an impact during the program. Some included survey data as well. Provided overview, progression, highlights of two participants' growth/changes, any program issues/concerns, suggestions to improve future programs at this location, and a conclusion on how Youth Odyssey was able to make an impact during the program. Some included survey data as well. Provided overview, progression, highlights of two participants' growth/changes, any program issues/concerns, suggestions to improve future programs at this location, and a conclusion on how Youth Odyssey was able to make an impact during the program. Some included survey data as well.

2016 Provided overview, progression, highlights of two participants' growth/changes, any program issues/concerns, suggestions to improve future programs at this location, and a conclusion on how Youth Odyssey was able to make an impact during the program. Some included survey data as well.

2016 This list was made during a camping trip made up of exclusively Youth Leaders. Jake, the facilitator leading the trip, had asked the group what they wanted 


\author{
Youth Odyssey \\ Organizational Chart \\ Youth Odyssey Certificate \\ of Incorporation
}

Youth Odyssey Bylaws

Youth Odyssey Board of

Directors Meeting

Minutes

Youth Odyssey Board of

Directors Meeting

Minutes

Youth Odyssey Board of

Directors Meeting

Minutes

Youth Odyssey Board of

Directors Meeting

Minutes

Youth Odyssey Board of

Directors Meeting

Minutes

Youth Odyssey Board of

Directors Meeting

Minutes

Youth Odyssey Board of

Directors Meeting

Minutes

Youth Odyssey Board of

Directors Meeting

Minutes

Youth Odyssey Board of

Directors Meeting

Minutes

Youth Odyssey Board of

Directors Meeting

Minutes

Youth Odyssey Board of

Directors Meeting

Minutes

Youth Odyssey Board of

Directors Meeting

Minutes

Youth Odyssey Board of

Directors Meeting

Minutes

Youth Odyssey Board of

Directors Meeting

Minutes
Youth Odyssey to help them with, and this was the resulting list.

2016 Organizational chart outlining positions and hierarchy of authority.

1997 Copy of original document incorporating Youth

Odyssey with the State of Texas and includes, among other aspects, organization's purpose.

2005 Document governed the affairs of Youth Odyssey.

9/18/12 Notes summarizing board of directors meeting

10/2/12 Notes summarizing board of directors meeting

11/27/12 Notes summarizing board of directors meeting

5/13/13 Notes summarizing board of directors meeting

6/5/13 Notes summarizing board of directors meeting. Discussed staffing, programming, financial issues, fundraising, and other business.

7/22/13 Notes summarizing board of directors meeting. Discussed staffing, programming, financial issues, fundraising, and other business.

8/20/13 Notes summarizing board of directors meeting. Discussed staffing, programming, financial issues, fundraising, and other business.

9/4/13 Notes summarizing board of directors meeting. Discussed staffing, programming, financial issues, fundraising, and other business.

1/5/14 Notes summarizing board of directors meeting. Discussed staffing, programming, financial issues, fundraising, and other business.

9/3/14 Notes summarizing board of directors meeting. Discussed staffing, programming, financial issues, fundraising, and other business.

10/1/14 Notes summarizing board of directors meeting. Discussed staffing, programming, financial issues, fundraising, and other business.

12/3/14 Notes summarizing board of directors meeting. Discussed staffing, programming, financial issues, fundraising, and other business.

1/7/15 Notes summarizing board of directors meeting. Discussed staffing, programming, financial issues, fundraising, and other business.

3/4/15 Notes summarizing board of directors meeting. Discussed staffing, programming, financial issues, fundraising, and other business. 
Youth Odyssey Board of Directors Meeting Minutes

Youth Odyssey Board of Directors Meeting Minutes

Youth Odyssey Board of Directors Meeting Minutes

Youth Odyssey Board of Directors Meeting Minutes

Youth Odyssey Board of Directors Meeting Minutes

Youth Odyssey Board of Directors Meeting Minutes

Youth Odyssey Board of Directors Meeting Minutes

Youth Odyssey Board of Directors Meeting Minutes

Youth Odyssey Board of Directors Meeting Minutes

Youth Odyssey Board of Directors Meeting Minutes

Youth Odyssey Board of Directors Meeting Minutes

Youth Odyssey Board of Directors Meeting Minutes

Youth Odyssey Board of Directors Meeting Minutes

Youth Odyssey Board of Directors Meeting Minutes

Youth Odyssey Board of Directors Meeting Minutes

Youth Odyssey Board of Directors Meeting Minutes

Youth Odyssey Board of Directors Meeting Minutes
4/1/15 Notes summarizing board of directors meeting. Discussed staffing, programming, financial issues, fundraising, and other business.

5/1/15 Notes summarizing board of directors meeting. Discussed staffing, programming, financial issues, fundraising, and other business.

6/3/15 Notes summarizing board of directors meeting. Discussed staffing, programming, financial issues, fundraising, and other business.

8/5/13 Notes summarizing board of directors meeting. Discussed staffing, programming, financial issues, fundraising, and other business.

9/2/15 Notes summarizing board of directors meeting. Discussed staffing, programming, financial issues, fundraising, and other business.

11/4/15 Notes summarizing board of directors meeting. Discussed staffing, programming, financial issues, fundraising, and other business.

12/2/15 Notes summarizing board of directors meeting. Discussed staffing, programming, financial issues, fundraising, and other business.

2/3/16 Notes summarizing board of directors meeting. Discussed staffing, programming, financial issues, fundraising, and other business.

3/2/16 Notes summarizing board of directors meeting. Discussed staffing, programming, financial issues, fundraising, and other business.

4/6/16 Notes summarizing board of directors meeting. Discussed staffing, programming, financial issues, fundraising, and other business.

5/4/16 Notes summarizing board of directors meeting. Discussed staffing, programming, financial issues, fundraising, and other business.

6/1/16 Notes summarizing board of directors meeting. Discussed staffing, programming, financial issues, fundraising, and other business.

7/6/16 Notes summarizing board of directors meeting. Discussed staffing, programming, financial issues, fundraising, and other business.

8/10/16 Notes summarizing board of directors meeting. Discussed staffing, programming, financial issues, fundraising, and other business.

9/7/16 Notes summarizing board of directors meeting. Discussed staffing, programming, financial issues, fundraising, and other business.

10/5/16 Notes summarizing board of directors meeting. Discussed staffing, programming, financial issues, fundraising, and other business.

11/2/16 Notes summarizing board of directors meeting. Discussed staffing, programming, financial issues, fundraising, and other business. 

Youth Odyssey Board of Directors Meeting Minutes

Youth Odyssey Program Director's Report

Youth Odyssey Program Director's Report

Youth Odyssey Program Director's Report

Youth Odyssey Program Director's Report

Youth Odyssey Program Director's Report

Youth Odyssey Program Director's Report

Youth Odyssey Program Director's Report

Youth Odyssey Program Director's Report

Youth Odyssey Program Director's Report

Youth Odyssey Program Director's Report
1/4/17 Notes summarizing board of directors meeting. Discussed staffing, programming, financial issues, fundraising, and other business.

2/1/11 Document prepared to update the Board of Directors about current state of affairs with Youth Odyssey. Includes information on current programs, staffing matters, camps, and any other going-ons. Presented to Board of Directors during board meetings.

3/9/11 Document prepared to update the Board of Directors about current state of affairs with Youth Odyssey. Includes information on current programs, staffing matters, camps, and any other going-ons. Presented to Board of Directors during board meetings.

4/20/11 Document prepared to update the Board of Directors about current state of affairs with Youth Odyssey. Includes information on current programs, staffing matters, camps, and any other going-ons. Presented to Board of Directors during board meetings.

5/18/11 Document prepared to update the Board of Directors about current state of affairs with Youth Odyssey. Includes information on current programs, staffing matters, camps, and any other going-ons. Presented to Board of Directors during board meetings.

$7 / 27 / 11$ Document prepared to update the Board of Directors about current state of affairs with Youth Odyssey. Includes information on current programs, staffing matters, camps, and any other going-ons. Presented to Board of Directors during board meetings.

9/9/11 Document prepared to update the Board of Directors about current state of affairs with Youth Odyssey. Includes information on current programs, staffing matters, camps, and any other going-ons. Presented to Board of Directors during board meetings.

11/1/11 Document prepared to update the Board of Directors about current state of affairs with Youth Odyssey. Includes information on current programs, staffing matters, camps, and any other going-ons. Presented to Board of Directors during board meetings.

1/18/12 Document prepared to update the Board of Directors about current state of affairs with Youth Odyssey. Includes information on current programs, staffing matters, camps, and any other going-ons. Presented to Board of Directors during board meetings.

2/21/12 Document prepared to update the Board of Directors about current state of affairs with Youth Odyssey. Includes information on current programs, staffing matters, camps, and any other going-ons. Presented to Board of Directors during board meetings.

3/28/12 Document prepared to update the Board of Directors about current state of affairs with Youth Odyssey. Includes information on current programs, staffing 
matters, camps, and any other going-ons. Presented to Board of Directors during board meetings.

5/7/12 Document prepared to update the Board of Directors about current state of affairs with Youth Odyssey. Includes information on current programs, staffing

Youth Odyssey Program Director's Report

Youth Odyssey Program Director's Report

Youth Odyssey Program Director's Report

Youth Odyssey Program Director's Report

Youth Odyssey Program Director's Report

Youth Odyssey Program Director's Report

Youth Odyssey Program Director's Report

Youth Odyssey Program Director's Report

Youth Odyssey Program Director's Report

Youth Odyssey Program Director's Report matters, camps, and any other going-ons. Presented to Board of Directors during board meetings.

9/18/12 Document prepared to update the Board of Directors about current state of affairs with Youth Odyssey. Includes information on current programs, staffing matters, camps, and any other going-ons. Presented to Board of Directors during board meetings.

10/2/12 Document prepared to update the Board of Directors about current state of affairs with Youth Odyssey. Includes information on current programs, staffing matters, camps, and any other going-ons. Presented to Board of Directors during board meetings.

11/27/12 Document prepared to update the Board of Directors about current state of affairs with Youth Odyssey. Includes information on current programs, staffing matters, camps, and any other going-ons. Presented to Board of Directors during board meetings.

5/13/13 Document prepared to update the Board of Directors about current state of affairs with Youth Odyssey. Includes information on current programs, staffing matters, camps, and any other going-ons. Presented to Board of Directors during board meetings.

6/5/13 Document prepared to update the Board of Directors about current state of affairs with Youth Odyssey. Includes information on current programs, staffing matters, camps, and any other going-ons. Presented to Board of Directors during board meetings.

8/20/13 Document prepared to update the Board of Directors about current state of affairs with Youth Odyssey. Includes information on current programs, staffing matters, camps, and any other going-ons. Presented to Board of Directors during board meetings.

9/4/13 Document prepared to update the Board of Directors about current state of affairs with Youth Odyssey. Includes information on current programs, staffing matters, camps, and any other going-ons. Presented to Board of Directors during board meetings.

10/2/13 Document prepared to update the Board of Directors about current state of affairs with Youth Odyssey. Includes information on current programs, staffing matters, camps, and any other going-ons. Presented to Board of Directors during board meetings.

11/6/13 Document prepared to update the Board of Directors about current state of affairs with Youth Odyssey. Includes information on current programs, staffing 
matters, camps, and any other going-ons. Presented to Board of Directors during board meetings.

12/4/13 Document prepared to update the Board of Directors about current state of affairs with Youth Odyssey. Includes information on current programs, staffing

Youth Odyssey Program Director's Report

Youth Odyssey Program Director's Report

Youth Odyssey Program Director's Report

Youth Odyssey Program Director's Report

Youth Odyssey Program Director's Report

Youth Odyssey Program Director's Report

Youth Odyssey Program Director's Report

Youth Odyssey Program Director's Report

Youth Odyssey Program Director's Report

Youth Odyssey Program Director's Report matters, camps, and any other going-ons. Presented to Board of Directors during board meetings.

1/5/14 Document prepared to update the Board of Directors about current state of affairs with Youth Odyssey.

Includes information on current programs, staffing matters, camps, and any other going-ons. Presented to Board of Directors during board meetings.

4/2/14 Document prepared to update the Board of Directors about current state of affairs with Youth Odyssey. Includes information on current programs, staffing matters, camps, and any other going-ons. Presented to Board of Directors during board meetings.

5/7/14 Document prepared to update the Board of Directors about current state of affairs with Youth Odyssey. Includes information on current programs, staffing matters, camps, and any other going-ons. Presented to Board of Directors during board meetings.

6/4/14 Document prepared to update the Board of Directors about current state of affairs with Youth Odyssey. Includes information on current programs, staffing matters, camps, and any other going-ons. Presented to Board of Directors during board meetings.

7/2/14 Document prepared to update the Board of Directors about current state of affairs with Youth Odyssey. Includes information on current programs, staffing matters, camps, and any other going-ons. Presented to Board of Directors during board meetings.

8/6/14 Document prepared to update the Board of Directors about current state of affairs with Youth Odyssey. Includes information on current programs, staffing matters, camps, and any other going-ons. Presented to Board of Directors during board meetings.

9/3/14 Document prepared to update the Board of Directors about current state of affairs with Youth Odyssey. Includes information on current programs, staffing matters, camps, and any other going-ons. Presented to Board of Directors during board meetings.

10/1/14 Document prepared to update the Board of Directors about current state of affairs with Youth Odyssey. Includes information on current programs, staffing matters, camps, and any other going-ons. Presented to Board of Directors during board meetings.

11/5/14 Document prepared to update the Board of Directors about current state of affairs with Youth Odyssey. Includes information on current programs, staffing 
matters, camps, and any other going-ons. Presented to Board of Directors during board meetings.

12/3/14 Document prepared to update the Board of Directors about current state of affairs with Youth Odyssey. Includes information on current programs, staffing

Youth Odyssey Program Director's Report

Youth Odyssey Program Director's Report

Youth Odyssey Program Director's Report

Youth Odyssey Program Director's Report

Youth Odyssey Program Director's Report

Youth Odyssey Program Director's Report

Youth Odyssey Program Director's Report

Youth Odyssey Program Director's Report

Youth Odyssey Program Director's Report

Youth Odyssey Program Director's Report matters, camps, and any other going-ons. Presented to Board of Directors during board meetings.

1/7/15 Document prepared to update the Board of Directors about current state of affairs with Youth Odyssey.

Includes information on current programs, staffing matters, camps, and any other going-ons. Presented to Board of Directors during board meetings.

2/4/15 Document prepared to update the Board of Directors about current state of affairs with Youth Odyssey. Includes information on current programs, staffing matters, camps, and any other going-ons. Presented to Board of Directors during board meetings.

3/4/15 Document prepared to update the Board of Directors about current state of affairs with Youth Odyssey. Includes information on current programs, staffing matters, camps, and any other going-ons. Presented to Board of Directors during board meetings.

4/1/15 Document prepared to update the Board of Directors about current state of affairs with Youth Odyssey. Includes information on current programs, staffing matters, camps, and any other going-ons. Presented to Board of Directors during board meetings.

5/6/15 Document prepared to update the Board of Directors about current state of affairs with Youth Odyssey. Includes information on current programs, staffing matters, camps, and any other going-ons. Presented to Board of Directors during board meetings.

6/3/15 Document prepared to update the Board of Directors about current state of affairs with Youth Odyssey. Includes information on current programs, staffing matters, camps, and any other going-ons. Presented to Board of Directors during board meetings.

8/5/15 Document prepared to update the Board of Directors about current state of affairs with Youth Odyssey. Includes information on current programs, staffing matters, camps, and any other going-ons. Presented to Board of Directors during board meetings.

9/2/15 Document prepared to update the Board of Directors about current state of affairs with Youth Odyssey. Includes information on current programs, staffing matters, camps, and any other going-ons. Presented to Board of Directors during board meetings.

10/7/15 Document prepared to update the Board of Directors about current state of affairs with Youth Odyssey. Includes information on current programs, staffing 
matters, camps, and any other going-ons. Presented to Board of Directors during board meetings.

12/2/15 Document prepared to update the Board of Directors about current state of affairs with Youth Odyssey. Includes information on current programs, staffing

Youth Odyssey Program Director's Report

Youth Odyssey Program Director's Report

Youth Odyssey Program Director's Report

Youth Odyssey Program Director's Report

Youth Odyssey Program Director's Report

Youth Odyssey Program Director's Report

Youth Odyssey Program Director's Report

Youth Odyssey Program Director's Report

Youth Odyssey Program Director's Report

Youth Odyssey Program Director's Report

\section{$1 / 13 / 16$}

matters, camps, and any other going-ons. Presented to Board of Directors during board meetings.

Document prepared to update the Board of Directors about current state of affairs with Youth Odyssey.

Includes information on current programs, staffing matters, camps, and any other going-ons. Presented to Board of Directors during board meetings.

2/3/16 Document prepared to update the Board of Directors about current state of affairs with Youth Odyssey.

Includes information on current programs, staffing matters, camps, and any other going-ons. Presented to Board of Directors during board meetings.

3/2/16 Document prepared to update the Board of Directors about current state of affairs with Youth Odyssey. Includes information on current programs, staffing matters, camps, and any other going-ons. Presented to Board of Directors during board meetings.

5/4/16 Document prepared to update the Board of Directors about current state of affairs with Youth Odyssey. Includes information on current programs, staffing matters, camps, and any other going-ons. Presented to Board of Directors during board meetings.

6/1/16 Document prepared to update the Board of Directors about current state of affairs with Youth Odyssey. Includes information on current programs, staffing matters, camps, and any other going-ons. Presented to Board of Directors during board meetings.

7/6/16 Document prepared to update the Board of Directors about current state of affairs with Youth Odyssey. Includes information on current programs, staffing matters, camps, and any other going-ons. Presented to Board of Directors during board meetings.

8/10/16 Document prepared to update the Board of Directors about current state of affairs with Youth Odyssey. Includes information on current programs, staffing matters, camps, and any other going-ons. Presented to Board of Directors during board meetings.

9/7/16 Document prepared to update the Board of Directors about current state of affairs with Youth Odyssey. Includes information on current programs, staffing matters, camps, and any other going-ons. Presented to Board of Directors during board meetings.

10/5/16 Document prepared to update the Board of Directors about current state of affairs with Youth Odyssey. Includes information on current programs, staffing 
matters, camps, and any other going-ons. Presented to Board of Directors during board meetings.

11/2/16 Document prepared to update the Board of Directors about current state of affairs with Youth Odyssey. Includes information on current programs, staffing

Youth Odyssey Program Director's Report

Youth Odyssey Program Director's Report

Youth Odyssey Program Director's Report

Youth Odyssey Resources for Activities Book

Youth Odyssey Soft Skills Manual

Youth Odyssey Hard Skills Manual

Youth Odyssey Program Narrative

Youth Odyssey Strategic Plan

Youth Odyssey Policies and Procedures

Amendment to Youth Odyssey Policies and

Procedures - Child Abuse

Prevention Policies and Procedures

Youth Odyssey 2015

Summer Camp Flyer

Youth Odyssey 2016

Summer Camp Flyer

Youth Odyssey Chris

Takes a Walk on the Wild Side matters, camps, and any other going-ons. Presented to Board of Directors during board meetings.

12/7/16 Document prepared to update the Board of Directors about current state of affairs with Youth Odyssey.

Includes information on current programs, staffing matters, camps, and any other going-ons. Presented to Board of Directors during board meetings.

1/4/17 Document prepared to update the Board of Directors about current state of affairs with Youth Odyssey. Includes information on current programs, staffing matters, camps, and any other going-ons. Presented to Board of Directors during board meetings.

n.d. Document serves as resources for games facilitators may use as part of teaching the Youth Odyssey curriculum.

2015 Collection of resources, mostly games and activities, that facilitators can use during games and initiatives.

2015 Document educates and guides reader on nuts and bolts concepts used during Youth Odyssey programming. Topics include Youth Odyssey rules, setting up camp, inventory, how to build a fire, how to use a compass, how to use a map, mountain biking, rappelling, low ropes, bouldering, high ropes, canoeing, kayaking, and back packing.

2014 Document summarizes, describes, and provides key points regarding the various Youth Odyssey programs. Also includes short narratives about the organization.

2016 Document listed organization's objective/strategy for board, staff, and volunteer development, financial matters (donors, finances, fundraisers, and granting), youth -related matters, promotions/marketing/and programs.

2005 Company policies and procedures manual.

2011 Document provides governing policy covering issues related to child abuse.

2015 Document adverised 2015 Adventure Leadership Camps. Provided information and a way to sign up.

2016 Document advertised 2016 Adventure Leadership Camps. Provided information and a way to sign up.

2017 Participant interview about experiences at Majesty Outdoors 


\title{
APPENDIX F: LIST OF IDENTIFIED CAPABILITIES
}

\author{
List of identified capabilities
}

$\begin{array}{lcc}\text { Theme Capability } & \text { Representative Quote } & \text { Similarity with } \\ \text { Nussbaum's 10 } \\ \text { Central Capabilities }\end{array}$

$\begin{array}{lll}\text { Theme } 1 & \begin{array}{l}\text { Choice to exercise } \\ \text { agency with new } \\ \text { passions and interests }\end{array} & \begin{array}{l}\text { "Show them there is a bigger world out there and that } \\ \text { whatever they want to do, whatever they want to } \\ \text { accomplish in their lives, they can do it!" Kathryn } \\ \text { (E4) }\end{array}\end{array}$

Theme 1 Freedom to engage in self-reflection

Theme 1 Opportunity to discover what they can do and be

Theme 1 Ability to engage in self-awareness

Theme 1 Choice to change perceptions of what is possible to do in life

Theme 1 Ability to think about aspects of life beyond the routine, to pursue what you value

Theme 2 Opportunity to achieve more sophisticated teamwork, communication, and problem-solving abilities

Theme 2 Freedom to make meaningful personal changes through attaining social skills
"[Youth Odyssey] taught [me] you really can do a lot of stuff. You're not limited to what you think you can do, or you're not limited to what people tell you that you can do, you're not limited by what people tell you you're going to become just because of where you from." Brian (P4)

"They've learned to discover themselves. Their strengths, and they show them new experiences, so I think through this, they'll give them goals and things to set for them." Alice (P2)

"[T]here's more past the point of their own nose." Lynn (P11)

"[T]hey've given her the tools, that freedom or that choice, [which] helped her see how much she can do..." Danielle (P6)

"[Youth Odyssey] let me know, 'man, there's so much more out there than just this town.' There's so much that I can see, so much that I can do, and I'm not limited [in what you can do]." Brian (P4) "My boys used to fight all the time, but since being in your program, they wouldn't fight as much...[and] do a lot conflict resolution and talk to each other about what the problem is and then sort it out without throwing each other across the room." Jake (E3)

"Things that don't land them in jail, things that put them on a path to success, whatever version of success may be, things that contribute positively to their lives and others... they are making better choices in life because of what they've done and seen in Youth Odyssey." Jake (E3)
Practical reason

Practical reason

Practical reason

Practical reason

Practical reason

Practical reason

Senses, imagination, and thought

Senses, imagination, and thought 
Theme 2 Freedom to make meaningful personal changes through attaining social skills

Theme 3 Choice to attend Youth Odyssey as much as you wish

Theme 3 Choice to access resources as much as you wish

Theme 3 Freedom to have a mental escape from daily life

Theme 3 Ability to access nonmonetary support (e.g. a support system)

Theme 3 Access to a personal life coach

Theme 3 Ability to benefit from a supportive group (e.g. a support system)

Theme 3 Opportunity to be a part of a bigger group
"Seeing kids go from quiet, young lady in sixth grade, whose seventh-grade brother overshadows her, not answering questions, to graduating secondin-command of her ROTC unit in high school. I've seen young ladies go from a flirtatious young woman in middle school and high school, having relationships left and right, to having a career as a medical assistant and making the most of her life, making better decisions for her life." Kathryn (E4) "[T] he freedom to choose if [my daughter] can make certain events. It's not like it's a mandatory type of thing... they've always been very open, if she couldn't make it." Danielle (P6)

"[I]t's awesome...I loved it, I always wanted to be there every weekend, I was gone. I never was home for the weekend, I always went on the camping and everything. All the activities to do...some of the things that we did, the camping, the trips to Goliad, all that, and I told her if she was interested then of course to go for it... You get a lot out of it if you take what's given." Leah (P6)

"I know when times are hard at home you don't wanna, you'd rather be anywhere than home. Would you rather be at a ropes course, at a program or a camping trip, or would you rather be at a like sitting, playing with the grass? Like so it's kind of a mental escape..." (Kira, E2)

"[I]t's important to have people who are there supporting you, which Youth Odyssey, I know [does]. I mean, the way they build relationships with the kids it's...a lifelong friendship." Maria (P14) "[T]here's someone on your side, that you have someone who encourages you, who sees potential in you, wants to see you succeed, and is willing to apply effort and time to ensure the possibility of your success." Sam (E1)

"What I think separates the average everyday person who's not participating in this program, let's say specifically in this community, from someone who isn't [participating in Youth Odyssey], is that there is a group of people, being the people who work here, and the board that supports us and the donors that support us that are actively giving time, and putting in effort to make sure that you succeed. You have a support system, and I think that's a very important part, otherwise you are doing it on your own." Sam (E1)

"[I]t's bigger than you. It's not about you...it's about each other...Y You're there for each other." Brian (P4)
Senses, imagination, and thought

N/A

Play

Affiliation; Play

Affiliation

Affiliation; Emotions

Affiliation; Emotions

Affiliation 
Theme 3 Opportunity to derive resources from network

Theme 3 Freedom to try new activities without paying for the cost
"[A Youth Odyssey member may say ' $h$ ] ey this is what I want to do, how do I figure this out, here are my goals, here are the steps to get there.' And then, boom, they're going to do it. So if, specifically an individual needs help with maybe resume writing, or they want to know more information about maybe being a contractor, then we will hook them up with one of our board members or a volunteer that we have, or sit down say, 'ok this is the opportunities that you have for this line of work or for this passion.'

We do that for those kids. Kathryn (E4)

"We give them more opportunities to try things...just getting them more exposed to different things that they wouldn't normally do...we go kayaking, we go scuba diving, we help at the farmer's market, we check out local farms, we check out cattle, hang out at the beach, backpacking, canoeing, we are going to be doing two new camps that focus on just boys and just girls, which we haven't figured out exactly what we are doing yet, but there might be some other neat stuff in there. So, yeah just getting them more exposed to different things that they wouldn't normally do." Jake (E2)
Senses, imagination, and thought; Practical reason 


\title{
CURRICULUM VITAE
}

\author{
Jeffrey F. Levine
}

\section{EDUCATION}

Ph.D. Anticipated graduation date: December, 2018
University of Louisville, Louisville, KY Educational Leadership, Evaluation and Organizational Development Specialization: Sport Administration Research area: Sport, law, and policy

J.D. $\quad 2008$

2004

B.A.

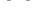

Certificate 2006
Tulane Law School, New Orleans, LA

Certificate in Sport Law

Sports Lawyers Journal, Managing Editor

The University of Michigan, Ann Arbor, MI Major: Sport Management and Communications

Humboldt University, Berlin, Germany Specialization: mediation, negotiation, alternative dispute resolution

\section{Academic Experience}

\section{Drexel University}

Philadelphia, PA

Assistant Clinical Professor

- Teaches sport management courses in the Department of Sport Management at the LeBow College of Business. Designs new class offerings based on student demand and developments within the sport management industry. Collaborates with colleagues on a variety of interdisciplinary topics/matters related to sport management. Teaches online, blended, traditional, and flipped classes. Classes taught included:

- $\quad$ SMT 110: The Business of Sport

- SMT 240: The Olympic Games

- Creating a record of scholarly activity through research examining the interconnections between sport, law, and policy.

- Developing record of service to the University, community, and profession. 


\title{
Texas A\&M University - Corpus Christi
}

\author{
Corpus Christi, TX
}

Assistant Professor

August 2016 - August 2018

- Taught sport management courses in the Department of Kinesiology. Teaching method included traditional, blended, and fully online classes. Classes taught included:

- KINE 4309: Finance Management in Sport

- KINE 4308 Facilities Design and Planning

- KINE 3335 Legal Issues in Sport

- KINE 3330 Sport Marketing

- KINE 2314 Introduction to Sport Management

- Established a record of scholarly activity.

- Created reputation in granting, securing $\$ 19,500$ in grants.

- Provided service to the University, community, and profession.

- Developed relationship with community partners as part of building rapport with local stakeholders.

\section{University of Louisville}

Louisville, KY

\section{Lecturer/Graduate Assistant}

August 2014 - June 2016

- Prepared and delivered all course materials for undergraduate and graduate level classes, including lectures, presentation slides, exams, assignments, case studies, and Blackboard course design. Classes taught included:

- Instructor, SPAD 571 Sport for Development, Peace and Social Change

- Co-Instructor, SPAD 561 Sport for Development: Botswana

- Instructor, SPAD 489 Legal Aspects of Sport

- Instructor, SPAD 404 Financial Principles of Sport

- Co-Instructor, SPAD 402 Internship in Sport Administration

- Co-Instructor, SPAD 401 Career Development in Sport Administration

- Instructor, SPAD 390 Sport Governance (online)

- Instructor, SPAD 382 Organizational Behavior in Sport

- Instructor, HSS 114 Fitness Walking

- Guest lecturers included:

- Introduction to Agency online lecture. SPAD 489, Legal Aspects in the Sport Industry. Fall, 2015

- Introduction to Contracts. SPAD 489, Legal Aspects in the Sport Industry. Fall, 2015

- Fundamentals of Contract Law and College Coaching Contracts. SPAD 689, Legal Aspects in the Sport Industry. Fall, 2015

- Sport for Development and Social Change. SPAD 705, Sport and Social Issues. Spring, 2015

- Premise Liability in Facility Management. SPAD 605, Facility Management. Fall 2014, Spring 2016

- Financial Matters in Kentucky Tennis. SPAD 605, Sport Facility Management. Fall 2014

- Legal Issues in Sports Marketing. SPAD 383, Sport Marketing. Fall 2014

- Research assistant duties included: 
- Performed research and literature on ambush marketing.

- Coded and analyzed 2014-15 University of Louisville student athlete academic satisfaction surveys.

- Performed research on the Fair Labor Standards Act and created memorandum of recent developments in sports law.

- Researched and drafted several memorandum on recent developments concerning the Fair Labor Standards Act and the amusement and recreation exemption related to sport management.

- Researched relevant international laws concerning disability rights.

- Researched issues concerning Title IX discrimination sexual assault lawsuits against universities.

\section{University of Louisville}

\section{Louisville, KY}

Faculty Lecturer/Adjunct Professor of Law January 2014 - July 2014

- Taught SPAD 489, Legal Aspects of Sport, SPAD 404, Sport Finance, and SPAD 661, Doctoral Level Sport Law.

- Appointed adjunct professor of law to co-teach Law 988.05, Sports Law, at the Brandeis School of Law.

\section{Concordia University}

Saint Paul, MN

Adjunct Instructor

October 2013 - October, 2016

- Taught KHS 391 - Undergraduate Level Legal Aspects of Sport - and KHS 540 - Graduate Level Legal Aspects of Sport. Both classes were taught online via WebEx distance learning software.

- Designed courses from the ground up focusing on using a multidisciplinary teaching approach including, but not limited to, lecturing, group activities, incorporating current events into discussion and guest lecturers to provide comprehensive overview/analysis of legal issues within sport.

- Provided students with industry-relevant documents to provide real life examples of concepts discussed in class.

\section{Northwestern University}

Evanston/Chicago, IL

Instructor

April 2013 - September 2013

- Served as instructor for MSA 405-0-50, Legal and Ethical Issues in Sport Management, a Masters level course.

- Utilized multidisciplinary teaching approach including, but not limited to, lecturing, group activities, incorporating current events into discussion and using guest lecturers to provide a comprehensive overview/analysis of legal and ethical issues within sport administration.

- Provided students with industry-relevant documents to illustrate real life examples of concepts discussed in class. 


\section{Southern Illinois University}

Carbondale, IL

Faculty Lecturer/Adjunct Professor of Law

August 2012 - May 2013

- Taught Kin. 360, Introduction to Sport Administration, Kin. 364, Legal and Ethical Aspects of Sport, Kin. 508, Administration of Athletics (a Masters level class), and Law 583, Sports Law, taught at the law school.

- Utilized multidisciplinary approach to class including lecture, class discussions, in-class activities, guest speakers and incorporation of current events to illustrate relevant class topics.

- Participated in departmental curriculum development process.

- Other duties included mentoring students, publishing scholarship and attending faculty meetings.

\section{Thomas Jefferson School of Law}

San Diego, CA

Adjunct Professor of Law

June 2012 - August, 2012

- Created and implemented a two-credit professional sports law course for the summer 2012 semester.

- Utilized Fuze Meeting online distance learning software to lead class and facilitate discussion.

- Class focused on sports law issues. Designed PowerPoint presentations to illustrate key points.

- Lectured on various sports law topics; taught core course concepts; led class discussions.

- Answered student questions; researched question and got back to student if unable to answer immediately.

- Designed and implemented activities simulating real life sports law issues; mentored students.

\section{Arizona Summit Law School}

Phoenix, AZ

Adjunct Professor of Law

May 2011 - August, 2012

- Designed three-credit law upper-level law school course covering material sports law issues/topics.

- Taught class focusing on sports law issues; devoted significant time to risk management, labor law/collective bargaining, antitrust law, intellectual property, constitutional law, agency and NCAA compliance issues.

- Lectured on various sports law topics; taught and communicated material legal concepts; led class discussions involving complex and difficult issues; designed and implemented inclass activities simulating real life sports law issues and application of novel facts.

- Advised school's sports and entertainment law society on a variety of topics and issues.

\section{Peer Reviewed Articles}


14. Hanna, C. D., Levine, J. F., \& Moorman, A. M. (2017). Whistleblower protection in college sports. Journal of Legal Aspects of Sport, 27, 209-226.

13. Svensson, P. G., \& Levine, J. F. (2017). Rethinking Sport-for-Development: The Capability Approach. Sport in Society, 20(7), 905-923.

12. Cintron, A. M., Levine, J.F., \& Hambrick, M. E. (2016). A case study of the National Hockey League: The question of expansion. Case Studies in Sport Management, $5(1), 17-23$.

11. Cohen, A., \& Levine, J. F. (2016). "This Class has Opened up my Eyes": Assessing Outcomes of a Sport-for-Development Classroom on Student Participants. Journal of Hospitality, Leisure, Sport \& Tourism Education, 19, 97-103.

10. Levine, J. F. (2016). Trademark Court Gives Sport Marketers Cause for Paws: Wolfskin v. New Millennium. Sport Marketing Quarterly, 25(1), 59-61.

9. Kobritz, J. I., \& Levine, J. F. (2013). Armageddon II: An Analysis of the issues surrounding the NHL lockout. American Journal of Management, 13(1), 53-65

8. Kobritz, J. I., \& Levine, J. F. (2013). The show cause penalty and the NCAA scope of power. Arizona State Sports and Entertainment Law Journal, 3(2), 29-48.

7. Kobritz, J. I., Levine, J. F. \& Palmer, S. C. (2012) Don Fehr trades his ball for a puck: Will he continue to score? The Jeffrey S. Moorad Sports Law Journal, 19(1), 521539.

6. Kobritz, J. I., \& Levine, J. F. (2012). Trying his luck at puck: Examining MLBPA history to determine Don Fehr's motivation for agreeing to lead the NHLPA and predicting how he will Fare, University of Denver Sports and Entertainment Law Journal, 12(1), 1-70.

5. Kobritz, J. I., \& Levine, J. F. (2011) Don Fehr leads the NHLPA: Does the NHL have anything to fear? Virginia Sports and Entertainment Law Journal, 11(2), 178-221.

4. Heitner, D. A., \& Levine, J. F. (2011) Corking the Cam Newton loophole, a sweeping suggestion, Harvard Journal of Sports and Entertainment Law, 2(1), 342-369.

3. Levine, J. F., \& Maravent, B. A. (2010) Fumbling away the season: Will the expiration of the NFL - NFLPA CBA result in the loss of the 2011 season and beyond, Fordham Intellectual Property, Media and Entertainment Law Journal, 20, 1419-1500.

2. Levine, J. F. (2008) A golden opportunity for global acceptance - How hosting the Olympic Games impacts a nation's economy and intellectual property rights with a focus on the right of publicity, The Sports Lawyers Journal, 15(1), 245-277.

1. Levine, J. F. (2007) Meeting the challenges of international brand expansion in professional sports: IP right enforcement in China through treaties, Chinese law and cultural mechanisms, Texas Review of Sport and Entertainment Law, 9, 203229. 


\section{Articles in Review}

3. Cintron, A. M., Levine, J. F., Williams, D., \& Kobritz, J. I. (In Review). Sin City betting on the Major Leagues? An analysis of the sport-based approach to economic redevelopment in Las Vegas.

2. Cintron, A. M., Levine, J. F., \& McCray, K. L. (In Review). Preventing sexual violence on college campuses: An investigation of current practices of conducting background checks on student athletes.

1. Levine, J. F., \& Gunn, I. (In 2nd Review). Peterson, Brady, and Elliot: Analyzing "the Trilogy" in light of the NFL commissioner's discipline authority.

\section{Manuscripts in Preparation}

Levine, J. F., Cintron, A. M., \& McCray, K. L. Conducting background checks on student athletes: Legal implications and policy recommendations. To be submitted to Journal of Legal Aspects of Sport (Manuscript in progress).

Levine, J. F., Kesterson, M., \& Sparveno, E. Exploring the benefit of sport for development and peace in the Colonias of South Texas. To be submitted to Journal of Sport for Development and Peace (Data analysis in progress).

Hanna, C. D., \& Levine, J. F. An empirical study to whistleblower protection in college sports. To be submitted to Journal of Legal Aspects of Sport (Working on IRB submission).

Levine, J.F., Hanna, C. D., \& Kobritz, J. I. The NCAA at a crossroads: Is the concept of institutional control outdated? To be submitted to Journal of Legal Aspects of Sport (Working on conceptual framework).

\section{Book Chapters and Non-Peer Reviewed Articles}

3. Levine, J. F. (2016). Sport for development and peace: A practical view from the trenches. In G. Bernstein (Ed.), Managing non-profit sport in recreation and sport management programs. Austin, TX: Sentia Publishing.

2. Bernstein, G., \& Levine, J. F. (2015) Corporate social responsibility and ethics in sport marketing, In G. Bernstein (Ed.), The Principles of Sport Marketing. (141-156). Urbana, IL: Sagamore Publishers.

1. Levine, J. F. (2015). Sports Law. In Sports Leadership: A Concise Reference Guide. (Dodds, M. \& Reese Jr., J.). Santa Barbra, CA: Mission Bell Media. 


\section{Presentations}

34. Hanna, C. D., \& Levine, J. F. (2019, June) The Williams Rule: Enhancing NCAA Hiring Diversity. To be presented at the North American Society for Sport Management Conference in New Orleans, Louisiana.

33. Menaker, B., Sheptak, R. D., Odio, M., \& Levine, J. F. (2019, June) The precariat in the sport industry: A discussion of the sport management academy's role in sport labor precarity. To be presented at the North American Society for Sport Management Conference in New Orleans, Louisiana.

32. Levine, J. F., Schmidt, S. H., \& Staurowsky, E. J. (2019, February) University responses to athlete activism at college campuses: Legal and political issues. To be presented at the Sport and Recreation Law Association Conference in Philadelphia, Pennsylvania.

31. Levine, J. F., \& Menaker, P. (2019, February) In a precarious position: The shrinking legal protections of minor league baseball players. To be presented at the Sport and Recreation Law Association Conference in Philadelphia, Pennsylvania.

30. Miller, J., Levine, J. F., \& Croft, C. (2019, February) University of Nebraska cancels home football game against the University of Akron: Could the Zips be zapped?

To be presented at the Sport and Recreation Law Association Conference in Philadelphia, Pennsylvania.

29. Kang, S., \& Levine, J. F. (2018, June) Examining virtual reality (VR) usage in sport. Presented at the North American Society for Sport Management Conference in Halifax, Nova Scotia.

28. Levine, J. F., \& Kobritz, J. I. (2018, February) The Helms-Burton Act: How do law and policy impact Cuban baseball? Presented at the Sport and Recreation Law Association Conference in San Antonio, Texas.

27. Levine, J. F., Hanna. C. D., \& Kobritz, J. I. (2018, February) The NCAA at a crossroads: Is the concept of institutional control outdated? Presented at the Sport and Recreation Law Association Conference in San Antonio, Texas.

26. Cintron, A. M., \& Levine, J. F. (2018, February) Conducting background checks on student athletes: Legal implications and policy recommendations. Presented at the Sport and Recreation Law Association Conference in San Antonio, Texas.

25. Gipson, C. M., \& Levine, J. F. (2017, November) Parental/guardian support: Can a program be successful without it? Presented at the North American Society for the Sociology of Sport in Windsor, Ontario.

24. Kobritz, J. I., \& Levine, J. F. (2017, September) Baseball Diplomacy: Raising the curtain on negotiations between Cuba. Presented at the European Association for Sport Management Conference in Bern, Switzerland. 
23. Brison, N, \& Levine, J. F. (2017, June) Giving credence to a voice: Balancing free speech rights of professional athletes with the rights of sports organizations in the new age of athlete activism. Presented at the North American Society for Sport Management Conference in Denver, Colorado.

22. Levine, J. F., Morris, E., Kobritz, J. I., \& Palolino, N. (2017, March) Responding to the Kaepernick Effect: Exploring potential legal issues and challenges in the new age of athlete activism. Presented at the Sport and Recreation Law Association Conference in Las Vegas, Nevada.

21. Cintron, A. M., Levine, J. F., Williams, D., \& Kobritz, J. I. (2017, March) Las Vegas Power Play: The gamble of professional sports in Sin City. Presented at the Sport and Recreation Law Association Conference in Las Vegas, Nevada.

20. Levine, J. F. (2016, June) Applying sport for development and peace in your own backyard: Experiential learning at Portland Elementary School. Presented at the North American Society for Sport Management Conference in Orlando, Florida.

19. Mueller, E., \& Levine, J. F. (2016, April) Sport as a human right: Empowering individuals with disabilities through sport and sustainable international capacity building. Presented at the Fourth Annual Ali Center Athletes and Social Change Forum in Louisville, Kentucky.

18. Levine, J. F. (2016, February) Rice, Peterson, and Brady: Analyzing "the Trilogy" in light of the NFL commissioner's discipline authority. Presented at the Sport and Recreation Law Association Conference in New Orleans, Louisiana.

17. Hanna, C.D. \& Levine, J. F. (2016, February) Defamation 2.0: Updating defamation law to address

today's technological issues. Presented at the Sport and Recreation Law Association Conference in New Orleans, Louisiana.

16. Schmidt, S.H., Levine, J. F. \& Hanna, C. D. (2016, February) Exploring a new world: An introduction and review of the legal concerns of eSport. Presented at the Sport and Recreation Law Association Conference in New Orleans, Louisiana.

15. Levine, J. F., Esherick, C. \& Kobritz, J. (2015, June) "Until I die, I Will be Suing the NBA": An Analysis of The Legal Issues Raised by the Donald Sterling Saga. Presented at the North American Society for Sport Management Conference in Ottawa, Canada.

14. Cintron, A. \& Levine, J. F. (2015, April) "Student Athlete Advocacy: The Path Toward a More Meaningful Future". Presented at the Third Annual Ali Center Athletes and Social Change Forum in Louisville, Kentucky.

13. Levine, J. F. \& Hanna, C. D (2015, March) "Defamation 2.0: Does the law of Defamation Work in a Digital age". Presented at the 2015 University of 
Cincinnati, University of Kentucky, and University of Louisville Joint Spring Research Conference in Louisville, Kentucky.

12. Moorman, A., Levine, J. F. \& Kobritz, J. (2015, March) How Much is too Much? Is the Unlimited Authority of the NFL Commissioner no Longer in the "Best Interest" of the Game. Presented at the Sport and Recreation Law Association Conference in Charlotte, North Carolina.

11. Levine, J. F. \& Hanna, C. D. (2015, March) The Whistleblower Dilemma for Athletic Departments and University Employees. Presented at the Sport and Recreation Law Association Conference in Charlotte, North Carolina.

10. Svensson, P. G. \& Levine, J. F. (2015, March) Examining Athletic Department Policies and Procedures Through the Lens of OCR's Guidelines on Sexual Violence. Presented at the Sport and Recreation Law Association Conference in Charlotte, North Carolina.

9. Levine, J. F. \& Svensson, P. G. (2015, February) Examining Sport for Development Policies Through the Capabilities Approach. Presented at the Applied Sport Management Association Conference in Baton Rouge, Louisiana.

8. Levine, J. F., Cintron, A. M. \& Hanna, C. D. (2015, February) Calling Your Bluff: A Case Against NHL Expansion into Las Vegas. Presented at the Applied Sport Management Association Conference in Baton Rouge, Louisiana.

7. Levine, J. F. (2014, March). Utilizing sport as part of the capabilities approach of development to accomplish social change. Presented at the Second Annual Ali Center Athletes and Social Change Forum in Louisville, Kentucky.

6. Levine, J. F. and Kobritz, J. (2014, March). Safe at home: legal and public policy rationale behind MLB's decision to eliminate home plate collisions. Presented at the Tenth Applied Sport Management Association Conference in Nashville, Tennessee.

5. Levine, J. F. (2014, February). Speaker Summit Sport Law Panel. Presented at the University of Louisville Sport Administration Speaker's Summit in Louisville, Kentucky.

4. Kobritz, J. and Levine, J. F. (2014, February). NFL concussion lawsuit settlement: The good, the bad and the ugly. Presented at the Sport and Recreation Law Association Annual Conference, Orlando, Florida.

3. Levine, J. F. (2012, November). Gladiators in the 21st Century: Addressing the Problem of Violence and Injuries. Panel presentation at the Thomas Jefferson School of Law Center for Sports Law and Policy Conference on in Athletics in San Diego, California.

2. Levine, J. F. (2011, November). The BCS and the Future of Big Time College Football. Panel presentation at the Thomas Jefferson School of Law Center for Sports Law and Policy Conference in San Diego, California. 
1. Levine, J. F. (2011, September). National Sports Law Negotiation Competition and Sports Law Symposium. Invited presentation at the Thomas Jefferson School of Law in San Diego, California.

\section{Awards and honors}

Levine, J.F. 2015-16 Bernard Patrick Maloy Graduate Student Research Award. Rice, Peterson, and Brady: Analyzing "the Trilogy" in light of the NFL commissioner's discipline authority. Awarded by the Sport and Recreation Law Association (SRLA) in the amount of $\$ 500$.

\section{Grants and Funding}

15. Levine, J. F., \& Kesterson, M. R. 2018. Impact Multiplier Grant (\$2,065.57 not funded). Magnifying impact and assessing community concerns through an outdoor community learning center (e.g. a Community Garden). Submitted to the Office of Community Engagement, Texas A\&M University - Corpus Christi.

14. Levine, J. F., \& Kesterson, M.R. 2018 Professional Development and Review Grant $(\$ 2,500$ funded). Grant to develop a three-credit hour flipped, blended, or fullyonline course on Blackboard. Funded by Project GRAD and the Office of Distance Education Learning Technologies, Texas A\&M University - Corpus Christi.

13. Levine, J. F., \& Kesterson, M. 2017 eLearning Program Development Grant ( $\$ 14,000$ funded). Grant to design a proposed sport management bachelors of arts program online. Funded by Project GRAD and the Office of Distance Education Learning Technologies, Texas A\&M University - Corpus Christi.

12. Levine, J. F. 2016 Research Enhancement Grant (\$2,500 funded). Grant to complete research proposal entitled Exploring the benefit of sport for development and peace in the Colonias of South Texas. Funded by the College of Education and Human Development, Texas A\&M University - Corpus Christi.

11. Levine, J. F. 2016 Faculty Development Research Program Grant (\$500 funded). Stipend to support grantee's individual research development agenda. Funded by the Division of Research, Commercialization and Outreach, Texas A\&M University - Corpus Christi.

10. Levine, J. F. Travel grant ( $\$ 100$ funded). Registration fee for the 2016 Sport and Recreational Law Association Conference to present. Funded by the Health and Sport Sciences Department, University of Louisville. 
9. Levine, J.F. Travel and lodging to Los Angeles, California for the 2015 DOHA GOALS Forum, Los Angeles as conference participant. Funded by the Olympism For Humanity Alliance by invitation. Granted.

8. Levine, J. F. Travel grant ( $\$ 350$ funded). Travel to Ottawa, Ontario for the 2015 North American Society for Sport Management Conference to present. Funded by the Health and Sport Sciences Department, University of Louisville.

7. Levine, J. F. Travel grant ( $\$ 175$ funded). Registration fee for the 2015 North American Society for Sport Management Conference in Ottawa, Canada to present. Funded by the Health and Sport Sciences Department, University of Louisville.

6. Levine, J. F. Travel grant ( $\$ 50$ funded). Registration fee for the 2015 Muhammad Ali Athletes for Social Change Forum to present. Funded by the Health and Sport Sciences Department, University of Louisville.

5. Levine, J. F. Travel grant ( $\$ 500$ funded). Travel to Charlotte, North Carolina for the 2015 Sport and Recreational Law Association Conference to present. Funded by the Health and Sport Sciences Department, University of Louisville.

4. Levine, J. F. Travel grant ( $\$ 175$ funded). Registration fee for the 2015 Sport and Recreational Law Association Conference to present. Funded by the Health and Sport Sciences Department, University of Louisville.

3. Levine, J. F. Travel grant ( $\$ 75$ funded). Registration fee for the 2015 Applied Sport Management Association Conference in Baton Rouge, Louisiana to present. Funded by the Health and Sport Sciences Department, University of Louisville.

2. Levine, J. F. 2015 Ford Foundation Fund ( $\$ 700$ funded). Recipient to participate in Trinidad and Tobago International Service Learning Program trip and intervention. Funded by the College of Education and Human Development, University of Louisville.

1. Levine, J. F. 2015 SPAD Scholarship Award (\$700 funded). Recipient to participate in Trinidad and Tobago International Service Learning Program trip and intervention. Funded by the Health and Sport Sciences Department, University of Louisville.

\section{Service}

\section{Professional and leadership Training}

2018 Texas A\&M University - Corpus Christi Certificate of professional development for best practices, online course design

2018 Texas A\&M University - Corpus Christi Certificate of Course Design and Development

2017 Texas A\&M University - Corpus Christi Broader Impacts Identity Workshop 
2017 Texas A\&M University - Corpus Christi Faculty Research Development Program Commercialization Workshop

2016 Texas A\&M University - Corpus Christi Faculty Development Research Program 2015 University of Pennsylvania Race and Equity Institute Certificate of Education 2015-16 University of Louisville School of Interdisciplinary Studies Graduate Teaching Assistant Academy - Cohort Participant

2015 Delphi Center for Teaching and Learning, Principles of Online Course Design Certificate of Completion

\section{University/College/Department}

College Research and Curriculum Innovation Committee - LeBow College of Business (2018)

Department Representative, Island Day, Texas A\&M University - Corpus Christi (2017 2018)

Member, Student Appeal Committee, Undergraduate Athletic Training Program, Department of Kinesiology, Texas A\&M University - Corpus Christi (2016 - 2018)

Member, Pre-Professional Interviews, Undergraduate Athletic Training Program, Department of Kinesiology, Texas A\&M University - Corpus Christi (2016 - 2018)

Member, Intercollegiate Athletics Council, Texas A\&M University - Corpus Christi $(2016-2018)$

Member, Intercollegiate Athletics Council Subcommittee on Compliance and Wellness, Texas A\&M University - Corpus Christi (2016 - 2018)

Member, College of Education and Human Development Curriculum Coordinating Committee, Texas A\&M University - Corpus Christi (2016 - 2018)

Grawemeyer Symposium, volunteer greeter, University of Louisville (Fall, 2015)

Member, Ali Center Forum for Social Change Committee (2015)

Interviewer, University of Louisville SPAD Masters Program Admission Committee $(2014-2016)$

Member, University of Louisville Sport Administration Speaker Summit Committee (2014-2015)

Member, University of Louisville CEHD Graduate Student Representative Committee (2014-2016)

Member, University of Louisville Conversations With Champions Committee (2014 2015) 
Sports Law Panel Co-Organizer and Moderator, University of Louisville SPAD Speaker Summit (2014)

Member, Southern Illinois University School of Education Marketing Committee (2013)

Guest speaker, Southern Illinois University Sport and Entertainment Law Society (2013)

Co-Faculty Advisor, Arizona Summit Law School Sport and Entertainment Law Society (2011-2012)

\section{Professional Service}

Levine, J. F. (2018, October 29). Introduction to Sport for Development and Peace. Presented to visiting delegation from India under the auspices of the Department of State's Sports visitor's Program, arranged by FHI 360.

Staurowsky, E. J., Menaker, B., \& Levine, J. F. (2018, October 26). California Judge Rules NCAA’s Show-Cause Order Violates State Law. Sports Litigation Alert.

Guest reviewer, Sport in Society (2017 - present)

Guest reviewer, Journal of Legal Aspects of Sport (2016 - present)

Member, North American Society for Sport Management Faculty-Student Mentor Initiative (2017 - Present)

Member, USAID Learning Lab for Sport for Development and Peace - Monitoring and Evaluation Group (2016 - Present)

Member, the Human Development and Capability Association (2015 - Present)

Member, North American Society for Sport Management (2014 - Present)

Member, Sport and Recreation Law Association (2014 - Present)

Regional Outreach Liaison, Sports Lawyers Association (2009 - 2015)

Member, Sports Lawyers Association (2006 - Present)

\section{Community Service}

Volunteer - Corpus Christi Food Bank (2016 - 2018)

Member, Antonio E. Garcia Arts and Education Center Advisory Council, Corpus Christi (2016 - 2018)

Faculty advisor, Texas A\&M University, Corpus Christi Club Rugby Team (2016 2018)

Member, Texas Jazz Festival Society (2016 - 2018) 
Member, Coastal Bend Bays Foundation (2016 - 2018)

Board of Directors, Cecilia: The Beauty of Science Foundation (2016 - 2018)

Portland Elementary College Awareness Program, Louisville, Kentucky (2015)

Executive Board Member and Secretary, Southern Illinois University Hillel (2012-2013)

Band Championship Assistant Chairman, Fiesta Bowl Committee (2012)

Member, Fiesta Bowl Committee (2012)

\section{Interviews}

Radio interview, Hockey Prospectus Radio, "Digging into the Glendale/Coyotes situation.” June, 2015.

Radio interview, Hockey Prospectus Radio, "The legalities of tanking in the NHL and talking NHL to Las Vegas." March, 2015.

Magazine interview, The Louisville Cardinal, "Taking a stand against scandal and coverup: administration and athletics returning ethics to the forefront." November, 2014.

Radio interview, Hockey Prospectus Radio, "Conflicts of interest and potential negligence liability for fighting in the N.H.L.” October, 2014.

Radio interview, British Broadcasting Company, "Legal implications of Adrian Peterson's arrest." September, 2014.

Radio interview, Hockey Prospectus Radio, "Dissecting the divorce between Pat Lafontaine and the Buffalo Sabres.” February, 2014.

Radio interview, Hockey Prospectus Radio, "The on ice and off ice issues facing the 2014 Winter Olympic Games in Sochi, Russia.” February, 2014.

Radio interview, Sports Radio 1220 ESPN Radio Poughkeepsie, NY, "Discussing the increasing amount of violence in professional sports and whether these acts will ever lead to criminal convictions." December, 2013.

Radio interview, Hockey Prospectus Radio, "Decoding the contents of the class action complaint against the NHL; did the league fail to live up to its duty to protect players." December, 2013.

Radio interview, Hockey Prospectus Radio, "Will the NHL face potential liability for its alleged failure to protect players from sustaining concussions?" October, 2013.

Magazine interview, Venues Today Magazine, "Bankruptcy no Road Block For Detroit Red Wings," July, 2013.

Magazine interview, Venues Today Magazine, “Outdoor Hockey to Increase in 2014", April, 2013. 
Magazine interview, Venues Today Magazine, "Markham Arena Gets Green Light", March, 2013.

Magazine interview, Venues Today Magazine, “Getting Back to Hockey”, January, 2013.

Magazine interview, Venues Today Magazine, “Arenas Brace For Second Lockout”, September, 2012.

Magazine interview, Venues Today Magazine, “49ers Fights Put Spotlight on Alcohol and Tailgating", August, 2011.

Newspaper interview, Pittsburgh Tribune Review, "Players Urging Judge to end NFL Lockout", April, 2011.

Newspaper interview, Pittsburgh Tribune Review, "NFL Players Move to Decertify, Delay Lockout", March, 2011.

Newspaper interview, Pittsburgh Tribune Review, "NFL Owners, Players Extend Negotiating Deadline by 24 Hours," March, 2011.

Radio interview, KNTR News Talk Radio, “Talking Sports Law Issues,” April, 2011.

Radio interview, Sports Radio 950AM ESPN Radio Rochester, NY, "Discussing NHL Off-Season and Legal Issues," March, 2010.

Radio interview, KLAV 1230 Las Vegas, Papa Joe Chevalier Show, "Discussing Brett Favre and Michael Vick." August, 2009.

Radio interview, KLAV 1230 Las Vegas, Papa Joe Chevalier Show, "Breaking down the American Needle Antitrust Case.” July, 2009.

\section{Sport Industry Experience}

The Business of Sports Network

Staff Writer businessofsportsnetwork.com

July 2009 - June 2011

- Served as senior writer for industry trade publication addressing business and legal issues within professional sports.

- Authored articles for network's four websites, the Business of Baseball, the Business of Football, the Business of Hockey and the Business of Basketball, all of which discussed or interpreted business aspects of current sports events.

- Articles led to invitations to appear on several nationally syndicated sports talk radio programs to discuss various relevant sports topics.

\section{Arizona Coyotes and Gila River Arena}

Law Clerk/Legal Department Attorney
Glendale, AZ

March 2008 - July 2008

- Provided counsel/analysis regarding legal issues of Phoenix Coyotes pro hockey club and Jobing.com Arena facility operations, including but not limited to, risk management, contractual, employment and intellectual property matters.

- Coordinated with marketing, sponsorship and HR departments in executing team policy. 
- Served as liaison between department leaders and legal counsel; oversaw the company's risk management committee.

- Coordinated with relevant stakeholders and worked alongside others to develop organizational policies.

One Sports and Entertainment, LLC

Phoenix, AZ

Founding Member

October 2007 - December, 2008

- Founding member of grass-roots sports and entertainment consulting firm.

- Synthesized custom legal and business solutions for clients in the professional sports and music fields.

- Developed and implemented client strategies/solutions related to marketing, branding, activation and business/legal with firm partners and other stakeholders; presented proposals to potential clients and partners such as Major League Baseball.

- Collaboratively worked alongside others to design and implement custom fundraising and sponsorship-based projects.

\section{Cleveland Cavaliers and Lake Erie Monsters}

Cleveland, $\mathrm{OH}$

Legal and Hockey Intern

May 2007 - July 2007

- Developed marketing, advertising, branding and grassroots policy for Lake Erie Monsters AHL pro hockey club.

- Participated in marketing, sales and branding meetings with senior management for the Cleveland Cavaliers.

- Counseled leadership and served as liaison to hockey operations in connection with launching of new hockey team.

- Supported general counsel by overseeing a range of diverse legal and business matters; drafted contracts.

Tulane University Athletic Department

New Orleans, LA

Legal Intern

September 2006 - November 2006

- Assisted Athletic Department with investigating premise liability and intellectual property issues.

- Introduced to NCAA compliance matters and analyzed basic compliance issues under supervision.

Miami Dolphins, LTD

Miami, FL

Operations Intern

August 2005 - October 2005

- Coordinated with facilities staff and operations personnel to facilitate practice and day-today operations.

- Assisted in the operation of Dolphins' Training Camp.

University of Michigan Athletic Department

Ann Arbor, MI

Operations Intern/Student Manager

February 2002 - May 2004 
- Was responsible for variety of duties assisting operations, facility and coaching staff in running an elite college football program.

- Performed logistical and support duties for all aspects of Michigan Varsity Football Program as assigned by coaches administrators and staff, including off-season, off-day, practice days and game days.

\section{Attorney Experience}

Singer Pistiner, PC

Phoenix, AZ

Of Counsel

March 2011 - January, 2014

- Possesses expert knowledge in the areas of sports law, intellectual property law, labor law, business law and bankruptcy; serves as expert sports law commentator.

- Advised and counseled clients on corporate, sports/entertainment, creditor/debtor and other transactional legal matters.

- Drafted business and corporate documents including, but not limited to, operating agreements, employee documents, endorsement/sponsorship agreements, non-disclosure agreements and other business agreements/contracts.

- Drafted litigation documents such as pleadings, motions, memoranda, correspondence and other documents.

- Researched legal issues and drafts opinion letters; negotiated various matters on clients' behalf.

- Participated in "Modest Means" program offering drastically reduced and pro bono serve/representation to members of public in need.

Wachtel, Biehn \& Malm

Lake Havasu City, AZ

Associate Attorney January 2009 - February, 2011

- Oversaw a diverse caseload of over one hundred open files involving litigation, transactional and bankruptcy-related matters; other practice areas included business transactions, foreclosures, landlord-tenant and collections.

- Routinely researched statutes, case law and other binding authority concerning transactional and litigation matters.

- Synthesized and reviewed commercial contracts, consumer contracts, notes and other agreements.

- Counseled clients on both pursuing and defending a diverse range of litigation matters.

- Maintained regular bankruptcy and collections practice; advised clients on Chapter 7 and Chapter 13 matters.

- Drafted motions and other substantive pleadings, internal and persuasive memoranda in support of motions. 
- Staff attorney at regional full service law firm. Served as a member of the firm's Document Control Group that specialized in regulatory compliance and discovery review processes.

- Analyzed opposing party's response to requests for production regarding responsiveness to substantive issues.

- Diagnosed and evaluated whether responding documents were subject to attorney-client privilege redaction and work product redaction.

\section{Attorney Awards}

Community Legal Services Outstanding Attorney Award for Mohave County, Arizona

Community Legal Services Attorney of the Year for Mohave County, Arizona (2009)

Volunteer Lawyers Program Attorney of the Year for Mohave County, Arizona (2009)

\section{Bar Admissions}

State of Michigan

State of Arizona

United States Federal Court, District of Arizona

United States Bankruptcy Court, District of Arizona 